\title{
Preliminary investigation of culvert outlet baffle block geometry and energy dissipation
}

\author{
Conrad Russell Baston \\ West Virginia University
}

Follow this and additional works at: https://researchrepository.wvu.edu/etd

\section{Recommended Citation}

Baston, Conrad Russell, "Preliminary investigation of culvert outlet baffle block geometry and energy dissipation" (2000). Graduate Theses, Dissertations, and Problem Reports. 1012.

https://researchrepository.wvu.edu/etd/1012

This Thesis is protected by copyright and/or related rights. It has been brought to you by the The Research Repository @ WVU with permission from the rights-holder(s). You are free to use this Thesis in any way that is permitted by the copyright and related rights legislation that applies to your use. For other uses you must obtain permission from the rights-holder(s) directly, unless additional rights are indicated by a Creative Commons license in the record and/ or on the work itself. This Thesis has been accepted for inclusion in WVU Graduate Theses, Dissertations, and Problem Reports collection by an authorized administrator of The Research Repository @ WVU. For more information, please contact researchrepository@mail.wvu.edu. 


\section{Preliminary Investigation of Culvert Outlet Baffle Block Geometry and Energy Dissipation}

\section{Conrad R. Baston}

Thesis submitted to the

College of Engineering at

West Virginia University

In partial fulfillment of

The requirements for the degree of

Master of Science

In

Civil and Environmental Engineering

Robert N. Eli, Ph.D., Chair

Donald D. Gray, Ph.D.

John M. Kuhlman, Ph.D.

Morgantown, West Virginia

2000 


\section{Abstract \\ Preliminary Investigation of Culvert Outlet Baffle Block Geometry and Energy Dissipation}

\section{Conrad R. Baston}

One method used to attenuate high-energy flow at culvert outlets, is the construction of baffle blocks. Baffle blocks are devices, generally of simplistic geometry, that impact the flow and reduce energy. The current baffle design used by the WVDOH has in some instances experienced problems with excessive sedimentation to the extent of causing culvert failure. The purpose of this investigation was to construct a testing device to allow for the testing of physical culvert and baffle block models and produce a preliminary design that would perform more efficiently than the current design. The new design would need to meet the following criteria:

- Reasonable construction on site

- Economically feasible

- Applicability to various culvert sizes and flowrates

- Self cleaning and low maintenance

- Re-establish natural flow conditions downstream of the outlet

Several models were constructed and tested. This thesis reviews the construction of all experimental equipment and the development of a preliminary design. 


\section{Acknowledgments}

I would like to thank the many people involved with the completion of this thesis. First, thanks to Dr. Robert N. Eli for the opportunity to obtain this degree and for his supervision and guidance throughout the project. Thanks to Dr. Donald D. Gray and Dr. John M. Kuhlman for being a part of this project and for their excellent tutelage in the classroom. Thanks to the WVDOH for providing the resources that made this project possible. Thanks to Sandy Wotring and David Turner for being such help in various tasks that could not have been done without them. Thanks to my mentor Jonathon Lester for all the help he provided everyday in the lab, class and gym. Thanks to my partner Belinda Weikle with all her help from the collaboration of our projects. Thanks to Duane Gaugler for his help in the lab and all the ideas he presented. Thanks to Elena Brevnova for all her help in class and various aspects of the project. Thanks to all my friends for being supportive and a source of relaxation when needed. Special thanks to my mother, Connie Baston, and sister, Heather Baston, for always being there when I need them and being such strong and independent women who are a constant source of admiration. Thanks to my father, Conrad D. Baston, and grandfather, Conrad E. Baston, for teaching me how to be strong and the importance of education. Thanks to all my family for teaching me the important things in life and for pushing me in the right direction. I would like to thank everyone for their support during my motorcycle accident especially Lisa Woodruff for being such a wonderful and loving addition to my life, and Steven Bennett the best brother I never had. Finally I would like to thank my aunt, Geraldine Eskew, for showing myself and everyone that has ever met her, what strength really is and God for blessing me with such wonderful friends and family. 


\section{Table of Contents}

$\underline{\text { Page }}$

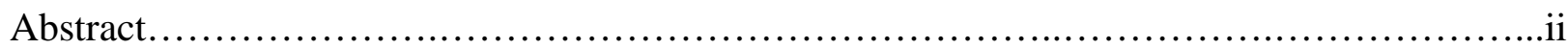

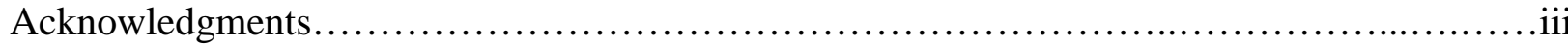

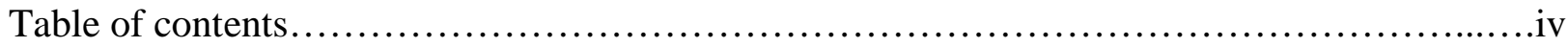

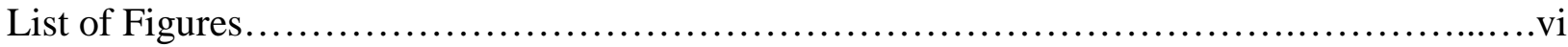

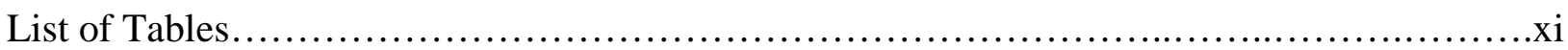

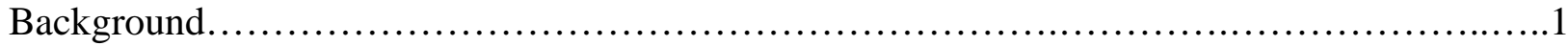

- 1.1 Problem Description...................................................

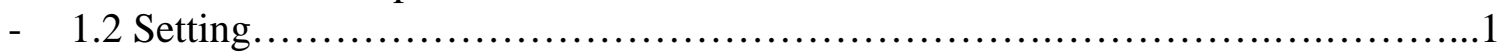

- 1.3 Current Design.............................................................

- $\quad 1.4$ Field Experiences With the Current Baffle Design.............................4

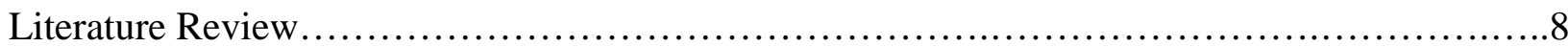

- $\quad 2.1$ The Hydraulic Jump...................................................

- $\quad 2.2$ Utah State (USU) Stilling Basin........................................ 14

- 2.3 Baffled Apron Spillway Dissipator.........................................18

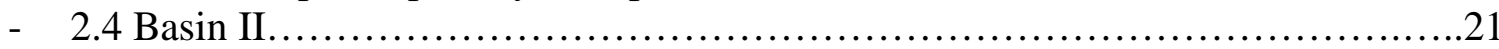

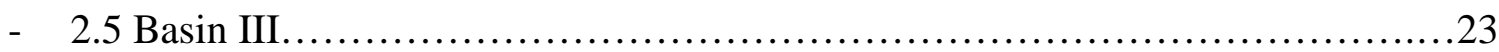

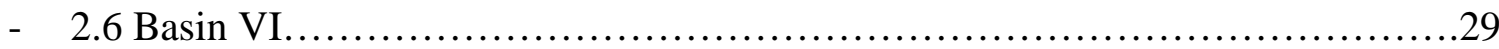

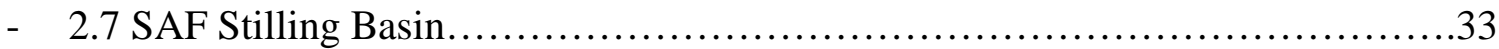

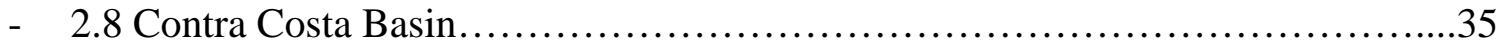

- 2.9 Hook Type Energy Dissipator.......................................... 40

- 2.10 Stilling Basin for Low Froude Number..................................45

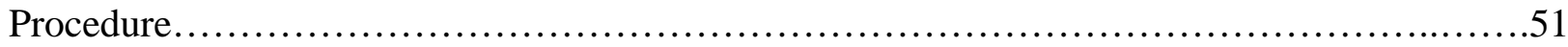

- $\quad 3.1$ Development of Experimental Equipment................................51

- 3.2 Pump Selection..........................................................51

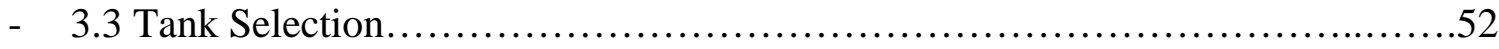

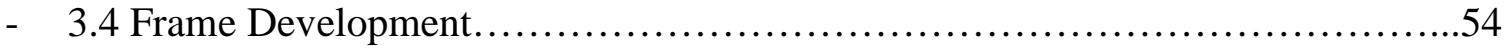

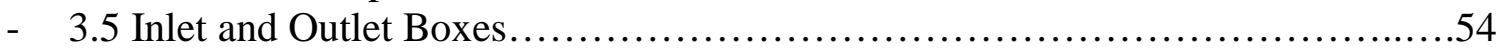

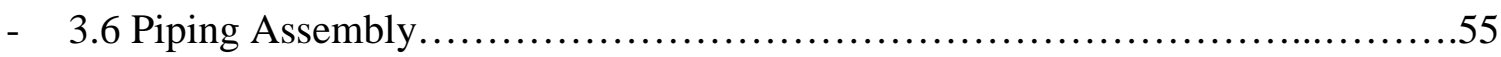

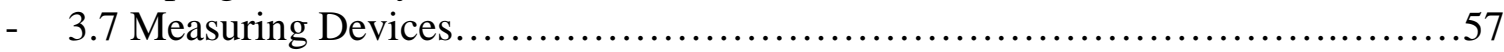

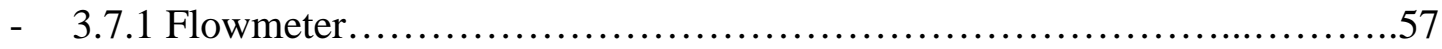

- $\quad 3.7 .2$ Piezometer Board........................................................ 58

- $\quad 3.7 .3$ Three-Point Depth Gage..............................................60

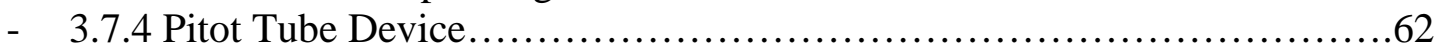

- $\quad 3.7 .5$ Slope Adjustment Device............................................64 


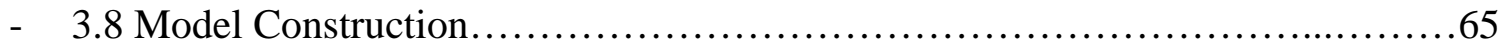

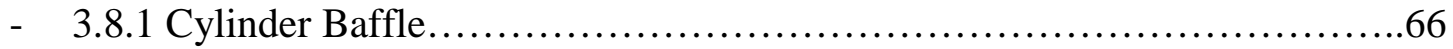

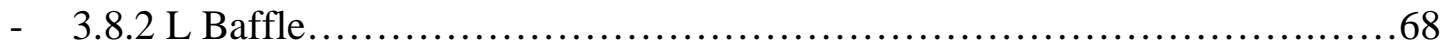

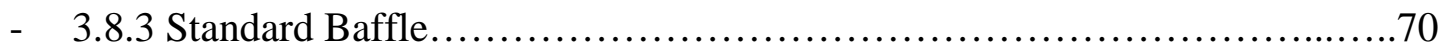

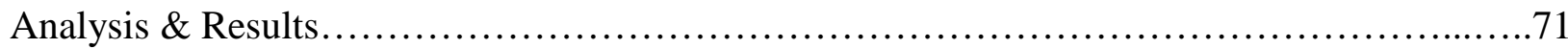

- 4.1 Data Collection............................................................ 71

- 4.2 Velocity Profile Investigation..............................................

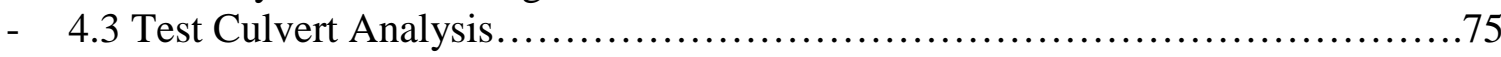

- 4.4 Equivalent Rectangular Froude Number......................................77

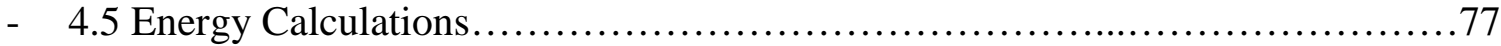

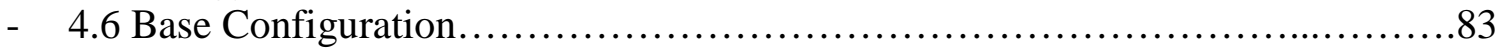

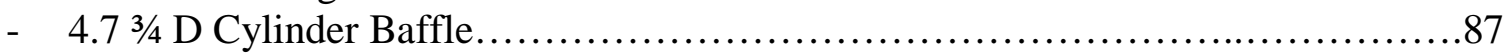

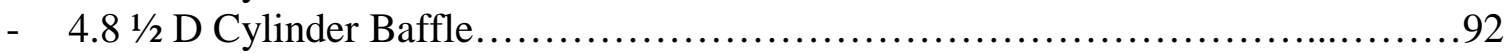

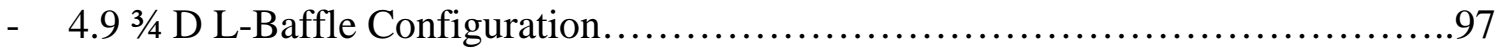

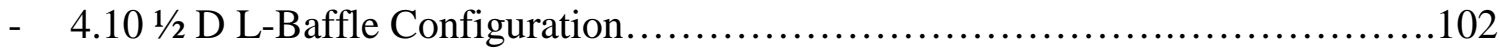

- 4.11 Standard Baffle Configuration..........................................107

- $\quad 4.12$ Comparison to "Natural" Energy Grade Line....................................113

- 4.13 Error Analysis........................................................... 115

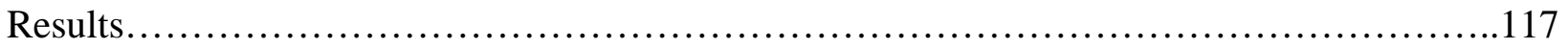

- 5.1 Comparison of Baffle Configurations.......................................117

- 5.2 Froude Number and Non-Dimensional Energy Difference......................123

- 5.3 Energy Dissipation Performance Parameter.................................128

Conclusions and Recommendations......................................................

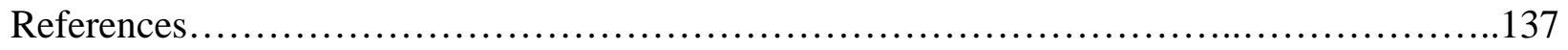

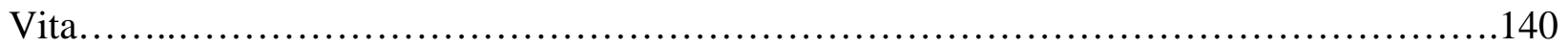




\section{List of Figures}

Figure $\quad \underline{\text { Page }}$

1.3.1 Plan View of Current WVDOH Standard Baffle Dissipator.............................

1.3.2 Front View of Current WVDOH Standard Baffle Dissipator...........................

1.3.3 Profile View of Current WVDOH Standard Baffle Dissipator........................4

1.4.1 First Example of a Typical Standard Baffle Installation.............................5

1.4.2 Second Example of a Typical Standard Baffle Installation............................6

1.4.3 Failure of a Multi-Baffle Energy Dissipator......................................

1.4.4 Failure of Baffle-type Energy Dissipator.....................................

2.1.2 Specific Head and Depth ...................................................... 10

2.1.3 Jump Profiles for Various Approach Froude Numbers...............................11

2.1.4 Hydraulic Jump Forms................................................... 12

2.2.1 Utah State University Stilling Basin.......................................... 15

2.2.2 Model USU Stilling Basin.............................................. 16

2.2.3 Design Parameters for USU Stilling Basin...................................... 17

2.3.1 Design Criteria for Baffle Apron Spillway Dissipator..............................18

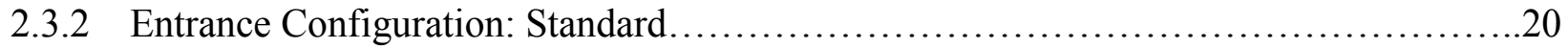

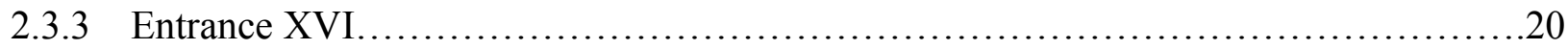

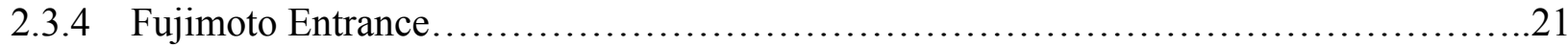

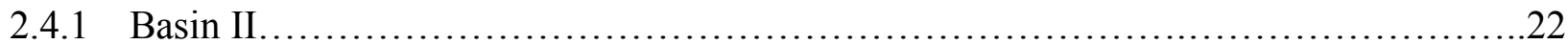

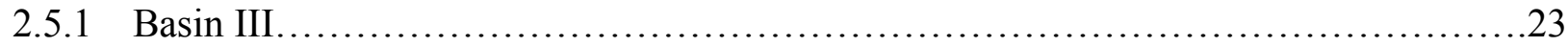

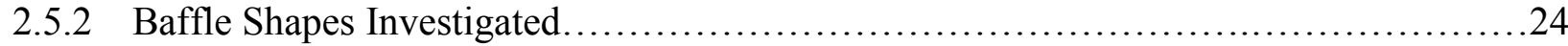

2.5.3 Water Surface Profile........................................................25

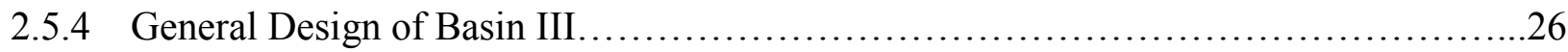

2.5.5 Basin III Length Determination................................................ 28

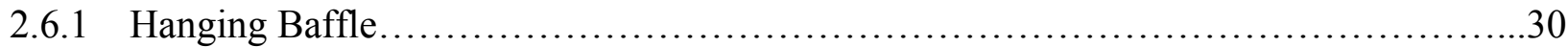

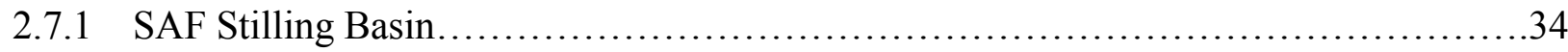

2.8.1 Baffle Height Determination................................................ 36

2.8.2 Length of Contra Costa Basin................................................. 37

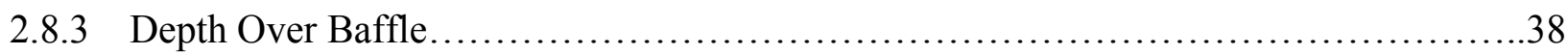

2.8.4 Contra Costa Energy Dissipator........................................... 39 
2.9.1 Warped Wingwall Stilling Basin...................................................40

2.9.2 Design Criteria for Straight Basin.................................................

2.9.3 Recommended Dimensions for Straight basin....................................42

2.9.4 Velocity Ratio vs. Froude Number.............................................. 43

2.9.5 Hook Dimensions for Warped Wingwall Basin.....................................44

2.10.1 Depth Ratio vs Froude Number........................................................ 49

2.10.2 Energy Loss vs Froude Number..................................................49

2.10.3 Length of Basin vs Froude Number..................................................50

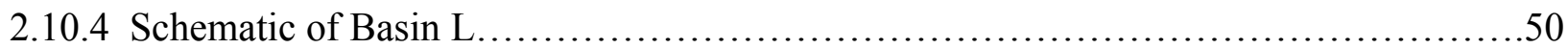

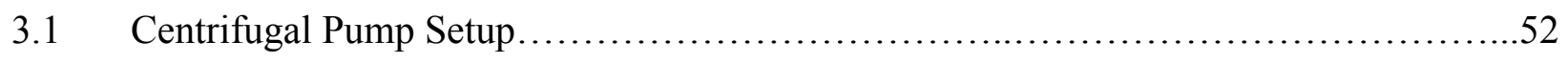

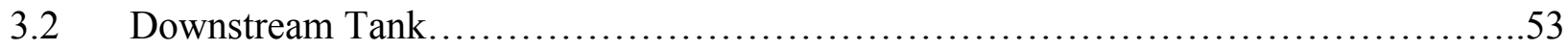

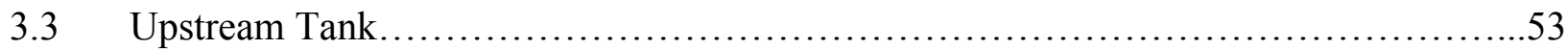

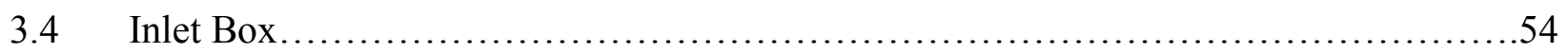

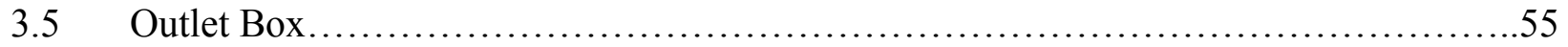

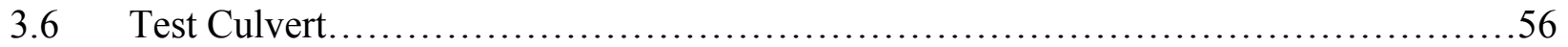

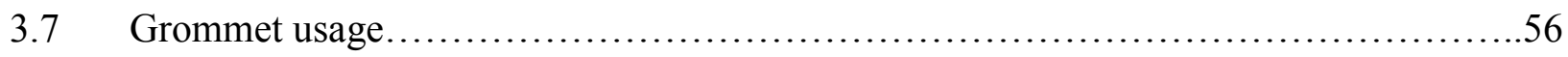

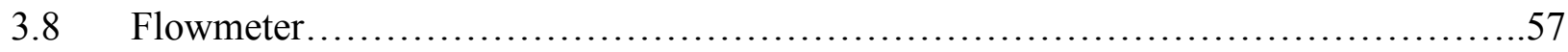

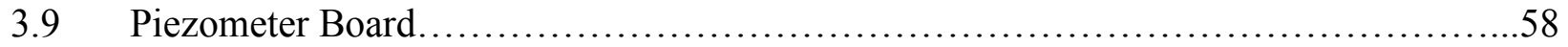

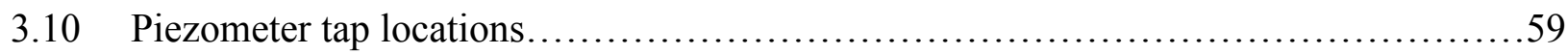

3.11 Points of Depth Measurement in Testing Channel......................................61

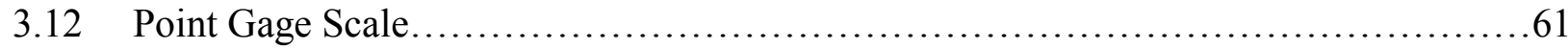

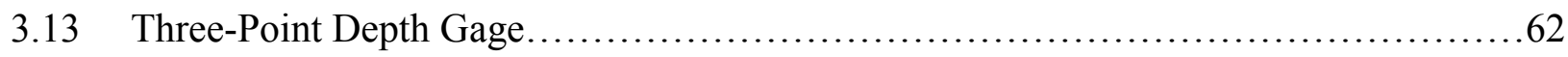

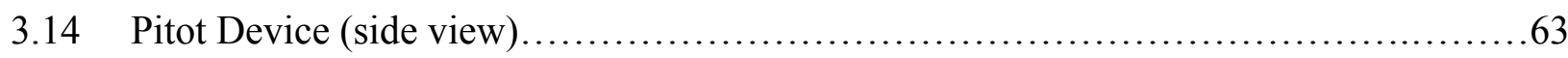

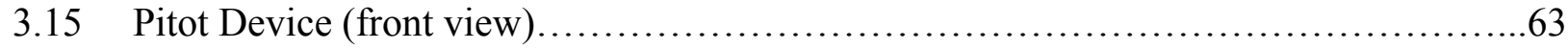

3.16 Outlet Box Slope Adjustment....................................................65

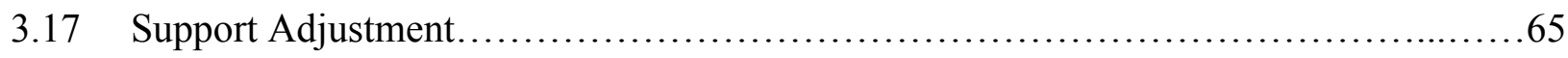

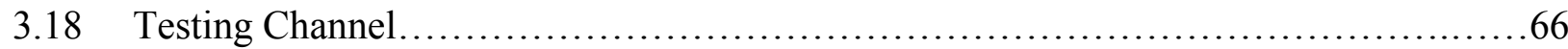

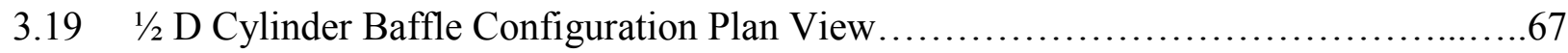

$3.201 / 2$ Diameter Cylinder Baffle Configuration Profile View..............................67

$3.213 / 4$ Diameter Cylinder Baffle Configuration Plan View...............................68

$3.223 / 4$ Diameter Cylinder Baffle Configuration Profile View..............................68 
$3.23 \quad \frac{1}{2}$ Diameter L Baffle Configuration Front View........................................69

$3.24 \quad 1 / 2$ Diameter L Baffle Configuration Profile View.........................................69

$3.25 \quad 3 / 4$ Diameter L Baffle Configuration Front View.......................................69

$3.263 / 4$ Diameter L Baffle Configuration Profile View......................................70

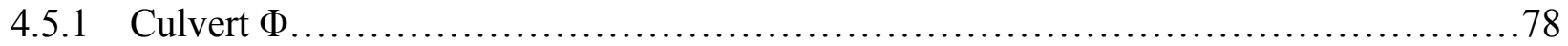

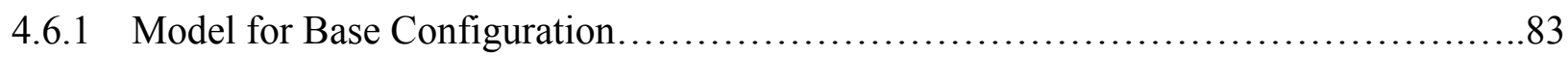

4.6.2 Plot of Depth for Base Configuration at 2\% Culvert Slope and 50-150 gpm..............83

4.6.3 Plot of Depth for Base Configuration at 4\% Culvert Slope and 50-150 gpm............84

4.6.4 Plot of Depth for Base Configuration at 6\% Culvert Slope and 50-150 gpm..............84

4.6.5 Plot of Depth for Base Configuration at 8\% Culvert Slope and 50-150 gpm..............85

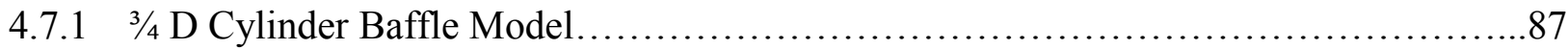

4.7.2 3/4 D Cylinder Baffle at 6\% Culvert Slope and $125 \mathrm{gpm} \ldots \ldots \ldots \ldots \ldots \ldots \ldots \ldots \ldots \ldots . . \ldots 1$

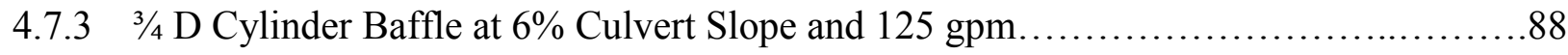

4.7.4 Plot of Depth for $3 / 4$ D Cylinder baffle at 2\% Culvert Slope and 50-200 gpm.............88

4.7.5 Plot of Depth for $3 / 4$ D Cylinder baffle at 4\% Culvert Slope and 50-200 gpm.............89

4.7.6 Plot of Depth for $3 / 4$ D Cylinder baffle at 6\% Culvert Slope and 50-200 gpm.............89

4.7.7 Plot of Depth for $3 / 4$ D Cylinder baffle at 8\% Culvert Slope and 50-200 gpm.............90

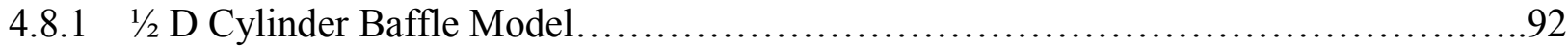

4.8.2 Plan of $1 \frac{1}{2}$ D Cylinder Baffle at 4\% Culvert Slope and 125 gpm......................92

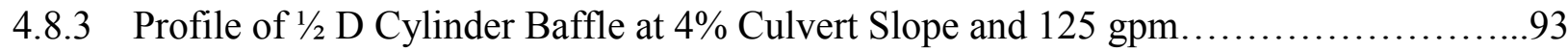

4.8.4 Plot of Depth for $1 / 2$ D Cylinder baffle at 2\% Culvert Slope and 50-200gpm.............93

4.8.5 Plot of Depth for $1 / 2$ D Cylinder baffle at 4\% Culvert Slope and 50-200 gpm.............94

4.8.6 Plot of Depth for $1 / 2$ D Cylinder baffle at 6\% Culvert Slope and 50-200 gpm..............94

4.8.7 Plot of Depth for $1 / 2$ D Cylinder baffle at 8\% Culvert Slope and 50-200 gpm.............95

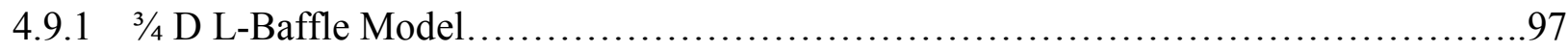

4.9.2 3/4 D L-Baffle at 4\% Culvert Slope and 125gpm..................................97

4.9.3 3/4 D L-Baffle Preliminary Test........................................................ 98

4.9.4 Plot of Depth for 3/4 D L-Baffle at 2\% Culvert Slope and 50-200 gpm................98

4.9.5 Plot of Depth for 3/4 D L-Baffle at 4\% Culvert Slope and 50-200 gpm..................99

4.9.6 Plot of Depth for 3/4 D L-Baffle at 6\% Culvert Slope and 50-200 gpm.................99

4.9.7 Plot of Depth for 3/4 D L-Baffle at 8\% Culvert Slope and 50-200 gpm................100 


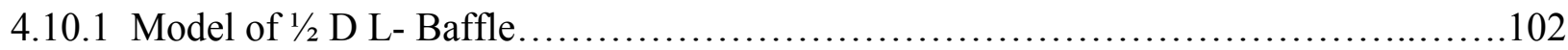

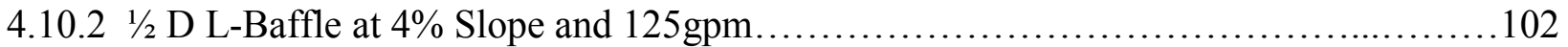

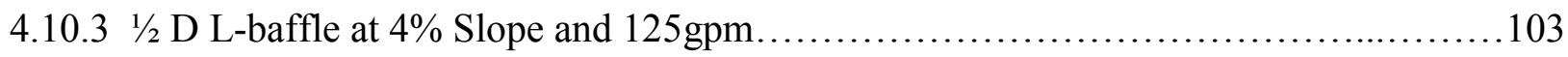

4.10.4 Plot of Depth for $1 / 2$ D L-baffle at 2\% Culvert Slope and 50-200 gpm...................103

4.10.5 Plot of Depth for $1 / 2$ D L-baffle at 4\% Culvert Slope and 50-200 gpm.................104

4.10.6 Plot of Depth for $1 / 2$ D L-baffle at 6\% Culvert Slope and 50-200 gpm...................104

4.10.7 Plot of Depth for $1 / 2$ D L-baffle at 8\% Culvert Slope and 50-200 gpm.................105

4.11.1 Model of Standard Baffle Configuration..............................................

4.11.2 Standard Baffle Configuration (Initial Testing) .................................. 108

4.11.3 Standard Baffle Configuration at 8\% Culvert Slope and $125 \mathrm{gpm} . \ldots \ldots \ldots \ldots \ldots \ldots \ldots . \ldots 108$

4.11.4 Plot of Depth for Standard Baffle at 2\% Culvert Slope and 50-200 gpm............... 109

4.11.5 Plot of Depth for Standard Baffle at 4\% Culvert Slope and 50-200 gpm................109

4.11.6 Plot of Depth for Standard Baffle at 6\% Culvert Slope and 50-200 gpm................110

4.11.7 Plot of Depth for Standard Baffle at 8\% Culvert Slope and 50-200 gpm...............110

4.12.1 Energy Grade Line Establishment .................................................113

5.1.1 Average Depth to Velocity Head Ratio vs. Average Non-Dimensional Energy

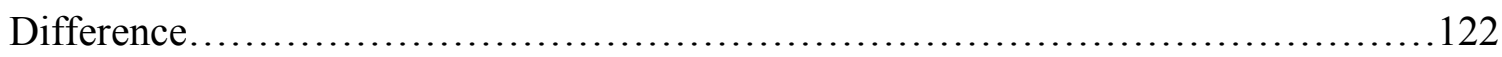

5.2.1 Base Configuration Froude Number at Culvert Outlet vs. Non-dimensional Energy

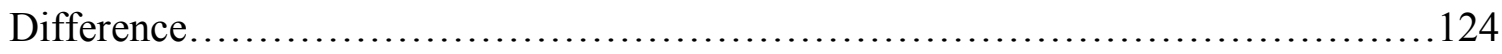

5.2.2 3/4 D Cylinder Configuration Froude Number at Culvert Outlet vs. Non-dimensional Energy Difference............................................................... 125

5.2.3 $1 / 2$ D Cylinder Configuration Froude Number at Culvert Outlet vs. Non-dimensional Energy Difference......................................................... 125

5.2.4 3/4 D L-baffle Configuration Froude Number at Culvert Outlet vs. Non-dimensional Energy Difference............................................................ 126

5.2.5 1/2 D L-baffle Configuration Froude Number at Culvert Outlet vs. Non-dimensional

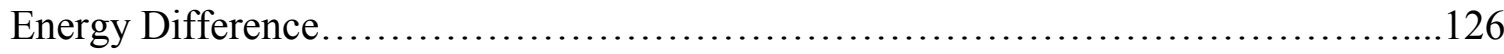

5.2.6 Standard Baffle Configuration Froude Number at Culvert Outlet vs. Non-dimensional

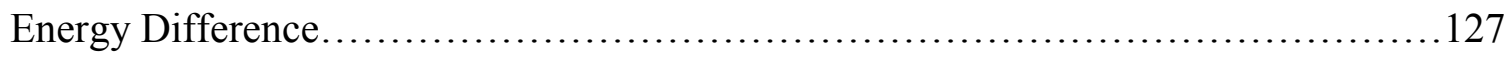

5.3.1 Location of E3, Value for Establishing the Energy Dissipation Performance

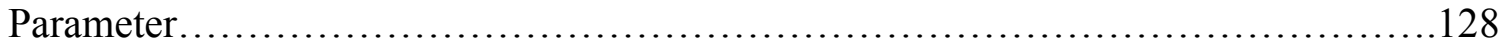




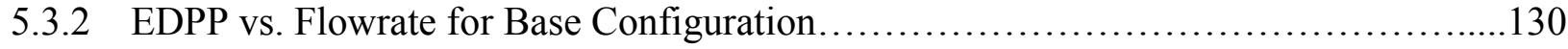

5.3.3 EDPP vs. Flowrate for $3 / 4$ D Cylinder Baffle........................................ 131

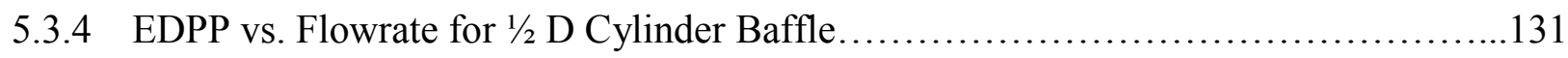

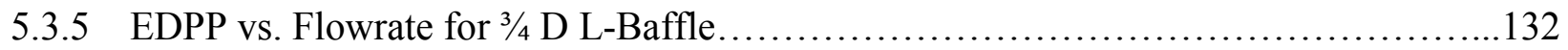

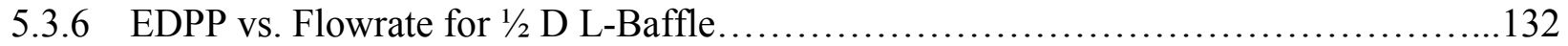

5.3.7 EDPP vs. Flowrate for Standard Baffle..................................... 133

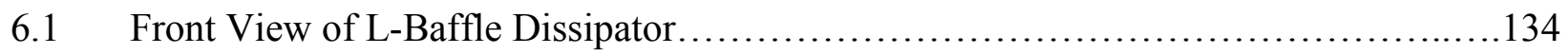

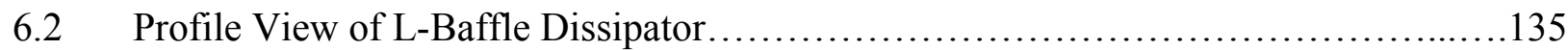

$6.3 \quad 1 / 2$ Diameter L-Baffle Right Isometric View.................................... 136 


\section{List of Tables}

$\underline{\text { Table }}$

$\underline{\text { Page }}$

1.3.1 Design Dimension as Multiple of Culvert Diameter for the Standard Baffle

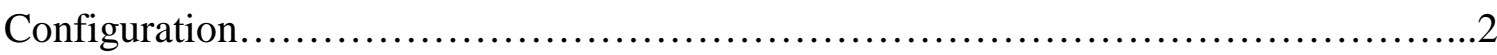

2.6.1 Basin VI Dimensions...........................................................

3.1 Distance to Piezometer Taps from Culvert Inlet.....................................59

3.2 Testing Channel Measurement Locations......................................60

4.2.1 Calculations for Velocity Profile Correction Factor................................73

4.2.2 Alpha Value obtained by Methods 1 and 2 (50gpm 8\%Slope)......................74

4.2.3 Alpha Values Obtained by Methods 1 and 2 (100 gpm 8\% Slope)...................75

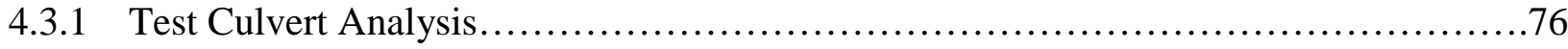

4.5.1 Test Culvert Data 2\% Slope................................................... 79

4.5.2 Test Culvert Data 4\% Slope.................................................... 79

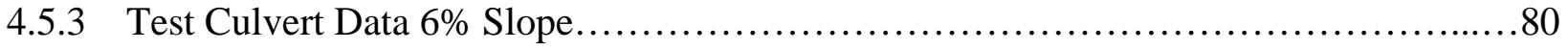

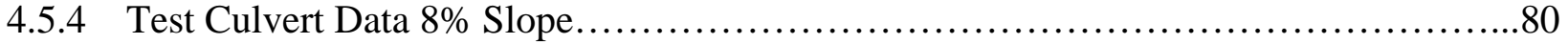

4.5.5 Example of Energy Calculations Performed................................... 82

4.6.1 Energy Calculation for Base Configuration at 2\% Culvert Slope.....................85

4.6.2 Energy Calculations for Base Configuration at 4\% Culvert Slope.....................86

4.6.3 Energy Calculations for Base Configuration at 6\% Culvert Slope.....................86

4.6.4 Energy Calculations for Base Configuration at 8\% Culvert Slope.....................86

4.7.1 Energy Calculations for 3/4 Diameter Cylinder Baffle at 2\% Culvert Slope..............90

4.7.2 Energy Calculations for 3/4 Diameter Cylinder Baffle at 4\% Culvert Slope..............91

4.7.3 Energy Calculations for 3/4 Diameter Cylinder Baffle at 6\% Culvert Slope.............91

4.7.4 Energy Calculations for 3/4 Diameter Cylinder Baffle at 8\% Culvert Slope.............91

4.8.1 Energy Calculations for 1/2 Diameter Cylinder Baffle at 2\% Culvert Slope.............95

4.8.2 Energy Calculations for 1/2 Diameter Cylinder Baffle at 4\% Culvert Slope............96

4.8.3 Energy Calculations for 1/2 Diameter Cylinder Baffle at 6\% Culvert Slope.............96

4.8.4 Energy Calculations for 1/2 Diameter Cylinder Baffle at 8\% Culvert Slope.............96

4.9.1 Energy Calculations for 3/4 Diameter L-Baffle at 2\% Culvert Slope..................100

4.9.2 Energy Calculations for 3/4 Diameter L-Baffle at 4\% Culvert Slope..................100

4.9.3 Energy Calculations for 3/4 Diameter L-Baffle at 6\% Culvert Slope..................101 
4.9.4 Energy Calculations for 3/4 Diameter L-Baffle at 8\% Culvert Slope..................101

4.10.1 Energy Calculations for 1/2 Diameter L-Baffle at 2\% Culvert Slope..................105

4.10.2 Energy Calculations for 1/2 Diameter L-Baffle at 4\% Culvert Slope..................106

4.10.3 Energy Calculations for 1/2 Diameter L-Baffle at 6\% Culvert Slope..................106

4.10.4 Energy Calculations for 1/2 Diameter L-Baffle at 8\% Culvert Slope..................106

4.11.1 Energy Calculations for Standard Baffle at 2\% Culvert Slope........................111

4.11.2 Energy Calculations for Standard Baffle at 4\% Culvert Slope........................111

4.11.3 Energy Calculations for Standard Baffle at 6\% Culvert Slope.........................111

4.11.4 Energy Calculations for Standard Baffle at 8\% Culvert Slope.......................112

4.12.1 Comparison Between "Natural" and Calculated Energy in Testing Channel.............114

4.13.1 Expected Error for Various Calculated Values...................................116

5.1.1 Comparison of Values for Non-Dimensional Energy Difference......................117

5.1.2 Uniform Flow Depth at Culvert Outlet and Testing Channel........................119

5.1.3 Comparison Between Velocity Head at Culvert Outlet and Testing Channel............120

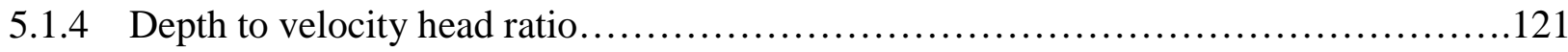

5.3.1 Values for E3 at Given Culvert Slopes.................................... 128

5.3.2 Values for the Energy Difference Performance Parameter (EDPP)..................129 


\section{Chapter 1 - Background}

\subsection{Problem Description}

In order to attenuate energy associated with high velocity flows at culvert outlets, baffle blocks are sometimes constructed. A baffle block is an appurtenance, generally of simple geometric dimensions, that is placed in the flow path to act as an impact surface to thus decrease the excessive energy present at some culvert outlets. Several baffle-type energy dissipators have been used by the West Virginia Division of Highways (WVDOH), in order to reduce the energy of high velocity flows present in some roadside culverts. Many of the baffle-type dissipators used by the WVDOH have operated successfully as they were designed. In a number of the dissipators however, debris and sediment have collected on the apron of the dissipator resulting in a clogged culvert and a need for maintenance. An additional concern is that the baffle devices are comprised of reinforced concrete and are generally expensive and difficult to build. This Thesis for a Master's Degree in Civil and Environmental Engineering, focusing in Hydrotechnical Engineering, will examine the effectiveness of the current baffle-type energy dissipator used by the WVDOH. The problems present with the current design will be investigated and solutions will be presented and discussed. Two alternative designs for providing adequate energy attenuation, economic feasibility, and low maintenance will be shown.

\subsection{Setting}

West Virginia, also known as the mountain-state, is best described as being steep and mountainous with lush vegetation, raging rivers and harsh terrain. In such a setting, natural drainage occurs by balancing the necessary energy attenuation for a given flow with the physical and erosive properties of the drainage channel being formed. This process constantly seeks a state of equilibrium as erosion and sedimentation occur and change the characteristics of the drainage channel over time. When man alters the environment by replacing the natural channel with a culvert, the equilibrium of the channel is disrupted. The flow characteristics are altered by a change in flow cross-section, roughness and possibly slope and direction. When the flow regime is altered, the rate of energy dissipation is changed. The change in energy dissipation 
will upset the natural equilibrium of the channel producing erosion or sedimentation that was formerly in balance in the natural drainage channel. In the case of erosion, the lower energy dissipation caused by the placement of a culvert must be dealt with to avoid damage to surrounding structures or the downstream channel itself.

\subsection{Current Design}

Engineering drawings of the current baffle-type energy dissipator, standard baffle, used by the WVDOH were available but no evidence of engineering development of the design was found. An in depth discussion of energy dissipators for use in roadside channels can be found in Federal Highway Administration (FHWA) HEC-14, 1983 (Hydraulic Design of Energy Dissipators for Culverts and Channels). In development of new designs for baffle-type dissipators to be used by the WVDOH the following important goals were set: 1) simplicity of design, 2) low construction cost, 3) effectiveness of energy dissipation, and 4) low sediment accumulation. In order to construct a scale model of the apron and baffle appurtenances, the various dimensions of the dissipator were taken from the WVDOH drawings and reproduced using Microstation CAD software for ease of interpretation and manipulation. The dimensions of the dissipator are all a function of pipe diameter with the exception of thickness and cutoff wall height, which are determined by the standard construction specifications. A schematic of the WVDOH energy dissipator is shown in Figures 1.3.1, 1.3.2, and 1.3.3. All dimensions vary with respect to culvert diameter with the exception with the exception of thickness, T, and cutoff wall height, W. The dimensions are shown as a multiple of culvert diameter in Table 1.3.1.

Table 1.3.1 Design Dimension as Multiple of Culvert Diameter for the Standard Baffle Configuration

\begin{tabular}{|c|c|}
\hline Dimension & $\begin{array}{c}\text { Multiple of } \\
\text { Diameter }\end{array}$ \\
\hline $\mathrm{L}$ & 1.2 \\
\hline $\mathrm{M}$ & 0.6 \\
\hline $\mathrm{N}$ & 1.2 \\
\hline $\mathrm{O}$ & 1.3 \\
\hline $\mathrm{P}$ & 3.9 \\
\hline $\mathrm{Q}$ & 1.8 \\
\hline
\end{tabular}




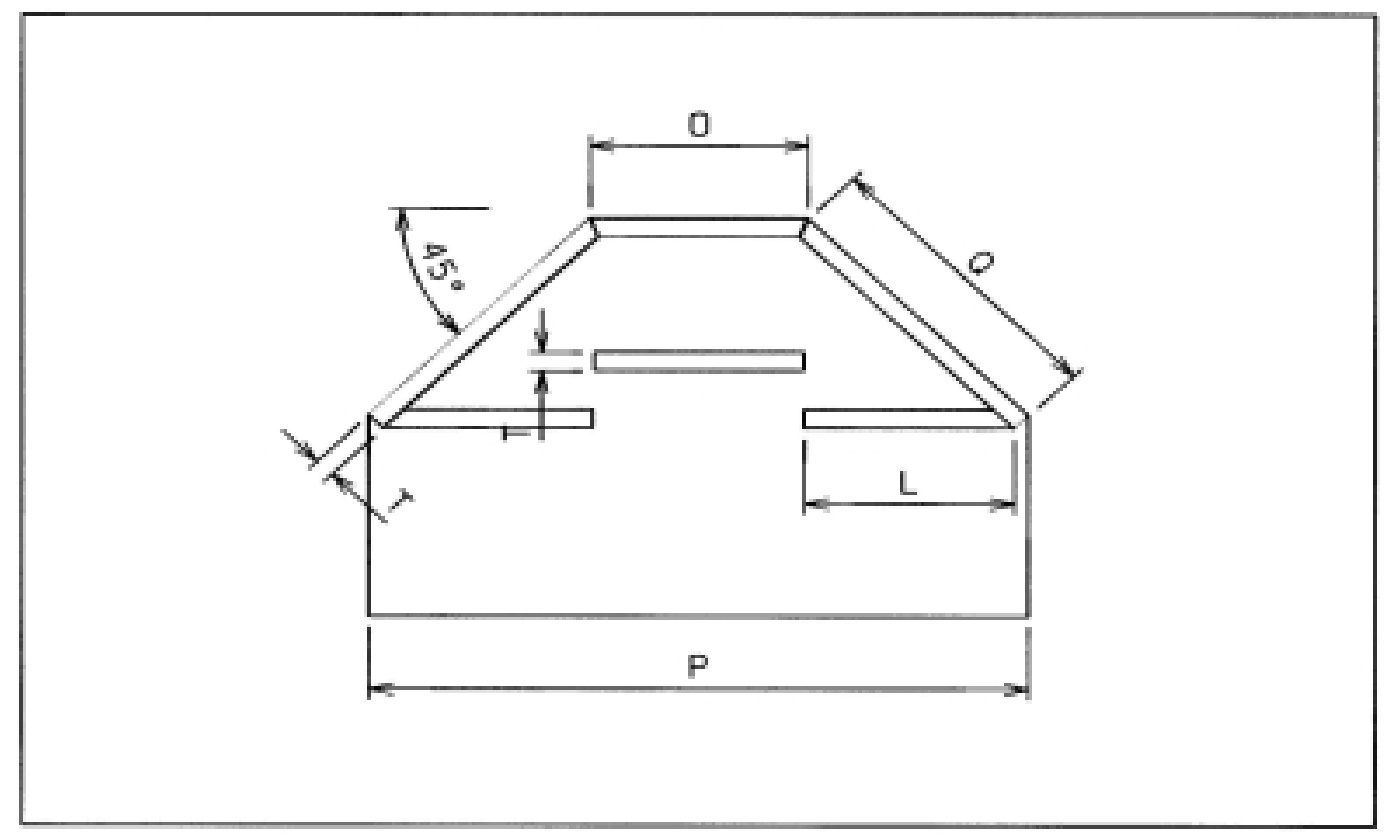

Figure 1.3.1 Plan View of Current WVDOH Standard Baffle Dissipator

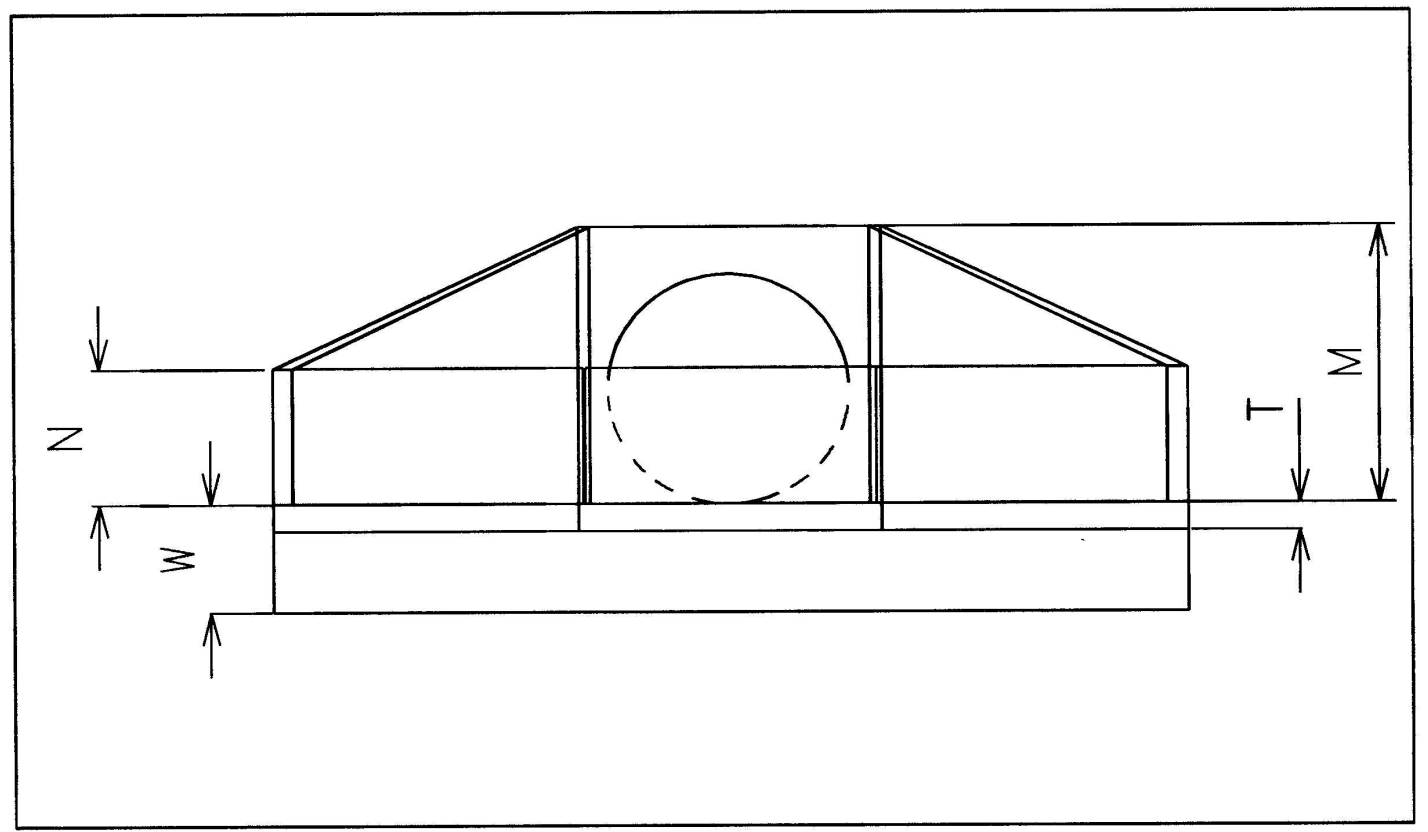

Figure 1.3.2 Front View of Current WVDOH Standard Baffle Dissipator 


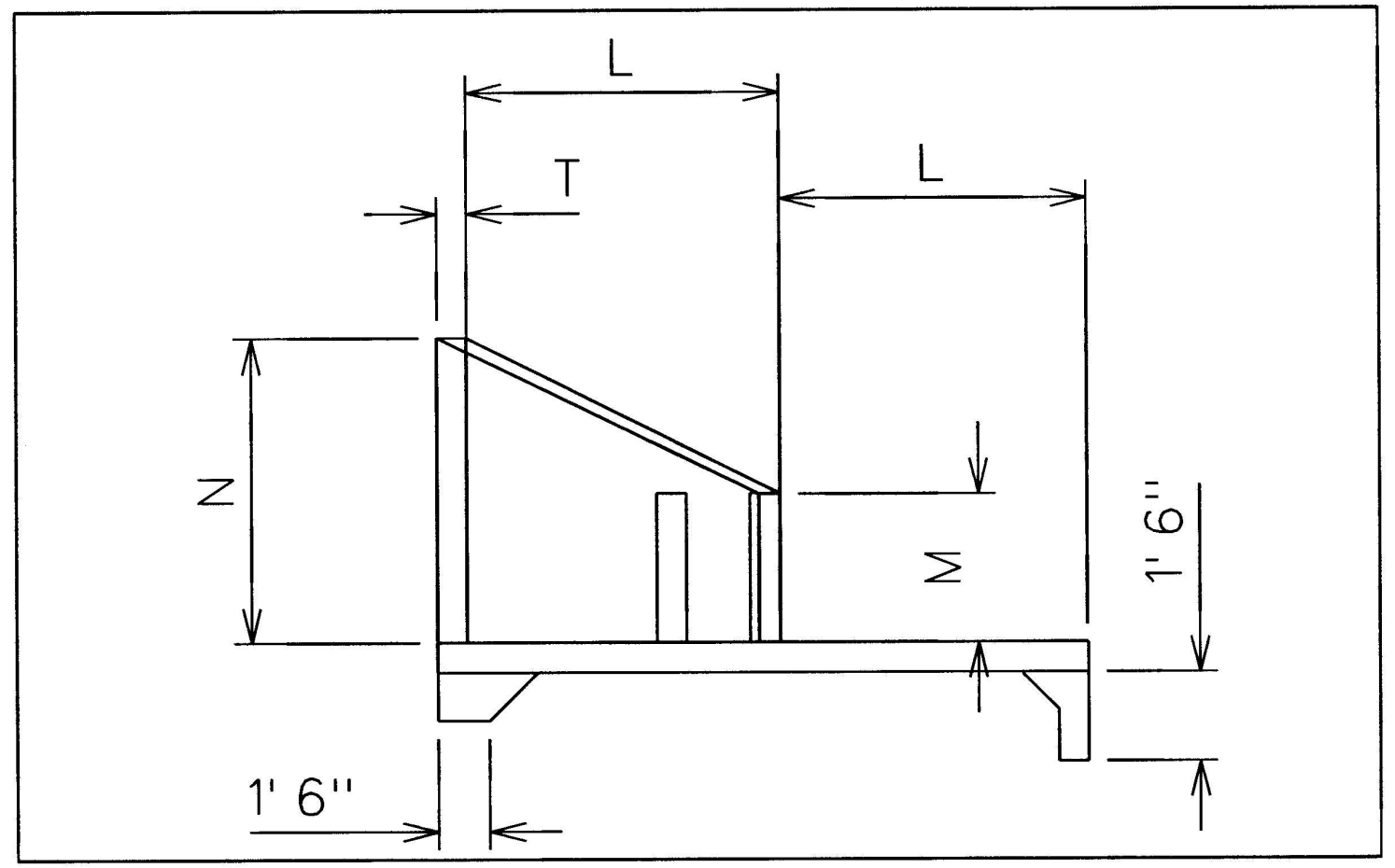

Figure 1.3.3 Profile View of Current WVDOH Standard Baffle Dissipator

Since the dimensions for the Dissipator were all a multiple of a given culvert diameter, construction of a scale model for hydraulic model studies was greatly simplified. Also, in the consideration of alternate designs, it was decided to maintain all associated geometries as multiples of culvert diameter for simplicity and ease of construction.

\subsection{Field Experiences With the Current Baffle Design}

Following the construction of several of the current Standard Baffle energy dissipators, successes and failures were observed by the WVDOH during operation. A successful performance was evidenced by satisfactory energy attenuation, displaying little erosion of the downstream channel. Several of the dissipators appeared to be operating successfully, and two examples are shown in Figures 1.4.1. And 1.4.2. 


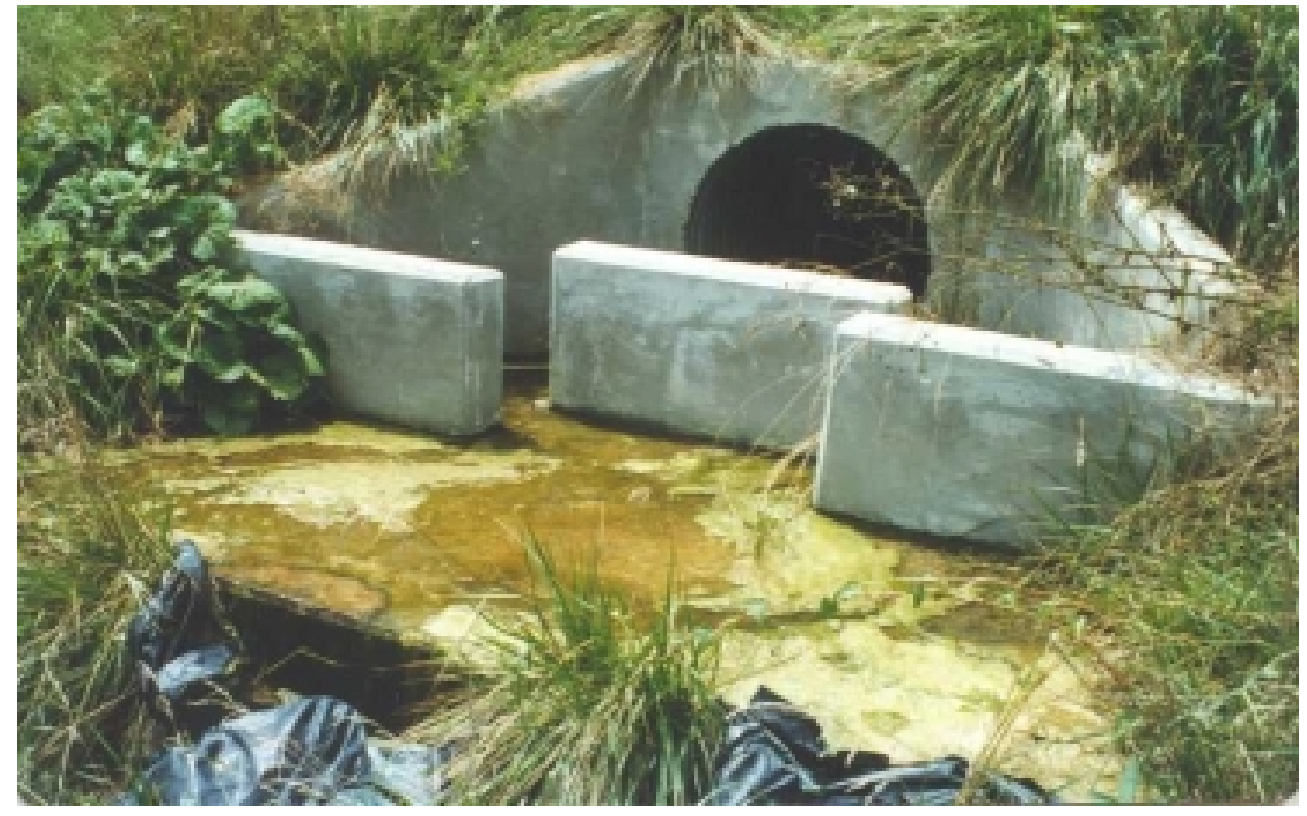

Figure 1.4.1 First Example of a Typical Standard Baffle Installation

Note that In Figure 1.4.1, there is no significant sedimentation on the apron of the dissipator and there is no erosion damage downstream. Since no experimental development of the current WVDOH Baffle-type dissipator could be located, the effectiveness of its design may only be ascertained by visual examination of its operation in the field. In Figure 1.4.2 another baffle is shown that appears to be operating successfully. However note that some debris is beginning to collect downstream of the center baffle. Also notice the light colored area located downstream of the center baffle. This may be indirect evidence of the presence of a "dead zone" where, under varying flowrates, more debris may collect and cause this dissipator to fail. Only continued monitoring over time will determine the ultimate effectiveness of the dissipators shown in Figures 1.4.1 and 1.4.2. 


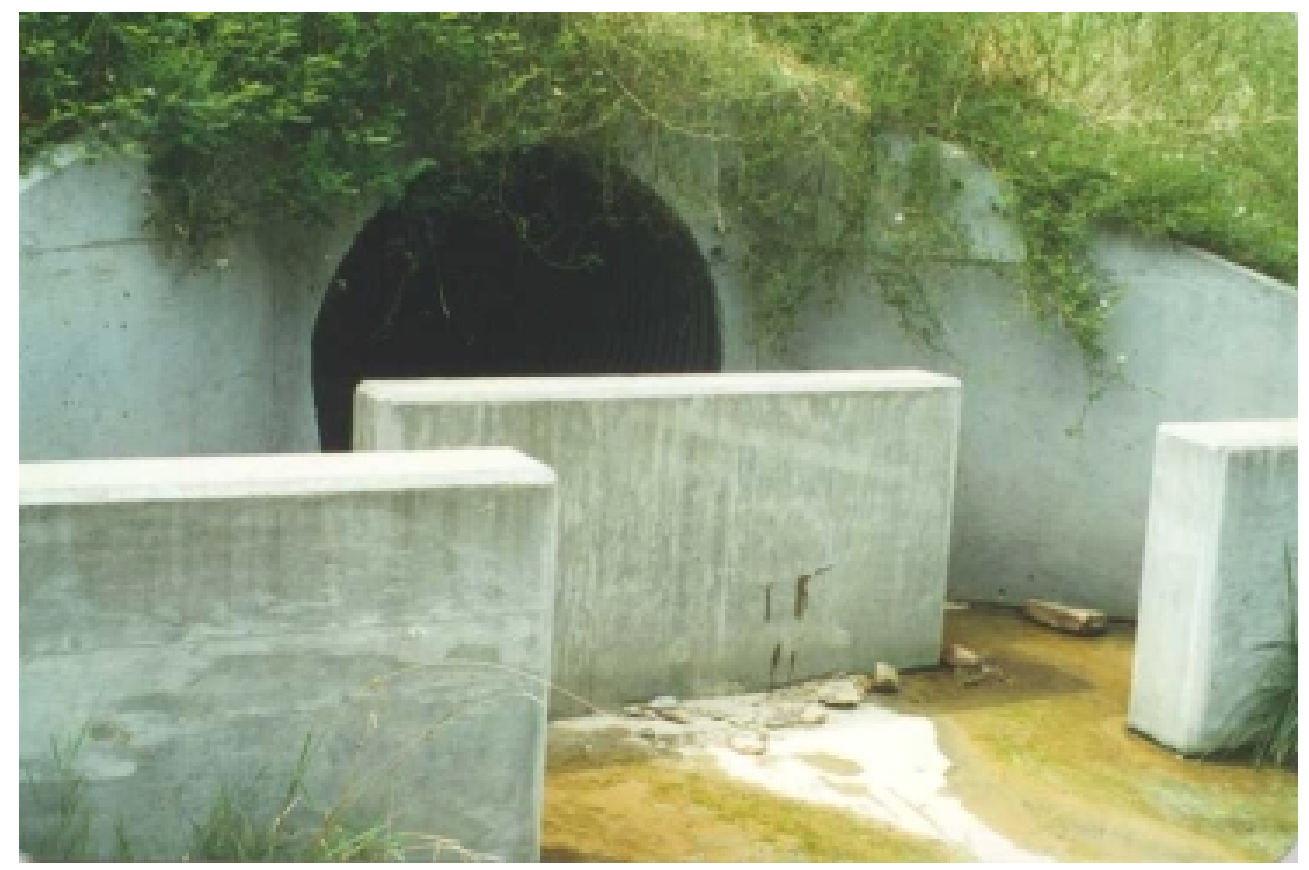

Figure 1.4.2 Second Example of a Typical Standard Baffle Installation

Failures of the Standard Baffle dissipators have occurred when large amounts of sediments have been deposited between the culvert outlet and the center baffle of the dissipator. Two obvious failures of the baffle-type dissipators are shown in Figures 1.4.3 and 1.4.4. The dissipator shown in Figure 1.4.3 is a multiple baffle design, and has large amounts of sedimentation. Obviously, the performance potential of this dissipator is significantly reduced. The dissipator uses an excessive number of baffle blocks and has a rather long apron, both of which have contributed to the failure of the device. The apron of the dissipator has been clogged with sediment, seriously degrading its performance. The Baffle-type dissipator shown in Figure 1.4.4 also failed after being placed into operation. The dissipator was totally clogged with sediment, and future storm events could cause the culvert to back up and damage the roadway, possibly overtop the fill, or damage upstream property. The money spent in the construction of these two examples was apparently wasted. 


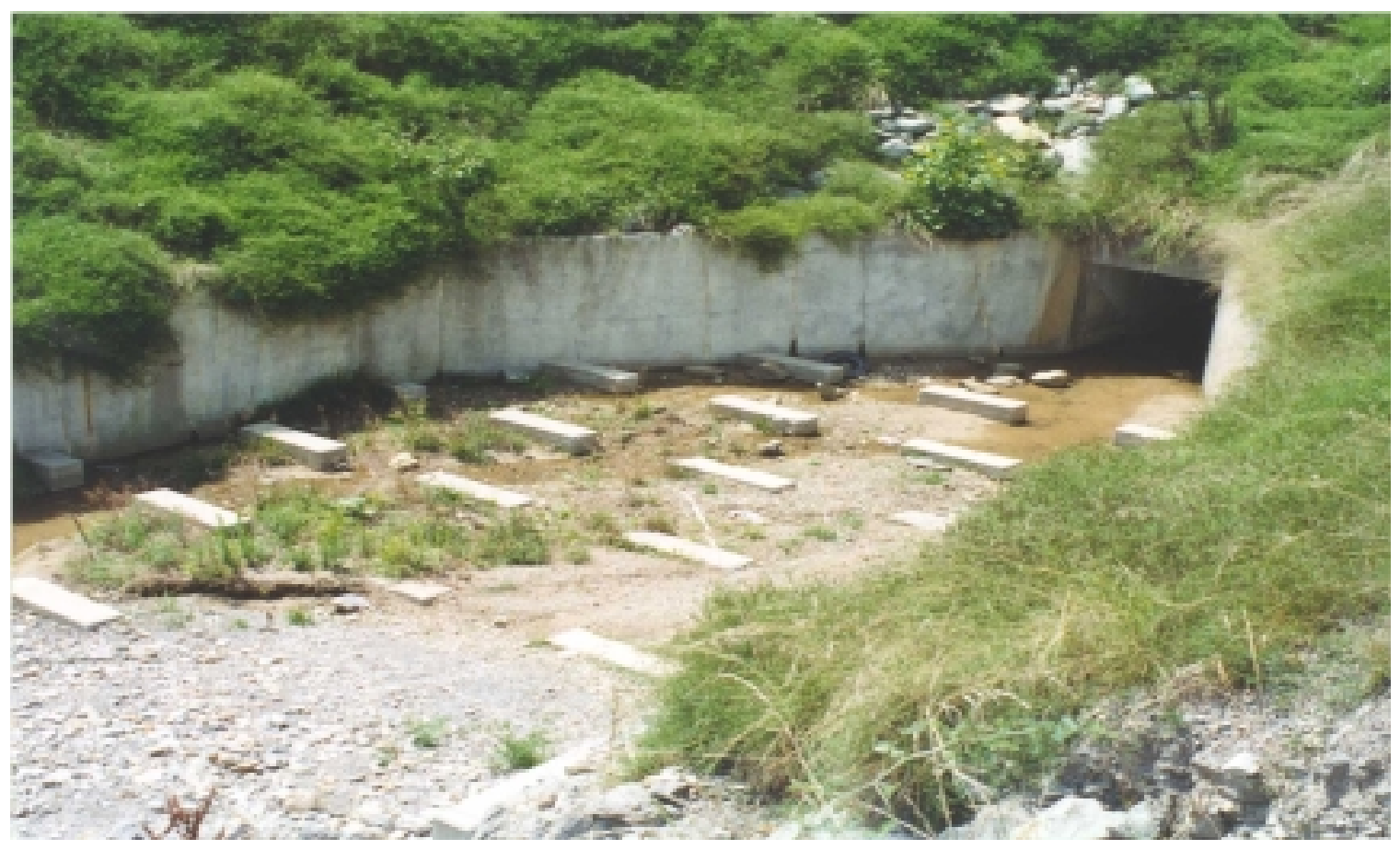

Figure 1.4.3 Failure of a Multi-Baffle Energy Dissipator

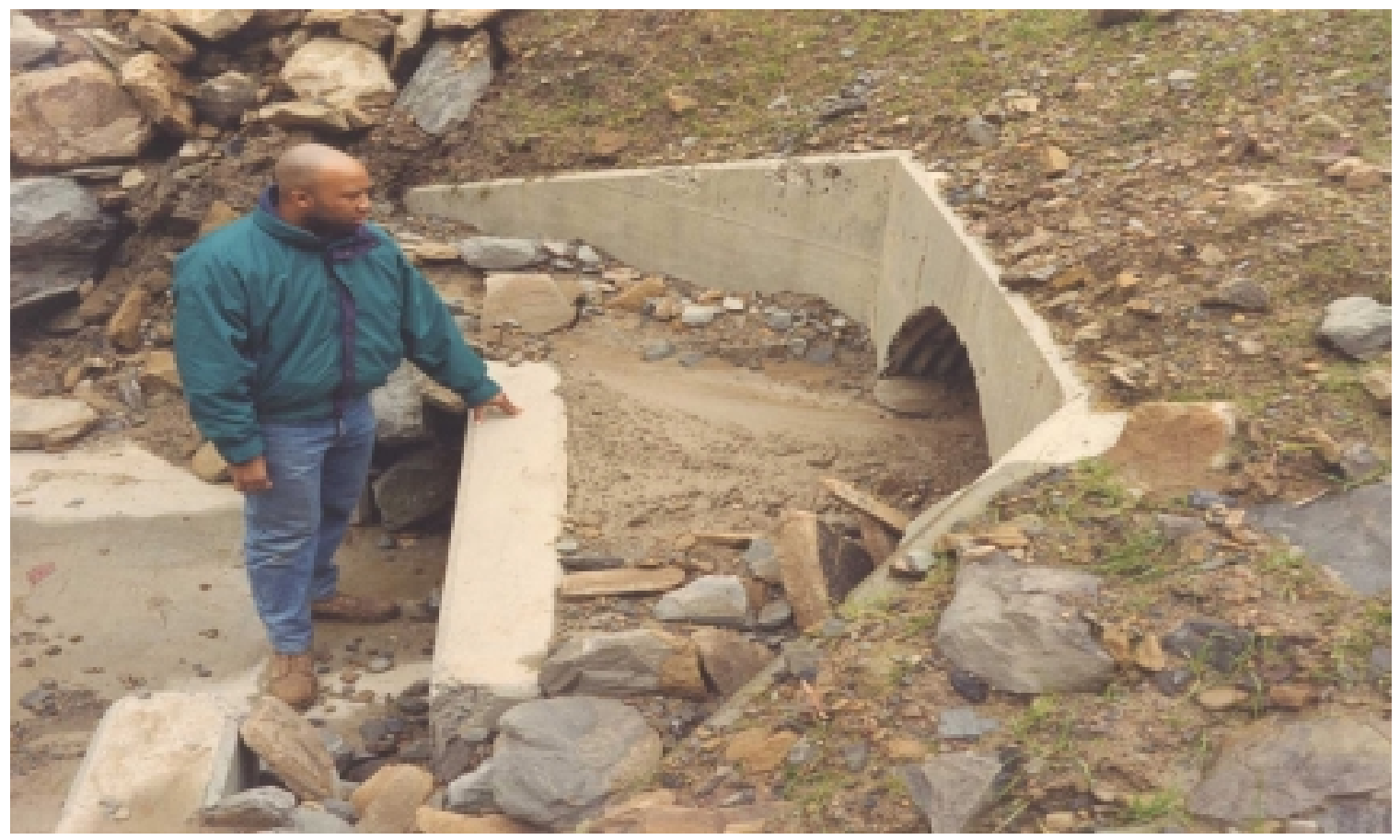

Figure 1.4.4 Failure of Baffle-type Energy Dissipator 


\section{Chapter 2 - Literature Review}

In order to produce a hydraulic jump that has characteristics of a reliable energy dissipator, it is beneficial to force a hydraulic jump to occur at a certain location and flowrate. The forced hydraulic jump is controlled by devices placed in a stilling basin and therefore can be applied much more suitably than the free hydraulic jump. The devices placed in the stilling basin are generally large polygonal shaped objects often called baffle blocks or chute blocks. The placements of baffle blocks in the stilling basin greatly aid in improving the characteristics of the forced hydraulic jump. Numerous stilling basins and energy dissipators have been fabricated for various applications in hydraulic structures. These structures range widely in many aspects due to the uniqueness of the situations in which they are applied. Since the performance of a given energy dissipator is subject to a factor of uncertainty, model studies of individual structures are usually performed. Many different energy dissipators have been designed over years of laboratory research. Upon review of various designs it becomes apparent that no general set of procedures can be determined for systematic design of an energy dissipator. Therefore to produce the most efficient design for a given situation it is necessary to model the flow specific to that situation. However, much insight can be gained by reviewing work others have performed which is the goal of this chapter. 


\subsection{The Hydraulic Jump}

When energy dissipation is required, flow must be either deflected or decelerated before being released from the dissipating structure. If this energy reduction is not accomplished effectively erosion to the downstream channel or damage to the hydraulic structure could occur. The most common way to cause this energy loss is by use of a hydraulic jump. Upstream of the hydraulic jump there are high levels of kinetic energy due to the high velocity of water exiting the hydraulic structure. This high level of energy is reduced by transferring kinetic energy to potential energy and by turbulent dissipation. The transfer to potential energy can be seen by the increase in depth downstream of the jump in the subcritical section of flow.

\subsubsection{Governing Equations}

The relationship between depths in a hydraulic jump, head loss through the jump, and the energy equation for the jump are given by (Roberson et al, 1995) for rectangular channels:

$$
\begin{aligned}
& \frac{y_{2}}{y_{1}}=\frac{1}{2}\left(\sqrt{1+8 F r_{1}^{2}}-1\right) \\
& \frac{V_{1}^{2}}{2 g}+y_{1}=\frac{V_{2}^{2}}{2 g}+y_{2}+h_{L} \\
& h_{L}=\frac{\left(y_{1}-y_{2}\right)^{3}}{4 y_{1} y_{2}}
\end{aligned}
$$

Where $\mathrm{y}_{1}$ and $\mathrm{y}_{2}$ are the upstream and downstream depths respectively, $\mathrm{V}_{1}$ and $\mathrm{V}_{2}$ are the upstream and downstream velocities, and $\mathrm{Fr}_{1}$ is the upstream Froude number. The Froude number, $\mathrm{Fr}$, is a dimensionless parameter and is important in establishing similitude between the model and prototype. The Froude number is given as:

$$
F r=\frac{V}{\sqrt{g y}}
$$

Where Fr, is the upstream Froude number, $\mathrm{V}$ and $\mathrm{y}$ are the upstream velocity and hydraulic depth, and $\mathrm{g}$ is the acceleration due to gravity. The Froude number is a ratio between flow velocity and surface wave velocity where: 


$$
F r^{2}=\frac{V^{2}}{g y}=\frac{\rho \frac{V^{2}}{y}}{\rho g} \cong \frac{\text { InertialForce }}{\text { BodyForce }}
$$

The law of similitude states that where gravitational forces predominate, as they do in open channel phenomena, the Froude number should have the same value in model and prototype (Peterka, 1958).

\subsubsection{Specific Head and Energy Loss}

Using the governing equations presented above one can calculate the energy lost in the jump by taking the difference between the specific head upstream and downstream. This difference is the loss of energy in depth of water due to the dissipation of energy caused by the jump. The upstream depth $\mathrm{y}_{1}$ and the downstream depth $\mathrm{y}_{2}$ are called conjugate depths and $\mathrm{y}_{2}$ is said to be sequent to $\mathrm{y}_{1}$ (Gray, 1999). Figure 2.1.2 shows the relationship between specific head and depth of the hydraulic jump. Specific head is the sum of the velocity head and depth relative to the local invert elevation. Note that $\mathrm{H}^{\prime}$ represents specific head and $\mathrm{H}_{1}$ ' and $\mathrm{H}_{2}$ ' represent the specific head upstream and downstream.

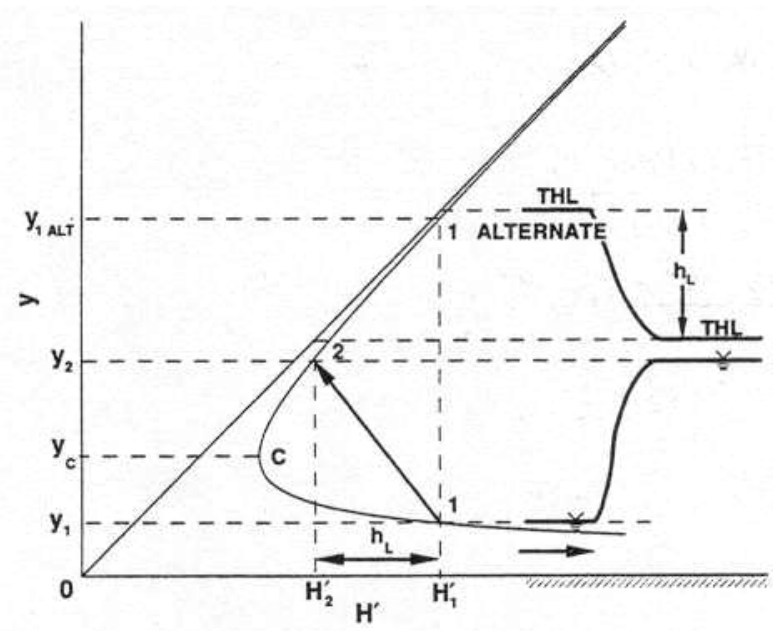

Figure 2.1.2 (Gray, 1999)

It is essential to know the magnitude of energy loss produced by the jump so that efficiencies of various dissipator designs can be evaluated. 


\subsubsection{Jump Length}

In order to determine the length of apron and height of sidewalls for a stilling basin, the length of the hydraulic jump must be determined. It is difficult to determine the length of the hydraulic jump due to its complex and random flow patterns. The formation of rollers and eddies, air entrainment, and a highly turbulent flow surface make the beginning and end of the jump difficult to locate. For practical applications, experimental data have been summarized in a non-dimensional form relating the approach Froude number, $\mathrm{Fr}_{1}$, and $\mathrm{L} / \mathrm{y}_{1}$ or $\mathrm{L} / \mathrm{y}_{2}$, where $\mathrm{L}=$ length of the jump. However, a simple but effective equation for determining the approximate length of a hydraulic jump is $\mathrm{L}_{\text {jump }}=6 \mathrm{y}_{2}$ for $4<\mathrm{Fr}_{1}<12$ (Chaudhry, 1993).

\subsubsection{Hydraulic Jump Profile}

It is necessary to determine the profile of the hydraulic jump in order to determine the amount of water that the dissipator apron must support. If the jump profile is known, the sidewalls of the dissipator can be designed to maximize economic efficiency. For example, if a given design produces a relatively shallow jump profile, the wingwall height can be minimized. For design purposes, the vertical pressure on the basin floor may be assumed to be the same as that corresponding to the hydrostatic pressure for the profile depth (Chaudry, 1993). Figure 2.1.3 shows the jump profiles for various approach Froude numbers.



Figure 2.1.3 Jump Profiles for Various Approach Froude Numbers

(Bakhmeteff and Matzke, 1936) 


\subsubsection{Hydraulic Jump Forms}

Energy absorption characteristics vary for different hydraulic jump forms. Therefore it is important to be able to classify the hydraulic jump into distinct forms. The hydraulic jump may occur in at least four different distinct forms on a horizontal apron, as shown in Figure 2.1.4 (Peterka, 1958).
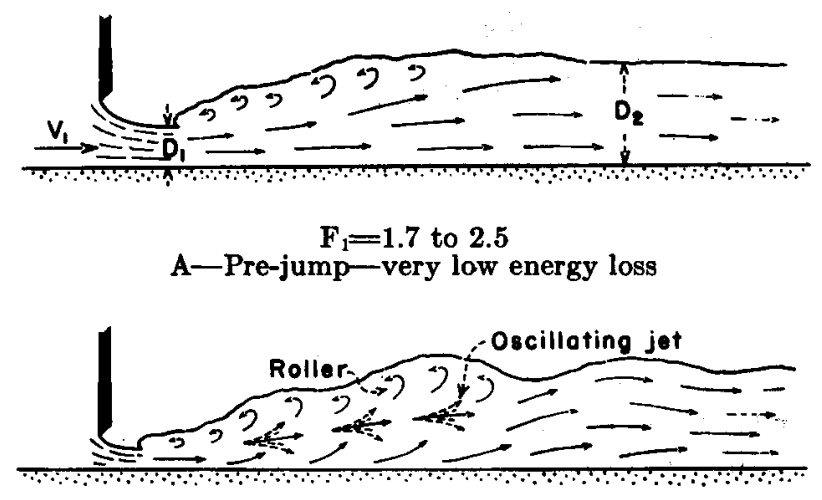

$$
\mathrm{F}_{1}=2.5 \text { to } 4.5
$$

B-Transition-rough water surface

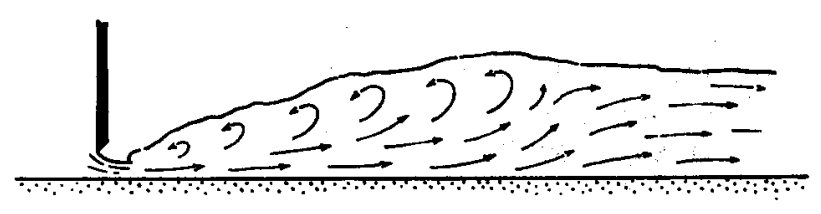

$F_{1}=4.5$ to 9.0 range of good jumps $\mathrm{C}$-Least affected by tail water variations

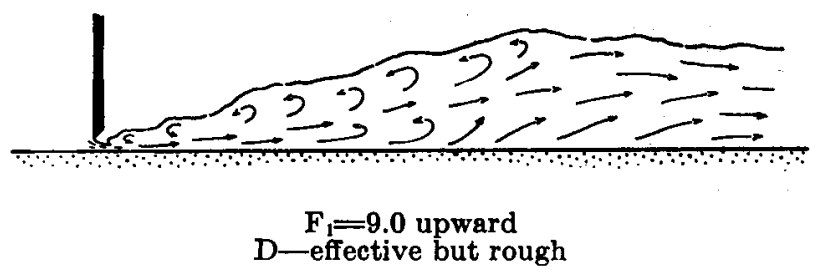

Figure 2.1.4 Hydraulic Jump Forms (Peterka, 1958)

Since the internal characteristics of the hydraulic jump vary with each form, it is convenient to catalog the jump with respect to some reference measure of the flow. This can be best accomplished by using the Froude number. Each of the four jump forms can be related to the approach Froude number and are defined as follows. 
Pre jump $\left(1<\mathrm{Fr}_{1}<2.5\right)$. For $1<\mathrm{Fr}_{1}<1.7, \mathrm{y}_{1}$ and $\mathrm{y}_{2}$ are approximately equal to each other, and only a slight ruffle is formed on the surface. This undulation results in very little energy dissipation. However as $\mathrm{Fr}_{1}$ approaches 1.7, a number of small rollers are formed on the water surface, although the downstream water surface remains smooth. The energy loss is again low in this jump.

Oscillating jump $\left(2.5<\mathrm{Fr}_{1}<4.5\right)$ The jet at the entrance to the jump oscillates from the bottom to the top at an irregular period. Turbulence may be near the channel bottom at one instant and at the water surface the next. These oscillations result in the formation of irregular waves, which may persist for long distances downstream of the jump. They may cause considerable damage to the channel banks. Therefore, this range of $\mathrm{Fr}_{1}$ should be avoided while designing an energy dissipater.

Steady jump $\left(4.5<\mathrm{Fr}_{1}<9\right)$. For this range, the jump forms steadily at the same location, and the position of the jump is least sensitive to the downstream flow conditions. The jump is well balanced and energy dissipation is considerable.

Strong jump $\left(\mathrm{Fr}_{1}>9\right)$. In this case the difference between the conjugate depths is large. At irregular intervals, slugs of water roll down the front of the jump face into the highvelocity jet and generates additional waves. The jump action is very rough and the dissipation rate is high.

(Chaudhry, 1993)

Consideration of these various forms of hydraulic jump will aid in maximizing the effectiveness of energy dissipater design.

\subsubsection{Shortcomings of the Hydraulic Jump}

A free hydraulic jump, which has been discussed to this point, is a jump that occurs without the aid of obstacles in the flowstream. The free hydraulic jump presents a desirable means for dissipating energy in high velocity flows. However, there are design considerations that make use of the free hydraulic jump generally impractical and economically undesirable. As 
seen with the oscillating case above, the hydraulic jump implemented at some ranges of Froude number can be destructive to the downstream channel as well as the hydraulic structure itself. If there is not significant tailwater depth downstream of the energy dissipator, excavation of the bed may be required in order to produce the jump (HEC 14, 1983). The main drawback of the free hydraulic jump is the length of structure needed to contain the jump to prevent the channel from being degraded (Peterka, 1978). In order to produce the most stable and economic energy dissipater, or stilling basin, it is necessary to alter these hydraulic jump characteristics.

A carefully designed stilling basin will not only improve the dissipation characteristics of a hydraulic jump, it will also shorten its length and stabilize the position of the jump so that it is not sensitive to fluctuations in tailwater level. This latter attribute makes the design safer.

(Roberson et al, 1995)

Stilling basins are seldom designed to confine the entire length of the hydraulic jump on the paved apron, first, for economic reasons, and second, because there are means for modifying the jump characteristics to obtain comparable or better performance characteristics in shorter lengths.

(Peterka, 1978)

This can be accomplished by introduction of the forced hydraulic jump. A forced hydraulic jump is caused by the artificial induction of change from supercritical flow to subcritical flow, aided by the placement of objects in the flow, which increase the conjugate depth. According to Chaudry the location of a hydraulic jump may be controlled by providing a number of appurtenances such as baffle blocks, sills, drops or rises in the channel bottom. (Chaudhry, 1993)

\subsection{Utah State University (USU) Stilling Basin}

\subsubsection{Background}

In 1970, a study was conducted at Utah State University to design a stilling basin that would serve to dissipate energy during a flow transition from closed conduit to open channel 
flow. The energy dissipation in the USU stilling basin, shown in Figure 2.2.1, is due mainly to shear drag, pressure drag, and the diffusion action of the submerged jet in the stilling basin.

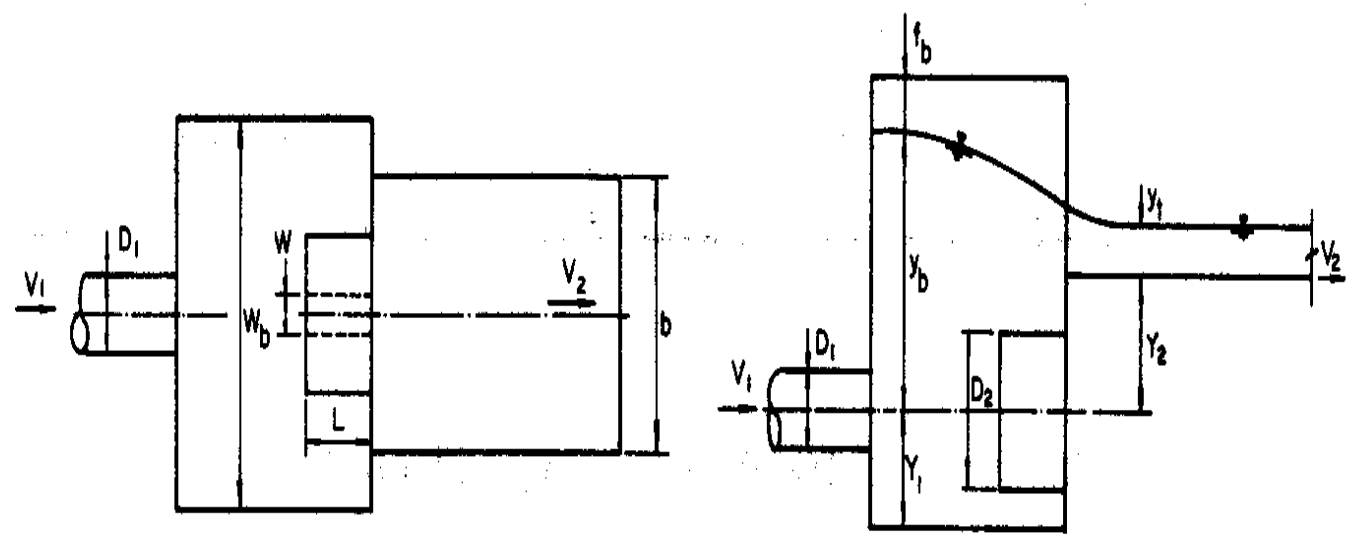

Figure 2.2.1 Utah State University Stilling Basin (Flammer et al., 1970)

Prior to the development of the basin design, the pipe entering the dissipator was investigated. The experimental equipment used for this investigation are as follows:

- $\quad 3 \frac{1}{4}$ in Diameter inlet pipe (initially) connected to a box-like stilling basin 18 in. wide and $10 \mathrm{in.} \mathrm{long}$

- A rectangular flume connected to the stilling basin with the same width as the basin

- A tail gate downstream of the basin to evaluate tail-water effects

- An elbow meter to establish discharge

In testing the dissipator pipe that would enter the USU basin, Flammer describes the procedure as follows:

In the design of the short pipe energy dissipator, the variables involved are the diameter of the dissipator pipe $\left(\mathrm{D}_{2}\right)$, the length of the dissipator pipe $(\mathrm{L})$, and the slit width $(\mathrm{W})$. In order to see how each of these variables affect the overall performance of the stilling basin, one of the three dimensions was varied while the other two were kept fixed. At the same time the geometry of the stilling basin was kept fixed.

(Flammer et al., 1970)

The criterion established for desirable results were based on the fluctuations of the water surface and boil heights. These fluctuations were measured by the use of a sonic wave transducer in conjunction with an $x-y$ recorder. Following the investigations of 
the dissipator pipe entering the USU dissipator, optimum ratios were defined. For the Slit-Width ratio (W/D) the value that established the best hydraulic performance was 0.5 and the optimum dissipator pipe length ratio (L/D) was found to be 1.0.

\subsubsection{Model Development}

Following the investigation of the pipe entering the stilling basin, design of the basin itself was completed and optimized. A steel box was constructed with a $6 \mathrm{ft}$ height, $4 \mathrm{ft}$ length, and $4 \mathrm{ft}$ width. The box was designed so that the basin dimensions could be altered by placing different false walls and floor into predetermined slots. Also a wooden flume was built to provide an outflow channel for the model basin. The general design of the USU model stilling basin is shown in Figure 2.2.2.
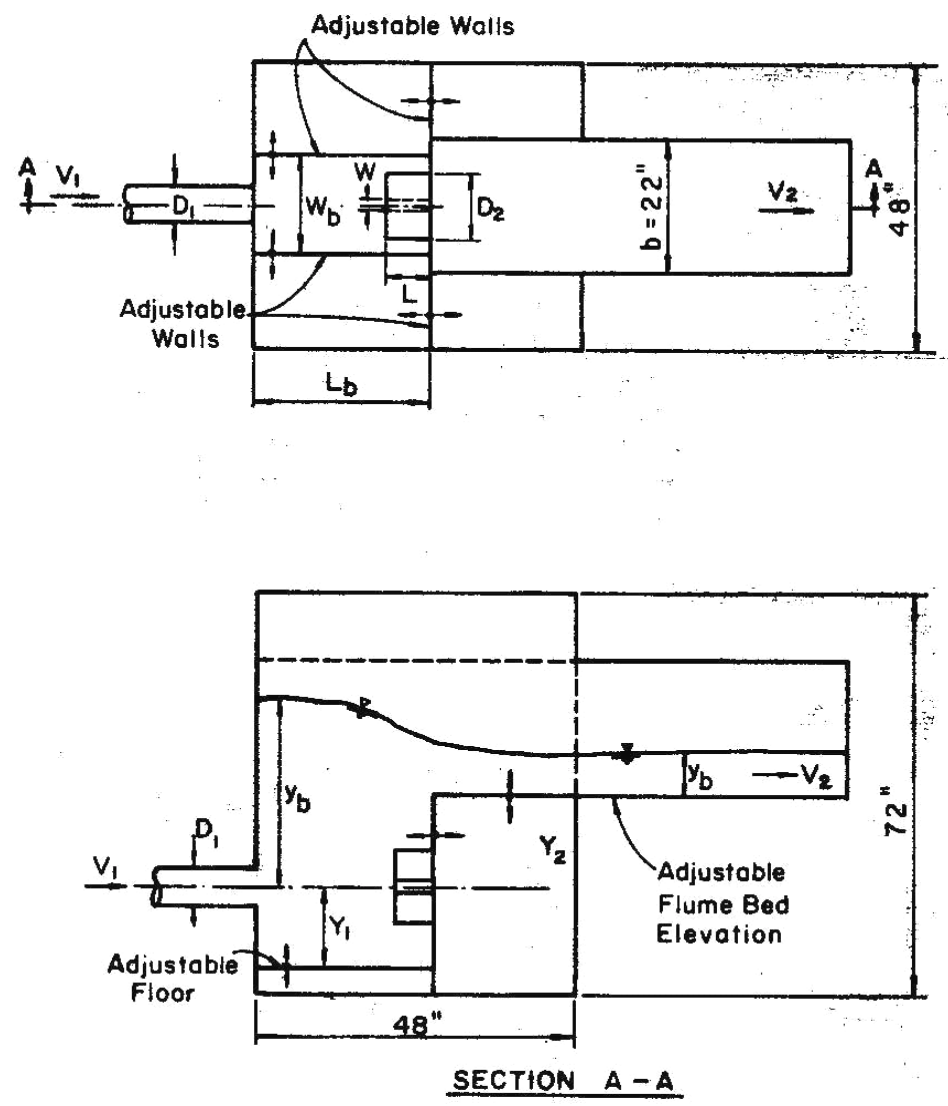

Figure 2.2.2 Model USU Stilling Basin (Flammer et al., 1970) 
The three pipe diameters that were used in testing the model were $3 \frac{1 / 4,6}{\text {, and }} 10 \mathrm{in}$. The three pipe selections were tested for various flowrates, using the ratios determined from the investigation of the inlet pipe. Next, one of the three dimensions for the basin was held fixed and the other two varied as in the inlet pipe investigation. Following experimentation, the best stilling basin width ratio was determined to be 6.77 as the greater basin width provided more lateral flow. The optimum length ratio with respect to the inlet and outlet diameter dimensions $\mathrm{D}_{1}$ and $\mathrm{D}_{2}$, shown in Figure 2.2.2 was found to be 3.5. (Flammer et al., 1970)

\subsubsection{Conclusions and Recommendations}

After the completion of experimental procedures a graphical relationship was developed to aid in the application of the design for the USU stilling basin. The relationship involved the tail water depth $y_{t}$, the outlet flume floor elevation $Y_{2}$, the height of boils in the stilling basin, and the basin width $\mathrm{W}_{\mathrm{b}}$. The stilling basin width and the amount of freeboard present, $f_{b}$, were related to the Froude number and the relative tail water elevation. Also the boil height above the tail water surface was found to be a function of the Froude number, and the relative elevation of the tail water

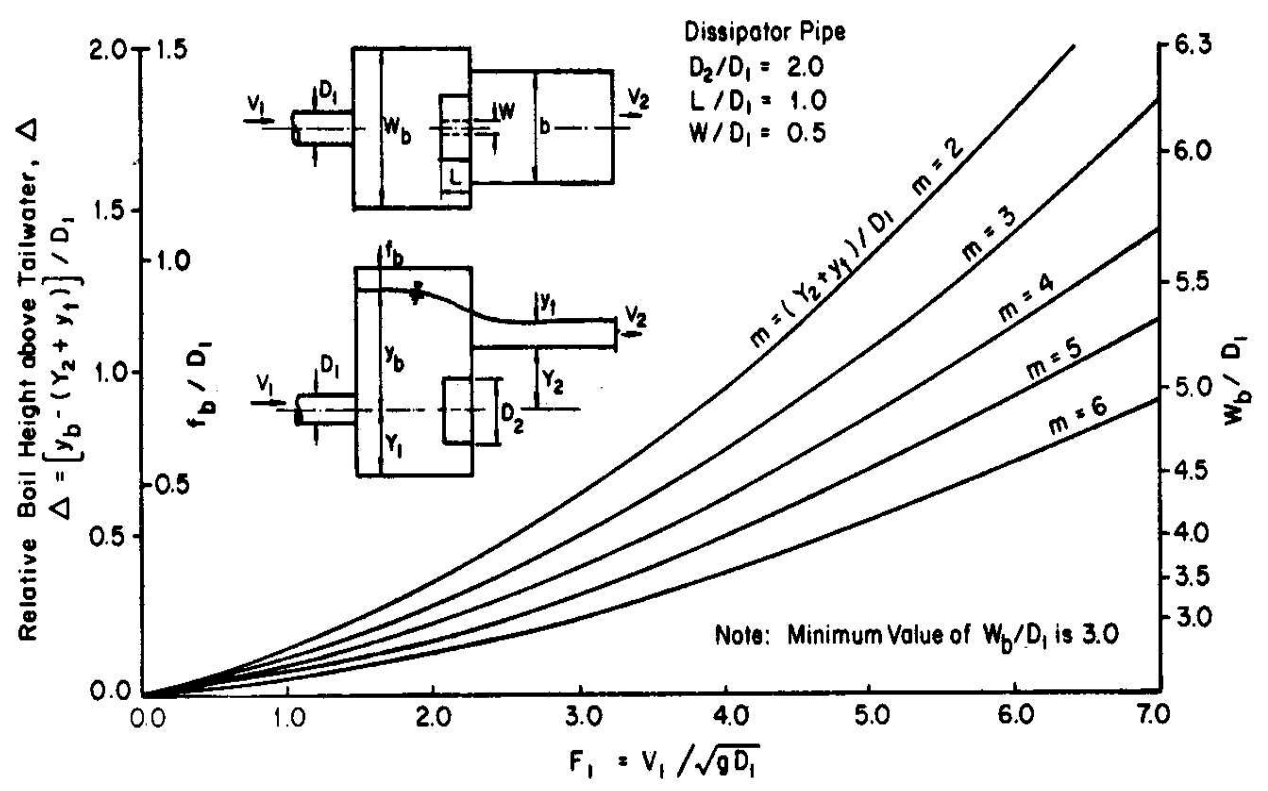

Figure 2.2.3 Design Parameters for USU Stilling Basin (Flammer et al. 1970) 
surface above the centerline of the pipe (Flammer et al., 1970). The graphical relationship for the design of the USU stilling basin is shown in Figure 2.2.3.

\subsection{Baffled Apron Spillway Dissipator}

\subsubsection{Dissipator Description}

In canal structures and some spillway works, Baffled Apron Energy Dissipators have been used as a means to dissipate the energy of a flow at a wasteway or drop. The dissipators have performed within their required design parameters in many instances with some reports of operation at twice the design discharge with no adverse effects of a short time period. In canal structures the dissipators require no tailwater, however some bed scour may occur at the outlet of the dissipator. The most favorable condition is the presence of a pool at the outlet which decreases the amount of scour, as compared to the lack of any tailwater. The dissipator generally consists of a sloping apron on a 2:1 slope with rows of evenly spaced baffled blocks along the structure. The baffles attenuate the energy related with a sudden drop in elevation by acting as an impact surface which redirects the flow (Rhone, 1977)

\subsubsection{Development}

The Baffled Apron Spillway Dissipator was developed from the observation of model studies in the laboratory and prototype operation in the field. This process was

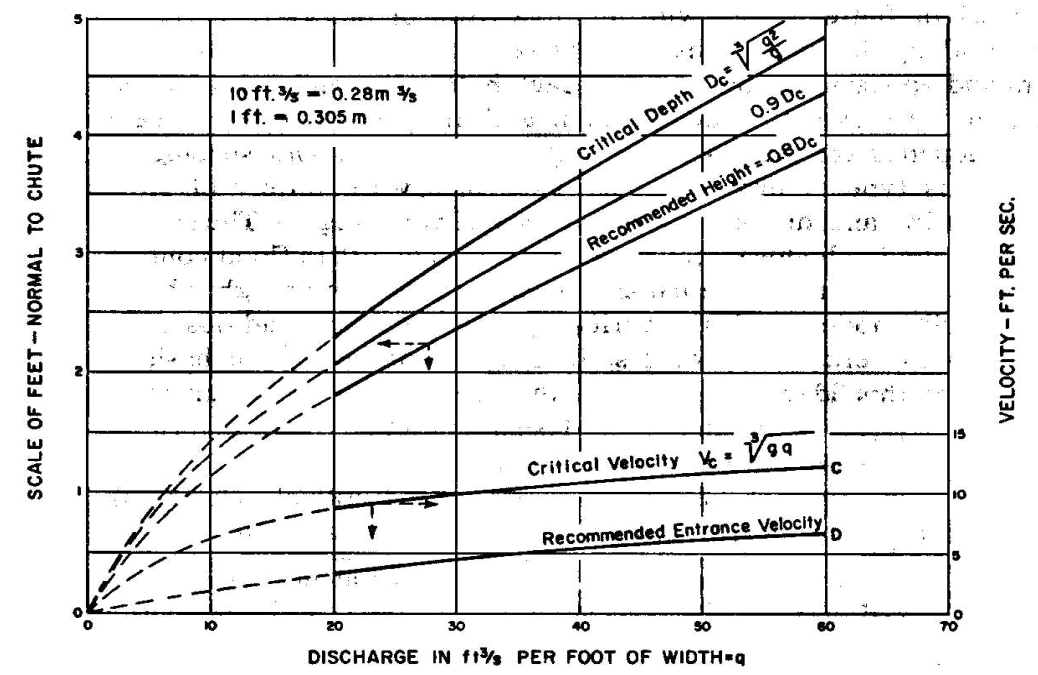

Figure 2.3.1 Design Criteria for Baffle Apron Spillway Dissipator (Rhone, 1977) 
repeated over the construction of several structures with improvements on successive designs. Some of the major concerns were excessive splashing and erosion of the channel bank. These problems were easily corrected with the use of rip-rap. Based on the studies conducted on this type of dissipator, design limitations were set and related to block height which are presented in graphical form as shown in Figure 2.3.1. The maximum unit discharge was set at $60 \mathrm{cfs} / \mathrm{ft}$ and the approach velocity had to be less than the critical velocity of the design flow based on the design discharge of the structure (Rhone, 1977).

\subsubsection{Extension of Application Range}

Once the Baffled Apron Energy Dissipator was operating successfully, there was a desire to extend the range of application of the dissipator to larger structures. The design curve was extended to higher flow discharges and new model studies were conducted. The first prototype location was at the Concully Spillway in Oregon. The Concully Spillway was designed for a unit discharge of $78 \mathrm{cfs} / \mathrm{ft}$ at a width of $150 \mathrm{ft}$, and a change in elevation of $65 \mathrm{ft}$. The dissipator operated successfully at this larger scale with a new found benefit of reducing nitrogen supersaturation in the downstream channel, which was extremely beneficial to the Oregon Department of Fish and Game. Following this success the dissipator was further studied and developed and design criteria ranged up to $300 \mathrm{cfs} / \mathrm{ft}$ for the design unit discharge. Model tests indicated that the flow conditions for the large-scale dissipator were similar to the smaller canal-type dissipators. There were typically no increase in the impact pressures after the third row of baffles and no sub-atmospheric pressures were measured (Rhone, 1977).

\subsubsection{Entrance Concerns}

The one aspect of the dissipator design that seemed in need of improvement was the entrance configuration. The first row of baffles caused an increase in water surface elevation and at times would collect debris. The first entrance developed is shown in Figure 2.3.2, along with the downstream spillway. This entrance produced the best flow conditions and was recommended if upstream water elevation is of no concern. 


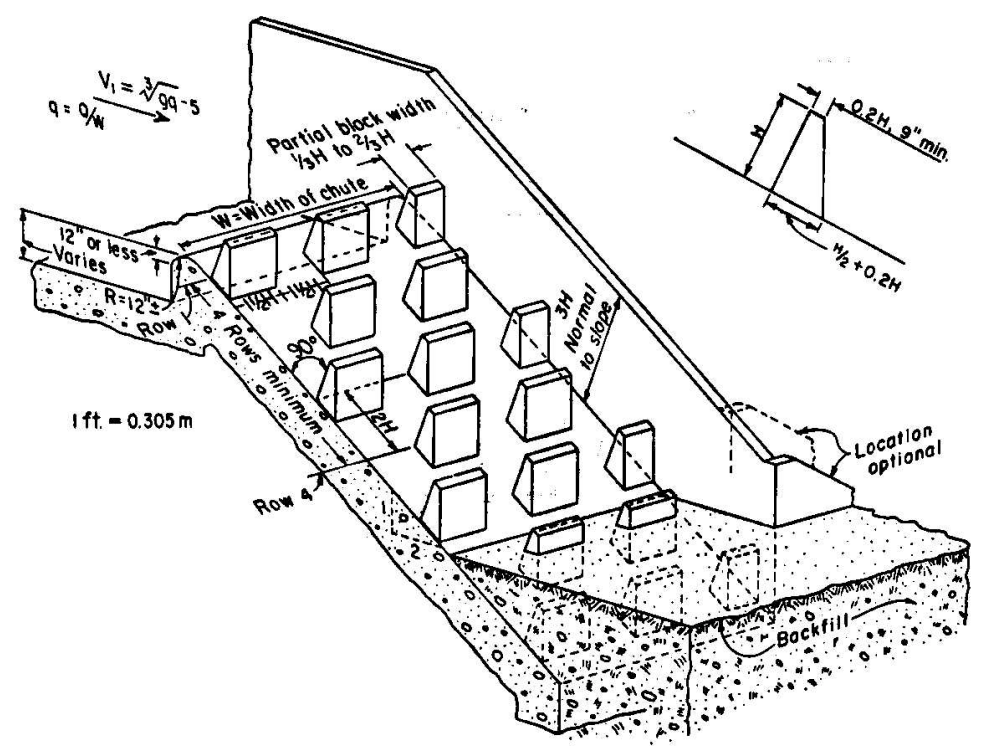

Figure 2.3.2 Entrance Configuration: Standard (Rhone, 1977)

The second entrance, entrance XVI, substituted a triangular block adjacent to the sidewalls. Upon investigation it was found that a large fin of water formed along the sidewall at the second row of blocks, but did not overtop the dissipator at the design sidewall height. The XVI entrance is displayed in Figure 2.3.3.

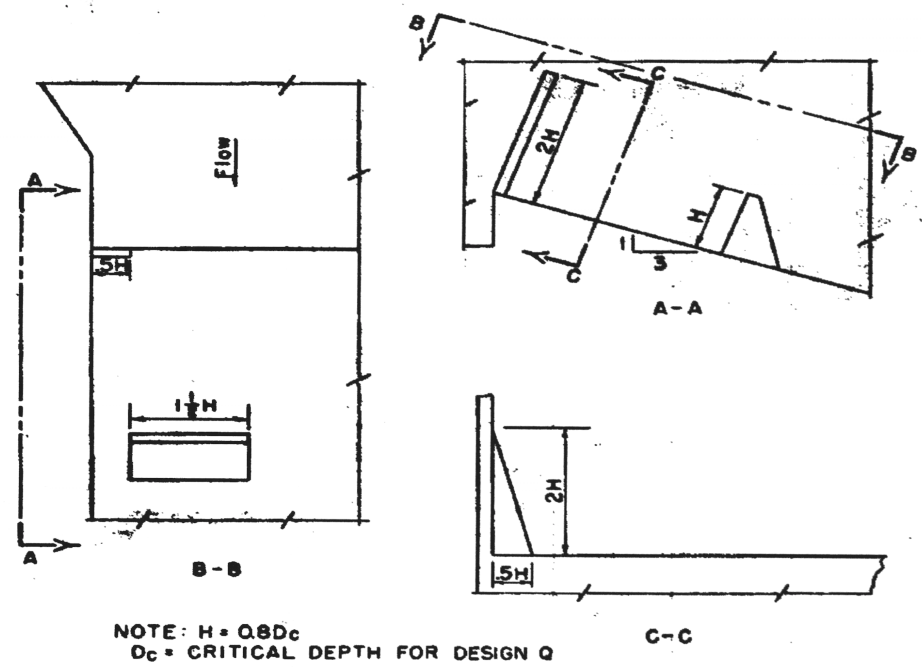

Figure 2.3.3 Entrance XVI (Rhone, 1977) 
The third entrance, termed the Fujimoto entrance, implemented a serrated broad crested weir. The weir replaced the first row of blocks and the second row of blocks were omitted. The Fujimoto entrance also produced acceptable entrance flow condition and is shown in Figure 2.3.4. Also note that the XVI and Fujimoto entrances produced no increase in upstream water elevation (Rhone, 1977).

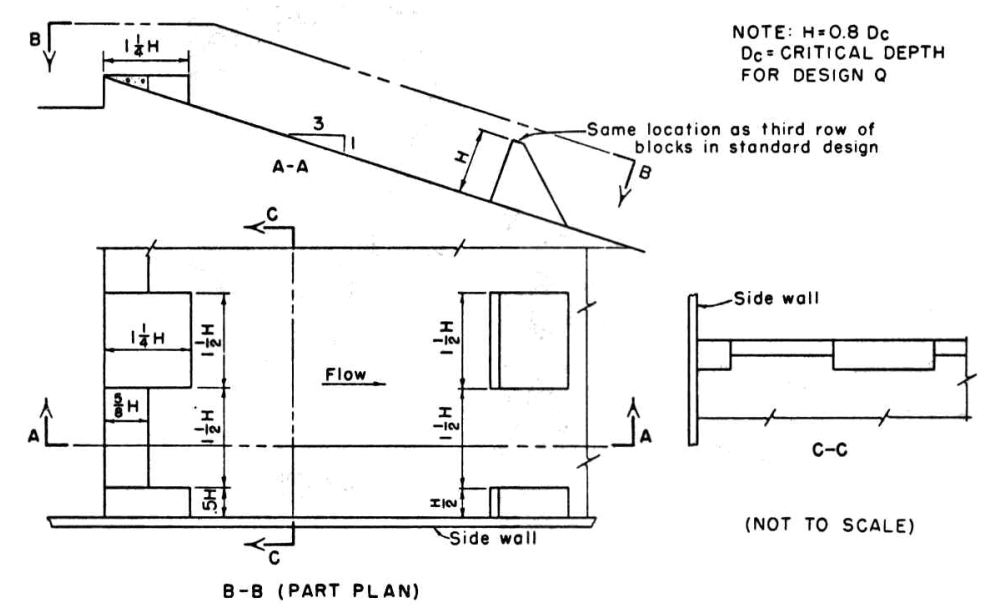

Figure 2.3.4 Fujimoto Entrance (Rhone, 1977)

\subsection{Basin II}

One obvious location that would necessitate the use of a stilling basin would be at the toe of a dam. In 1958 Peterka studied several configurations for stilling basins, one of which is designed for high earth dams and large canal structures, named Basin II. This basin employs the use of chute blocks at the upstream end and a dentated sill near the downstream end. Baffle piers (blocks) are not used in Basin II because of the relatively high velocities entering the jump ( Peterka, 1978).

The object of these tests was to generalize the design, and determine the range of operating conditions for which this basin is best suited. Since many basins of this type have been designed, constructed, and operated, some of which were checked with models, the principle task in accomplishing the first objective was to tabulate and analyze 
the dimensions of existing structures. Only structures on which firsthand information was available were used. (Peterka, 1978)

The dimensions of Basin II are shown in Figure 2.4.1, and are helpful in understanding the data collected by Peterka.

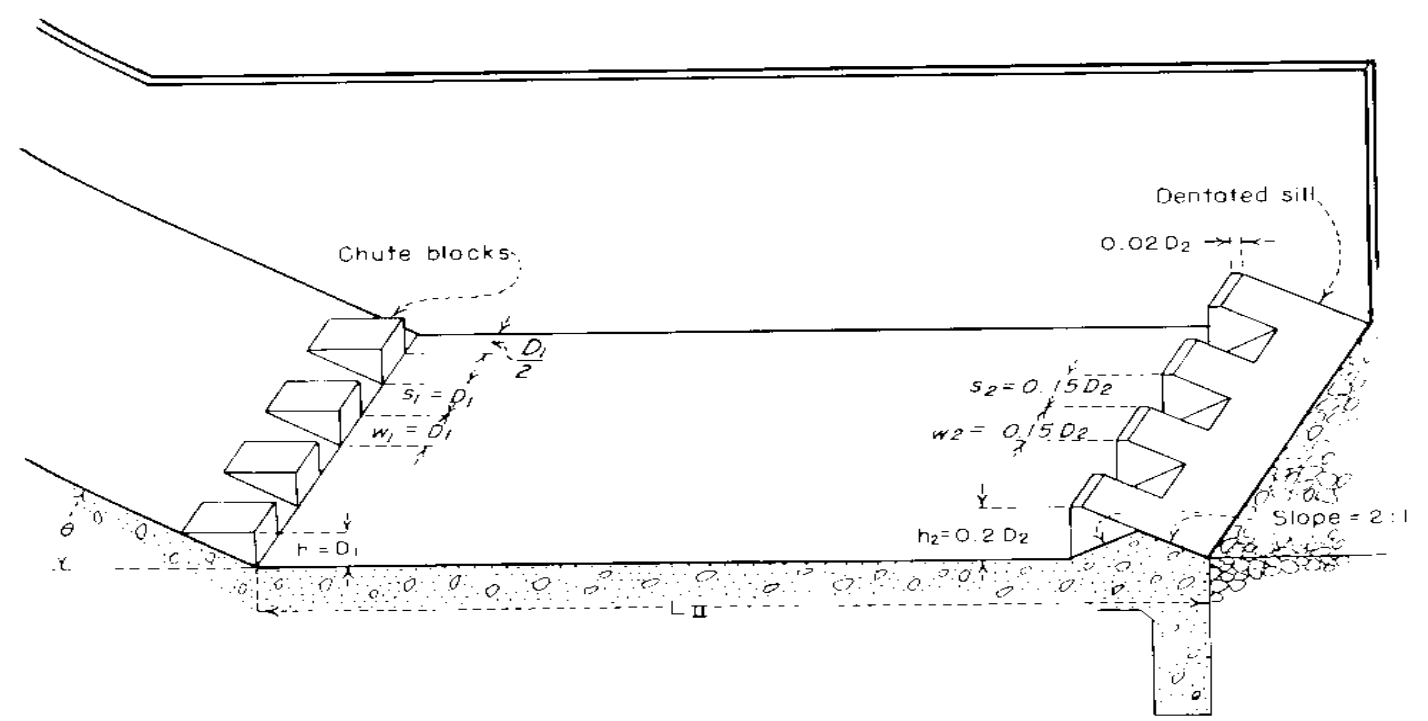

Figure 2.4.1 Basin II (Peterka, 1978)

Peterka summarized the compilation of data gathered on the Basin II energy dissipater as follows. The height of the structures studied showed a maximum fall from headwater to tailwater of 179 feet, a minimum of 14 feet, and an average of 85 feet. The width of the stilling basins ranged from 1,197.5 feet to 20 feet. The flowrate per foot of basin width varied from 760 $\mathrm{ft}^{3} / \mathrm{s}$ to $52 \mathrm{ft}^{3} / \mathrm{s}$ with $265 \mathrm{ft}^{3} / \mathrm{s}$ as the median. The calculated velocity $\mathrm{V}_{1}$ entering the basin ranged from 108 to $38 \mathrm{ft} / \mathrm{s}$. The depth of flow $\mathrm{D}_{1}$ ranged from 8.80 to $0.60 \mathrm{ft}$. The value for the Froude number varied from 4.31 to 22.00 . Finally the actual depth of tail water above the stilling basin floor ranged from 12 to $60 \mathrm{ft}$.

\subsubsection{Tail-water Depth}

Based on the data collected on Basin II, Peterka concludes that, on the average, the basin floor was set to produce the tail-water necessary for the conjugate or necessary depth. This is 
seen by the ratio of actual tail water depth to calculated conjugate depth, where the average value for the ratio was 0.99 .

\subsubsection{Chute Blocks}

The majority of the stilling basins analyzed by Peterka implemented the use of chute blocks. Where chute blocks were absent, either no devices were used or there was a solid step. Baffle and Chute blocks are somewhat similar in appearance but they function differently.

Chute blocks at the upstream end of a basin tend to corrugate the jet, lifting a portion of it from the floor to create a greater number of energy dissipating eddies, resulting in a shorter length of jump than would be possible without them. These Blocks also reduce the tendency of the jump to sweep off the apron at tail water elevations below conjugate depths. (Peterka, 1978)

\subsection{Basin III}

Basin III was found to be used most widely in short stilling basins for canal structures, small outlet works, and small spillways. Peterka explains that Basin III is often operating at relatively low discharges and therefore is too conservative and economically unfeasible. In order to reduce the costs related to Basin III it is necessary to place baffle blocks downstream of the chute blocks and simplify the parameters of the end sill. Basin III is illustrated in the following figure:

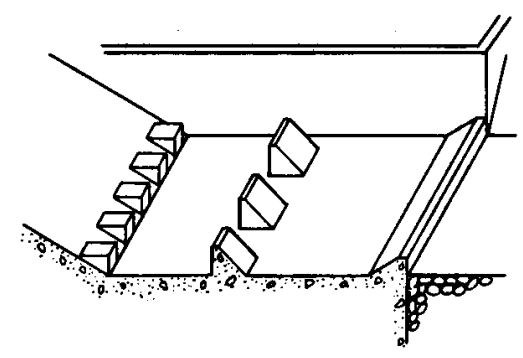

Figure 2.5.1 Basin III (Peterka, 1978)

In order to avoid the onset of cavitation on the baffle blocks the velocities at the entrance to the stilling basin are limited to 50 -60 feet per second and discharges per foot of width are to be less 
than 200 cubic feet per second. Peterka examines 14 different basins in order to generalize the range in which Basin III will operate satisfactorily.

\subsubsection{Experimental Considerations}

Peterka considers various arrangements of stilling basin configurations in order to optimize effectiveness.

The most effective way to shorten a stilling basin is to modify the jump by the addition of appurtenances, that must be self cleaning or nonclogging. This restriction limits the appurtenances to baffle piers or sills, which can be incorporated into the stilling basin apron. Numerous experiments were performed using various types and arrangements of baffle piers and sills in order to obtain the best possible solution. (Peterka, 1978)

Several tests were applied with various arrangements and are displayed in Figure 2.5.2.
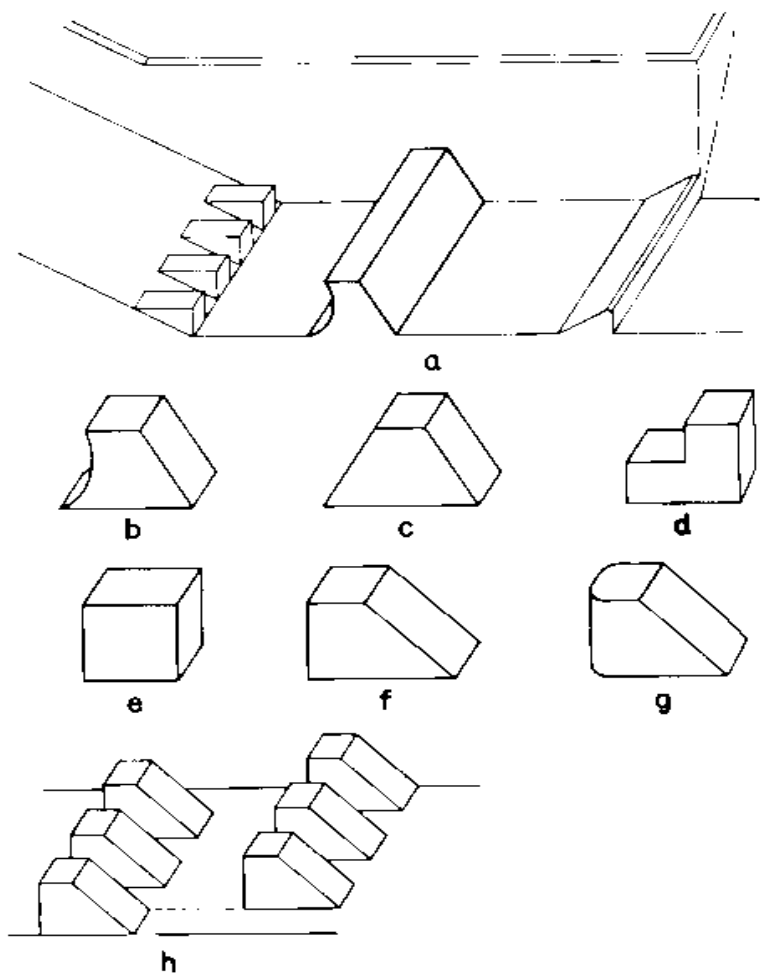

Figure 2.5.2 Baffle Shapes Investigated (Peterka, 1978) 
As seen in the above figure, arrangement (a) consists of chute blocks followed by a solid curved wall and an end sill. Following several tests with the curved wall at various locations Peterka concluded that arrangement (a) required a significant tail water depth in order to be effective. Next Peterka replaced the solid curved wall (a) with Baffle blocks (b). The baffle blocks performed well at certain dimensions and produced a water surface profile similar to that shown in Figure 2.5.3.

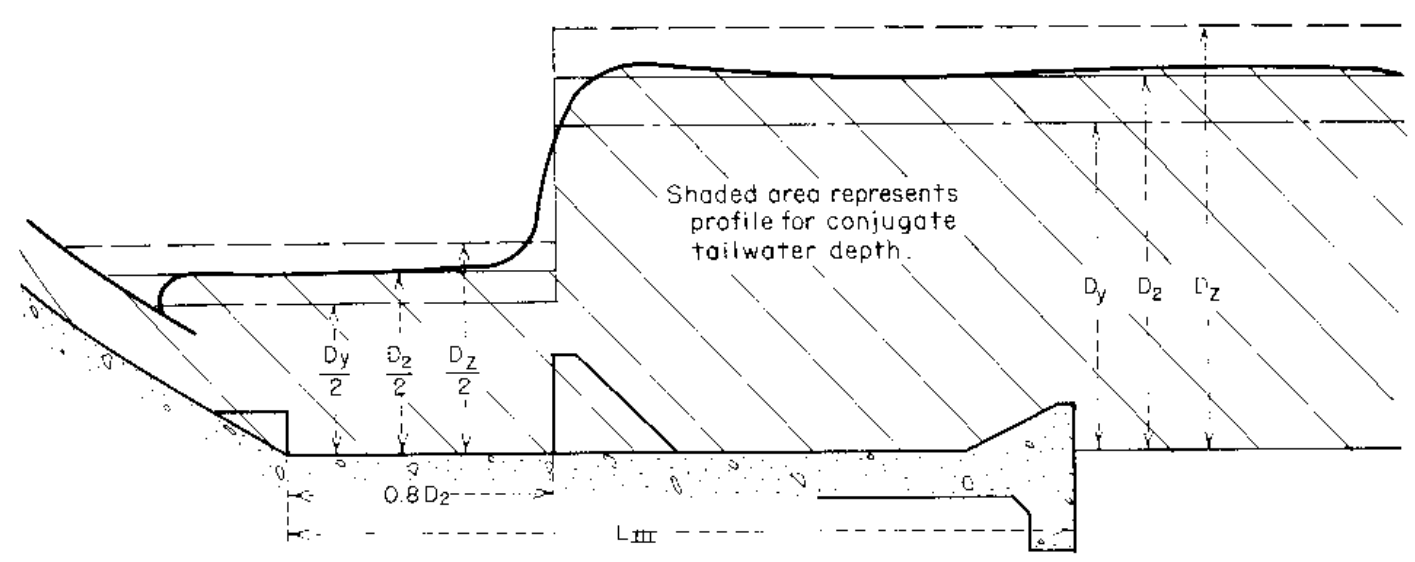

Figure 2.5.3 Water Surface Profile (Peterka, 1978)

Peterka terms block (c) ineffective since a high velocity jet shot over the front surface and the downstream conditions were turbulent with waves. Block (d) was used in single and double rows and produced a similar effect as to that shown by (c). Block (e) was found to be effective when the optimal dimensions were found. The jump formed by the use of Block (e) displayed a nearly vertical upstream face and the downstream section was nearly flat and smooth. Block (f) produced nearly identical results as Block (e), which Peterka attributes to the vertical upstream face. Block ( $\mathrm{g}$ ) is identical to Block (f) with rounded corners. It was found that the rounding of the corners dramatically reduced the effectiveness of the device. From these tests Peterka concludes that the vertical upstream face is of key importance to the formation of an effective and stable jump. He also concludes that the use of a second row of blocks, arrangement (h), was of little effect (Peterka, 1978).

In fact, a double row of blocks that had rounded corners did not perform as well as a single row of blocks "b", "e", or "f." Even slight rounding of the corners tended to 
streamline the block and reduce its effectiveness as an impact device. As block " $\mathrm{f}$ " is usually preferable from a construction standpoint, it was used throughout the remaining tests to determine a general design with respect to height, width, spacing, and position on the apron. (Peterka, 1978)

In addition to studying the effects of baffle block arrangement the characteristics of the end sill were also examined. It was determined that when the chute and baffle blocks were arranged properly, the end sill was of little or no effect. It was therefore concluded that a dentated end sill was not required and that any solid type of end sill would be efficient. The only function served by the end sill, after the chute and baffle blocks are arranged correctly, is to direct any remaining bottom currents upward to prevent scour.

The generalized final design, as defined by Peterka is shown in figure 2.5.4.

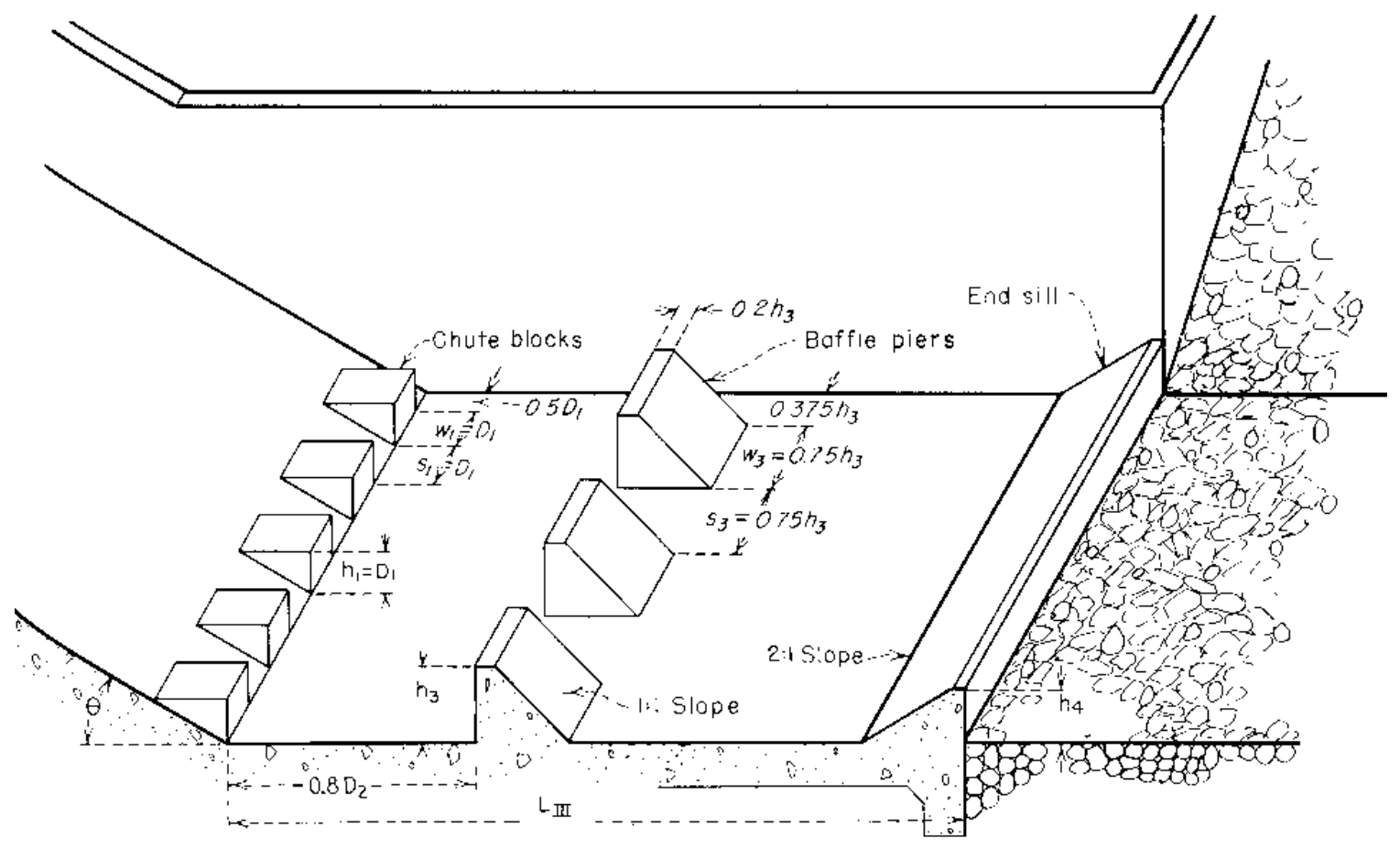

Figure 2.5.4 General Design of Basin III (Peterka, 1978)

Peterka describes this basin as using impact as its primary dissipation force where the baffle blocks perform the brunt of the work. The chute blocks are implemented to aid in stabilizing the jump and directing the upstream flow, and the end sill is for scour control (Peterka, 1978). 


\subsubsection{Performance}

Basin III proved to be more hydraulically stable than Basin I and II, Basin I being the formation of a hydraulic jump on a horizontal apron. Basin III produced a steep face at the upstream end of the jump and there was a decreased amount of action due to waves downstream. Basin III also has a large factor of safety against sweepout and operates satisfactorily for Froude numbers greater than 4.0. Cavitation becomes a concern when approach velocities are greater than 50- 60 feet per second. Peterka suggests the use of Basin II when high velocities are expected, to avoid cavitation damage on the baffle blocks. From Figure 2.5.4 notice that the height, width and spacing of the chute blocks are equal to D1. Peterka discourages the use of chute blocks greater than D1 due to the "overshooting" of the baffle blocks that may occur. The height of the baffle blocks increased with Froude number and the most effective width and spacing was determined to be $3 / 4 \mathrm{~h}_{3}$. Peterka discourages staggering the chute and baffle blocks, since there is no increase in the effectiveness and construction difficulties arise. The best location of the baffle blocks was found to be $0.8 \mathrm{D}_{2}$ where $\mathrm{D}_{2}$ is the conjugate tail water depth. Deviation from the suggested dimensions may produce cascades, jump sweepout, waves and other effects that decrease the efficiency of the dissipator. The most effective baffle blocks found by this study were shapes (e) and (f). Peterka again cautions that rounding the edges of a baffle block reduce the occurrence of eddies which aid in energy attenuation and should therefore be avoided. A tail water depth equal to the conjugate depth is recommended for Basin III. If the tail water depth is less than conjugate depth, exiting surface velocities are high and the chances for the occurrence of scouring effects are increased. Also, if the baffle blocks are eroded over their service life, having a tail water depth equal to the conjugate depth will aid in increasing the life of the block (Peterka, 1978).

\subsubsection{Basin III Rules and Recommendations}

Based on the experimental data and verification tests performed by Peterka on Basin III the following set of rules and recommendations is presented.

1. Basin III operates most efficiently when the tail water depth is equal to the conjugate depth $\mathrm{D}_{2}$. 
2. The length of Basin III can be found from Figure 2.5.5, shown below. Notice that the length needed for Basin III is one half the length needed for a "free" jump on a horizontal apron.

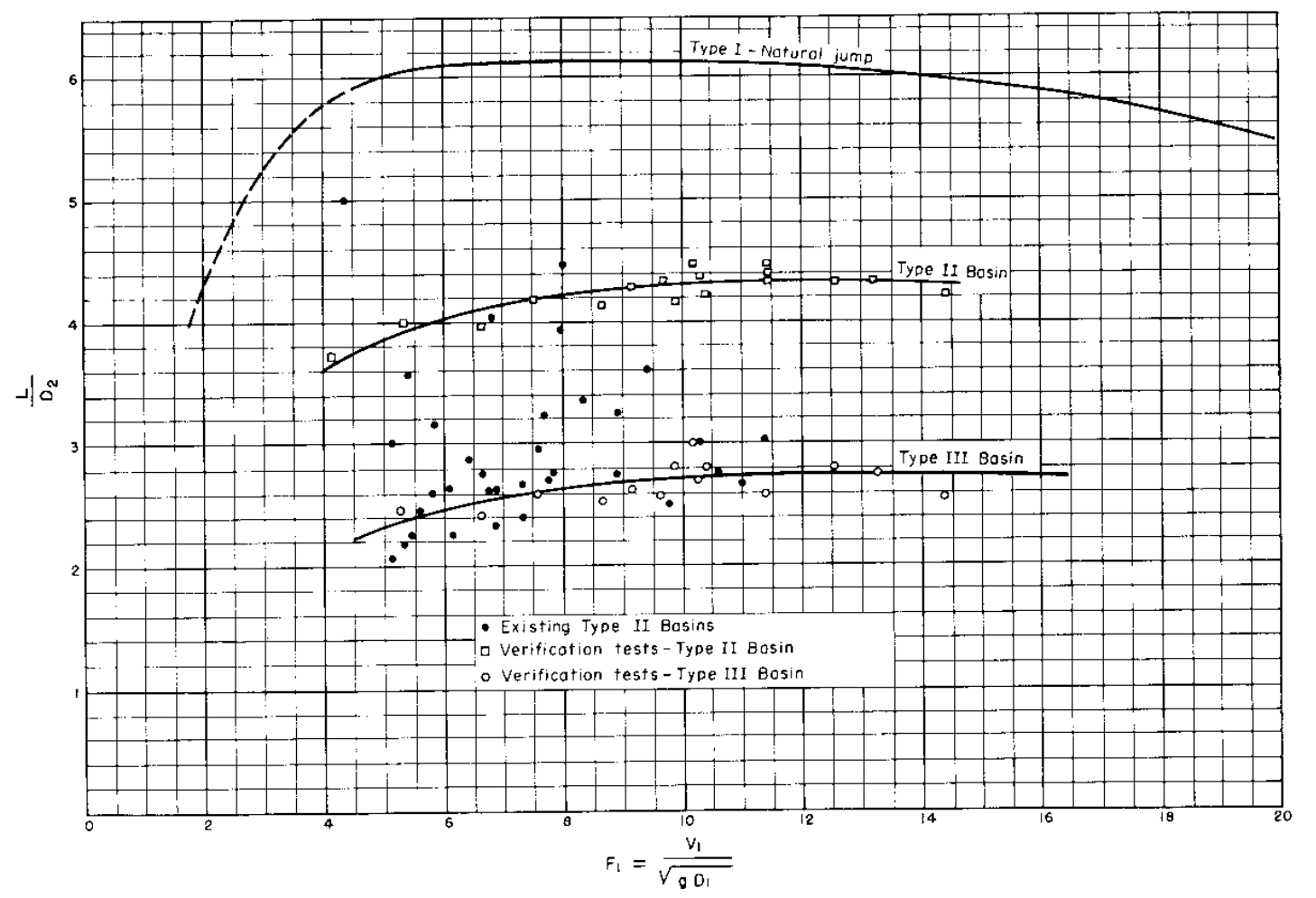

Figure 2.5.5 Basin III Length Determination (Peterka, 1978)

3. Basin III is applicable for Froude numbers as low as approximately 4.0.

4. The height, width, and spacing of the blocks are determined by the average depth of flow entering the basin, $\mathrm{D}_{1}$. Width of the blocks can be decreased as long as spacing is decreased a like amount. If the flow entering the basin is less than 8 inches, the block height should be no less than 8 inches.

5. The most effective baffle block is one that has a vertical upstream face.

6. The upstream face of the baffle block should be $0.8 \mathrm{D}_{2}$ from the downstream face of the chute blocks.

7. The slope of the end sill is 2:1 upward in the direction of flow.

8. Rounding the baffle blocks, chute blocks, or end sill may reduce their effectiveness by fifty percent. To prevent rounding due to erosion, Chamfers may be applied. 
9. For slopes greater than 45 degrees a radius of $R>4 D_{1}$ be used at the intersection of the chute and basin apron.

10. The slope of the chute has little effect on the jump unless long flat slopes are present.

\subsection{Basin VI}

Another stilling basin investigated by Peterka is sometimes termed the "Hanging Baffle" energy dissipator. This dissipator is based on impact attenuation and is contained in a box-like structure that is small compared to other dissipator structures. One important feature of Basin VI is that it does not require any tail water depth to be effective. Basin VI is designed mainly for pipe and small outlet works but it is possible to modify it to accommodate open channel flow. Basin VI is designed to accommodate velocities up to approximately 30 feet per second. For discharges greater than this several basins can be constructed side by side to accommodate the flow. Basin VI is more effective at dissipating energy than a hydraulic jump at the same Froude number.

Basin VI was developed to handle the need for 50 or more energy dissipators that were to be used on an irrigation project. The basins had to be relatively small and were required to operate without tail water. Instead of preparing 50 separate model studies, Peterka developed a single setup that could be modified to simulate a range of expected field conditions.

\subsubsection{Testing}

Hydraulic models were constructed that could be scaled up to predict the performance of the prototype in the field. Basin VI was tested in a tail box that had a trapezoidal channel constructed of gravel to approximate downstream conditions. Gravel sizes were varied throughout the experiments and a tailgate was constructed downstream to evaluate tail water effects.

It was decided that some device placed in the dissipator was needed that would produce the same results downstream of the dissipater no matter what conditions were imposed upstream. The vertical "hanging baffle" produced the same results downstream regardless of the upstream conditions, within the limits defined. This greatly aided the design by eliminating some variables form the design considerations. Following this variable reduction it was found that for 
velocities less than 30 feet per second, the width of the basin became a function of discharge as seen in Figure 2.6.1.
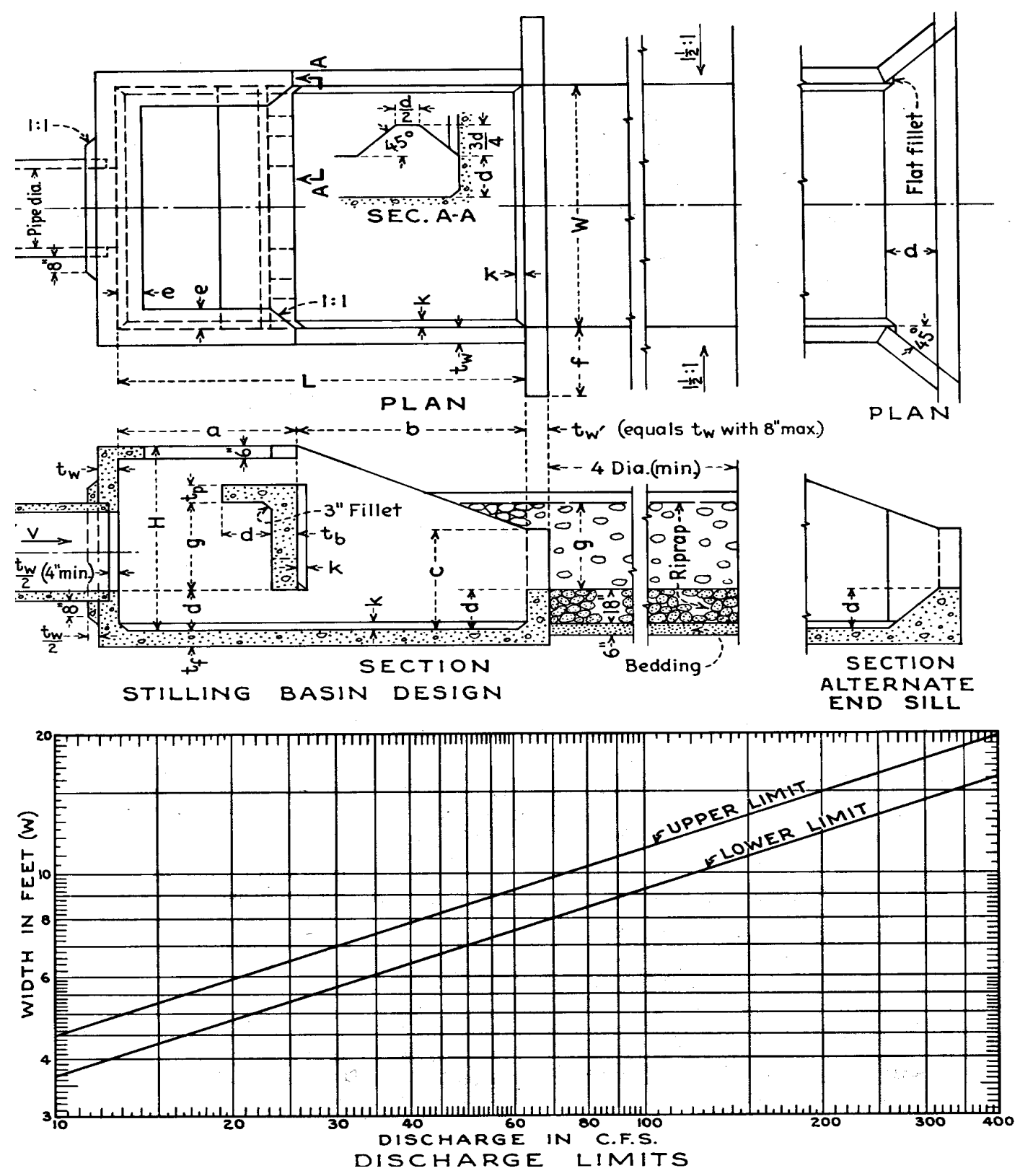

Figure 2.6.1 (Peterka, 1978)

Various tests were performed to determine the upper and lower limit lines of Figure 2.6.1. Once these lines were determined an average was taken to determine the most likely width of basin per given discharge (Peterka, 1978). 


\subsubsection{Energy attenuation}

In Basin VI, energy reduction is accomplished by the impact of the flow with the vertical hanging baffle. The horizontal portion of the baffle and the floor of the apron serve to create eddies and aid in energy dissipation. These factors eradicate the need for tail water depth that would be needed for a hydraulic jump basin. Having tail water present will improve the performance of Basin VI in creating a smoother water surface profile downstream and reducing the chance for erosion. However, excessive tail water depth will cause the overtopping of the hanging baffle, which is not desired (Peterka, 1978).

\subsubsection{Basin VI Rules and Recommendations}

Based on the experimental data and verification tests performed by Peterka on Basin VI the following set of rules and recommendations is presented.

1. Basin VI should be used where the velocity at the entrance to the stilling basin does not greatly exceed 30 feet per second.

2. The dimensions of basin VI are determined from the maximum discharge, and multiple units placed side by side may be the most economical in certain cases.

3. The necessary pipe area is to be computed from the expected velocity and discharge. If an open channel is implemented in lieu of a pipe, the channel should be narrower than the basin with an invert elevation the same as the pipe.

4. Moderate tail water depth will improve the effectiveness of the basin, although it is not necessarily required. For best performance apply a tail water equal to $\mathrm{d}+\mathrm{g} / 2$.

5. Suggested thicknesses of various dimensions of the basin are given in Table 2.6.1 in columns 14 through 18. 


\begin{tabular}{|c|c|c|c|c|c|c|c|c|c|}
\hline 1 & 2 & 3 & 4 & 5 & 6 & 7 & 8 & 9 & \\
\hline Diameter (in.) & Area (ft2) & $\begin{array}{l}\text { Max Discharge } \\
\text { Q (second- } \\
\text { feet) }\end{array}$ & W & $\mathrm{H}$ & $\mathrm{L}$ & a & $b$ & $c$ & \\
\hline 18 & 1.77 & 21 & 5'6" & 4'3" & 7'4" & 3'3" & 4'1" & $2^{\prime} 4^{\prime \prime}$ & \\
\hline 24 & 3.14 & 38 & 6'9" & 5'3" & $9^{\prime}$ & 3'11" & 5'1" & $2^{\prime} 10^{\prime \prime}$ & \\
\hline 30 & 4.91 & 59 & $8^{\prime}$ & 6'3" & $10^{\prime} 8 "$ & $4^{\prime} 7^{\prime \prime}$ & 6'1" & 3'4" & \\
\hline 36 & 7.07 & 85 & 9'3" & 7'3" & $12^{\prime} 4 "$ & $53^{\prime \prime}$ & 7'1" & 3'10" & \\
\hline 42 & 9.62 & 115 & $10^{\prime} 6 "$ & $8^{\prime}$ & $14^{\prime}$ & $6^{\prime}$ & $8^{\prime}$ & $4{ }^{\prime} 5^{\prime \prime}$ & \\
\hline 48 & 12.57 & 151 & $11 ' 9 "$ & $9^{\prime}$ & $15^{\prime} 8^{\prime \prime}$ & 6'9" & 8'11" & 4'11" & \\
\hline 54 & 15.9 & 191 & $13^{\prime}$ & 9'9" & $17^{\prime} 4 "$ & $7^{\prime} 4^{\prime}$ & $10^{\prime}$ & $5^{\prime} 5^{\prime \prime}$ & \\
\hline 60 & 19.63 & 236 & 14'3" & $10 ' 9 "$ & $19^{\prime}$ & $8^{\prime}$ & $11^{\prime}$ & 5'11" & \\
\hline 72 & 28.27 & 339 & $16^{\prime} 6 "$ & 12'3" & 22 & 9'3" & $12 ' 9^{\prime \prime}$ & 6'11" & \\
\hline 10 & 11 & 12 & 13 & 14 & 15 & 16 & 17 & 18 & 19 \\
\hline$d$ & e & $f$ & $\mathrm{G}$ & Tw & $\mathrm{Tf}$ & tb & $\mathrm{tp}$ & $\mathrm{K}$ & $\begin{array}{l}\text { Suggested } \\
\text { RipRap Size }\end{array}$ \\
\hline 0'11" & 0'6" & 1'6" & 2'1" & 6" & $6.5^{\prime \prime}$ & 6" & 6" & 3" & 4" \\
\hline 1'2" & 0'6" & $2^{\prime}$ & 2'6" & 6" & $6.5^{\prime \prime}$ & 6" & 6" & 3" & 7" \\
\hline 1'4" & 0'8" & 2'6" & $3^{\prime}$ & 6" & $6.5^{\prime \prime}$ & 7" & 7" & 3" & $8.5^{\prime \prime}$ \\
\hline 1'7" & 0'8" & $3^{\prime}$ & 3'6" & 7" & 7.5" & 8" & 8" & 3" & 9.0" \\
\hline 1'9" & 0'10" & $3^{\prime}$ & 3'11" & 8" & 8.5" & 9" & 8" & 4" & $9.5^{\prime \prime}$ \\
\hline $2^{\prime}$ & 0'10" & $3^{\prime}$ & 4'5" & $9^{\prime \prime}$ & $9.5^{\prime \prime}$ & $10 "$ & 8" & 4" & $10.5^{\prime \prime}$ \\
\hline 2'2" & $1^{\prime}$ & $3^{\prime}$ & 4'11" & 10" & $10.5^{\prime \prime}$ & $10 "$ & 8" & 4" & 12.0" \\
\hline 2'5" & $1^{\prime}$ & $3^{\prime}$ & $5^{\prime} 4^{\prime \prime}$ & $11 "$ & $11.5^{\prime \prime}$ & $11 "$ & 8" & 6" & 13.0" \\
\hline 2'9" & 1'3" & $3^{\prime}$ & 6'2" & $12^{\prime \prime}$ & $12.5^{\prime \prime}$ & $12 "$ & 8" & 6" & 14.0" \\
\hline
\end{tabular}

Table 2.6.1 Basin VI Dimensions (Peterka, 1978)

6. Suggested sizes for the riprap protective blanket are given in column 19 of

Table 2.6.1. This value represents the minimum size of stone that will not be susceptable to movement in the flow. The rock size selected should be equal or greater to the size given in Table 2.6.1. One equation applicable for determining the size of stone, assuming the rock has a specific gravity of 2.65 is: $\quad \mathrm{Vb}=2.6^{*}(\mathrm{~d})^{\wedge}(1 / 2)$

where $\mathrm{V}_{\mathrm{b}}=$ bottom velocity in feet per second $\mathrm{d}=$ diameter of rock in inches

This equation is accurate up to velocities of 16 feet per second, in excess of this velocity accuracy is unknown.

7. The inlet of the pipe or channel can be tilted downward up to 15 degrees 
without harming the performance of the basin. For slopes greater than 15 degrees a length of horizontal pipe should be placed just upstream of the basin at approximately 2 or more diameters in length.

8. A vent, approximately one-sixth the pipe diameter in size may need to be installed if a hydraulic jump is expected to form in the downstream length of pipe. The vent can be located at any location upstream of the jump.

9. The implementation of an end sill and a 45 degree wall design will reduce chances of erosion and produce the best overall performance.

\subsection{SAF Stilling Basin}

The St. Anthony Falls, SAF, stilling basin was developed to implement the use of a hydraulic jump to dissipate energy. Model studies were performed to develop design criteria for the basin by the Soil Conservation Service at the University of Minnesota. The basin is intended for use on small spillways, canals, and outlet works, for Froude numbers ranging from 1.7-17. The basin length is reduced to 80 percent of the length of a free hydraulic jump basin by the use of chute blocks, baffle blocks, and an end sill (Blaisdell, 1959).

\subsubsection{Design Procedures}

For non-circular culverts the width of the basin $\mathrm{W}_{\mathrm{B}}$ is equal to the width of the culvert $\mathrm{W}_{\mathrm{O}}$. If the basin is applied to a circular conduit, the width of the basin, $\mathrm{W}_{\mathrm{B}}$, is given by the following equation:

$$
W_{B}=0.3\left|\frac{Q}{D^{2.5}}\right|
$$

In determining the length of the basin, $\mathrm{L}_{\mathrm{B}}$, the proportional relationship between the Froude number range, 1.7-17, and the theoretical sequent depth was utilized, found from the hydraulic jump equation.

$$
y_{j}=y_{1} \frac{\left(\sqrt{1+8 F r_{1}^{2}}-1\right)}{2}
$$


Next an equation for $L_{B}$ is developed:

$$
L_{B}=4.5 \frac{y_{j}}{F r^{0.76}}
$$

The width and spacing of the chute blocks used to direct the flow is equal to $0.75 \mathrm{y}_{1}$, with a height equal to $\mathrm{y}_{1}$. Staggering of the baffle blocks with respect to the chute blocks should be performed and placement should be $\mathrm{L}_{\mathrm{B}} / 3$ downstream of the chute blocks. The baffle blocks should occupy 40-50 percent of the basin width and should not be closer than $3 \mathrm{y}_{1} / 8$ to the sidewalls. The end sill height is defined as $0.07 \mathrm{y}_{\mathrm{j}}$, with $\mathrm{y}_{\mathrm{j}}$ being the theoretical sequent depth based on $\mathrm{y}_{1}$. The construction of wingwalls should be of equal length and height to the sidewalls of the basin and the wingwall top slope should be 1:1. If the wingwalls are located at 45 degrees to the centerline of the outlet, the best conditions for energy attenuation are obtained. The orientation of the basin sidewalls depends on the type of dissipater. If a rectangular basin is constructed the walls of the stilling basin can be parallel. If a flared stilling basin is constructed the sidewalls may diverge as an extension of the transition sidewalls. The sidewall height is based on the maximum design tailwater depth and is defined as $y_{j} / 3$. At the end of the stilling basin a cutoff wall must be placed to prevent degradation of the basin. The dimensions of the

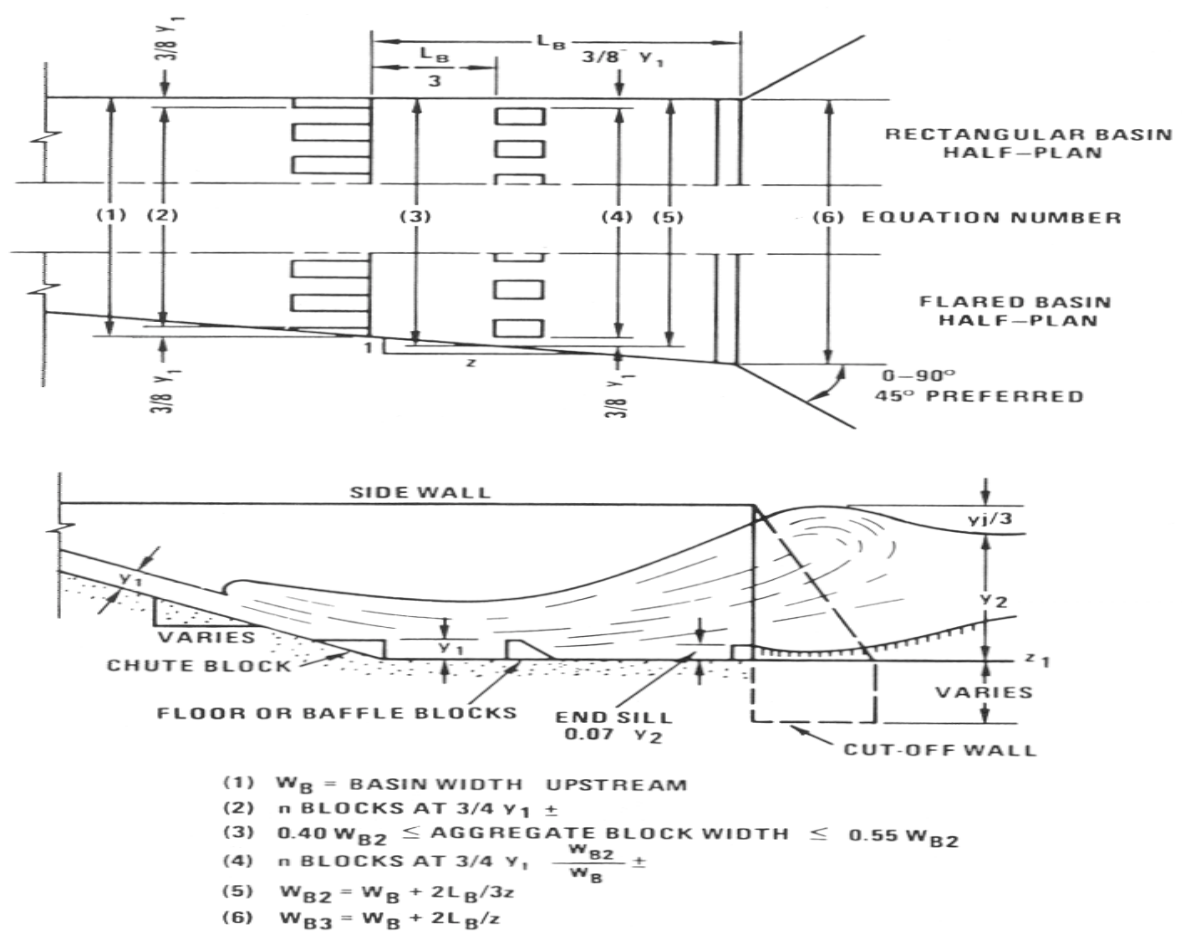

Figure 2.7.1 SAF Stilling Basin (Blaisdell, 1959) 
cutoff wall are dependent on the characteristics of the site where the basin is placed. Therefore the cutoff wall should be of depth significant to deal with the maximum expected erosion. Figure 2.7.1 displays the various geometeries associated with the SAF stilling basin (Blaisdell, 1959).

\subsection{Contra Costa Basin}

The University of California at Berkley, along with Contra Costa County, California, designed the Contra Costa basin. In order for the basin to be effective for use the following criteria had to be met:

- applicability for various culvert sizes and flow conditions

- fabrication on site must be easy

- economically feasible

- drain by gravity at no flow conditions

- must be self cleaning and have low maintenance needs

- must reestablish natural flow conditions downstream of the basin

The Contra Costa basin was intended for small to medium size culverts of any cross-section. The flow conditions for use of the basin are to be sites where the depth of flow at the outlet is less than the culvert diameter and of medium to high velocity. The basin was designed to operate without tailwater; therefore the presence of tailwater increases the effectiveness of the basin to above required criteria (Keim, 1962).

\subsubsection{Design Procedures}

The first step in designing the basin is to determine the depth of flow, $\mathrm{y}_{\mathrm{e}}$, at the outlet of the culvert in question. For rectangular, or box culverts, $\mathrm{y}_{\mathrm{e}}=\mathrm{y}_{\mathrm{n}}$. For non-rectangular crosssections, the flow depth must be converted to the equivalent rectangular flow depth. To convert to a rectangular cross-section from circular, elliptical, parabolic, etc., the equivalent rectangular cross-section must have a width equal to twice the depth of flow, $y_{e}=(A / 2)^{1 / 2}$. In determining the Froude number, $\mathrm{y}_{\mathrm{e}}$ is used instead of the actual depth, with $\mathrm{F}_{\mathrm{r}}$ defined as:

$$
F_{r}=\left|\frac{V}{\sqrt{g y_{e}}}\right|
$$




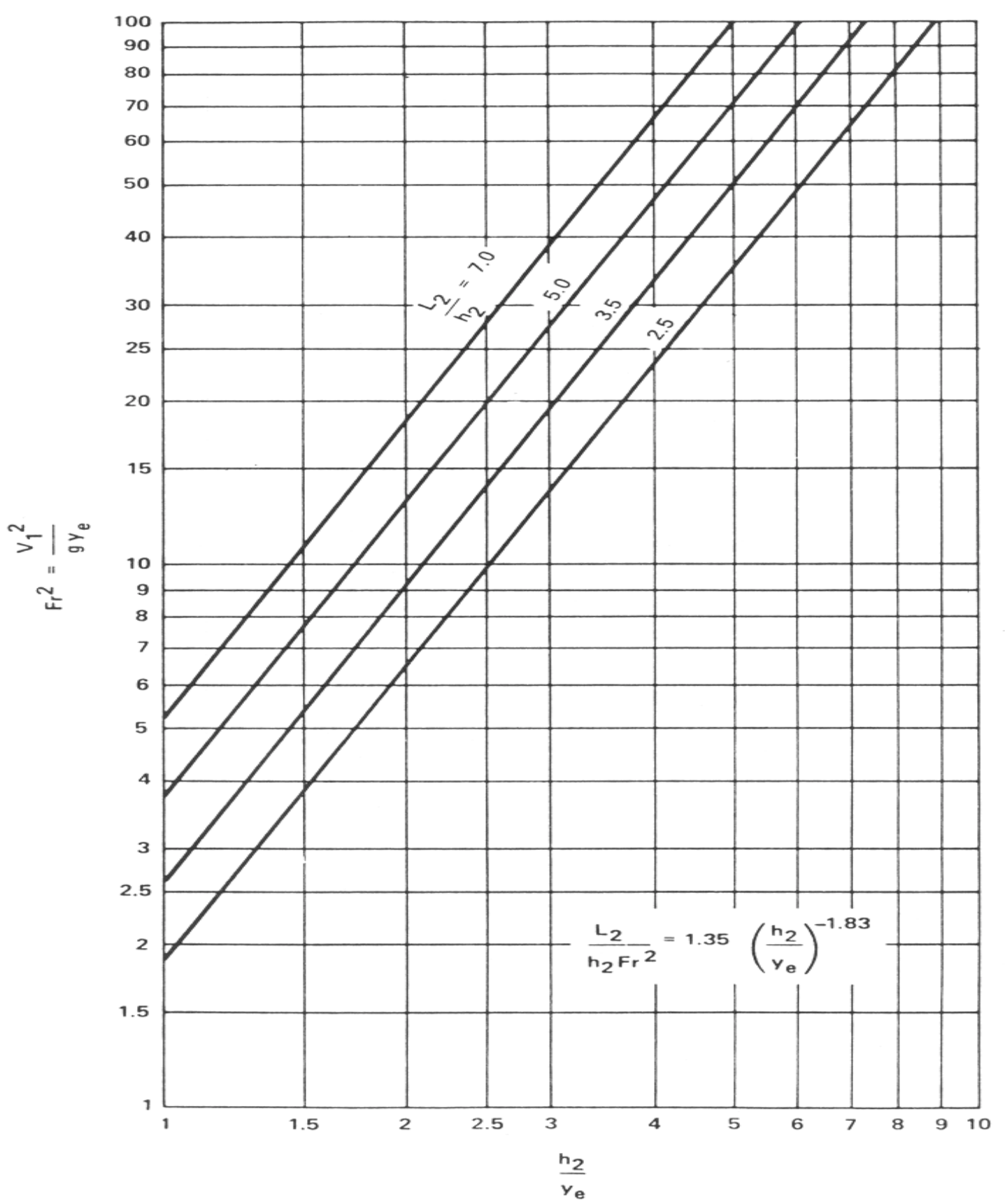

Figure 2.8.1 Baffle Height Determination (Keim, 1962)

Next, $\mathrm{Fr}^{2}$, and an assumed value of $\mathrm{L}_{2} / \mathrm{h}_{2}$ are entered into Figure 2.8.1 to determine a trial height for the second baffle, $\mathrm{h}_{2}$ (Keim, 1962).

The equation defining the lines in Figure 2.8.1 were changed slightly from those used by a previous investigation. This was done to allow for the conversion from non-rectangular to rectangular cross-sections for computing the flow depth $\mathrm{y}_{\mathrm{e}}$. The original equation is shown below:

$\left|\frac{L_{2}}{h_{2}}\right| F r^{2}=1.2\left(\left.\frac{h_{2}}{y_{O}}\right|^{1.8}\right.$ 
The modified form of the equation is given as:

$\left|\frac{L_{2}}{h_{2}}\right| F r^{2}=1.35\left(\left.\frac{h_{2}}{y_{e}}\right|^{1.8}\right.$

The remaining dimensions of the basin are determined from the following two equations that remain unchanged from the original source.

$\left|\frac{L_{3}}{L_{2}}\right|=3.75\left(\frac{h_{2}}{L_{2}}\right)^{0.68}$
$\left|\frac{y_{2}}{h_{2}}\right|=1.3\left(\frac{L_{2}}{h_{2}}\right)^{0.36}$

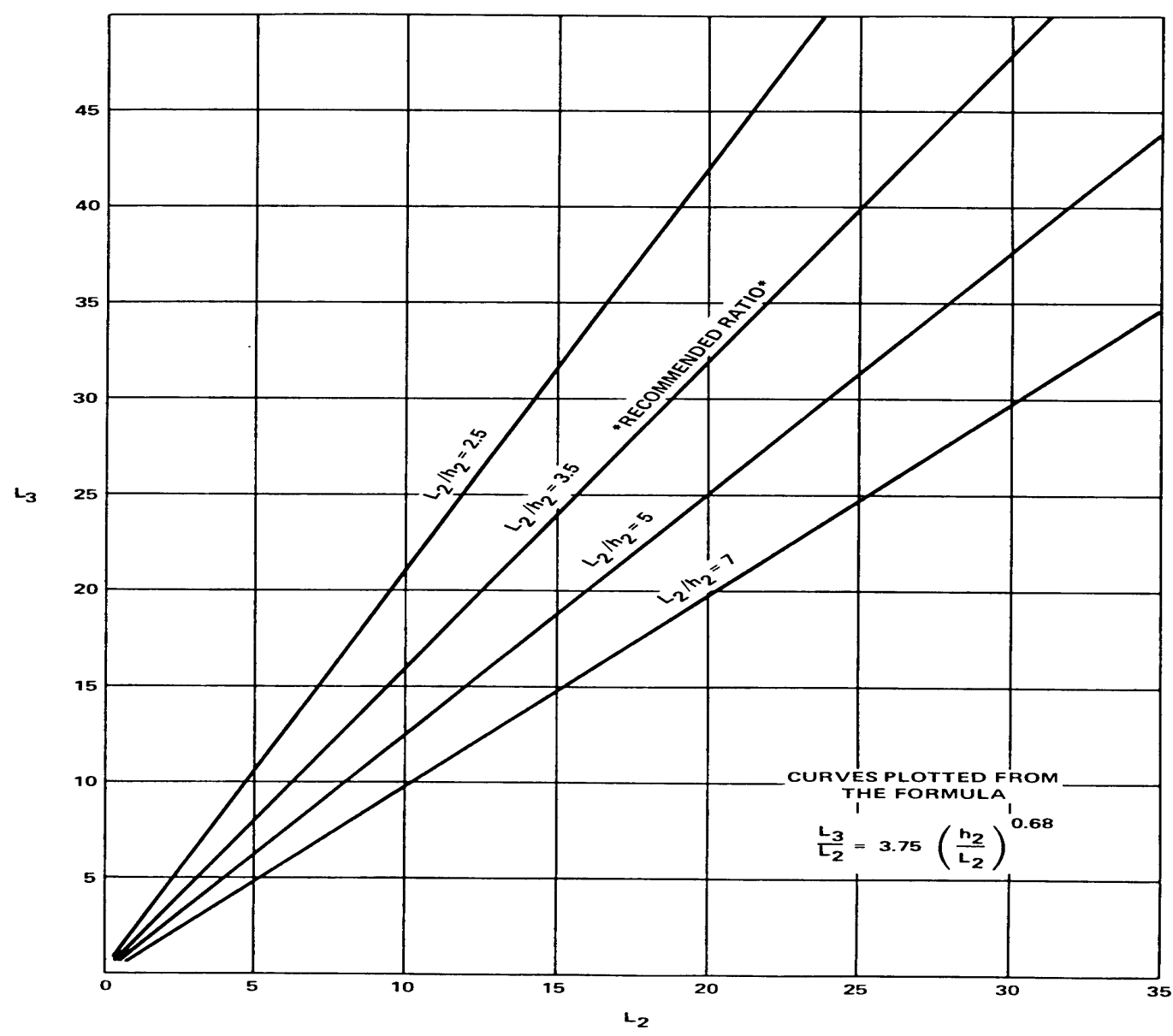

Figure 2.8.2 Length of Contra Costa Basin (Keim, 1962) 
The above two equations are plotted in Figures 2.8.2 and 2.8.3 respectively. The three equations may be used solely to determine the various dimensions of the basins but Figures 2.8.1, 2.8.2, and 2.8.3 are suggested for convenience (Keim, 1962).

In the experiments conducted on this basin, values for $\mathrm{L}_{2} / \mathrm{h}_{2}$ ranged from 2.5-7.0. The value recommended by the literature is 3.5 where this is economically feasible. Once the values for $h_{2}$ and $L_{2}$ are determined from Figure 2.8.1, $L_{3}$ can be found by implementing Figure 2.8.2. If the dimensional variables obtained by the figures will not fit the physical or economical constraints of the site, a new value for $\mathrm{L}_{2} / \mathrm{h}_{2}$ must be selected and another iteration performed. Also note that the value for $\mathrm{h}_{2} / \mathrm{y}_{\mathrm{e}}$ should always be greater than one.

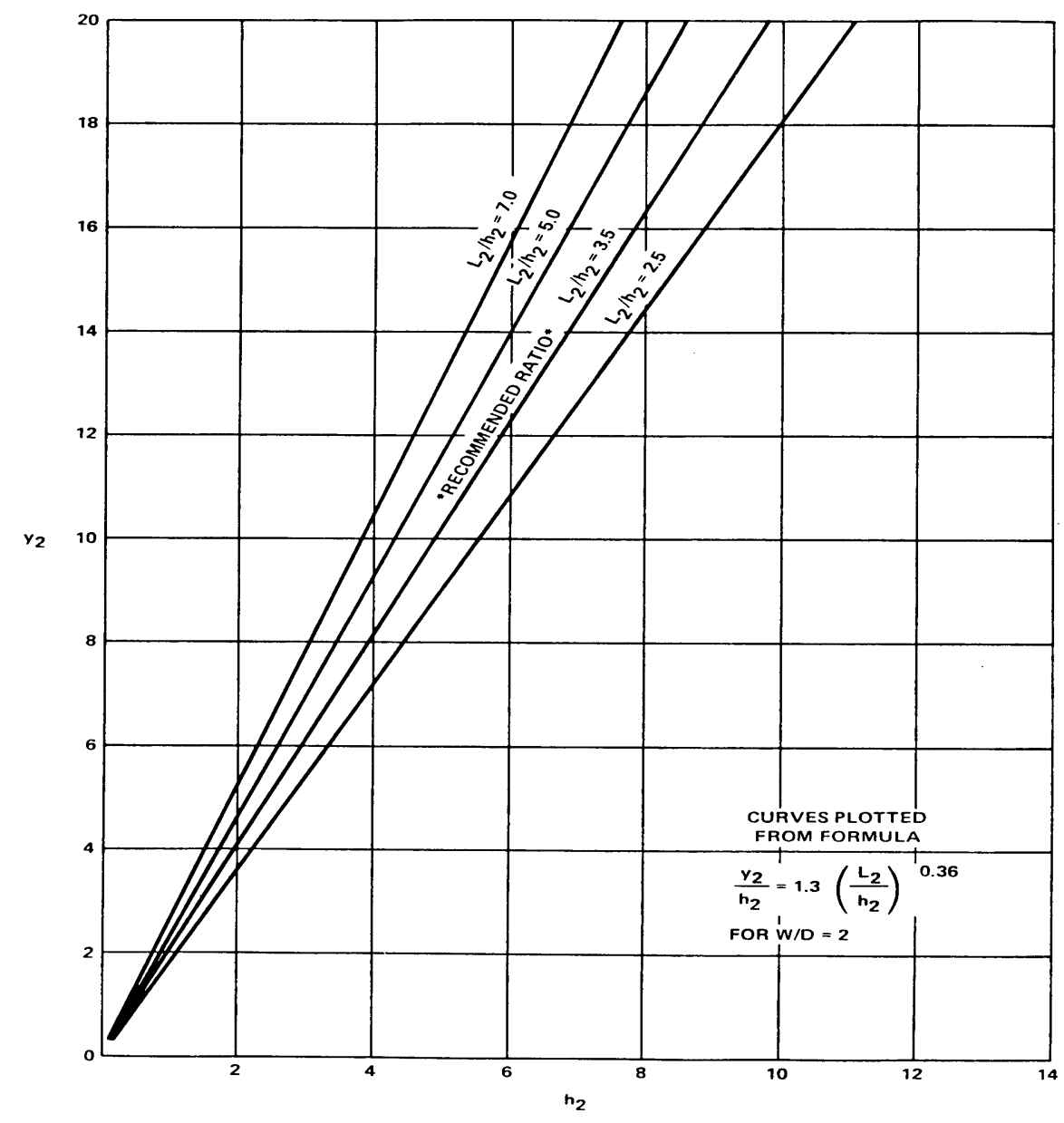

Figure 2.8.3 Depth Over Baffle (Keim, 1962) 
The various dimensions of the Contra Costa basin are displayed in Figure 2.8.4. The first baffle height $h_{1}$, is one half the second baffle height $h_{2}$. The position of the first and second baffle blocks is $\mathrm{L}_{2}$ for the second baffle and $\mathrm{L}_{2} / 2$ for the first baffle. The side slope for all the experimental runs on the trapezoidal basin were $1: 1$. The basin width, $\mathrm{W}$, can vary from 1 to 3 times the culvert diameter and the basin floor should be constructed nearly level. The height of the end sill can range from 6 to 10 percent of $y_{3}$. Once all of the dimensions are determined with the constraints of the site in mind, the value for the maximum water surface depth, $y_{2}$, can be found from Figure 2.8.3 (Keim, 1962).
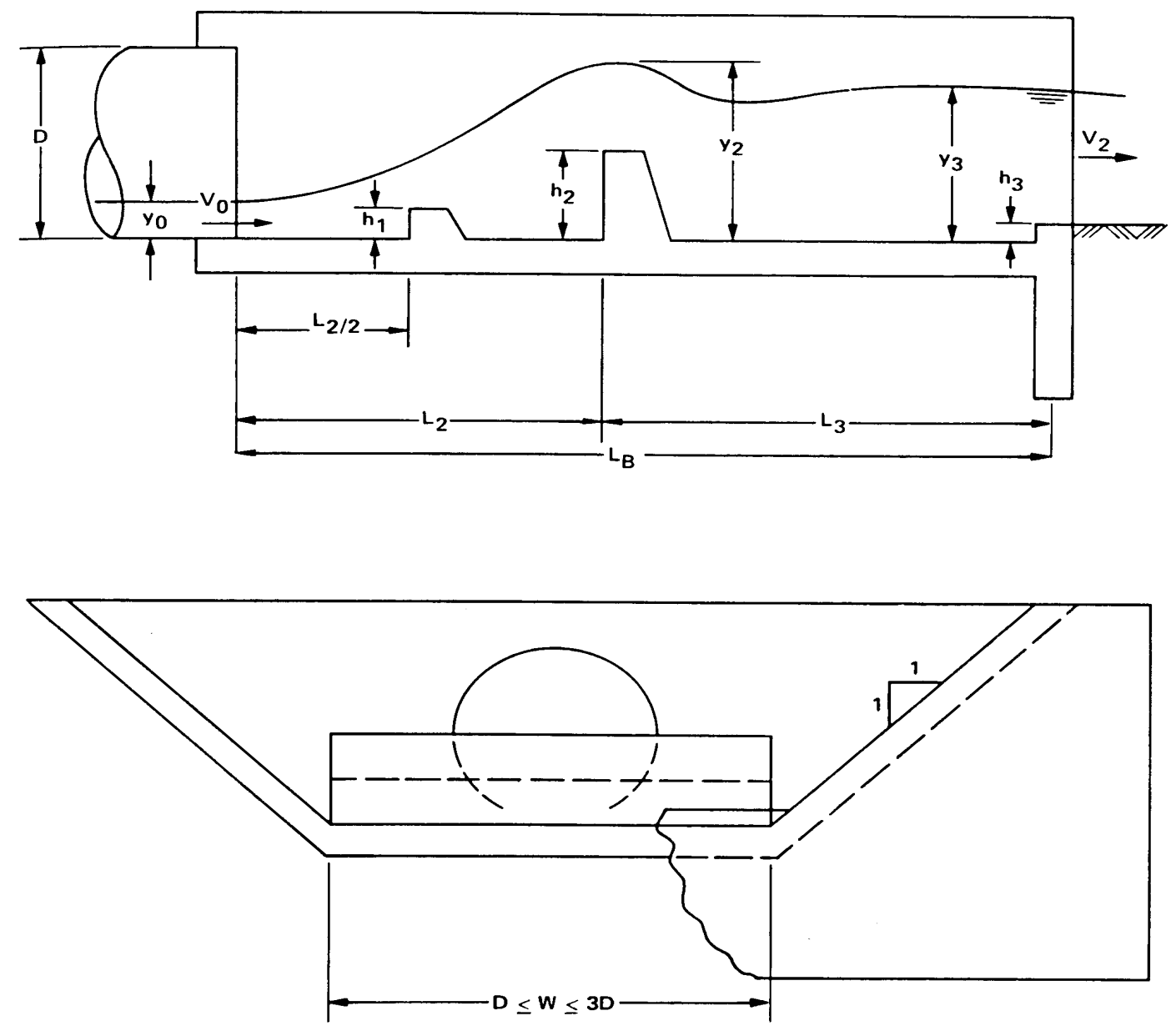

Figure 2.8.4 Contra Costa Energy Dissipator (Keim, 1962) 


\subsection{Hook Type Energy Dissipator}

The Hook, also known as Aero-type, basin was developed based on two different hydraulic model tests. One model implemented a tapered floor and warped wingwalls that diverged from vertical to a side slope of 1.5:1, as shown in Figure 2.9.1. The second model utilized a constant cross-section trapezoidal channel, as displayed in Figure 2.9.2. The Hook dissipator was designed initially for large arch culverts with low tailwater, but can be applied circular or box--type cross-sections. The Froude number range for which the dissipator is applicable is 1.8-3.0. Design and development of the Hook dissipator was performed at the University of California along with the Bureau of Public Roads and the California Division of Highways (MacDonald, 1967).

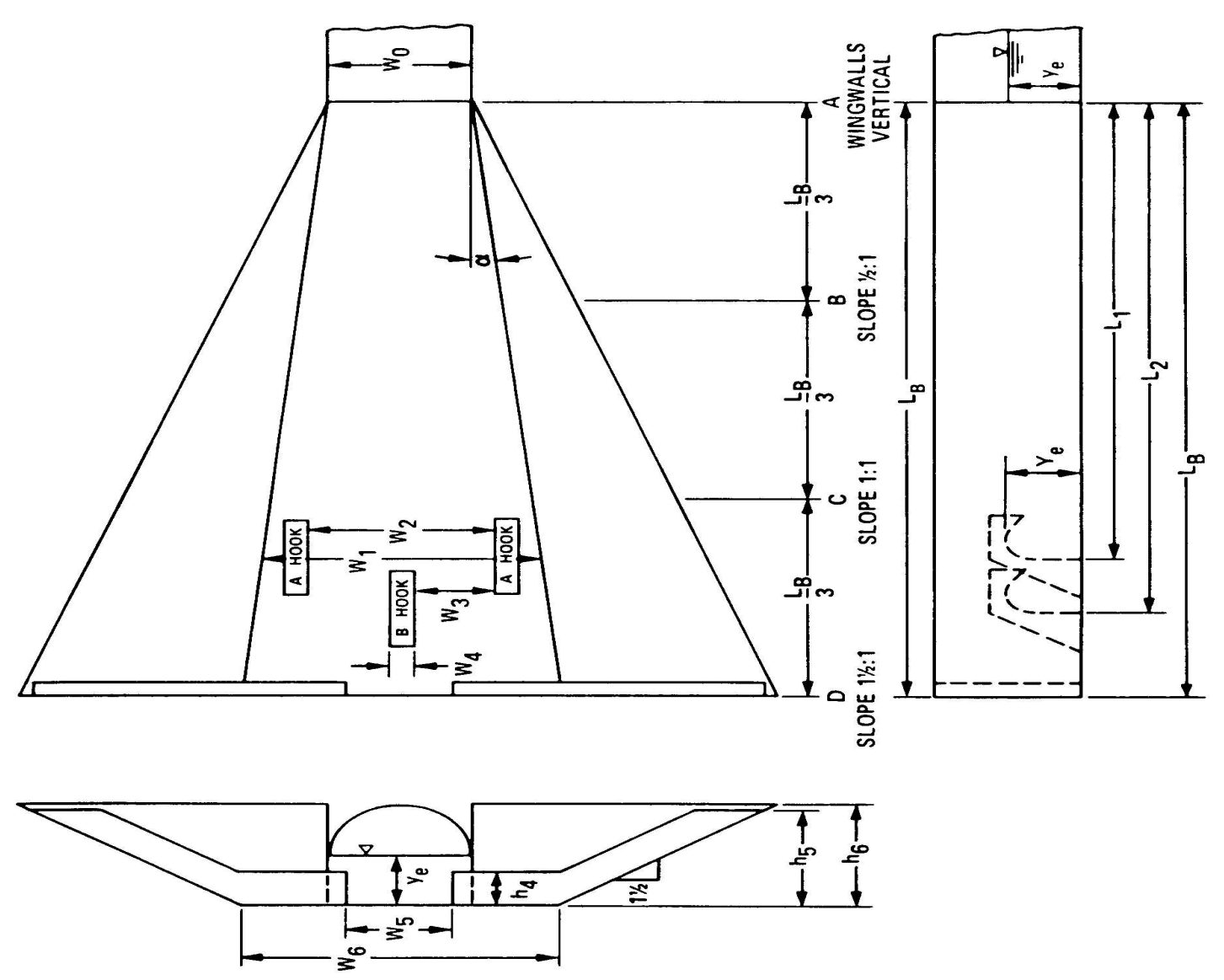

Figure 2.9.1 Warped Wingwall Stilling Basin (MacDonald, 1967) 

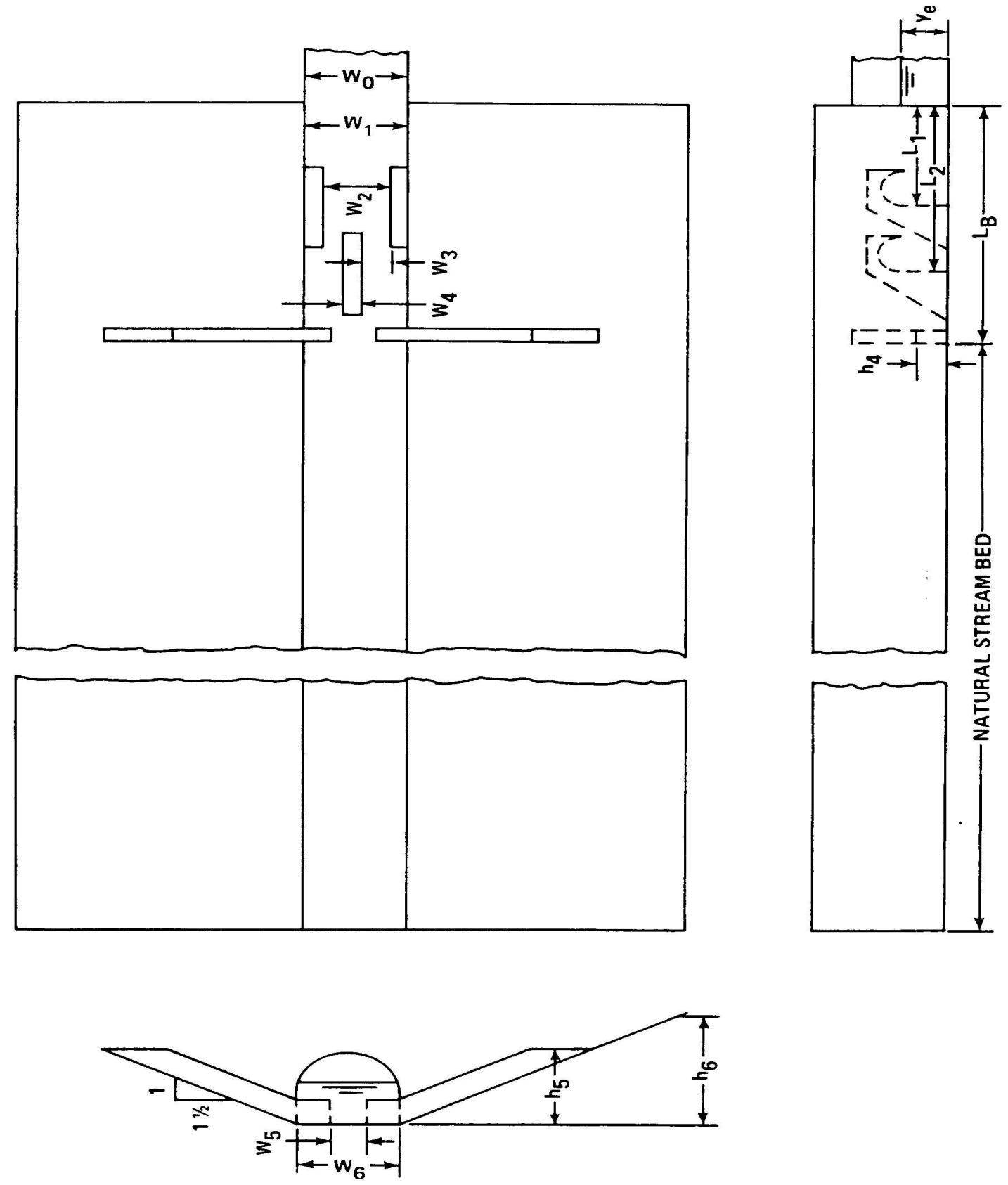

Figure 2.9.2 Design Criteria for Straight Basin (MacDonald, 1967)

\subsubsection{Straight Trapezoidal Basin}

The straight trapezoidal type basin will be discussed first, as shown in Figure 2.9.2. In the trapezoidal form of the Hook energy dissipator, the cross-sectional geometry is approximately the same as the natural channel before installation of the culvert. Some of the 
design variables between the straight trapezoidal and warped wingwall basins are different. For example, in the straight trapezoidal basin the hooks and end sill are located upstream closer to the outfall of the culvert. Testing determined that for a constant flowrate, widening of the basin reduced the velocity downstream of the basin. Also, flattening the slopes of the sidewalls improved the attenuation of energy for Froude number values up to 3.0 (MacDonald, 1967).

\subsubsection{Design Recommendations (Straight Trapezoidal Basin)}

(MacDonald, 1967) The dimensions shown below are the suggested design parameters for the Straight Trapezoidal Basin.

$\mathrm{L}_{\mathrm{B}}=3.0 \mathrm{~W}_{\mathrm{o}}$

$\mathrm{L}_{1}=1.25 \mathrm{~W}_{\mathrm{o}}$

$\mathrm{L}_{2}=2.1 \mathrm{~W}_{\mathrm{o}}$

$\mathrm{W}_{2}=0.65 \mathrm{~W}_{\mathrm{o}}$

$\mathrm{W}_{5} / \mathrm{W}_{6}=0.33$

$\mathrm{h}_{4} / \mathrm{y}_{1}=0.67$

$\mathrm{h}_{5} / \mathrm{h}_{6}=0.70$

$\mathrm{h}_{6}=3.33 \mathrm{y}_{\mathrm{e}}$ (for $1.5: 1$ side slopes)

$\mathrm{h}_{6}=2.69 \mathrm{y}_{\mathrm{e}}$ (for $2: 1$ side slopes)

$\mathrm{W}_{\mathrm{o}}=$ Width of rectangular culvert $\left(\right.$ For non-rectangular $\mathrm{W}_{\mathrm{o}}=2 \mathrm{y}_{\mathrm{e}}$ where $\mathrm{y}_{\mathrm{e}}=(\mathrm{A} / 2)^{1 / 2}$

$\mathrm{W}_{6}=$ Bottom width of trapezoidal channel

$\mathrm{W}_{6} / \mathrm{W}_{\mathrm{o}}$ can be up to 2 without affecting performance (see Figure 2.9.4)

$\mathrm{W}_{4}=0.16 \mathrm{~W}$

$\mathrm{W}_{3} / \mathrm{W}_{4}$ should be greater than or equal to 1

Refer to Figures 2.9.2 and 2.9.3 for dimensions.

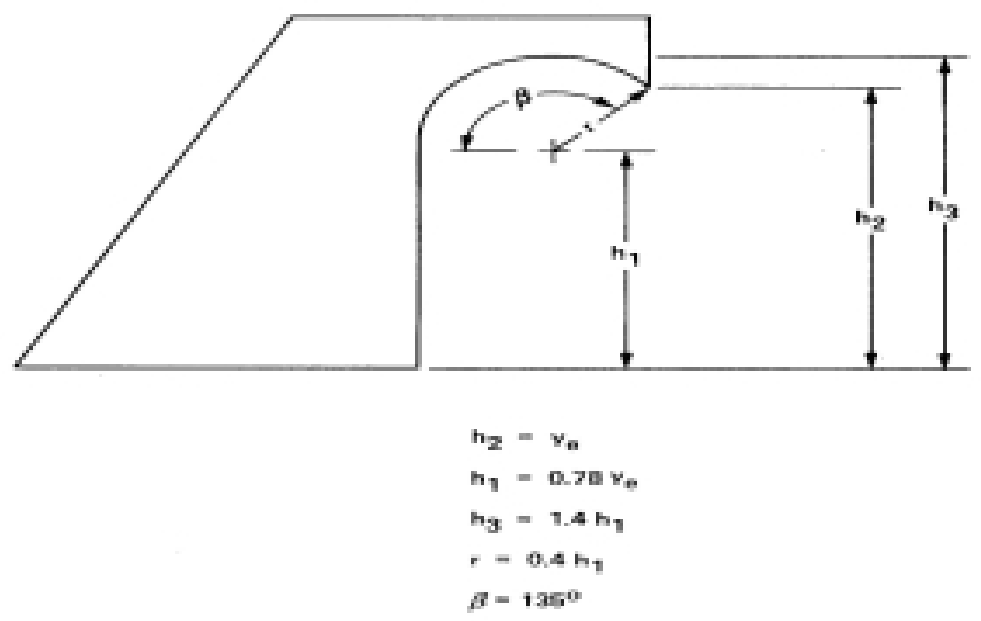

Figure 2.9.3 Recommended Dimensions for Straight basin (MacDonald, 1967) 


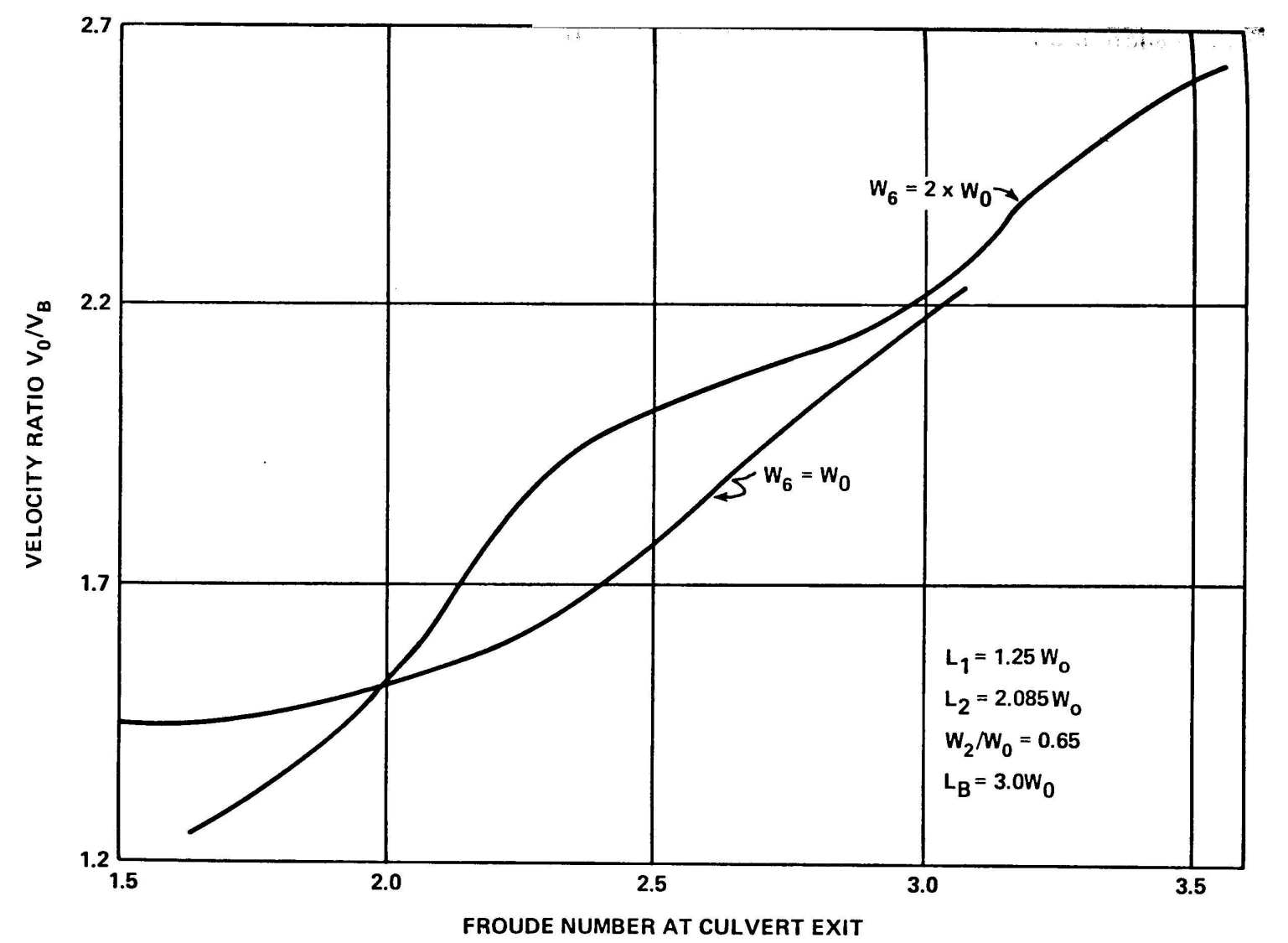

Figure 2.9.4 (MacDonald, 1967)

\subsubsection{Warped Wingwall Basin Type}

(MacDonald, 1967) In designing the Warped Wingwall type Hook basin, judgment is needed to allow enough width for efficient operation, but not so much that too much flow is passing between the hooks. Each time the Warped Wingwall type Hook basin is used, the spacing between the hooks should fall between 1.5-2.5 times the hook width. The basin becomes more effective for increasing values of the velocity ratio, $V_{\mathrm{o}} / \mathrm{V}_{\mathrm{B}}$. The best value for the flare angle is 5.5 degrees per side $($ alpha $=0.10)$ for $\mathrm{F}_{\mathrm{r}}>2.45$. The dissipator effectiveness decreases rapidly for increasing Froude number for flare angles above 5.5 degrees. Therefore 5.5 degrees should be the maximum value for the flare angle. 


\subsubsection{Design Recommendations (Warped Wingwall Hook Basin)}

The following design recommendations are presented for the Warped Wingwall Hook Basin:

- For the maximum velocity reduction, the tangent of the flare angle should equal 0.10 .

- The best range of $\mathrm{L}_{1} / \mathrm{L}_{\mathrm{B}}$ for the A-hooks is $0.75-0.80$

- The best range of $\mathrm{L}_{2} / \mathrm{L}_{\mathrm{B}}$ for the B-hook is 0.83-0.89

- The best width of opening at the end sill ratio, $\mathrm{W}_{5} / \mathrm{W}_{6}$, is 0.33

- The best end sill height is approximately $2 / 3$ the flow depth at the culvert outlet, $\mathrm{h}_{4} / \mathrm{y}_{\mathrm{e}}$ $=0.67, \mathrm{y}_{\mathrm{e}}=(\mathrm{A} / 2)^{1 / 2}$

- Tests did not indicate a specific optimum for the end sill height. The value used may be 0.94 for $\mathrm{h}_{5} / \mathrm{h}_{6}$.

- For wide hooks the velocity reduction will be maximized, but the apparent maximum flowrate (i.e. the flow rate just before excessive over-topping of the wingwalls) will be reduced. In addition, as the hooks become wider, the spacing between them and the walls decreases and may not be sufficient for the passage of debris. For these reasons a thickness ratio $\mathrm{W}_{4} / \mathrm{y}_{\mathrm{e}}=0.16$, the minimum value tested, is recommended. The design should be adjusted to the proper spacing.

- The basin length cannot be assigned a fixed value since it depends on site conditions. However, the shorter basin lengths give high velocity reduction over most of the range of Froude numbers tested.

- $\quad$ The recommended hook dimensions are shown in Figure 2.9.5

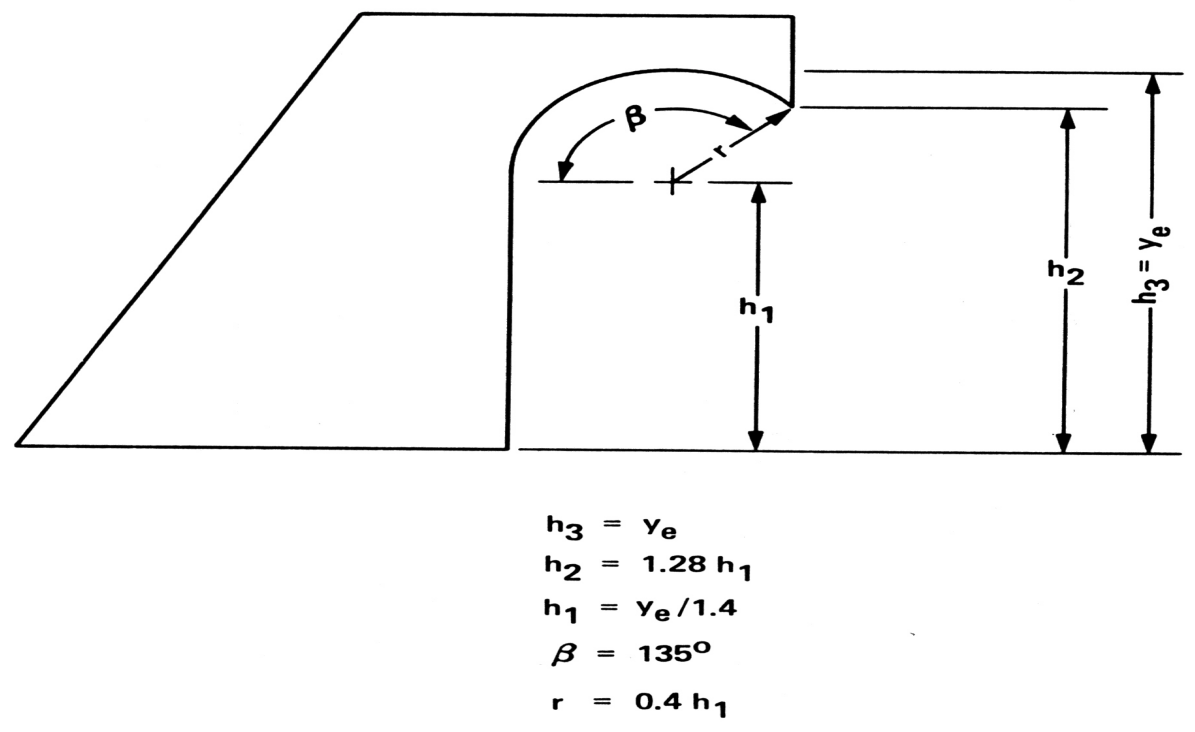

Figure 2.9.5 Hook Dimensions for Warped Wingwall Basin (MacDonald, 1967) 
- The height of wingwalls $\left(\mathrm{h}_{6}\right)$ should be at least twice the flow depth at the culvert exit or $2 \mathrm{y}_{\mathrm{e}}$. This was the height used in the study to determine apparent maximum flowrate. The apparent maximum flowrate was the condition used to determine the velocity ratios and Froude numbers. Therefore the prototype basin should be supplied with additional freeboard.

- Depending on final velocity and soil conditions, some scour can be expected downstream of the basin. The designer should, where necessary, provide riprap protection in this area.

- Where large debris is expected, armor plating the upstream face of the hooks with steel is recommended. (MacDonald, 1967)

\subsection{Stilling Basin Design for Low Froude Number}

\subsubsection{Overview}

As discussed in previous sections, introducing appurtenances into a stilling basin reduces the length need to produce a hydraulic jump, increasing the energy dissipation by decreasing the sequent depth. This makes the basin design more economic by reducing the materials needed to produce the full development of a hydraulic jump. In 1975, design criteria for basins with high upstream Froude numbers were well established, but no well-developed design criteria existed for basin that operated in the lower Froude number range of 2.5-4.5 (Bhowmik, 1975). Therefore the Illinois State Water Survey began investigations of stilling basins that operated in this Froude number range. Since irrigation structures, diversion or low head spillways, and culvert outlet works operate at Froude numbers of 2.5-4.5, the investigation was necessitated. The experiments performed tested ordinary hydraulic jumps and baffled stilling basins, both on horizontal aprons.

\subsubsection{Design Considerations for Low Froude Number Stilling Basins}

In considering the construction of a Low Froude Number Stilling Basin the following factors were considered:

- Absolute size of the structure

- Frequency of operation

- Durability of the channel bed downstream from the stilling basin

- The use of chute blocks, baffle blocks, and other appurtenances 
The formation of the hydraulic jump was transmitted farther upstream on the basin, stability of the basin was increased, and wave action was reduced with the addition of non-streamlined baffle-type appurtenances. Also when the tail-water depth was not significant enough to produce a hydraulic jump, sweepout of the jump was prevented. An end sill was also implemented in the testing of the Low Froude Number basins. The use of an end sill deflected the high velocity jet from the floor of the apron toward the surface of the water, preventing the erosion of loose bed materials downstream (Bhowmik, 1975).

\subsubsection{Hydraulic Jump Characteristics for Froude Numbers Less Than $\mathbf{4 . 5}$}

As discussed previously the type of hydraulic jump formed depends on the value of the approach Froude number. Between the values of 1.7-2.5 a weak jump forms where there are small rollers on the surface but downstream the water surface remains smooth. From 2.5-4.5 the formation of an oscillating jet becomes apparent fluctuating from the surface to the apron floor with no apparent discernible period. The oscillations formed from Froude number 2.5-4.5 produce undesirable wave activity downstream of the basin. The design for a Low Froude Number Stilling Basin considered the elimination of the wave activity present on the Froude Number range of 2.5-4.5.

(Bhowmik, 1975) In the case of an ordinary hydraulic jump, the two independent characteristics are the initial depth, D, and the initial velocity, V, at the entrance to the stilling basin. The Froude number associated with the flow entering the stilling basin is given by equation 2.1.4. Utilizing the momentum equation the relationship between $\mathrm{D}, \mathrm{Fr}$ and $\mathrm{D}_{2}$, the sequent depth, and other geometric properties of the basin can be determined. In the analysis it is generally assumed that the boundary shear stress can be neglected, the velocity distribution is uniform before and after the jump, and the pressure distribution is hydrostatic with some variation near the water surface. With these assumptions the relationship between $D_{2} / D$ and $F$ for a rectangular basin floor is:

$$
\frac{D_{2}}{D}=\frac{1}{2}\left|\left(1+8 F^{2}\right)^{\frac{1}{2}}-1\right|
$$


Whenever the boundary roughness is such that the shear stress cannot be neglected, an additional term must appear which will show an increase in downstream depth for the same upstream depth and Froude number. Surface rollers are generated in a hydraulic jump as a result of the presence of non-collinear but equal pressure and dynamic forces. Part of this roller is continually torn away and passes downstream as vortices, so that the total energy lost is the summation of all the energies of these vortices. In any real fluid, viscosity brings about the conversion of all these energies into thermal energy. Since the thermal energies cannot be recovered the hydraulic jump is an irreversible phenomenon.

(Bhowmik, 1975) Introduction of different artificial roughnesses, such as chute blocks, baffle blocks and end sills, in a stilling basin can control the formation of a hydraulic jump at various locations on the apron depending upon the tail-water depth. These artificial roughnesses can forcibly form the jump at the entrance section of the stilling basin and thus confine the jump within a specified limit making it practical to predict the location of the jump. The most common stilling basin on a horizontal floor is a rectangular basin with an end sill and one or two rows of baffle blocks. With some adjustment of the tail-water depth, the jump can be stabilized on the basin's apron with the aid of baffle blocks and an end sill.

Following Bhowmik's discussion of the ordinary and forced hydraulic jump, he addresses the effects of turbulent pressure fluctuations on a stilling basin. Bhowmik indicates the importance of considering pressure fluctuations associated with a turbulent velocity profile in order to correctly design the baffle appurtenances for not only uplift forces but also to withstand the onset of cavitation. Bhowmik cites the experimental work performed by the U. S. Bureau of Reclamation (USBR) in the study of cavitation damage on baffle appurtenances at subatmospheric pressures. The critical areas of cavitation damage as reported by the USBR were on the sides of the chute blocks near the bottom (USBR, 1963). No turbulent pressure fluctuations were collected in Bhowmik's study since the fluctuating water surface profile at the low Froude number range would not produce reliable values.

\subsubsection{Data Collection and Experimental Procedures}

The experiments for this study were performed at the hydraulic laboratory of the Illinois State Water Survey. The tests were run in a $2 \mathrm{ft}$ wide $60 \mathrm{ft}$ long glass walled tilting flume, 
consisting of a constant head tank and re-circulation system as well as various other instrumentation.

For the case of the ordinary hydraulic jump, a jump was formed downstream of a sluice gate by adjustment of the tail-water depth. In order to obtain a given flow condition, flowrate, sluice gate opening, and tail water depth were adjusted. The first data set was begun at a Froude number equal to 2.5 and then increased for successive trials. Measurements taken included: flowrate, upstream and downstream depth of flow, and hydraulic jump length. Also, photographs were taken and comments were recorded as necessary.

The case of the forced hydraulic jump followed the same description as the ordinary hydraulic jump, excepting the addition of an end sill, baffle blocks or both. Chute blocks were not tested since the experiments were performed on a horizontal apron with the formation of the jump occurring downstream of a sluice gate. The jump length was determined by visual observation. In the majority of the experimental runs the profile of the jump became parallel to the floor of the flume at or before the end sill. Therefore the jump length was measured from the toe of the jump to the location of the end sill.

\subsubsection{Results and Conclusions}

Bhowmik begins by stating the complexity involved in the design of hydraulic jump type stilling basins. No two stilling basins perform exactly the same in all respects: however, a generalized design criteria can be attained for stilling basins subjected to similar flow conditions and performing under similar circumstances (Bhowmik, 1975). Throughout the experimental tests, several graphical relationships were produced for the ordinary and forced hydraulic jumps. The two forms of jumps were compared in order to determine the energy dissipation characteristics obtained by the addition of appurtenances such as baffles and end sills. Three non-dimensional variables were implemented and plotted with respect to Froude number:

- $\quad \mathrm{D}_{2} / \mathrm{D}_{1}$ the depth ratio

- $\quad \mathrm{E}_{\mathrm{L}} / \mathrm{E}_{1}$ the energy loss ratio

- $\quad \mathrm{L} / \mathrm{D}_{2}$ the length ratio

Examples of these graphical relationships are shown in Figures 2.10.1, 2.10.2, and 2.10.3.

A baffle arrangement, termed Basin L, performed satisfactorily and was adopted for implementation in the field. The arrangement of Basin L is shown in Figure 2.10.4. 


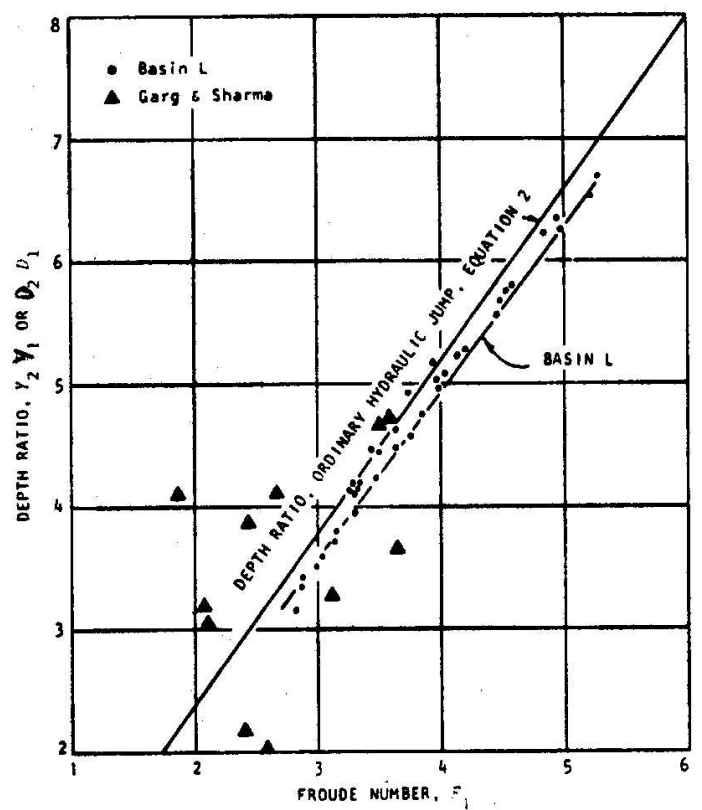

Figure 2.10.1 Depth Ratio vs Froude Number (Bhowmik, 1975)

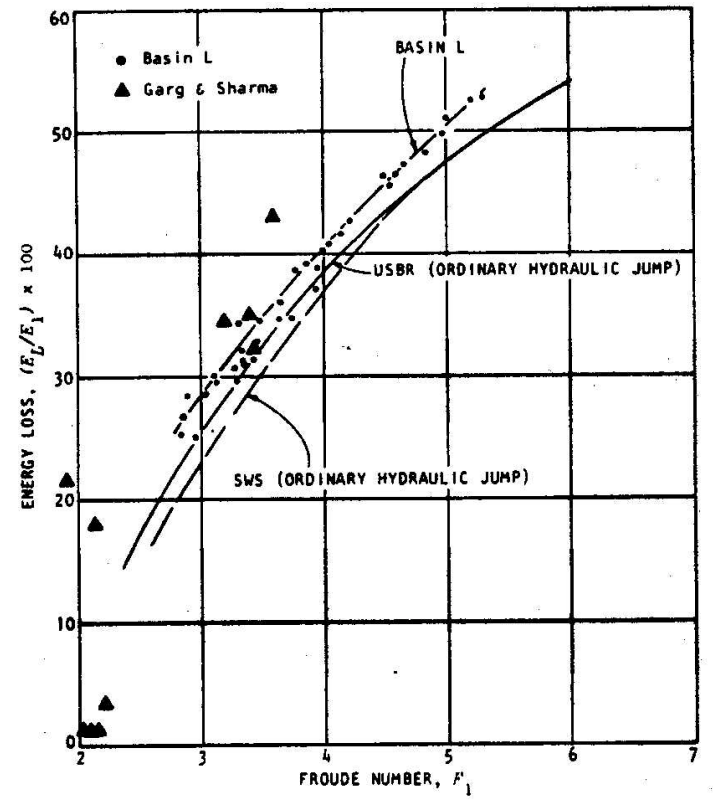

Figure 2.10.2 Energy Loss vs Froude Number (Bhowmik, 1975) 


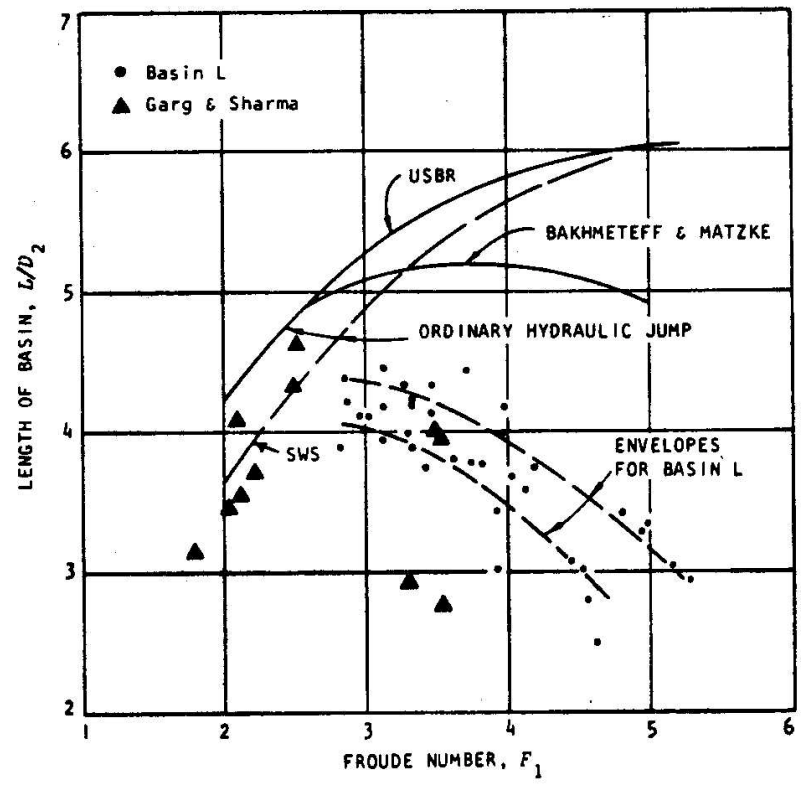

Figure 2.10.3 Length of Basin vs Froude Number (Bhowmik, 1975)

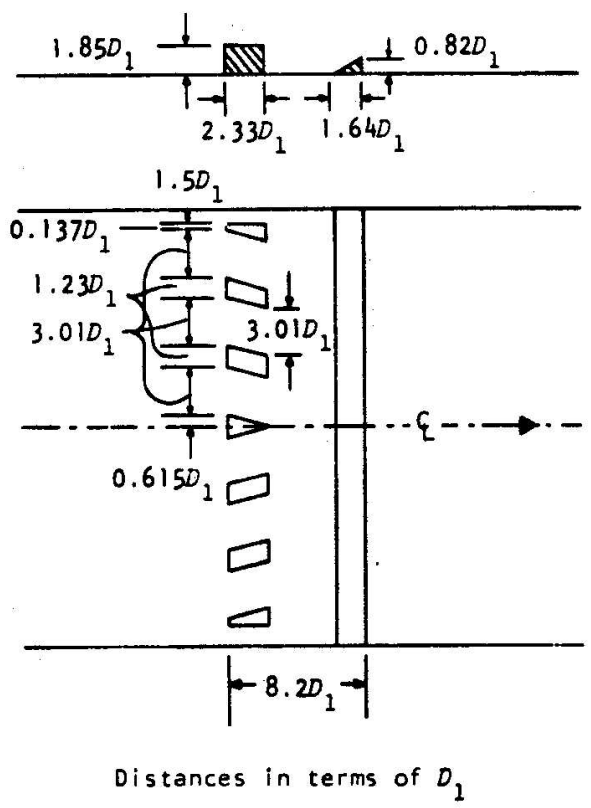

Figure 2.10.4 Schematic of Basin L (Bhowmik, 1975) 


\section{Chapter 3 - Procedure}

\subsection{Development of Experimental Equipment}

At the beginning of the research project the decision was made to construct a flume at WVU to allow for the testing of physical scale models. The construction of a "custom-built" flume would allow for modifications that would become necessary over the life of the project. The flume consisted of two tanks to allow for re-circulation of water, necessary piping, and various measuring devices. The flume was designed to accommodate a range of slopes and be within the economic constraints of the project budget, and was to be housed in the Civil Engineering Hydraulics Lab at West Virginia University (Room SB-35, Engineering Science Building).

\subsection{Pump Selection}

A centrifugal pump was selected to produce the re-circulation of water necessary for the experiments. The pump was to operate at low head and would need to accommodate a range of flowrates. Preliminary calculations were performed using standard culvert capacity relationships to assure that the flume would properly model flow conditions that are expected in the field. The selection of a 4.25 in. diameter culvert model required that the maximum flow capacity be approximately 200 gpm under inlet control conditions. This flow rate was used in determining the specifications needed for the pump. For a submerged culvert at the inlet the following equation applies (FHWA HDS \#5, 1985):

$$
\frac{H W_{i}}{D}=c\left|\frac{Q}{A D^{0.5}}\right|+Y-0.5 S^{2}
$$

Where

- $\quad H W_{i}=$ Headwater depth above inlet control section invert (ft)

- $\quad D=$ Interior height of culvert Barrel (ft)

- $Q=$ Discharge (cfs)

- $A=$ Full cross sectional area of culvert barrel $\left(\mathrm{ft}^{2}\right)$

- $\quad S=$ Culvert Barrel Slope $(\mathrm{ft} / \mathrm{ft})$

- $\quad Y, c=$ Constants from inlet control design equations

With the test culvert Diameter at 4.25 in. and assuming $1 \mathrm{ft}$ of headwater and 10\% slope, Q was found to be approximately $200 \mathrm{gpm}$, validating the original assumption. The pump selected was 
purchased from Interstate Pump Company, and provided slightly over 200 gpm at 25 feet of head, which provided a small amount of excess capacity. The pump setup is shown in Figure 3.1 .

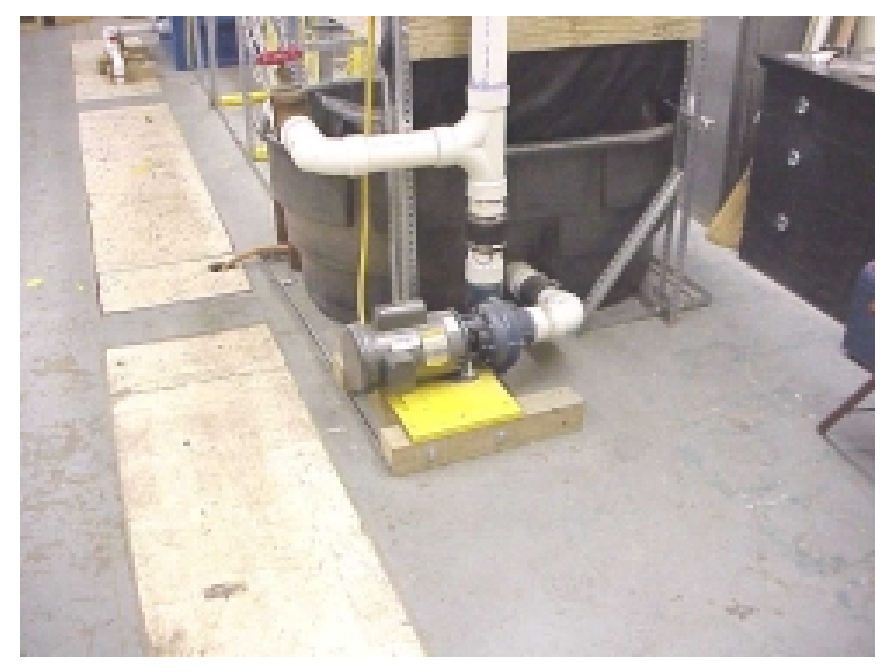

Figure 3.1 Centrifugal Pump Setup

\subsection{Tank Selection}

In order for the flume to properly re-circulate an adequate supply of water, two tanks were needed. The upstream tank needed to be tall, to supply sufficient head, while the downstream tank needed to be short so that they would accommodate for slope adjustment and still meet the volume requirements on the intake side of the pump. It was determined that the necessary volume for the operation of the flume was approximately 500 gallons. The downstream tank, a 150-gallon ovular agricultural tank, was obtained from an agricultural supply store, and is shown in Figure 3.2. Due to the unusual dimensional requirements of the upstream tank, it was impossible to obtain it through commercial providers. Therefore, the decision was made to construct a custom designed upstream tank. The upstream tank was constructed from $3 / 4$ inch pressure treated plywood reinforced with $2 \times 4$ framing. The tank dimensions were 3' $\times 3$ ' $x 5^{\prime}$ with an approximate volume of 340 gallons. A square opening, 1.5'x 1.5', was cut in the front of the upstream tank in preparation for the addition of the inlet box. 


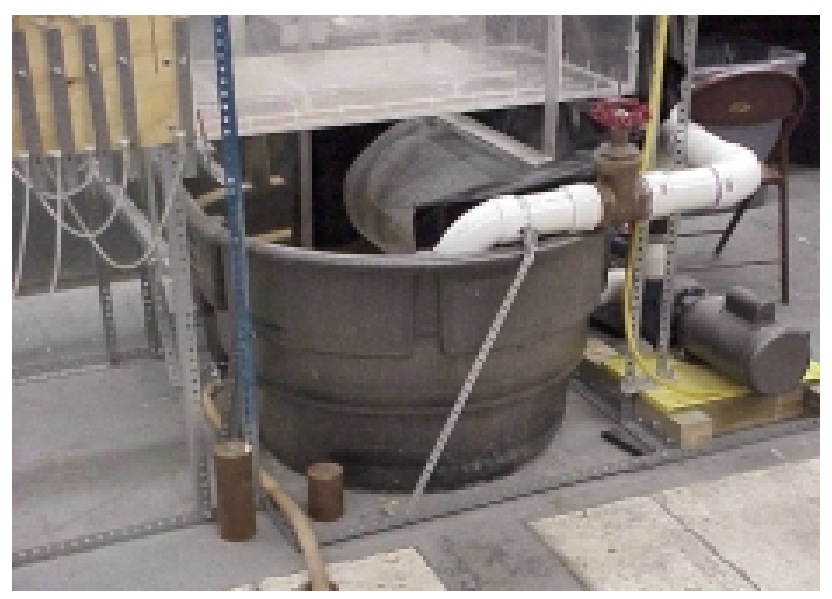

Figure 3.2 Downstream Tank

The inlet box will be described in greater detail in another section. The completed blue and yellow upstream tank is shown in Figure 3.3. In the initial design stage of the upstream tank, a pond liner was to be used as a bladder for water containment. This proved difficult to install since the seams could not be easily fused to prevent water leakage. This problem was rectified by the removal of the pond liner and application of a waterproof coating on the inside surface of the plywood. The coating chosen was an elastomeric polymer, originally intended for sealing roofs. After several coatings of the polymer were applied, the tank was sufficiently waterproofed. It was found to be necessary to reinforce the outside of the upstream tank with $2 \mathrm{x}$ 4 framing due to hydrostatic forces.

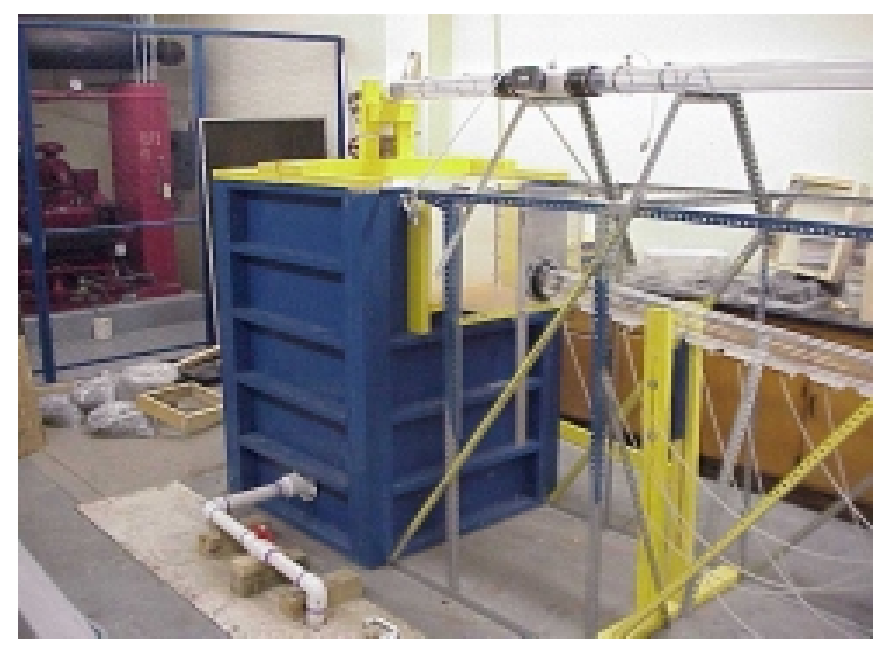

Figure 3.3 Upstream Tank 
The outside of the upstream tank was painted for aesthetic purposes as well as for mold prevention due to the constant high humidity in the hydraulics lab.

\subsection{Frame Development}

In order to provide a structure to accommodate piping, piezometer bank, flow meter, slope adjustment, testing channel, and to keep the tanks in a fixed position, a frame was developed. The frame consisted of perforated, galvanized 1.25-inch angle iron, which provided an easy means of construction. The framing was simply cut to size and bolted together with 5/16-inch bolts. Trapezoidal braces were constructed on the top of the frame to provide a cradle for the piping. The frame also allows for slope adjustment, which will be discussed in greater detail in another section.

\subsection{Inlet and Outlet Boxes}

Two cast acrylic boxes were constructed to allow for visual examination of physical phenomenon present in the planned hydraulic model studies. The inlet box dimensions were 1.5' x $1.5^{\prime}$ x $1.5^{\prime}$ and was constructed from 0.5 -inch thick cast acrylic. The inlet box was constructed to create uniform and steady flow conditions approaching the inlet of the model culvert. The inlet box is shown below in Figure 3.4.

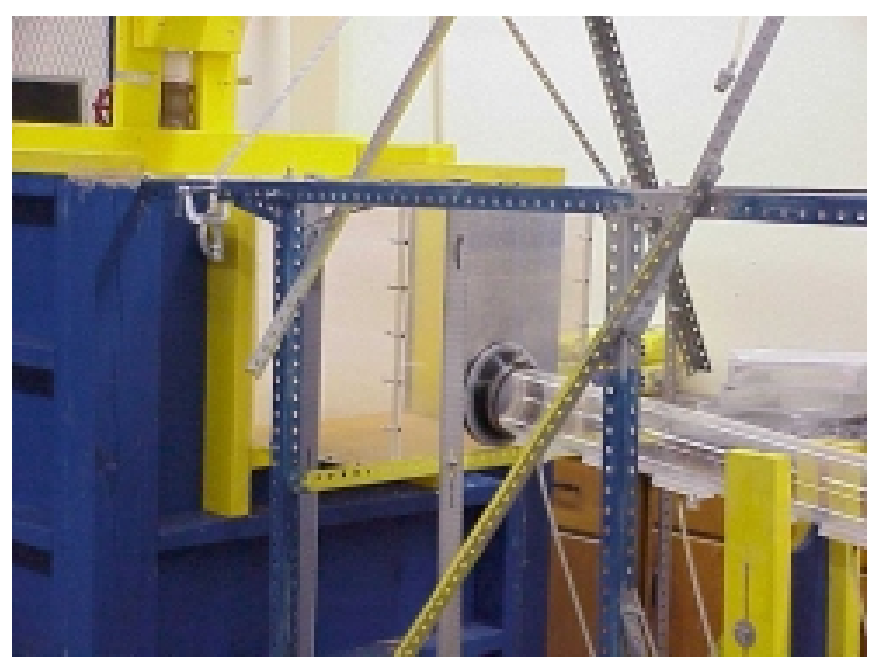

Figure 3.4 Inlet Box

The outlet box dimensions were 2' x 4' x 1.04'. It was also constructed from 0.5 -inch thick cast acrylic. Twenty 2 -inch diameter holes and eight 1.5 -inch diameter holes were cut in 
the downstream floor of the outlet box to provide adequate drainage exiting through the floor of the outlet box. A screen was constructed from 0.25-inch hardware cloth and placed over the drilled out holes to prevent debris from entering the downstream tank. The purpose of the outlet box was to serve as a container for the hydraulic models.

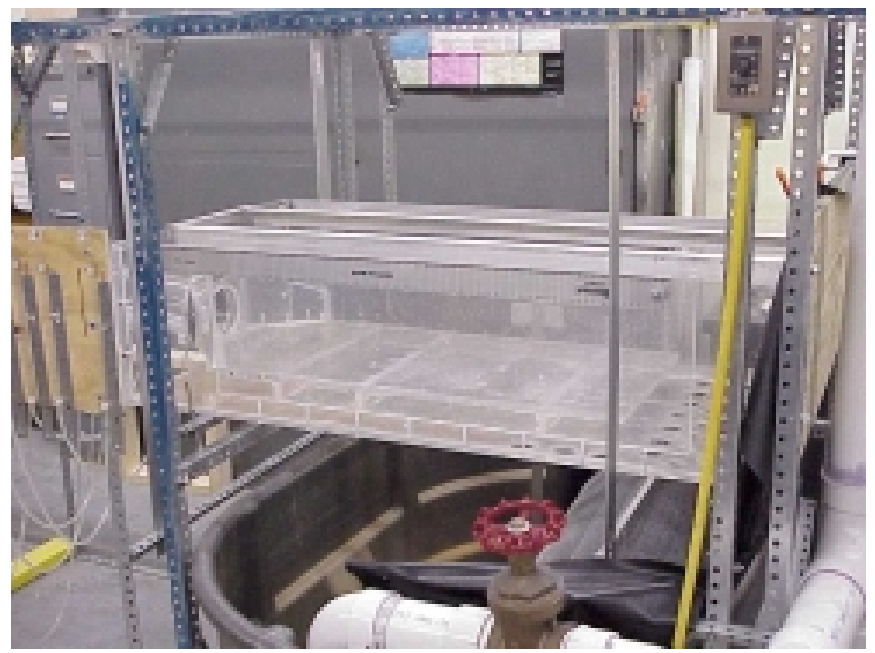

Figure 3.5 Outlet Box

A testing channel constructed from the same 0.5 -inch thick cast acrylic was placed within the outlet box. This testing channel will be discussed in greater detail in another section. The outlet box is shown in Figure 3.5.

\subsection{Piping Assembly}

The water supply piping network for the testing flume was constructed of $3 \mathrm{in}$. PVC sewer pipe. Clear acrylic pipe was selected for the model culvert. The PVC pipe proved easy to work with as all fittings could be glued together, and cutting the pipe to size could be accomplished with simple tools. Two 3 in. gate valves provided the flow adjustments needed for experimental runs. One gate valve was located at the upstream tank, near the end of the supply line from the pump, and was used to regulate the flow. The second gate valve was placed at the outlet tank and served as a bypass valve. To provide a low flow capability, the bypass valve was opened to allow some of the supply line flow to re-circulate back into the outlet tank. This bypass was necessary in order to maintain a minimum required pump flow rate during low discharge testing (about 50gpm). The supply line was extended vertically downward into the upstream tank so that the submerged jet would dissipate excess turbulent energy in the flow prior 
to reaching the culvert inlet. The test culvert was comprised of 4.25 in. inside diameter extruded acrylic pipe. One major problem with the test culvert was keeping it sealed at the inlet and outlet boxes, while still allowing for slope adjustment. Sealing was accomplished by the use of two rubber grommets attached to the inlet and outlet boxes with custom washers machined from standard plastic stock. The grommets were attached to the pipe with pipe clamps and proved extremely effective at sealing the test culvert and allowing for slope adjustment, Figure 3.7. The test culvert is shown in Figure 3.6.

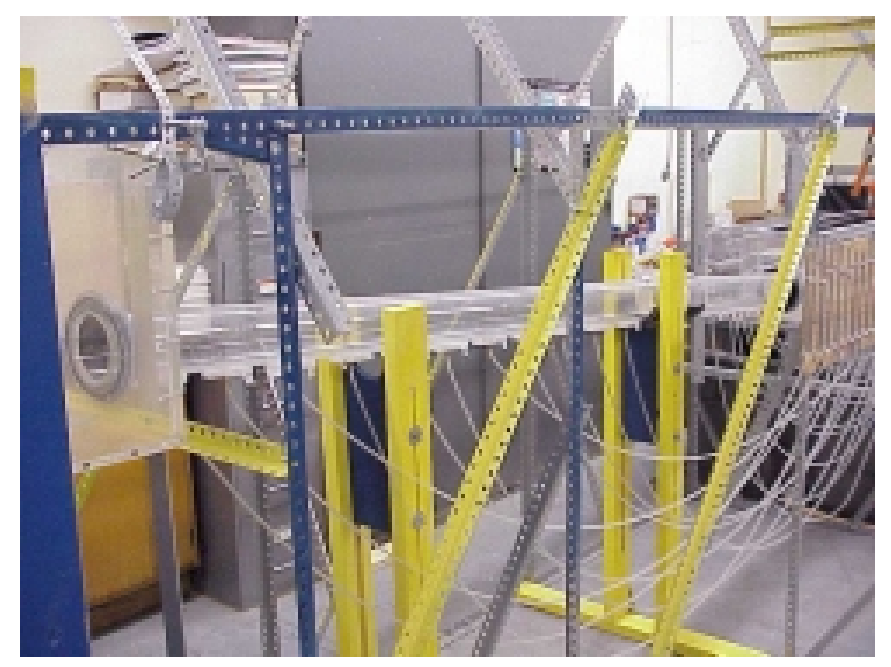

Figure 3.6 Test Culvert

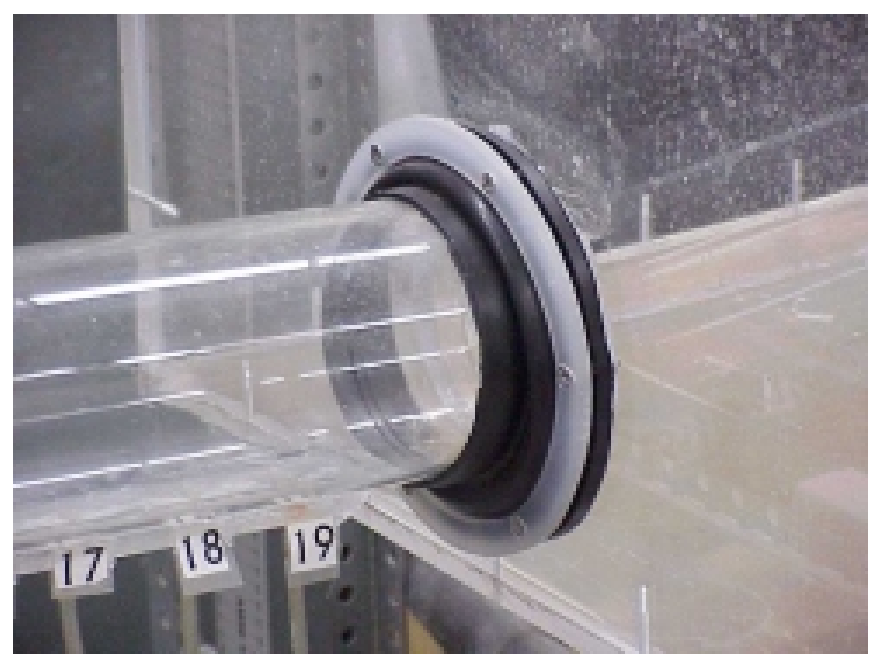

Figure 3.7 Grommet usage 


\subsection{Measuring Devices}

To provide data crucial for hydraulic calculations, several measuring devices were used. The devices implemented in the experimental procedures are as follows:

- Flowmeter

- Piezometer Board

- Three-Point Depth Gage

- Pitot Tube Device

- Slope Adjustment Devices

The measuring devices are discussed in further detail in this section, along with associated problems, corrections, and construction considerations where appropriate.

\subsubsection{Flowmeter}

A flowmeter was purchased that read flowrate in gpm over a range of 40-450 gpm with \pm $2.0 \%$ full scale linearity and $\pm 1.0 \%$ full scale repeatability. The mechanism used was a paddle wheel with magnetic inserts. The flowmeter would produce a flowrate based on the rate of rotation of the paddle wheel. The flowmeter is shown in Figure 3.8.

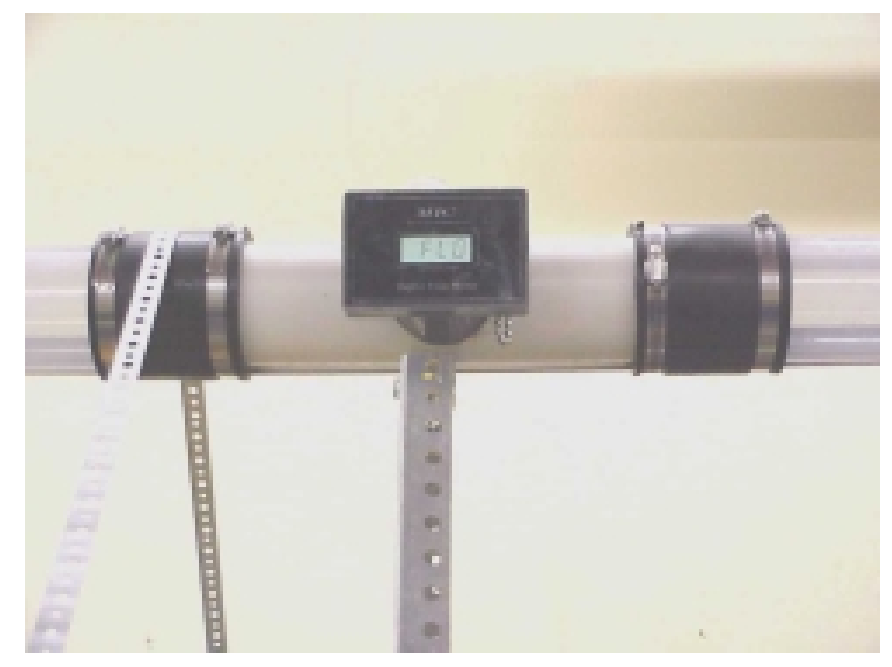

Figure 3.8 Flowmeter

Initially, the supply line from the downstream to upstream tank, contained a double elbow bend upstream of the flowmeter. This location produced erroneous flowmeter readings with high fluctuations. It was determined that the double bend was producing vortices that were causing the incorrect readings. It was also suspected that air was being trapped at certain locations in the 
supply line. To correct these problems three modifications were made. First, the double elbow bend was removed and replaced with a single elbow. Second, the overhead supply line was replaced with transparent 3 in. PVC pipe to allow for visual inspection of the flow entering and exiting the flowmeter. Third, several air bleeds were placed along the overhead supply line to remove trapped air from the line. These corrections eliminated the problems mentioned, and provided greater assurance of accurate measurements.

\subsubsection{Piezometer Board}

In order to measure the water surface elevation at various locations in the test culvert, a piezometer board was constructed. The board consisted of $19-1 / 4 \mathrm{in}$. Plexiglas tubes affixed to a $1 / 4$ in. plywood board. Scales were mounted next to the tubes with bolts and wing nuts that could travel vertically, in a milled slot, to allow for the establishment of a zero reading. The tubes were attached to tygon tubing at the bottom, then were connected to the test culvert at various points through brass fittings. First, small $1 / 32$ in. diameter holes were drilled in the test culvert invert to serve as the piezometer tap. Next, the brass fittings were threaded into small rectangular blocks of Plexiglas that were, in turn, glued to the test culvert around the previously drilled holes. This produced a row of piezometer taps along the invert of the test culvert from which flow depth could be established. The piezometer setup is shown in Figure 3.9. The location of each piezometer tap is shown In Figure 3.10 and the distance to each tap from the test culvert inlet are shown in Table 3.1.

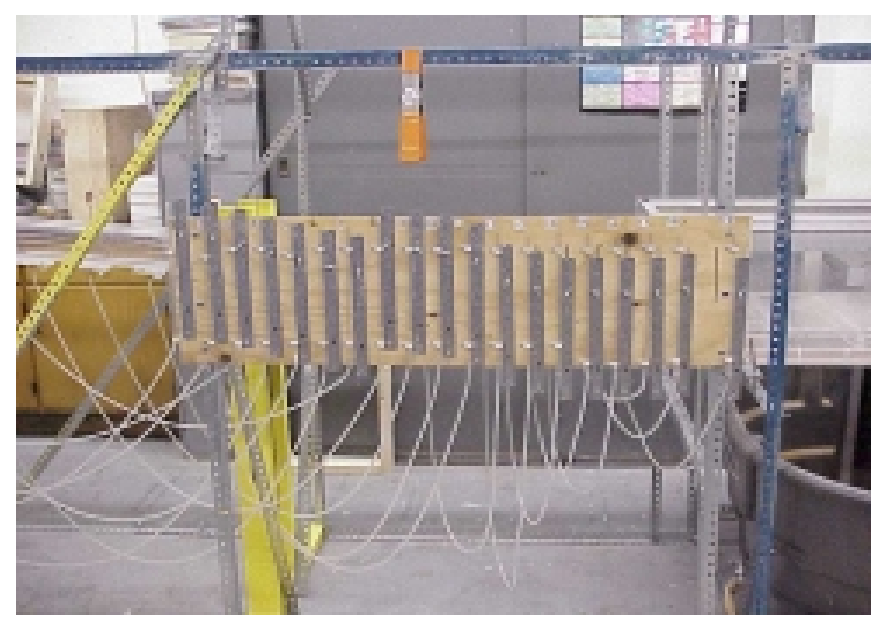

Figure 3.9 Piezometer Board 


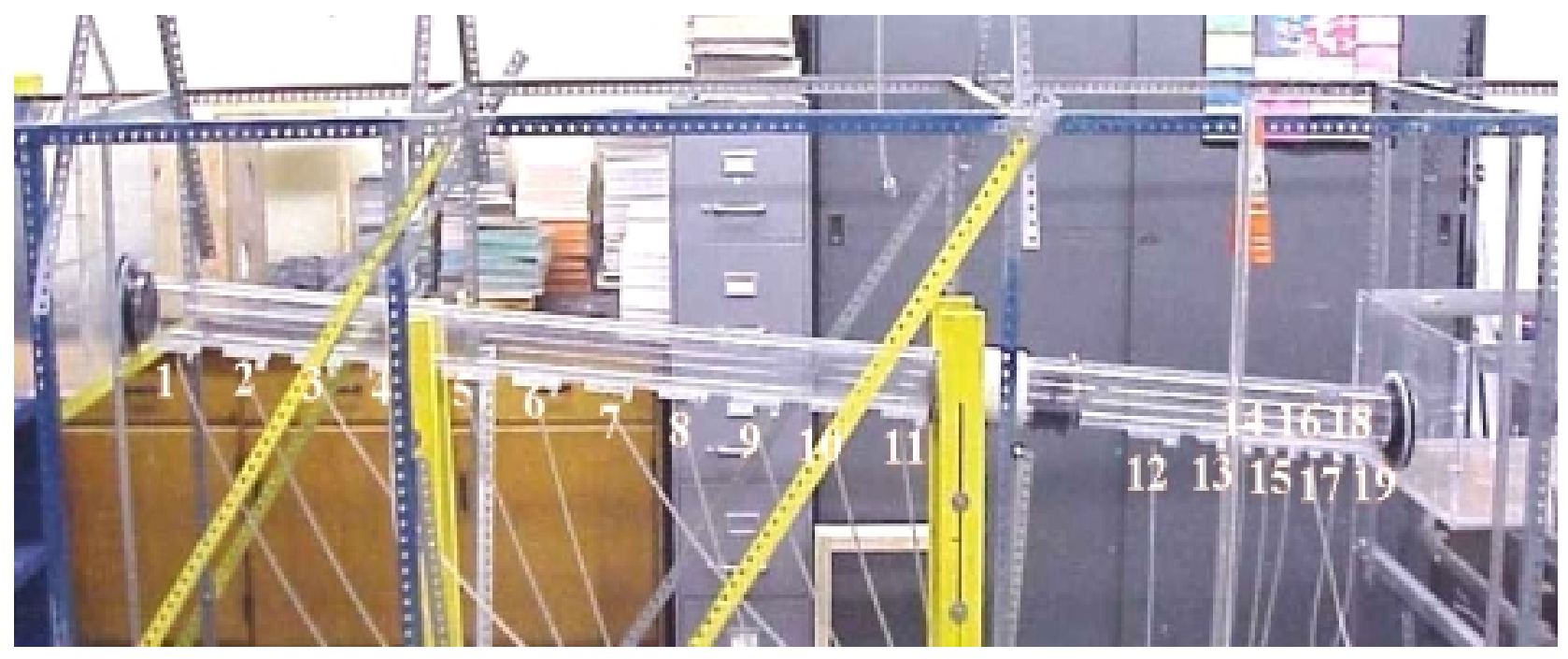

Figure 3.10 Piezometer tap locations

\begin{tabular}{|c|c|}
\hline \multicolumn{2}{|c|}{$\begin{array}{c}\text { Table 3.1 Distance to } \\
\text { Piezometer Taps from Culvert } \\
\text { Inlet }\end{array}$} \\
\hline Tap Number & $\begin{array}{c}\text { Distance from Test } \\
\text { Culvert Inlet (in) }\end{array}$ \\
\hline 1 & 5.125 \\
\hline 2 & 10.625 \\
\hline 3 & 16.5 \\
\hline 4 & 22.625 \\
\hline 5 & 28.875 \\
\hline 6 & 34.625 \\
\hline 7 & 40.625 \\
\hline 8 & 46.625 \\
\hline 9 & 52.75 \\
\hline 10 & 58.75 \\
\hline 11 & 64.75 \\
\hline 12 & 86.25 \\
\hline 13 & 92 \\
\hline 14 & 94 \\
\hline 15 & 96 \\
\hline 16 & 98 \\
\hline 17 & 100 \\
\hline 18 & 102 \\
\hline 19 & 104 \\
\hline & \\
\hline
\end{tabular}




\subsubsection{Three-point Depth Gage}

To obtain water depth flowing on various hydraulic models, a point gage was borrowed from an existing flume and modified by adding two lateral points. The modified three-point depth gage was to provide a more accurate representation of the average flow depth along any cross section in the test channel. The point gage had a verneir scale that was accurate to $.001 \mathrm{ft}$. The scale is shown in Figure 3.12. First, the center point was lowered to the water surface and a reading was taken. Next the lateral points were lowered and another reading was taken. The average of the "inside" and "outside" depth reading is the average flow depth for that cross section. A track was constructed of $1 \frac{1}{2}$ in. aluminum angle that allowed the point gage to travel along the testing channel. Depth readings were taken at eight points along the channel. A schematic of the location of the eight points, labeled $A$ through $G$ is shown in Figure 3.11. The distance to the points, measured from the culvert outlet, are shown in Table 3.2.

\begin{tabular}{|c|c|}
\hline \multicolumn{2}{|c|}{$\begin{array}{c}\text { Table 3.2 Testing Channel } \\
\text { Measurement Locations }\end{array}$} \\
\hline $\begin{array}{c}\text { Point of } \\
\text { Measurement }\end{array}$ & $\begin{array}{c}\text { Distance from } \\
\text { Culvert Outlet (in) }\end{array}$ \\
\hline A & 3.25 \\
\hline B & 3.75 \\
\hline C & 4.50 \\
\hline D & 10.00 \\
\hline E & 16.25 \\
\hline F & 23.50 \\
\hline G & 30.00 \\
\hline H & 35.75 \\
\hline
\end{tabular}




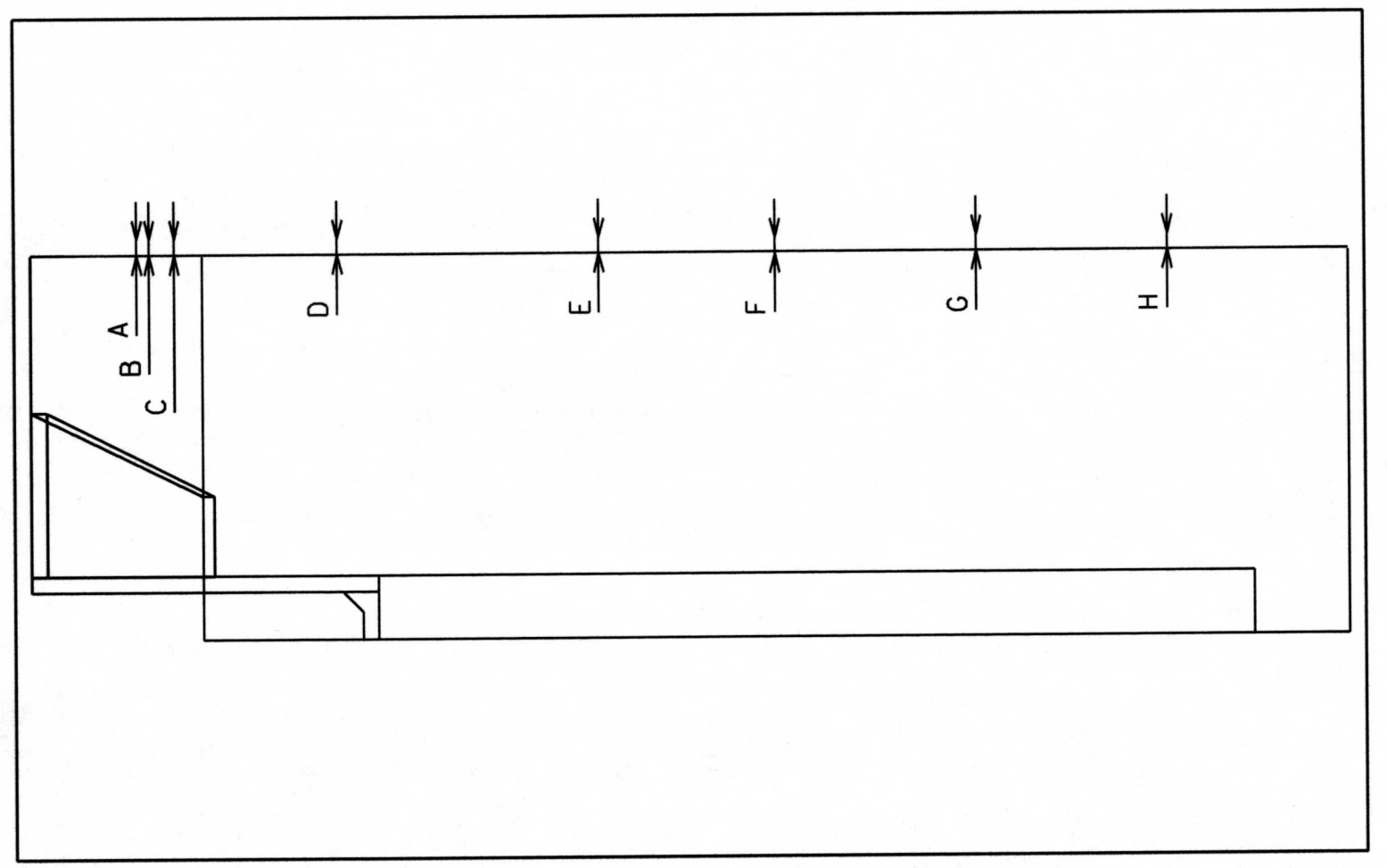

Figure 3.11 Points of Depth Measurement in Testing Channel

To provide longitudinal measurement along the testing channel, a scale was bolted on the outside of the outlet box and a pointer was attached to the side of the gage. The three-point depth gage is shown in Figure 3.13.

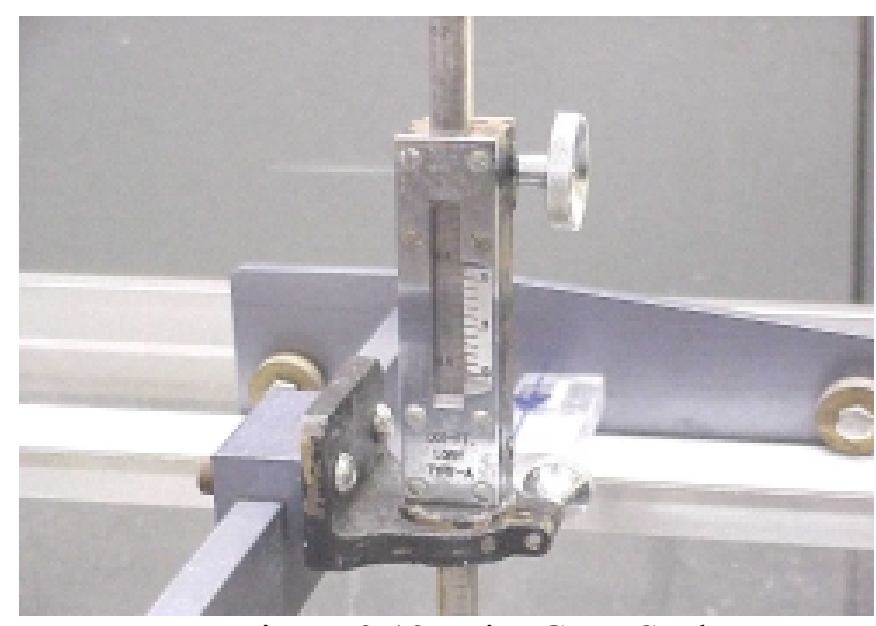

Figure 3.12 Point Gage Scale 


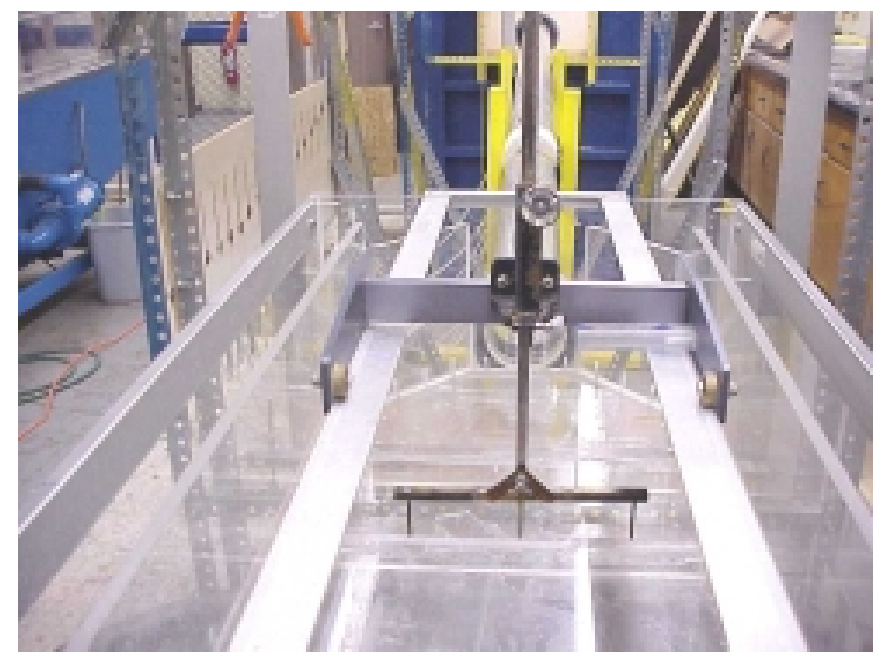

Figure 3.13 Three-Point Depth Gage

\subsubsection{Pitot Tube Device}

In order to assure that the velocity head was accurately calculated for various model tests, it was decided that the traverse velocity profile for the rectangular test section needed to be established. The data acquired would be used to verify that traverse velocity variations did not produce a significant variation from unity in the velocity head correction factor. A Pitot tube was constructed using $5 \mathrm{~mm}$-glass tubing. When this tube was first tested there were many oscillations present, so a $3 \mathrm{~mm}$-glass tube was inserted inside the horizontal section of the existing tube to produce a damping effect. Next the Pitot tube was clamped into a Plexiglas cradle and then fitted to a Plexiglas slide and track to allow for vertical and lateral adjustments. A metric scale and pointer were then fixed to the apparatus to allow for depth and total head measurements. The rectangular channel cross section was then divided into 15 evenly spaced subsections and tic marks were placed on the surface of the Plexiglas track. The completed apparatus can be seen in Figures 3.14 and 3.15. 


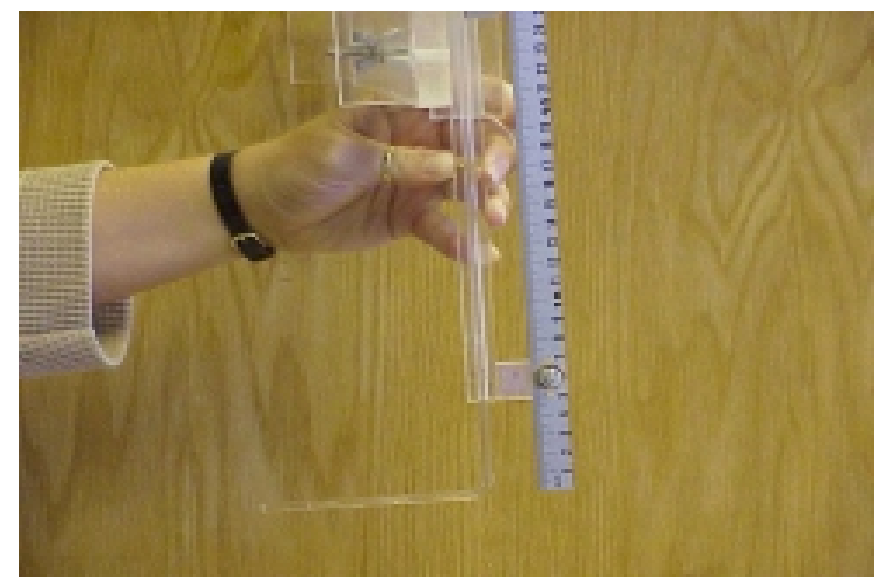

Figure 3.14 Pitot Device (side view)

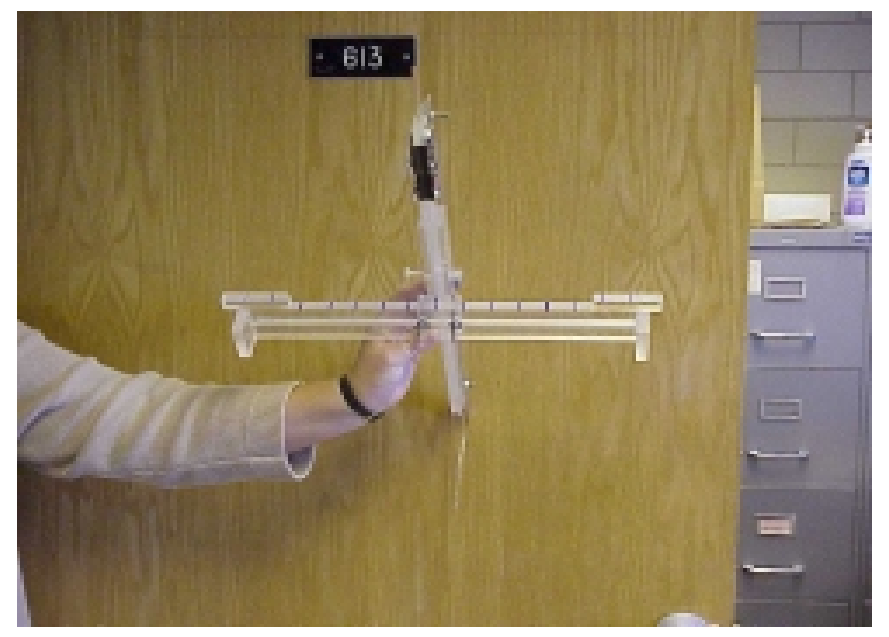

Figure 3.15 Pitot Device (front view)

In applying the Pitot tube for establishing the velocity profile the energy equation was utilized:

$$
\frac{p}{\gamma}+\alpha \frac{V^{2}}{2 g}+z=\text { PitotMeasurement }
$$

The first term, which represents local pressure head, is assumed to be the depth of water above the centerline of the Pitot tube (hydrostatic assumption). The second term, which represents the 
local velocity head, was computed in $\mathrm{mm} / \mathrm{s}$ with the value for acceleration due to gravity being $9.81 \mathrm{~m} / \mathrm{s}^{2}$. The last term represents the datum elevation that was taken as the height above the false floor in the rectangular channel. The datum was established by placing the center of the Pitot tube at the surface of the false floor and recording the depth from the scale attached to the Pitot apparatus.

To determine the value for the velocity correction factor, $\alpha$, the following expression was used:

$$
\alpha=\frac{{ }_{1}^{15} u^{3} d A}{V^{3} A}
$$

Where $\alpha$ is the value for the velocity head correction factor. The point velocity found from the Pitot tube is represented by $u$. The term dA represents each incremental area at which a corresponding measurement was taken. The values in the numerator are then summed from 115 , as there were 15 sections of measurement. In the denominator V represents average the velocity and A is the total cross-sectional area of the flow. Since flow depths were small, only one velocity measurement was made per incremental area. This measurement was made at a point just below the water surface corresponding to full submergence of the Pitot tube.

\subsubsection{Slope Adjustment Devices}

Culvert slopes of 2, 4, 6 and $8 \%$ were selected for testing in the experimental runs. Therefore it was necessary to provide a slope adjustment capability. To allow for slope variation, the outlet box rested on adjustable supports at the front and back of the box. The supports could be bolted at incremental heights on the vertical columns on either side of the box. Two pieces of all-thread steel rod were attached to the support on the left and right of the box, along with another piece of steel angle. This piece of steel angle could be adjusted by lifting up the box and turning nuts on the threaded rod to achieve the desired height. Next, a datum was established by attaching five scales to the frame, using surveying equipment, and then all slope adjustments were calculated based on that elevation. One scale was placed at the test culvert inlet and the other four around the outlet box so it could easily be leveled. The slope adjustment setup is shown in Figure 3.16 as well as a close-up of the support adjustment in Figure 3.17. 


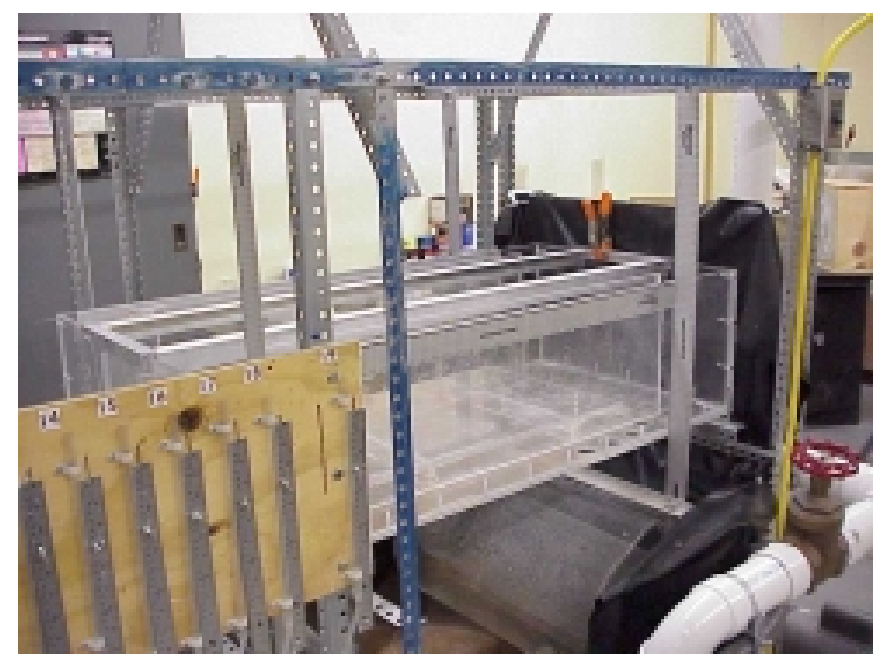

Figure 3.16 Outlet Box Slope Adjustment

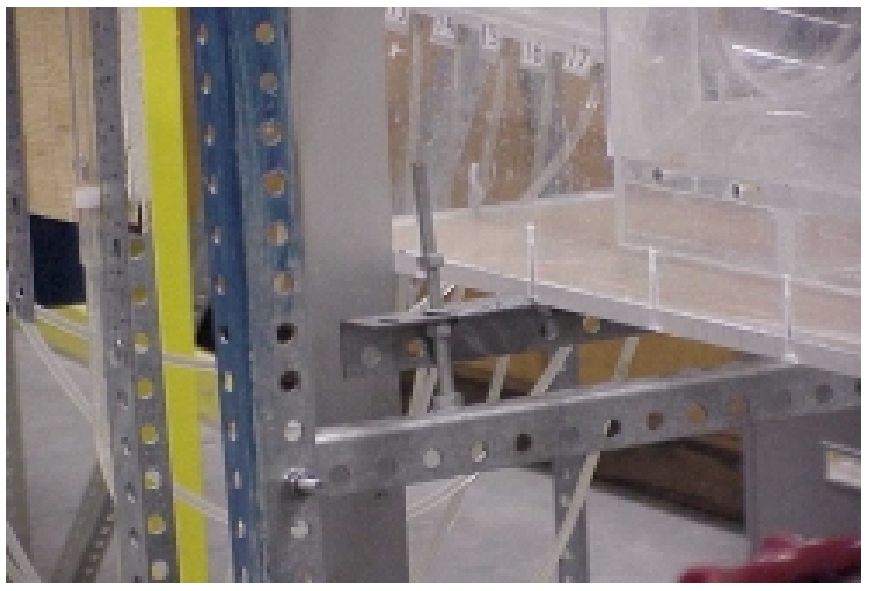

Figure 3.17 Support Adjustment

\subsection{Model Construction}

Three main components were constructed to perform hydraulic model tests of baffle blocks used for energy dissipation; a model apron, a testing channel, and the baffle blocks to be tested. Since plans were available for the existing culvert apron design, the scale model was easily constructed of 0.5 -in. thick cast acrylic. All dimensions were expressed as a function of culvert diameter and the scale model was constructed. A rectangular testing channel was used to contain the flow within lateral boundaries. To produce the rectangular channel, two vertical walls were attached to the model apron, and two concrete pallets with embedded stone were built 
to simulate downstream channel conditions. Also, two vertical extensions were added to the wingwalls to prevent flows from short-circuiting over the wingwalls. The testing channel is shown in Figure 3.18.

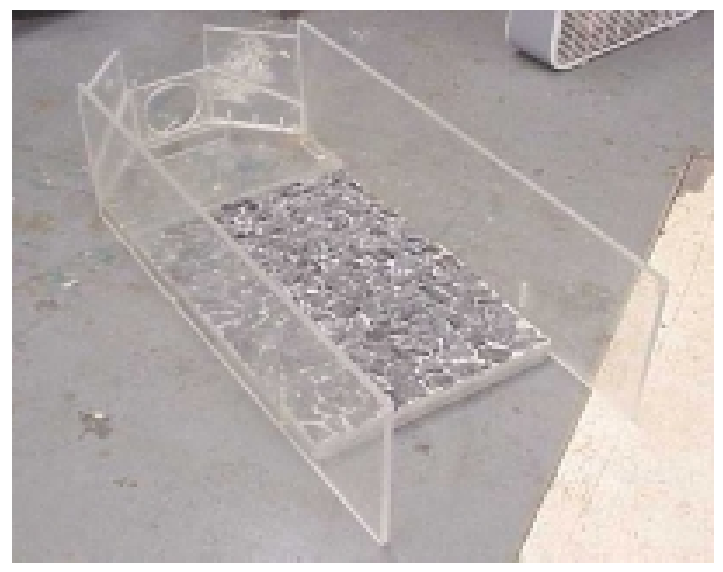

Figure 3.18 Testing Channel

Five baffle block configurations were tested and are listed below:

- Base Configuration

- $\quad 1 / 2$ Diameter Cylinder Baffle

- $\quad 3 / 4$ Diameter Cylinder Baffle

- $\quad 1 / 2$ Diameter L Baffle

- $\quad 3 / 4$ Diameter L Baffle

- Standard Baffle

The Base Configuration consisted of no baffles, no obstructions in the flow, and was used as a reference point. The other configurations are discussed in the following sections.

\subsubsection{Cylinder Baffles}

For the Cylinder Baffles $1 / 2$ and $3 / 4$ diameter refer to the non-dimensional height of the cylinders. In both cases the cylinder diameter was equal to $1 / 4$ the culvert diameter. Three cylinders are placed in an isosceles triangle one diameter downstream of the outlet. Since the major concern of the existing design was excessive sedimentation, circular baffles were intended to provide better self-cleaning. The isosceles triangle arrangement was picked due to simplistic geometry and to allow the deflected flow from the lead baffle to impact the two baffles downstream. The model baffles were held in place using silicone cement, since excessive screw 
holes in the model apron floor were undesirable. The $1 / 2$ and $3 / 4$ diameter cylinder baffle arrangement dimensions are shown in Figures 3.19 through 3.22.

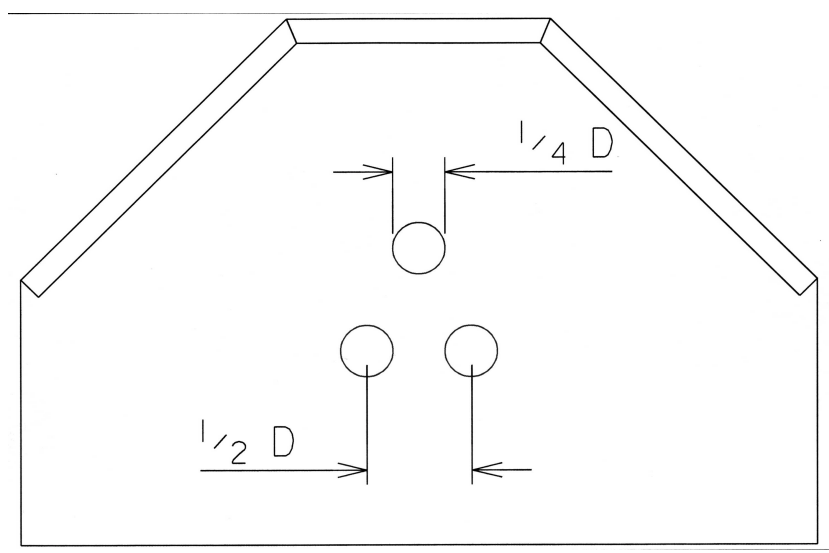

Figure 3.19 1⁄2 D Cylinder Baffle Configuration Plan View

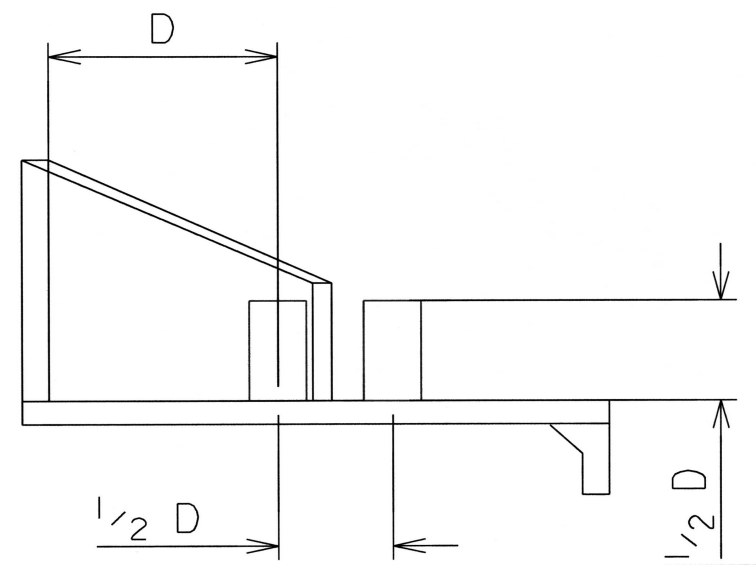

Figure $3.201 \frac{1}{2}$ Diameter Cylinder Baffle Configuration Profile View 


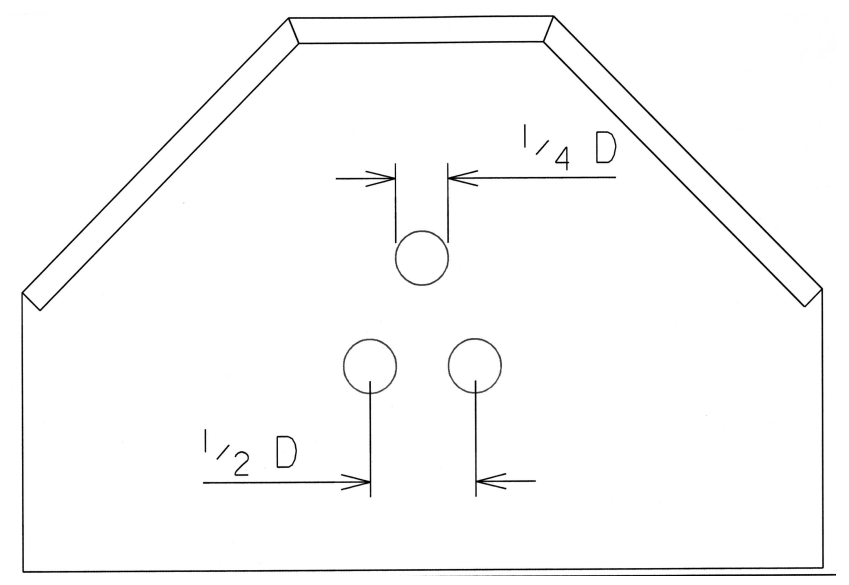

Figure 3.21 3/4 Diameter Cylinder Baffle Configuration Plan View

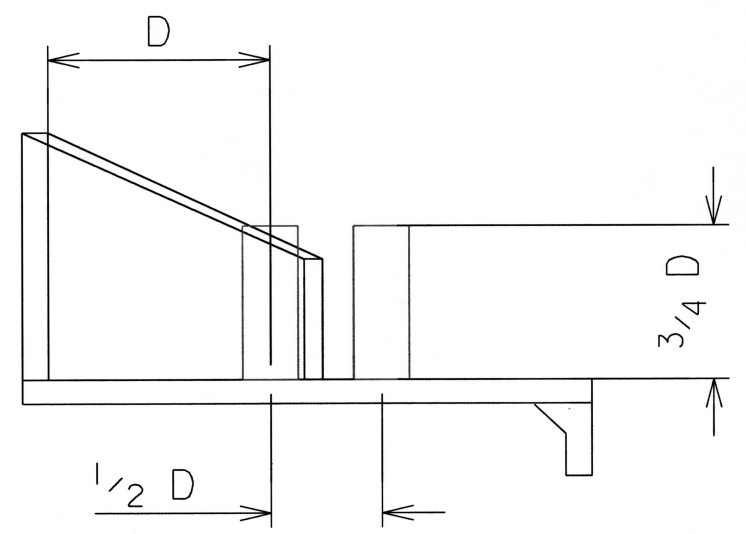

Figure 3.22 3/4 Diameter Cylinder Baffle Configuration Profile View

\subsubsection{Baffle}

For the $1 / 2$ and $3 / 4$ L Baffle configurations the height of the baffle was again a fraction of the culvert diameter. The width of the L Baffle was equal to the culvert diameter, and a lip was added to the top of the baffle to produce a turning effect in the flow. The length of the lip was equal to $1 / 4$ of the culvert diameter. The L Baffles were located at the downstream edge of the culvert apron. This location should be beneficial to construction by allowing reinforcing rebar to tie into the toe of the culvert apron producing added strength. The lip was constructed of 1/8 in. sheet aluminum stock attached to the top of the baffle by machine screws. The $1 / 2$ and $3 / 4$ L Baffle configurations are shown in Figures 3.23 through 3.26. 


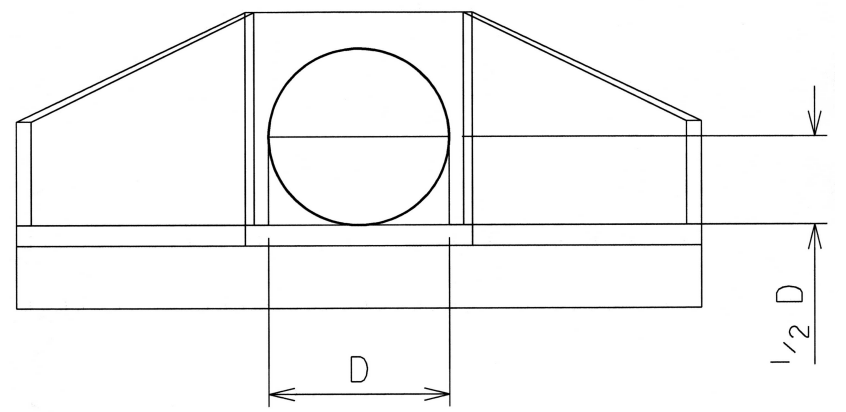

Figure 3.23 1 12 Diameter L Baffle Configuration Front View

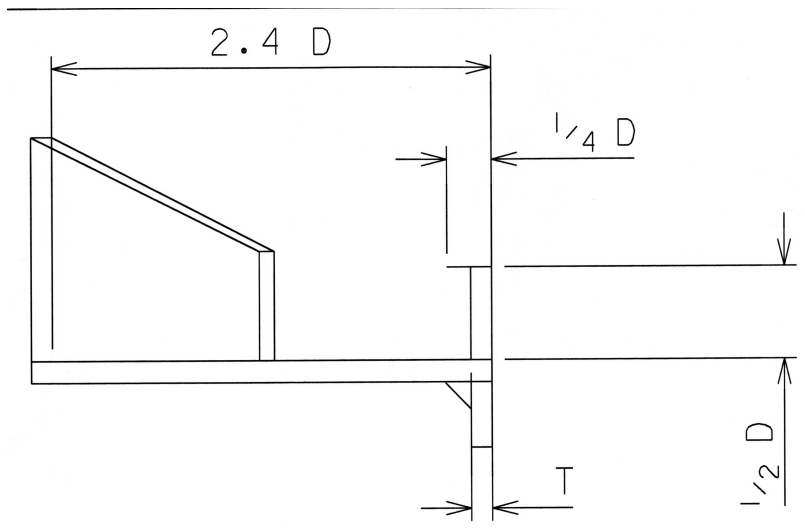

Figure 3.24 1/2 Diameter L Baffle Configuration Profile View

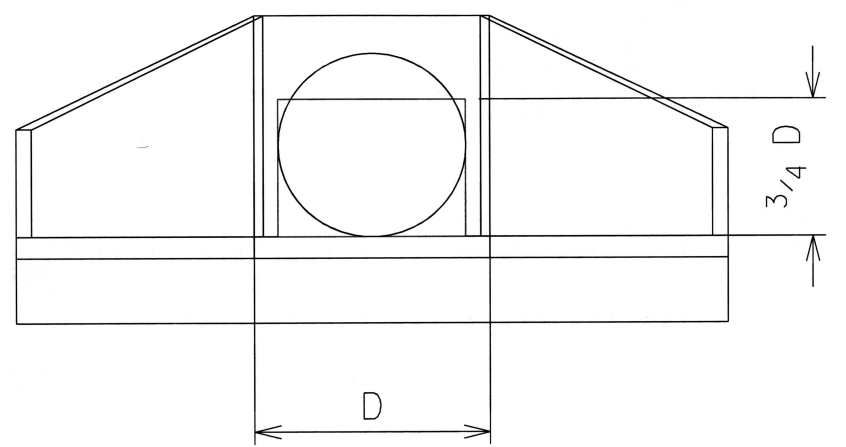

Figure 3.25 3/4 Diameter L Baffle Configuration Front View 


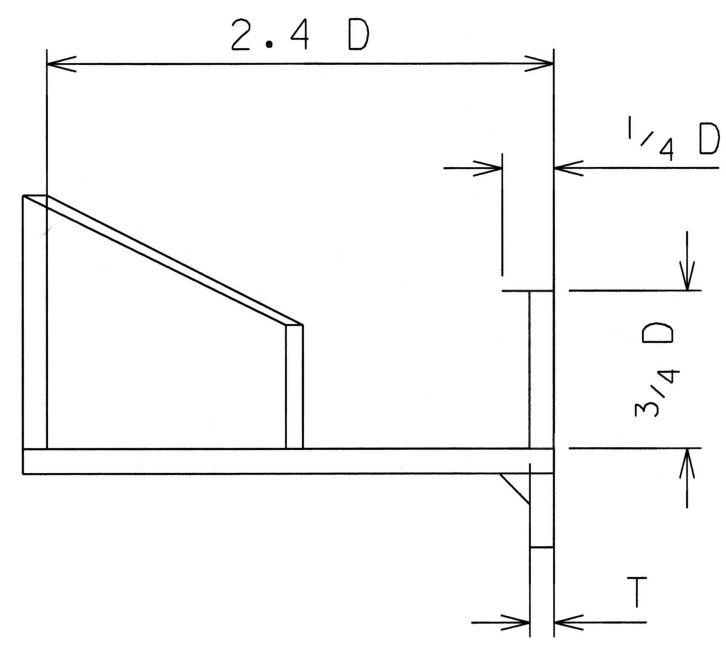

Figure 3.26 3/4 Diameter L Baffle Configuration Profile View

\subsubsection{Standard Baffle}

The Standard Baffle configuration is the current design used by the WVDOH. Testing was performed on this configuration to determine problems associated with the design as well as provide a means for comparison with the previous configurations. The design dimensions were presented in Chapter 1, Figures 1.3.1 through 1.3.3. 


\section{Chapter 4 - Analysis}

Following the completion of the testing flume, project goals were developed for the investigation of the baffle configurations. In order for the baffle configuration to meet the goals

of the project the following criteria had to be satisfied:

- Construction on site must be reasonable

- Economically feasible

- Applicability to various culvert sizes and flowrates

- Self cleaning and low maintenance

- Re-establish natural flow conditions downstream of the outlet

The configurations developed were intended for small to medium sized culverts, typically 2-12 feet, of various cross-section. The configurations were designed to operate without the presence of tail-water. Where tail-water was present the effectiveness of the configurations increased.

\subsection{Data Collection}

Following the completion of the testing flume, several baffle shapes and configurations were tested by a trial and error process. The purpose was to narrow the focus to what appeared to be the best performing baffle configuration. After the trial phase the six baffle configurations to be tested were defined and testing methods were established. Each experimental run required the measurement of five main parameters.

- Slope

- Headwater at inlet

- Piezometer readings

- Three point depth data

- Flow rate

A data sheet was developed to accommodate the various data taken. Culvert slopes tested were $2,4,6$, and $8 \%$. Headwater was read at the beginning of each test, measured from the inlet invert of the test culvert. Piezometer readings were taken before the pump was turned on to establish a tare reading (zero depth). Depth readings were taken along the testing channel at eight points using the three-point depth gage. The depth reading was computed as an average of the middle point reading and the reading from the two lateral points. Along with the three-point depth measurements the flow behavior at the culvert outlet, interaction with the wingwalls, and any 
adverse effects were noted based on visual observation. Flowrates of 50, 75, 100, 125, 150, and 200 gpm were applied to each baffle configuration at each of the four slopes.

\subsection{Velocity Profile Investigation}

To determine the value for alpha, the velocity head correction factor, the following expression was used:

$\alpha=\frac{{ }_{1}^{15} u^{3} d A}{V^{3} A}$

Where:

$$
\begin{aligned}
& \alpha=\text { Velocity correction factor } \\
& u=\text { Point velocity found from the pitot tube } \\
& d a=\text { Incremental area at which measurements were taken } \\
& V=\text { Average Velocity } \\
& A=\text { Total cross sectional area of the flow }
\end{aligned}
$$

The values in the numerator are then summed from 1 to 15 , as there were 15 sections of measurement. Initial calculations were performed at $50 \mathrm{gpm}$ and $8 \%$ slope, since the flow appearance at $8 \%$ slope appeared the most non-uniform. The first method used values obtained solely from the Pitot tube. Table 4.2.1 lists the data measurements and results of the computations. 


\begin{tabular}{|c|c|c|c|c|c|c|c|c|c|}
\hline $\begin{array}{c}1 \\
\text { Width } \\
\text { Increments }\end{array}$ & $\begin{array}{c}2 \\
\text { Depth from } \\
\text { bottom of } \\
\text { tube }\end{array}$ & $\begin{array}{c}3 \\
\text { Pitot } \\
\text { Reading }\end{array}$ & $\begin{array}{c}4 \\
\text { Pitot } \\
\text { Depth }\end{array}$ & $\begin{array}{c}5 \\
\text { Depth from } \\
\text { center of tube }\end{array}$ & $\begin{array}{c}6 \\
\text { p/gamma }\end{array}$ & $\begin{array}{c}7 \\
\text { Point } \\
\text { Velocity @ } \\
\text { section }\end{array}$ & $\begin{array}{c}8 \\
\text { Area @ } \\
\text { section }\end{array}$ & $\begin{array}{c}9 \\
\left(u^{3}\right) d A\end{array}$ & $\begin{array}{c}10 \\
\text { Incremental } \\
\text { Flowrate }\end{array}$ \\
\hline (Section) & $(\mathrm{mm})$ & $(\mathrm{mm})$ & $(\mathrm{mm})$ & $(\mathrm{mm})$ & $(\mathrm{mm})$ & $(\mathrm{mm} / \mathrm{s})$ & $\left(\mathrm{mm}^{\wedge} 2\right)$ & & $\left(\mathrm{mm}^{\wedge} 3 / \mathrm{s}\right)$ \\
\hline 1 & 241 & 45 & 250 & 243.5 & 6.5 & 869 & 317 & $2.078 \mathrm{E}+11$ & 275150 \\
\hline 2 & 241 & 60 & 247 & 243.5 & 3.5 & 1053 & 317 & $3.694 \mathrm{E}+11$ & 333322 \\
\hline 3 & 241 & 85 & 248 & 243.5 & 4.5 & 1257 & 317 & $6.282 \mathrm{E}+11$ & 397867 \\
\hline 4 & 242 & 125 & 249 & 244.5 & 4.5 & 1537 & 289 & $1.050 \mathrm{E}+12$ & 444452 \\
\hline 5 & 248 & 135 & 253 & 250.5 & 2.5 & 1612 & 124 & $5.191 \mathrm{E}+11$ & 199739 \\
\hline 6 & 248 & 140 & 253 & 250.5 & 2.5 & 1642 & 124 & $5.488 \mathrm{E}+11$ & 203473 \\
\hline 7 & 248 & 150 & 253 & 250.5 & 2.5 & 1701 & 124 & $6.097 \mathrm{E}+11$ & 210742 \\
\hline 8 & 248 & 153 & 253 & 250.5 & 2.5 & 1715 & 124 & $6.253 \mathrm{E}+11$ & 212520 \\
\hline 9 & 248 & 160 & 253 & 250.5 & 2.5 & 1758 & 124 & $6.727 \mathrm{E}+11$ & 217768 \\
\hline 10 & 248 & 155 & 253 & 250.5 & 2.5 & 1729 & 124 & $6.410 \mathrm{E}+11$ & 214284 \\
\hline 11 & 248 & 145 & 253 & 250.5 & 2.5 & 1672 & 124 & $5.790 \mathrm{E}+11$ & 207139 \\
\hline 12 & 248 & 140 & 253 & 250.5 & 2.5 & 1642 & 124 & $5.488 \mathrm{E}+11$ & 203473 \\
\hline 13 & 241 & 140 & 247 & 243.5 & 3.5 & 1636 & 317 & $1.387 \mathrm{E}+12$ & 518091 \\
\hline 14 & 241 & 90 & 246 & 243.5 & 2.5 & 1310 & 317 & $7.119 \mathrm{E}+11$ & 414805 \\
\hline 15 & 241 & 75 & 246 & 243.5 & 2.5 & 1192 & 317 & $5.369 \mathrm{E}+11$ & 377580 \\
\hline SUMS: & & & & & & 22326 & 3180 & $9.636 \mathrm{E}+12$ & 4430403 \\
\hline
\end{tabular}

The first column, width increments, is the section number assigned to each location of measurement. The second column, depth from bottom of tube, is the location of the water surface found by locating the point at which the Pitot tube first contacts the surface of the flow. The third column, Pitot reading, is the value obtained by recording the height of water that appeared in the Pitot tube. Note that due to oscillations, the Pitot reading was an average based on visual inspection. The fourth column, Pitot depth, is the location of the Pitot tube when it was placed into the flow to obtain a Pitot reading. The fifth column, depth from center of tube, is an adjustment of column two. In order to produce more accurate results, the initial water surface measurement was taken from the bottom of the tube and then a half diameter adjustment was applied to give the water surface elevation from the center of the tube. Column six, p/gamma, is the height of the column of water from the center of the Pitot tube to the surface of the flow, (column 4) minus (column 5). Column seven, point velocity @ section, is the value for u as determined from the energy equation solving for V. Column eight, area @ section, is the value of the incremental cross sectional area at the corresponding width increment. The value for width is found by dividing the total width of the channel, $413 \mathrm{~mm}$, by the number of width increments, 15. The height for the incremental cross-sectional area is found by subtracting the 
datum elevation from the depth of water from the center of the tube. Column $9,\left(u^{3}\right) d A$ is the product of the cube of the point velocity and the incremental area, (column $\left.7^{3}\right) *($ column 8$)$. Column 10 is the incremental flowrate found by the product of columns seven and eight. Note that columns eight, nine and ten are summed with the total at the bottom.

For the first method of determining alpha by the Pitot data alone, the value for the numerator is the sum of column nine. The value for the average velocity, $\mathrm{V}$, is found by dividing the total of the incremental flow rates by the total of the incremental areas. The value for $\mathrm{A}$ is the sum of the incremental areas.

A second method of determining alpha was by the use of data obtained by experiments performed using the three-point depth gage and flow meter. The average velocity was calculated based on the flow meter discharge, and the total cross sectional area of the flow was based on the three point gage measurement. Alpha was calculated by using the same numerator values as in the first method, however the denominator values were obtained from the three point gage data. The values obtained from the two methods are displayed in Table 4.2.2.

\begin{tabular}{|c|c|c|c|}
\hline \multicolumn{3}{|c|}{ Table 4.2.2 Alpha Value obtained by Methods 1 } \\
and 2 (50gpm 8\%Slope)
\end{tabular}

The same procedure was performed at $100 \mathrm{gpm}$ and $8 \%$ slope and the velocity correction factor obtained by the two methods at this setting is displayed in Table 4.2.3. The values obtained from the three-point gage, were obviously less accurate than the Pitot data. Since there was a potential inconsistency between the average velocity and the point velocity measurements, the results of the second method were not used. These two tests, at 50 gpm and 100 gpm, were examined and expected to be typical values. The value for the velocity correction factor was nearly equal to unity in the Pitot tube analysis, it was not considered in energy calculations. 


\begin{tabular}{|c|c|c|c|}
\hline \multicolumn{3}{|c|}{$\begin{array}{c}\text { Table 4.2.3 Alpha Values Obtained by Methods 1 } \\
\text { and } 2 \text { (100 gpm 8\% Slope) }\end{array}$} \\
\hline $\begin{array}{c}\text { Results Based on Pitot } \\
\text { Data }\end{array}$ & $\begin{array}{c}\text { Results from Three Point } \\
\text { Data }\end{array}$ \\
\hline $\begin{array}{c}\text { Average } \\
\text { Velocity } \\
(\mathrm{mm} / \mathrm{s})\end{array}$ & 1797 & $\begin{array}{c}\text { Average } \\
\text { Velocity } \\
(\mathrm{mm} / \mathrm{s})\end{array}$ & 1626 \\
\hline Area $\left(\mathrm{mm}^{2}\right)$ & 4667 & Area $\left(\mathrm{mm}^{2}\right)$ & 3880 \\
\hline Alpha & 1.046 & Alpha & 1.698 \\
\hline
\end{tabular}

\subsection{Test Culvert Analysis}

It became apparent that uniform flow depth was approached at the test culvert outlet for each of the flowrates and slopes used. To obtain the best representative value of uniform flow depth at the test culvert outlet, piezometer data for each slope and flowrate for the six configurations was compiled in Microsoft excel. The spreadsheet, titled Test Culvert Analysis, contained the depth data for all 19 piezometers for each configuration. Since the reading obtained from the piezometer is the depth of water above the tap opposite the direction of gravity, a conversion was used to give the depth of flow perpendicular to the culvert invert. The equation is simply a trigonometric operation and was performed as follows:

$y_{n}=\frac{\left(R_{a}-R_{t}\right)}{\operatorname{CoS}(\theta)}$

Where:

$R_{a}=$ The actual Reading from the piezometer

$R_{t}=$ The tare reading for the piezometer

$y_{n}=$ Uniform flow depth perpendicular to the test culvert invert

$\theta=$ Slope of the test culvert (decimal)

The 19 piezometer tap values were examined and it was concluded that the values had reached uniform flow conditions from taps $10-19$ in most instances. Where wave action was pronounced or the presence of a jump was detected, those tap readings were not considered. The taps that most accurately depicted uniform flow depth were then averaged and recorded for each 
slope and flowrate. The values were then summarized in a table for each configuration and averaged again over the six experimental configurations. The result is the value used for uniform flow depth at the test culvert outlet for a given slope and flow rate, shown in red in Table 4.3.1 (Test Culvert Uniform Flow Depth Analysis). Since the uniform flow depth and corresponding Froude number are referred points for each slope and discharge combination, it was highly beneficial to adopt a single value for each parameter to facilitate data presentation.

\begin{tabular}{|c|c|c|c|c|c|c|c|c|}
\hline \multicolumn{9}{|c|}{ Table 4.3.1 Test Culvert Analysis } \\
\hline \multicolumn{9}{|c|}{ Uniform Flow Depth in Test Culvert (in) } \\
\hline $\begin{array}{c}\text { Culvert } \\
\text { Slope (\%) }\end{array}$ & $\begin{array}{l}\text { Flowrate } \\
\text { (gpm) }\end{array}$ & $\begin{array}{c}\text { Base } \\
\text { Configuration }\end{array}$ & $\begin{array}{c}\text { CYL Baffle } \\
\mathrm{H}=0.75 \mathrm{D}\end{array}$ & $\begin{array}{c}\text { CYL Baffle } \\
\mathrm{H}=0.5 \mathrm{D}\end{array}$ & L-Baffle $\mathrm{H}=0.75 \mathrm{D}$ & L-Baffle $\mathrm{H}=0.5 \mathrm{D}$ & $\begin{array}{l}\text { Standard } \\
\text { Baffle }\end{array}$ & $\begin{array}{c}\text { Average } \\
\text { Uniform flow } \\
\text { depth over runs } \\
\text { (in) }\end{array}$ \\
\hline 2 & 50 & 1.39 & 1.40 & 1.43 & 1.39 & 1.41 & 1.46 & 1.41 \\
\hline 2 & 75 & 1.69 & 1.68 & 1.71 & 1.69 & 1.72 & 1.75 & 1.71 \\
\hline 2 & 100 & 1.99 & 1.96 & 2.00 & 1.96 & 1.96 & 2.02 & 1.98 \\
\hline 2 & 125 & 2.22 & 2.19 & 2.22 & 2.22 & 2.23 & 2.24 & 2.22 \\
\hline 2 & 150 & 2.41 & 2.38 & 2.42 & 2.38 & 2.42 & 2.40 & 2.40 \\
\hline 2 & 200 & - & 2.63 & 2.63 & 2.64 & 2.66 & 2.61 & 2.63 \\
\hline 4 & 50 & 1.25 & 1.25 & 1.22 & 1.26 & 1.26 & 1.22 & 1.24 \\
\hline 4 & 75 & 1.55 & 1.53 & 1.51 & 1.50 & 1.55 & 1.49 & 1.52 \\
\hline 4 & 100 & 1.75 & 1.81 & 1.75 & 1.75 & 1.82 & 1.78 & 1.78 \\
\hline 4 & 125 & 1.98 & 2.04 & 1.97 & 1.99 & 1.98 & 2.01 & 1.99 \\
\hline 4 & 150 & 2.16 & 2.22 & 2.16 & 2.17 & 2.23 & 2.17 & 2.19 \\
\hline 4 & 200 & - & 2.48 & 2.40 & 2.44 & 2.45 & 2.27 & 2.41 \\
\hline 6 & 50 & 1.12 & 1.12 & 1.10 & 1.13 & 1.09 & 1.12 & 1.11 \\
\hline 6 & 75 & 1.36 & 1.37 & 1.36 & 1.38 & 1.37 & 1.37 & 1.37 \\
\hline 6 & 100 & 1.61 & 1.58 & 1.59 & 1.59 & 1.59 & 1.61 & 1.59 \\
\hline 6 & 125 & 1.81 & 1.80 & 1.82 & 1.95 & 1.82 & 1.83 & 1.82 \\
\hline 6 & 150 & 2.00 & 1.98 & 1.98 & 2.05 & 2.00 & 2.01 & 2.00 \\
\hline 6 & 200 & - & 2.26 & 2.27 & 2.28 & 2.26 & 2.22 & 2.26 \\
\hline 8 & 50 & 1.22 & 1.07 & 1.03 & 1.11 & 1.18 & 1.06 & 1.08 \\
\hline 8 & 75 & 1.43 & 1.28 & 1.27 & 1.37 & 1.44 & 1.31 & 1.32 \\
\hline 8 & 100 & 1.66 & 1.50 & 1.49 & 1.56 & 1.60 & 1.53 & 1.53 \\
\hline 8 & 125 & 1.86 & 1.72 & 1.70 & 1.77 & 1.87 & 1.74 & 1.74 \\
\hline 8 & 150 & 2.03 & 1.90 & 1.87 & 1.94 & 2.05 & 1.93 & 1.92 \\
\hline 8 & 200 & - & 2.20 & 2.08 & 2.24 & 2.28 & 2.14 & 2.21 \\
\hline
\end{tabular}




\subsection{Equivalent Rectangular Froude Number}

In the early stages of channel data analysis, it became apparent that the calculated Froude number, at the culvert outlet, was misleading when used as a non-dimensional flow reference downstream. The Froude number was based on the circular cross-section of the test culvert, which was the source of the problem. A transformation from circular to rectangular cross section was found in the development of the Contra Costa energy dissipator, reviewed in HEC-14, 1983. The circular to rectangular transform eliminated the complex variance of cross-sectional properties with the increase of flow depth. HEC-14 states that for oval, circular, elliptical or other shapes, the flow at the culvert must be converted to an equivalent rectangular cross-section with a width equal to twice the depth of flow. The equivalent rectangular flow depth, $y_{e}$, is determined from the following relationship:

$$
y_{e}=\left|\frac{A}{2}\right|^{\frac{1}{2}}
$$

Where:

$$
y_{e}=\text { the equivalent rectangular flow depth }
$$

$A=$ Area of the flow cross-section

Following the transform of the flow depth, the equivalent rectangular Froude number can be determined from using $y_{\mathrm{e}}$ rather than the hydraulic depth at the culvert outlet. So the relationship for the Froude number becomes:

$$
F r=\frac{V}{\sqrt{g y_{e}}}
$$

The introduction of the transformed rectangular cross-section avoids the misleading reversal in Froude number magnitude (that approaches zero) as a round pipe nears full flow. Values obtained for the uniform flow depth, from Section 4.3, were converted to the equivalent rectangular flow depth for purposes of calculating the Froude number.

\subsection{Energy Calculations}

Based on the uniform flow depth established from Section 4.3, the following parameters were obtained for application in the spreadsheet: 
- Culvert $\Phi$

- Flow Area

- Velocity at test culvert outlet

- Flow depth at culvert outlet

Culvert $\Phi$ was the sector angle used to calculate the cross-sectional area of the flow at a given flow depth. Culvert $\Phi$ is depicted in Figure 4.5.1.

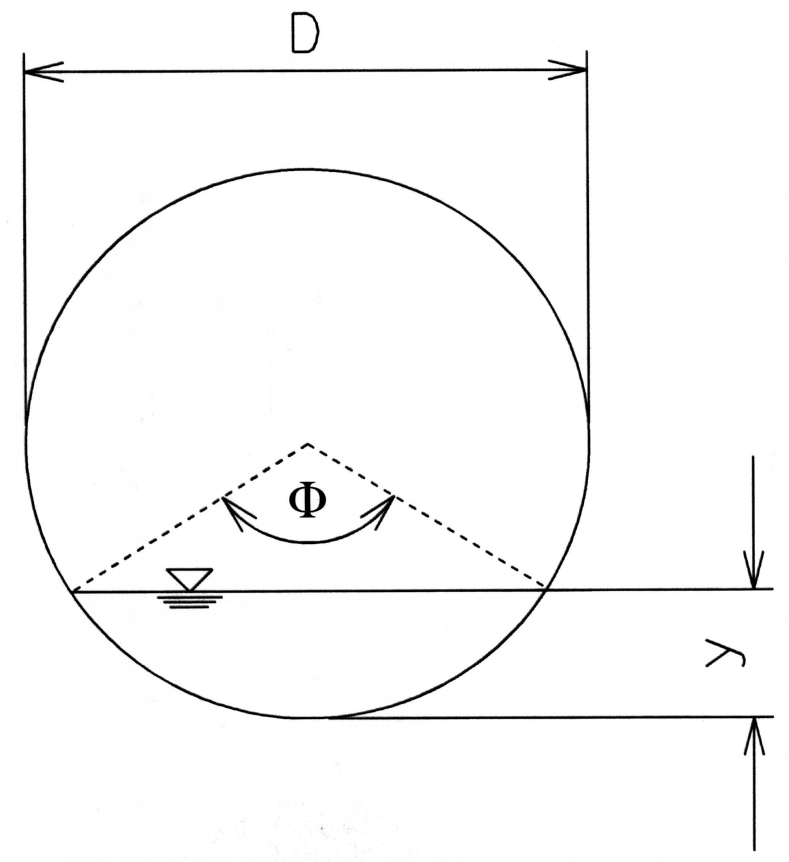

Figure 4.5.1 Culvert $\Phi$

Given a value for the depth of flow in the test culvert, $\Phi$ was determined from the following equation:

$\Phi=2 \operatorname{COS}^{-1}\left|1-\frac{2 y}{D}\right|$

The flow area of a given test was found from a relation involving the diameter of the test culvert and culvert $\Phi$, shown below.

$A=\frac{D^{2}}{8}(\Phi-\operatorname{SIN} \Phi)$ 
Since the cross-sectional area of the flow and the flowrate were both known, the velocity could easily be determined by dividing the flowrate by the cross-sectional area. The adopted values of uniform flow depth from Section 4.3 for the test culvert at a set slope and flowrate, are shown in Tables 4.5.1 through 4.5.4.

\begin{tabular}{|c|c|c|c|c|c|}
\hline \multicolumn{5}{|c|}{ Table 4.5.1 Test Culvert Data 2\% Slope } \\
\hline $\begin{array}{c}\text { Flow Rate } \\
(\mathrm{gpm})\end{array}$ & $\begin{array}{c}\text { Uniform } \\
\text { Flow } \\
\text { Depth (in) }\end{array}$ & Culvert $\Phi$ & $\begin{array}{c}\text { Flow Area } \\
\left.\text { (in }^{2}\right)\end{array}$ & $\begin{array}{c}\text { Velocity at } \\
\text { Test Culvert } \\
\text { Outlet (in/s) }\end{array}$ & $\begin{array}{c}\text { Equivalent } \\
\text { Rectangular } \\
\text { Flow Depth at } \\
\text { Test Culvert } \\
\text { Outlet (in) }\end{array}$ \\
\hline 50 & 1.41 & 2.46 & 4.12 & 46.7 & 1.44 \\
\hline 75 & 1.71 & 2.75 & 5.33 & 54.2 & 1.63 \\
\hline 100 & 1.98 & 3.01 & 6.48 & 59.4 & 1.80 \\
\hline 125 & 2.22 & 3.23 & 7.50 & 64.1 & 1.94 \\
\hline 150 & 2.40 & 3.40 & 8.26 & 69.9 & 2.03 \\
\hline 200 & 2.63 & 3.62 & 9.23 & 83.5 & 2.15 \\
\hline
\end{tabular}

\begin{tabular}{|c|c|c|c|c|c|}
\hline \multicolumn{5}{|c|}{ Table 4.5.2 Test Culvert Data 4\% Slope } \\
\hline $\begin{array}{c}\text { Flow Rate } \\
(\mathrm{gpm})\end{array}$ & $\begin{array}{c}\text { Uniform } \\
\text { Flow } \\
\text { Depth (in) }\end{array}$ & Culvert $\Phi$ & $\begin{array}{c}\text { Flow Area } \\
\left.\text { (in }^{2}\right)\end{array}$ & $\begin{array}{c}\text { Velocity at } \\
\text { Test Culvert } \\
\text { Outlet (in/s) }\end{array}$ & $\begin{array}{c}\text { Equivalent } \\
\text { Rectangular } \\
\text { Flow Depth at } \\
\text { Test Culvert } \\
\text { Outlet (in) }\end{array}$ \\
\hline 50 & 1.24 & 2.29 & 3.46 & 55.7 & 1.31 \\
\hline 75 & 1.52 & 2.57 & 4.56 & 63.3 & 1.51 \\
\hline 100 & 1.78 & 2.81 & 5.62 & 68.5 & 1.68 \\
\hline 125 & 1.99 & 3.02 & 6.54 & 73.6 & 1.81 \\
\hline 150 & 2.19 & 3.20 & 7.35 & 78.6 & 1.92 \\
\hline 200 & 2.41 & 3.41 & 8.29 & 92.8 & 2.04 \\
\hline
\end{tabular}




\begin{tabular}{|c|c|c|c|c|c|}
\hline \multicolumn{5}{|c|}{ Table 4.5.3 Test Culvert Data 6\% Slope } \\
\hline $\begin{array}{c}\text { Flow Rate } \\
(\mathrm{gpm})\end{array}$ & $\begin{array}{c}\text { Uniform } \\
\text { Flow } \\
\text { Depth (in) }\end{array}$ & Culvert $\Phi$ & $\begin{array}{c}\text { Flow Area } \\
\left(\mathrm{in}^{2}\right)\end{array}$ & $\begin{array}{c}\text { Velocity at } \\
\text { Test Culvert } \\
\text { Outlet (in/s) }\end{array}$ & $\begin{array}{c}\text { Equivalent } \\
\text { Rectangular } \\
\text { Flow Depth at } \\
\text { Test Culvert } \\
\text { Outlet (in) }\end{array}$ \\
\hline 50 & 1.11 & 2.15 & 2.96 & 65.0 & 1.22 \\
\hline 75 & 1.37 & 2.41 & 3.95 & 73.1 & 1.41 \\
\hline 100 & 1.59 & 2.64 & 4.86 & 79.3 & 1.56 \\
\hline 125 & 1.82 & 2.85 & 5.78 & 83.2 & 1.70 \\
\hline 150 & 2.00 & 3.03 & 6.58 & 87.8 & 1.81 \\
\hline 200 & 2.26 & 3.27 & 7.66 & 100 & 1.96 \\
\hline
\end{tabular}

\begin{tabular}{|c|c|c|c|c|c|}
\hline \multicolumn{5}{|c|}{ Table 4.5.4 Test Culvert Data 8\% Slope } \\
\hline $\begin{array}{c}\text { Flow Rate } \\
(\mathrm{gpm})\end{array}$ & $\begin{array}{c}\text { Uniform } \\
\text { Flow } \\
\text { Depth (in) }\end{array}$ & Culvert $\Phi$ & $\begin{array}{c}\text { Flow Area } \\
\left.\text { (in }^{2}\right)\end{array}$ & $\begin{array}{c}\text { Velocity at } \\
\text { Test Culvert } \\
\text { Outlet (in/s) }\end{array}$ & $\begin{array}{c}\text { Equivalent } \\
\text { Rectangular } \\
\text { Flow Depth at } \\
\text { Test Culvert } \\
\text { Outlet (in) }\end{array}$ \\
\hline 50 & 1.08 & 2.11 & 2.84 & 67.7 & 1.19 \\
\hline 75 & 1.32 & 2.36 & 3.75 & 77.1 & 1.37 \\
\hline 100 & 1.53 & 2.58 & 4.61 & 83.5 & 1.52 \\
\hline 125 & 1.74 & 2.78 & 5.47 & 88.0 & 1.65 \\
\hline 150 & 1.92 & 2.95 & 6.23 & 92.6 & 1.77 \\
\hline 200 & 2.21 & 3.22 & 7.46 & 103 & 1.93 \\
\hline
\end{tabular}

Since the uniform flow depth was kept constant at a given slope and flowrate, the remainder of the calculations dealt with comparing the conditions at the culvert outlet and downstream in the testing channel. The parameters obtained from the rectangular channel are as follows:

- Average Flow Depth

- Flow Area

- Velocity

The average flow depth was obtained by examining the values for flow depth from the threepoint gage along the designated eight points of measurement. Plots of the water surface elevation for a given run were then examined to identify any values that were outliers due to wave action or experimental error. The points that were termed acceptable, as best displaying 
average flow depth in the testing channel, were then averaged to produce the mean flow depth in the testing channel. The flow area of a given run was determined from the product of the average flow depth with the width of the testing channel. The velocity was found by simply dividing the flowrate by the cross-sectional area of the flow. The cross-sectional area of flow over the rip-rap was calculated based on a flat bed at the same height as the apron. The rip-rap was previously installed such that its effective bed elevation was the same as the apron elevation (based on the assumption of volumetric equivalency). Next, the Froude number at the culvert outlet was calculated as described in Section 4.4. The Froude number was also calculated in the testing channel. The Froude number at the culvert outlet and testing channel were calculated to provide a non-dimensional reference to flow conditions.

The energy at the culvert outlet was calculated from the following expression:

OutletEnergy $=\frac{V^{2}}{2 g}+y=$ SpecificHead

Where:

- $\quad V=$ Average velocity at culvert outlet

- $\quad g=$ acceleration due to gravity

- $\quad \mathrm{y}=$ uniform flow depth at the culvert outlet (actual depth)

The energy in the testing channel was found from the same equation, excepting that velocity and uniform flow depth are those relating to the testing channel. The energy at the culvert outlet and testing channel are then compared in the form of a non-dimensional energy difference of the following form:

$$
\text { Non-Dim.Energy Difference }=\frac{\text { Outlet Energy }- \text { Culvert Energy }}{\text { CulvertEnergy }}
$$

An example of the spreadsheet format used for the energy calculations, for a given slope and configuration, is shown in Table 4.5.5. In following sections, each tested baffle configuration will be presented and discussed with the results presented in this latter format. 


\begin{tabular}{|c|c|c|c|c|c|c|c|c|}
\hline & \multicolumn{3}{|c|}{ Testing Channel Data } & \multicolumn{2}{|c|}{$\begin{array}{c}\text { Froude Number } \\
\text { Comparison }\end{array}$} & \multicolumn{3}{|c|}{ Energy Calculations } \\
\hline $\begin{array}{c}\text { Flowrate } \\
\text { (gpm) }\end{array}$ & $\begin{array}{l}\text { Flow } \\
\text { Depth in } \\
\text { Channel } \\
\text { (in) }\end{array}$ & $\begin{array}{c}\text { Flow Area } \\
\left(\text { in }^{2}\right)\end{array}$ & $\begin{array}{l}\text { Velocity } \\
\text { (in/s) }\end{array}$ & $\begin{array}{c}\text { Froude } \\
\text { Number at } \\
\text { Culvert } \\
\text { Outlet }\end{array}$ & $\begin{array}{c}\text { Froude } \\
\text { Number in } \\
\text { Testing } \\
\text { Channel }\end{array}$ & $\begin{array}{c}\text { Energy at } \\
\text { Culvert } \\
\text { Outlet (in) }\end{array}$ & $\begin{array}{l}\text { Energy in } \\
\text { Testing } \\
\text { Channel } \\
\text { (in) }\end{array}$ & $\begin{array}{c}\text { Non- } \\
\text { dimensional } \\
\text { Energy } \\
\text { Difference }\end{array}$ \\
\hline 50 & & & & & & & & \\
\hline 75 & & & & & & & & \\
\hline 100 & & & & & & & & \\
\hline 125 & & & & & & & & \\
\hline 150 & & & & & & & & \\
\hline 200 & & & & & & & & \\
\hline
\end{tabular}




\subsection{Base Configuration}

The base configuration was tested to investigate the flow conditions when no baffles were located on the culvert apron. The testing of the base configuration allowed for a comparison between the performance of successive trials. The flow path expanded from the culvert outlet, with a general spreading across the channel apron and localized disturbances and wave action on the simulated channel bed. The model for the base configuration is shown in Figure 4.6.1. Graphs of the depth for tests conducted at 2, 4, 6, and 8\% slopes are shown in Figures 4.6.2 through 4.6.5.

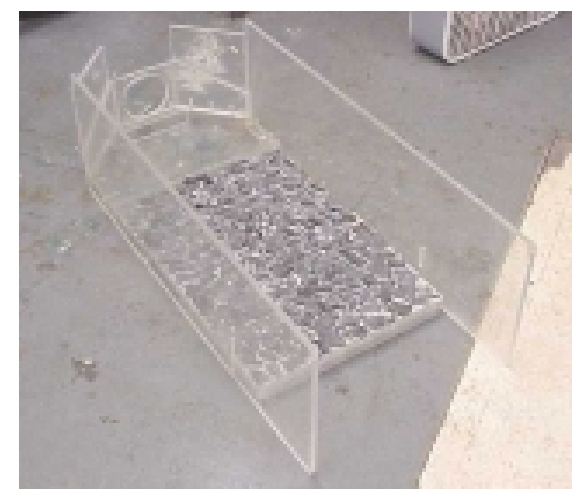

Figure 4.6.1 Model for Base Configuration

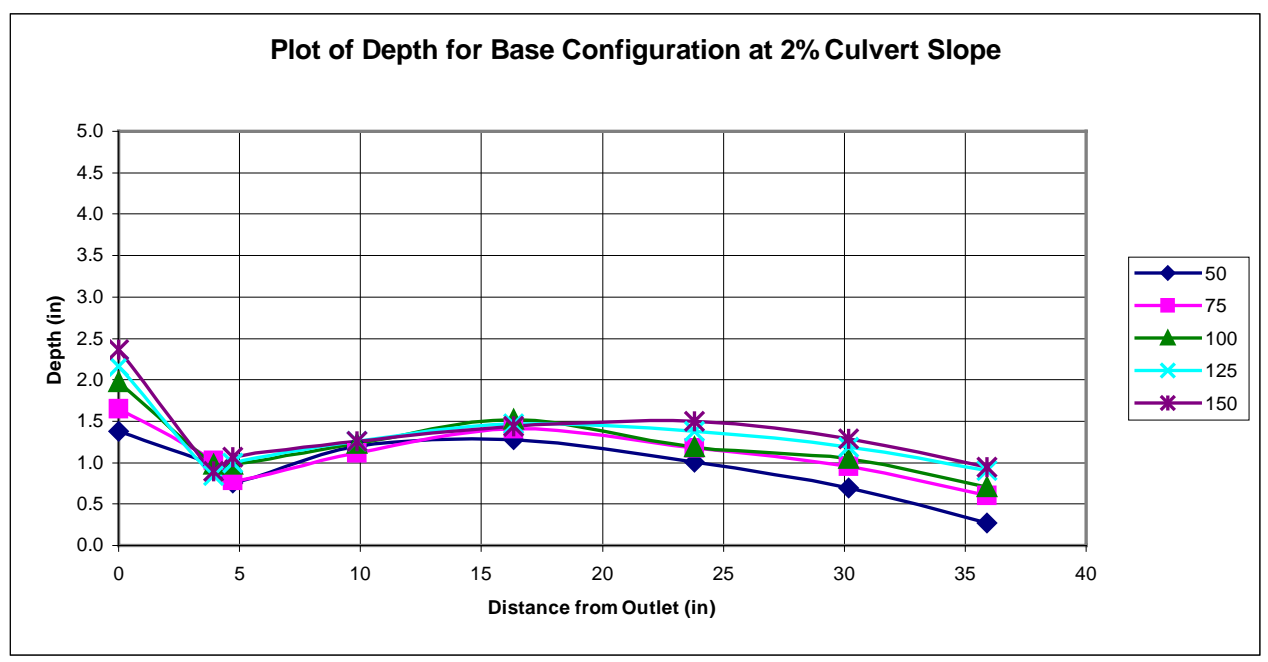

Figure 4.6.2 Plot of Depth for Base Configuration at 2\% Culvert Slope and 50-150 gpm 


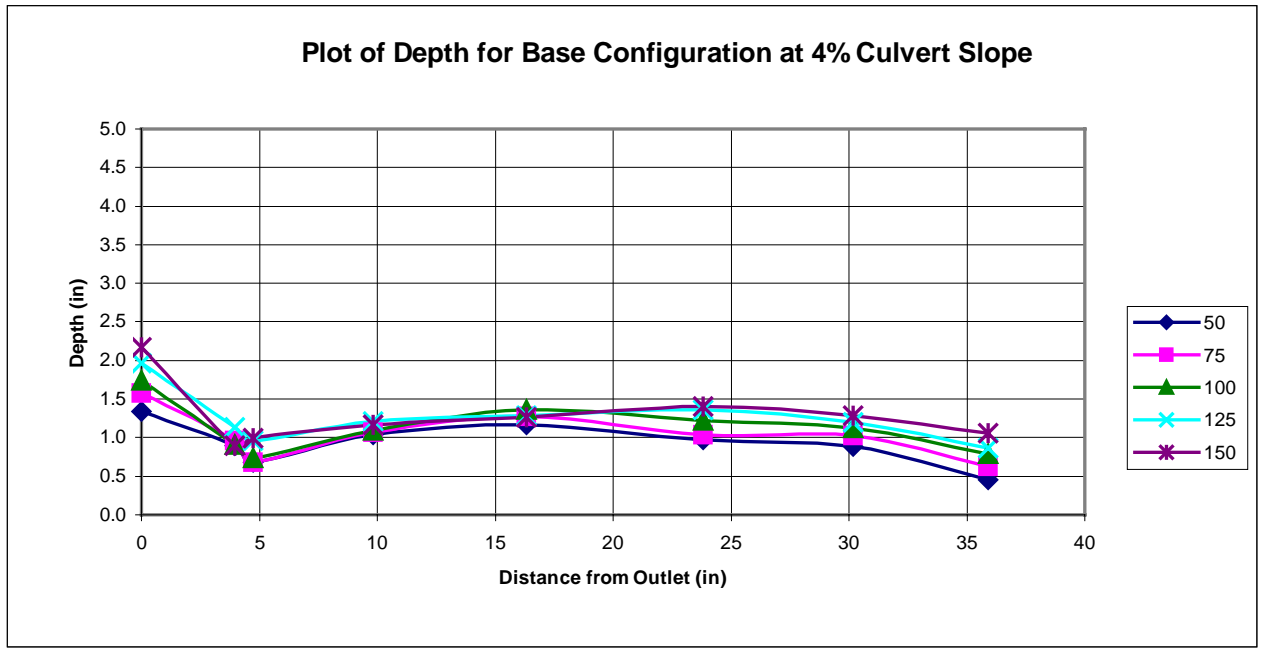

Figure 4.6.3 Plot of Depth for Base Configuration at 4\% Culvert Slope and $50-150 \mathrm{gpm}$

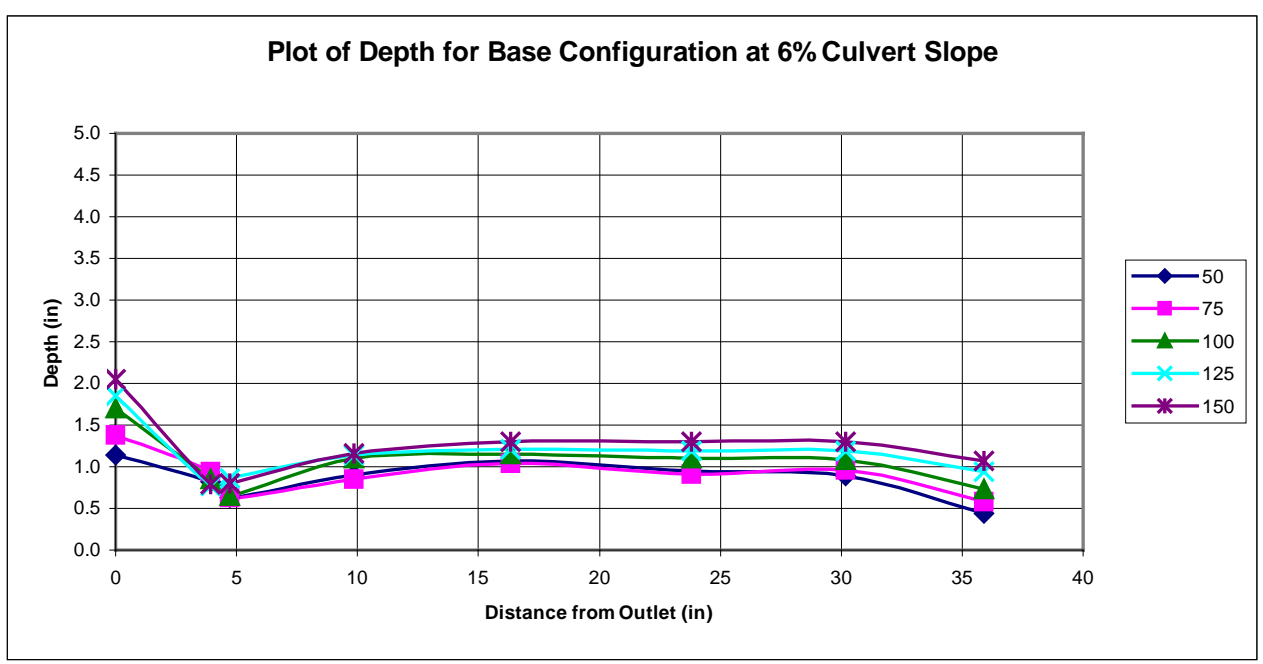

Figure 4.6.4 Plot of Depth for Base Configuration at 6\% Culvert Slope and 50-150 gpm 


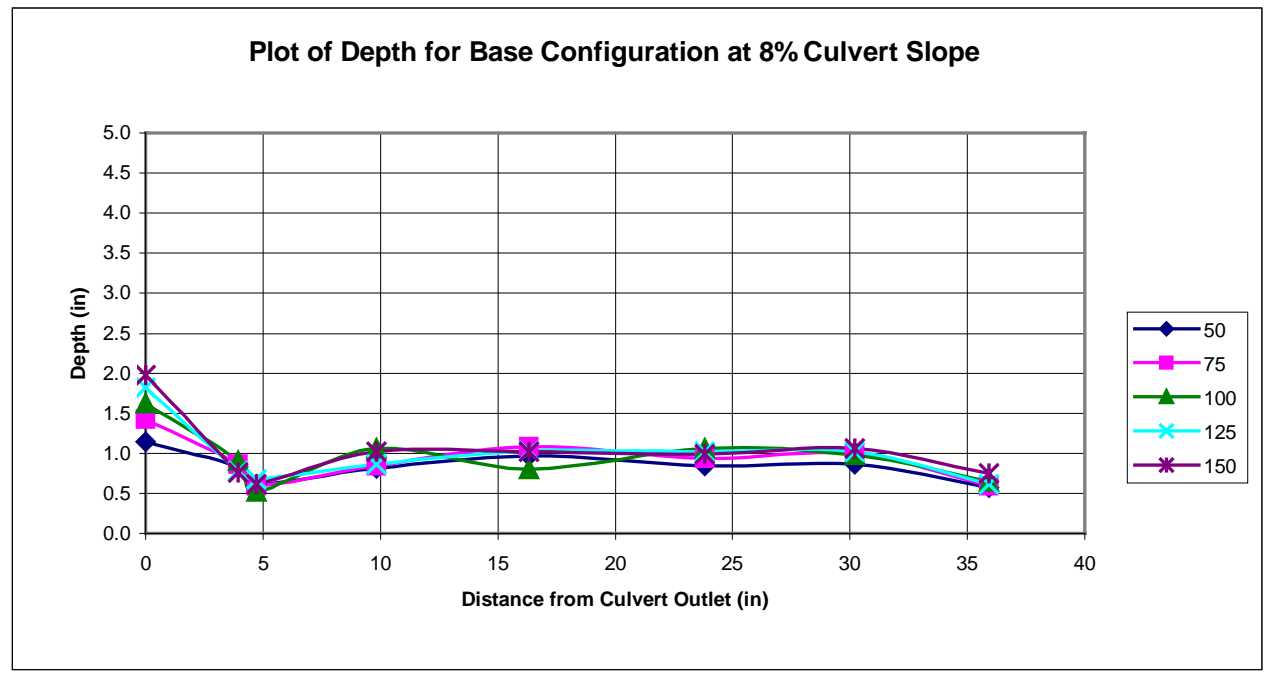

Figure 4.6.5 Plot of Depth for Base Configuration at 8\% Culvert Slope and 50-150 gpm

After the water surface elevation was established, uniform flow depth was determined by performing an average over the points in the channel that best represented uniform flow. From the flow depth and the results from Section 4.3, the aforementioned energy calculations were conducted. The results for the energy calculations for the base configuration are shown in Tables 4.6.1 through 4.6.4.

\begin{tabular}{|c|c|c|c|c|c|c|c|c|}
\hline \multicolumn{7}{|c|}{ Table 4.6.1 Energy Calculation for Base Configuration at 2\% Culvert Slope } \\
\hline \multicolumn{2}{|c|}{ Testing Channel Data } & \multicolumn{2}{|c|}{$\begin{array}{c}\text { Froude Number } \\
\text { Comparison }\end{array}$} & \multicolumn{3}{c|}{ Energy Calculations } \\
\hline $\begin{array}{c}\text { Flowrate } \\
\text { (gpm) }\end{array}$ & $\begin{array}{c}\text { Flow } \\
\text { Depth in } \\
\text { Channel } \\
\text { (in) }\end{array}$ & $\begin{array}{c}\text { Flow Area } \\
\text { (in }{ }^{2}\end{array}$ & $\begin{array}{c}\text { Velocity } \\
\text { (in/s) }\end{array}$ & $\begin{array}{c}\text { Froude } \\
\text { Number at } \\
\text { Culvert } \\
\text { Outlet }\end{array}$ & $\begin{array}{c}\text { Froude } \\
\text { Number in } \\
\text { Testing } \\
\text { Channel }\end{array}$ & $\begin{array}{c}\text { Energy at } \\
\text { Culvert } \\
\text { Outlet (in) }\end{array}$ & $\begin{array}{c}\text { Energy in } \\
\text { Testing } \\
\text { Channel } \\
\text { (in) }\end{array}$ & $\begin{array}{c}\text { Non- } \\
\text { dimensional } \\
\text { Energy } \\
\text { Difference }\end{array}$ \\
\hline 50 & 1.24 & 20.0 & 9.63 & 1.98 & 0.440 & 4.23 & 1.36 & 0.680 \\
\hline 75 & 1.26 & 20.4 & 14.1 & 2.16 & 0.640 & 5.51 & 1.52 & 0.724 \\
\hline 100 & 1.38 & 22.3 & 17.3 & 2.25 & 0.749 & 6.54 & 1.76 & 0.731 \\
\hline 125 & 1.36 & 22.0 & 21.8 & 2.34 & 0.952 & 7.54 & 1.98 & 0.738 \\
\hline 150 & 1.35 & 21.8 & 26.5 & 2.49 & 1.16 & 8.72 & 2.26 & 0.741 \\
\hline 200 & & & & & & & & \\
\hline
\end{tabular}




\begin{tabular}{|c|c|c|c|c|c|c|c|c|}
\hline \multicolumn{7}{|c|}{ Table 4.6.2 Energy Calculations for Base Configuration at 4\% Culvert Slope } \\
\hline & \multicolumn{3}{|c|}{ Testing Channel Data } & $\begin{array}{c}\text { Froude Number } \\
\text { Comparison }\end{array}$ & \multicolumn{3}{|c|}{ Energy Calculations } \\
\hline $\begin{array}{c}\text { Flowrate } \\
(\mathrm{gpm})\end{array}$ & $\begin{array}{c}\text { Flow } \\
\text { Depth in } \\
\text { Channel } \\
\text { (in) }\end{array}$ & $\begin{array}{c}\text { Flow Area } \\
\text { (in }{ }^{2}\end{array}$ & $\begin{array}{c}\text { Velocity } \\
\text { (in/s) }\end{array}$ & $\begin{array}{c}\text { Froude } \\
\text { Number at } \\
\text { Culvert } \\
\text { Outlet }\end{array}$ & $\begin{array}{c}\text { Froude } \\
\text { Number in } \\
\text { Testing } \\
\text { Channel }\end{array}$ & $\begin{array}{c}\text { Energy at } \\
\text { Culvert } \\
\text { Outlet (in) }\end{array}$ & $\begin{array}{c}\text { Energy in } \\
\text { Testing } \\
\text { Channel } \\
\text { (in) }\end{array}$ & $\begin{array}{c}\text { Non- } \\
\text { dimensional } \\
\text { Energy } \\
\text { Difference }\end{array}$ \\
\hline 50 & 1.01 & 16.3 & 11.8 & 2.47 & 0.598 & 5.26 & 1.19 & 0.774 \\
\hline 75 & 1.11 & 18.0 & 16.0 & 2.62 & 0.774 & 6.70 & 1.45 & 0.784 \\
\hline 100 & 1.24 & 20.0 & 19.3 & 2.69 & 0.881 & 7.85 & 1.72 & 0.781 \\
\hline 125 & 1.28 & 20.7 & 23.2 & 2.78 & 1.04 & 9.00 & 1.98 & 0.780 \\
\hline 150 & 1.32 & 21.3 & 27.1 & 2.89 & 1.20 & 10.2 & 2.27 & 0.777 \\
\hline 200 & & & & & & & & \\
\hline
\end{tabular}

\begin{tabular}{|c|c|c|c|c|c|c|c|c|}
\hline \multicolumn{7}{|c|}{ Table 4.6.3 Energy Calculations for Base Configuration at 6\% Culvert Slope } \\
\hline \multicolumn{2}{|c|}{ Testing Channel Data } & \multicolumn{2}{c|}{$\begin{array}{c}\text { Froude Number } \\
\text { Comparison }\end{array}$} & \multicolumn{3}{c|}{ Energy Calculations } \\
\hline $\begin{array}{c}\text { Flowrate } \\
\text { (gpm) }\end{array}$ & $\begin{array}{c}\text { Flow } \\
\text { Depth in } \\
\text { Channel } \\
\text { (in) }\end{array}$ & $\begin{array}{c}\text { Flow Area } \\
\left.\text { (in }{ }^{2}\right)\end{array}$ & $\begin{array}{c}\text { Velocity } \\
\text { (in/s) }\end{array}$ & $\begin{array}{c}\text { Froude } \\
\text { Number at } \\
\text { Culvert } \\
\text { Outlet }\end{array}$ & $\begin{array}{c}\text { Froude } \\
\text { Number in } \\
\text { Testing } \\
\text { Channel }\end{array}$ & $\begin{array}{c}\text { Energy at } \\
\text { Culvert } \\
\text { Outlet (in) }\end{array}$ & $\begin{array}{c}\text { Energy in } \\
\text { Testing } \\
\text { Channel } \\
\text { (in) }\end{array}$ & $\begin{array}{c}\text { Non- } \\
\text { dimensional } \\
\text { Energy } \\
\text { Difference }\end{array}$ \\
\hline 50 & 0.97 & 15.7 & 12.3 & 3.00 & 0.635 & 6.57 & 1.16 & 0.823 \\
\hline 75 & 0.97 & 15.7 & 18.4 & 3.14 & 0.950 & 8.29 & 1.41 & 0.830 \\
\hline 100 & 1.11 & 18.0 & 21.4 & 3.23 & 1.03 & 9.73 & 1.70 & 0.825 \\
\hline 125 & 1.20 & 19.4 & 24.9 & 3.25 & 1.16 & 10.8 & 2.00 & 0.815 \\
\hline 150 & 1.30 & 21.0 & 27.5 & 3.32 & 1.23 & 12.0 & 2.28 & 0.810 \\
\hline 200 & & & & & & & & \\
\hline
\end{tabular}

\begin{tabular}{|c|c|c|c|c|c|c|c|c|}
\hline \multicolumn{7}{|c|}{ Table 4.6.4 Energy Calculations for Base Configuration at 8\% Culvert Slope } \\
\hline & \multicolumn{3}{|c|}{ Testing Channel Data } & $\begin{array}{c}\text { Froude Number } \\
\text { Comparison }\end{array}$ & \multicolumn{3}{c|}{ Energy Calculations } \\
\hline $\begin{array}{c}\text { Flowrate } \\
\text { (gpm) }\end{array}$ & $\begin{array}{c}\text { Flow } \\
\text { Depth in } \\
\text { Channel } \\
\text { (in) }\end{array}$ & $\begin{array}{c}\text { Flow Area } \\
\left.\text { (in }{ }^{2}\right)\end{array}$ & $\begin{array}{c}\text { Velocity } \\
\text { (in/s) }\end{array}$ & $\begin{array}{c}\text { Froude } \\
\text { Number at } \\
\text { Culvert } \\
\text { Outlet }\end{array}$ & $\begin{array}{c}\text { Froude } \\
\text { Number in } \\
\text { Testing } \\
\text { Channel }\end{array}$ & $\begin{array}{c}\text { Energy at } \\
\text { Culvert } \\
\text { Outlet (in) }\end{array}$ & $\begin{array}{c}\text { Energy in } \\
\text { Testing } \\
\text { Channel } \\
\text { (in) }\end{array}$ & $\begin{array}{c}\text { Non- } \\
\text { dimensional } \\
\text { Energy } \\
\text { Difference }\end{array}$ \\
\hline 50 & 0.89 & 14.4 & 13.4 & 3.15 & 0.723 & 7.01 & 1.12 & 0.840 \\
\hline 75 & 1.01 & 16.3 & 17.7 & 3.35 & 0.900 & 9.01 & 1.41 & 0.843 \\
\hline 100 & 0.94 & 15.3 & 25.2 & 3.45 & 1.32 & 10.6 & 1.77 & 0.833 \\
\hline 125 & 1.02 & 16.6 & 29.0 & 3.48 & 1.46 & 11.8 & 2.12 & 0.820 \\
\hline 150 & 1.02 & 16.6 & 34.9 & 3.55 & 1.75 & 13.0 & 2.60 & 0.801 \\
\hline 200 & & & & & & & & \\
\hline
\end{tabular}




\section{7 3/4 Diameter Cylinder Baffle Configuration}

Sedimentation and blockage in the current baffle design used by the WVDOH was a major problem. The idea behind the cylinder baffle arrangements was to see how a streamlined baffle would perform as opposed to standard rectangular designs. Since the need was for the total energy downstream of the culvert outlet to return to the level of energy present under natural stream conditions, the hypothesis was that the partial streamlining of the baffle would produce enough energy attenuation, without causing significant sedimentation. The flow exiting the culvert outlet split around the first cylinder and impacted the next two where it was again deflected. Vertical spray was also present at all three cylinders, reaching heights of $2 \mathrm{D}$ based on visual inspection. Little water depth was accumulated on the culvert apron. The model of the configuration is shown in Figure 4.7.1. Typical flow regimes are depicted in Figures 4.7.2 and 4.7.3

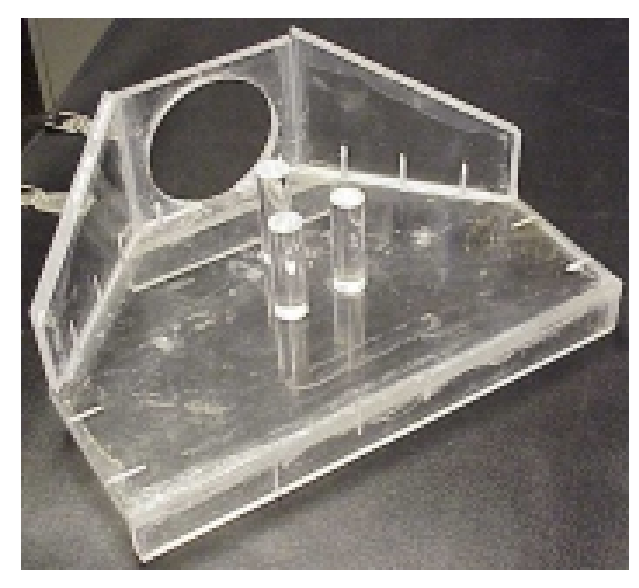

Figure 4.7.1 3/4 D Cylinder Baffle Model

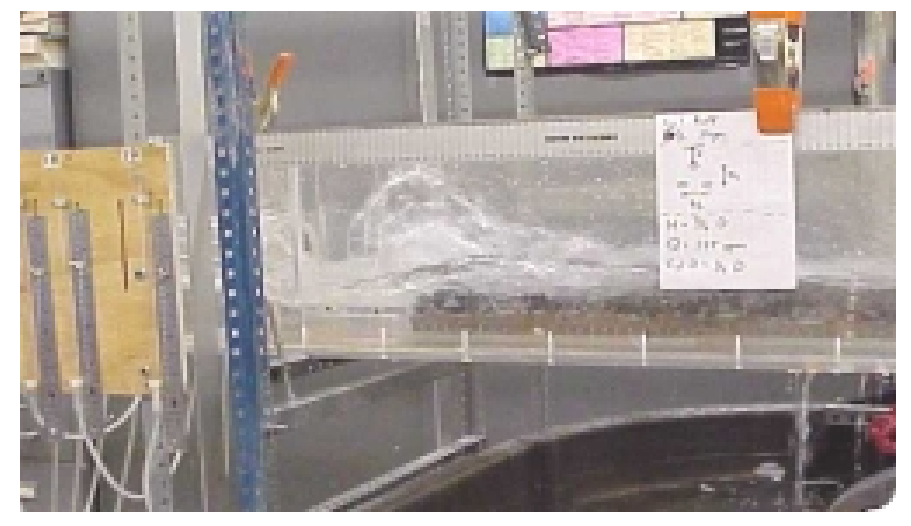

Figure 4.7.2 3/4 D Cylinder Baffle at 6\% Culvert Slope and $125 \mathrm{gpm}$ 


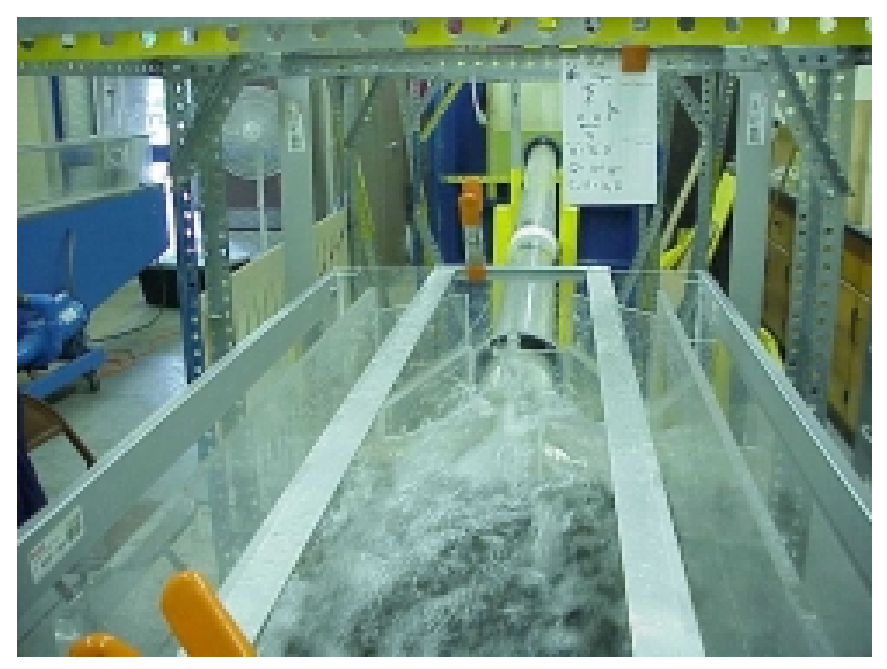

Figure 4.7.3 3/4 D Cylinder Baffle at 6\% Culvert Slope and $125 \mathrm{gpm}$

The graphs of depth for the configuration are shown in Figures 4.7.4 through 4.7.7. Energy calculations for the $3 / 4$ D Cylinder Baffle are shown in Tables 4.7.1 through 4.7.4.

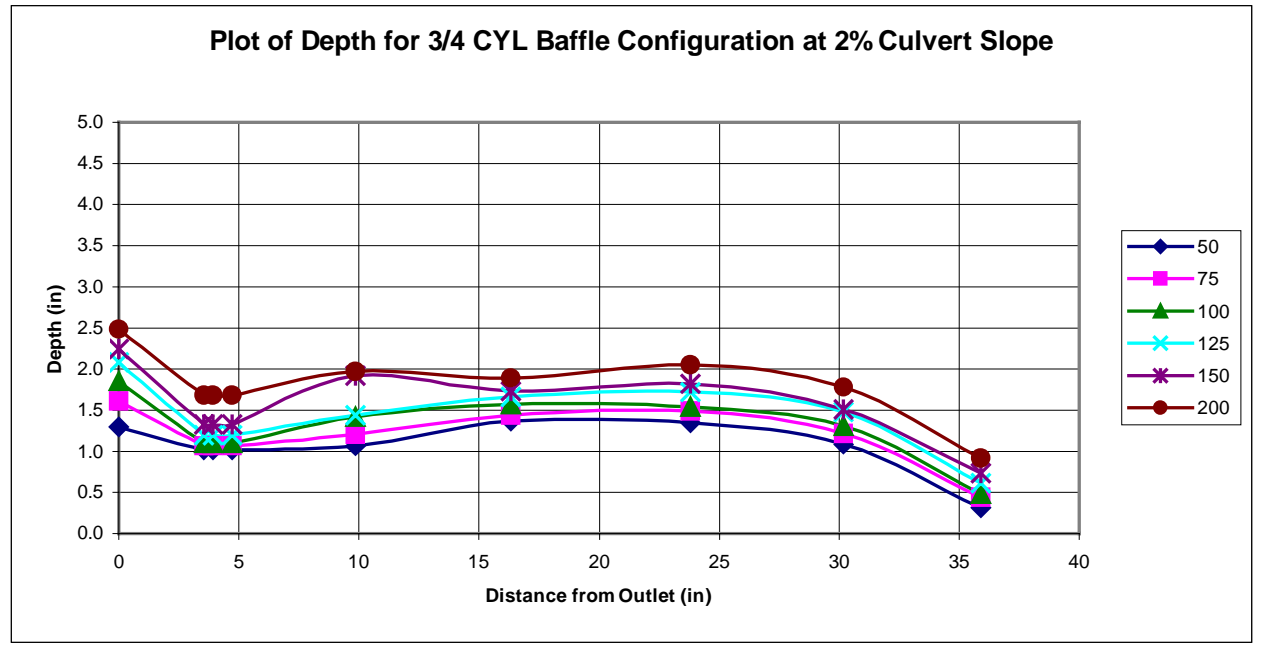

Figure 4.7.4 Plot of Depth for 3/4 D Cylinder baffle at 2\% Culvert Slope and 50-200 gpm 


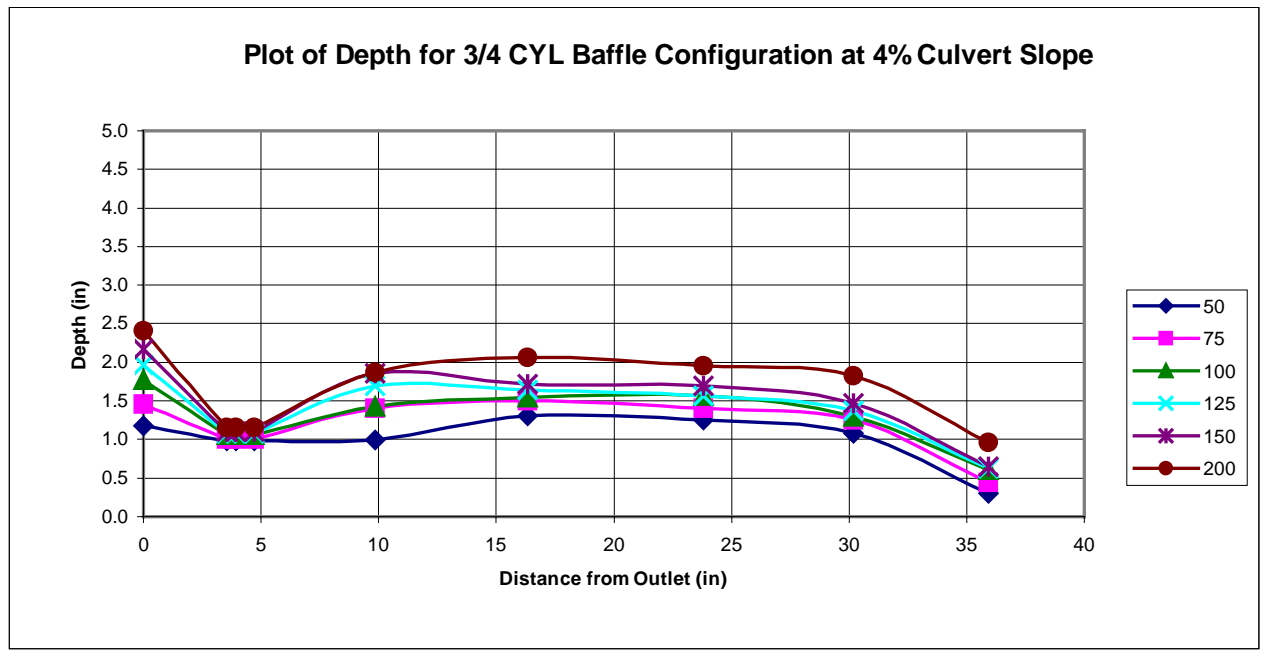

Figure 4.7.5 Plot of Depth for 3/4 D Cylinder baffle at 4\% Culvert Slope and 50-200 gpm

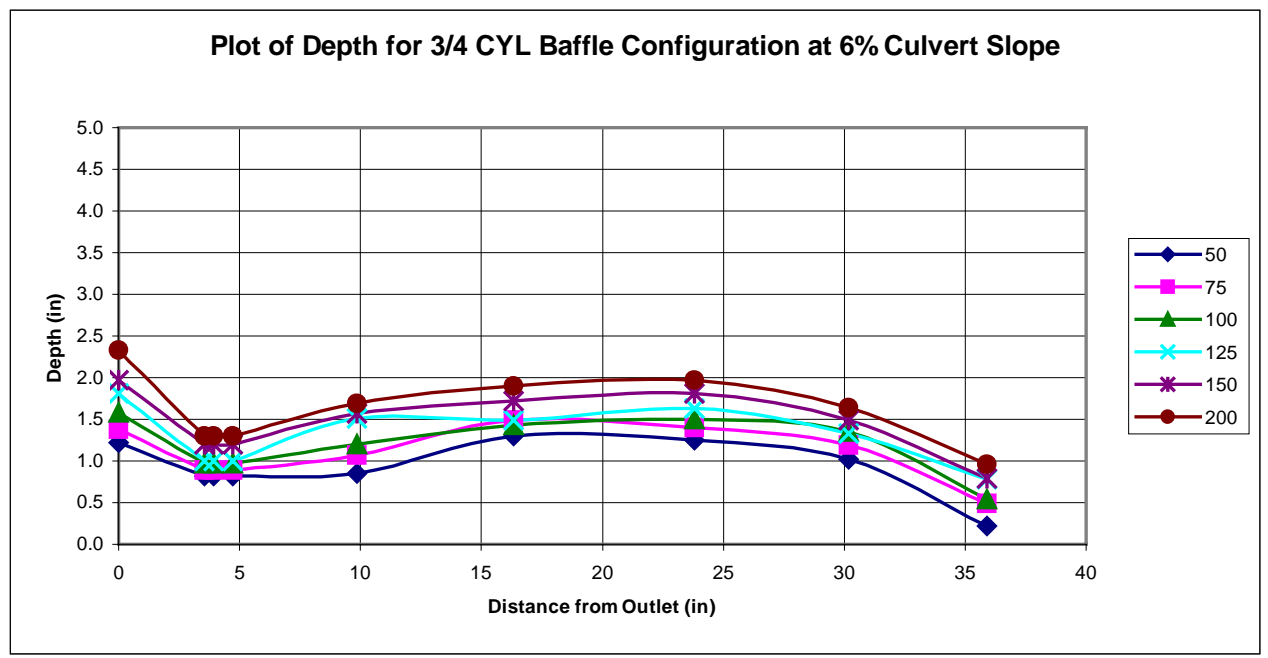

Figure 4.7.6 Plot of Depth for 3/4 D Cylinder baffle at 6\% Culvert Slope and 50-200 gpm 


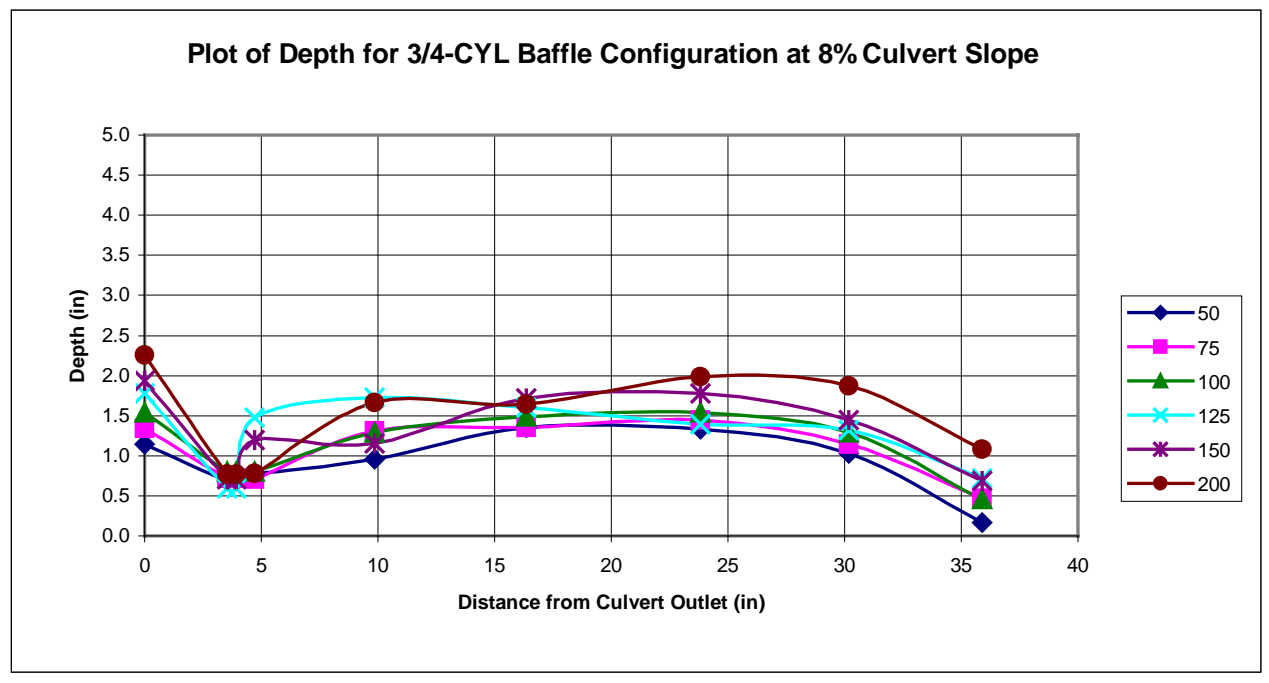

Figure 4.7.7 Plot of Depth for 3/4 D Cylinder baffle at 8\% Culvert Slope and 50-200 gpm

\begin{tabular}{|c|c|c|c|c|c|c|c|c|}
\hline \multicolumn{7}{|c|}{ Table 4.7.1 Energy Calculations for 3/4 Diameter Cylinder Baffle at 2\% Culvert Slope } \\
\hline \multicolumn{2}{|c|}{ Testing Channel Data } & \multicolumn{2}{|c|}{$\begin{array}{c}\text { Froude Number } \\
\text { Comparison }\end{array}$} & \multicolumn{3}{c|}{ Energy Calculations } \\
\hline $\begin{array}{c}\text { Flowrate } \\
\text { (gpm) }\end{array}$ & $\begin{array}{c}\text { Flow } \\
\text { Depth in } \\
\text { Channel } \\
\text { (in) }\end{array}$ & $\begin{array}{c}\text { Flow Area } \\
\text { (in }{ }^{2}\end{array}$ & $\begin{array}{c}\text { Velocity } \\
\text { (in/s) }\end{array}$ & $\begin{array}{c}\text { Froude } \\
\text { Number at } \\
\text { Culvert } \\
\text { Outlet }\end{array}$ & $\begin{array}{c}\text { Froude } \\
\text { Number in } \\
\text { Testing } \\
\text { Channel }\end{array}$ & $\begin{array}{c}\text { Energy at } \\
\text { Culvert } \\
\text { Outlet (in) }\end{array}$ & $\begin{array}{c}\text { Energy in } \\
\text { Testing } \\
\text { Channel } \\
\text { (in) }\end{array}$ & $\begin{array}{c}\text { Non- } \\
\text { dimensional } \\
\text { Energy } \\
\text { Difference }\end{array}$ \\
\hline 50 & 1.22 & 19.7 & 9.78 & 1.98 & 0.451 & 4.23 & 1.34 & 0.683 \\
\hline 75 & 1.34 & 21.7 & 13.3 & 2.16 & 0.587 & 5.51 & 1.57 & 0.715 \\
\hline 100 & 1.46 & 23.6 & 16.3 & 2.25 & 0.689 & 6.54 & 1.80 & 0.725 \\
\hline 125 & 1.58 & 25.5 & 18.9 & 2.34 & 0.764 & 7.54 & 2.04 & 0.730 \\
\hline 150 & 1.75 & 28.3 & 20.4 & 2.49 & 0.787 & 8.72 & 2.29 & 0.738 \\
\hline 200 & 1.92 & 31.1 & 24.7 & 2.90 & 0.908 & 11.6 & 2.72 & 0.767 \\
\hline
\end{tabular}




\begin{tabular}{|c|c|c|c|c|c|c|c|c|}
\hline \multicolumn{7}{|c|}{ Table 4.7.2 Energy Calculations for 3/4 Diameter Cylinder Baffle at 4\% Culvert Slope } \\
\hline \multicolumn{2}{|c|}{ Testing Channel Data } & $\begin{array}{c}\text { Froude Number } \\
\text { Comparison }\end{array}$ & \multicolumn{3}{c|}{ Energy Calculations } \\
\hline $\begin{array}{c}\text { Flowrate } \\
\text { (gpm) }\end{array}$ & $\begin{array}{c}\text { Flow } \\
\text { Depth in } \\
\text { Channel } \\
\text { (in) }\end{array}$ & $\begin{array}{c}\text { Flow Area } \\
\text { (in) }\end{array}$ & $\begin{array}{c}\text { Velocity } \\
\text { (in/s) }\end{array}$ & $\begin{array}{c}\text { Froude } \\
\text { Number at } \\
\text { Culvert } \\
\text { Outlet }\end{array}$ & $\begin{array}{c}\text { Froude } \\
\text { Number in } \\
\text { Testing } \\
\text { Channel }\end{array}$ & $\begin{array}{c}\text { Energy at } \\
\text { Culvert } \\
\text { Outlet (in) }\end{array}$ & $\begin{array}{c}\text { Energy in } \\
\text { Testing } \\
\text { Channel } \\
\text { (in) }\end{array}$ & $\begin{array}{c}\text { Non- } \\
\text { dimensional } \\
\text { Energy } \\
\text { Difference }\end{array}$ \\
\hline 50 & 1.16 & 18.8 & 10.3 & 2.47 & 0.485 & 5.26 & 1.30 & 0.754 \\
\hline 75 & 1.39 & 22.5 & 12.8 & 2.62 & 0.555 & 6.70 & 1.60 & 0.761 \\
\hline 100 & 1.46 & 23.6 & 16.3 & 2.69 & 0.686 & 7.85 & 1.80 & 0.770 \\
\hline 125 & 1.57 & 25.3 & 19.0 & 2.78 & 0.772 & 9.00 & 2.03 & 0.774 \\
\hline 150 & 1.69 & 27.3 & 21.2 & 2.89 & 0.829 & 10.2 & 2.27 & 0.777 \\
\hline 200 & 1.93 & 31.2 & 24.7 & 3.31 & 0.905 & 13.6 & 2.72 & 0.800 \\
\hline
\end{tabular}

\begin{tabular}{|c|c|c|c|c|c|c|c|c|}
\hline \multicolumn{7}{|c|}{ Table 4.7.3 Energy Calculations for 3/4 Diameter Cylinder Baffle at 6\% Culvert Slope } \\
\hline \multicolumn{2}{|c|}{ Testing Channel Data } & \multicolumn{2}{c|}{$\begin{array}{c}\text { Froude Number } \\
\text { Comparison }\end{array}$} & \multicolumn{3}{c|}{ Energy Calculations } \\
\hline $\begin{array}{c}\text { Flowrate } \\
\text { (gpm) }\end{array}$ & $\begin{array}{c}\text { Flow } \\
\text { Depth in } \\
\text { Channel } \\
\text { (in) }\end{array}$ & $\begin{array}{c}\text { Flow Area } \\
\left.\text { (in }{ }^{2}\right)\end{array}$ & $\begin{array}{c}\text { Velocity } \\
\text { (in/s) }\end{array}$ & $\begin{array}{c}\text { Froude } \\
\text { Number at } \\
\text { Culvert } \\
\text { Outlet }\end{array}$ & $\begin{array}{c}\text { Froude } \\
\text { Number in } \\
\text { Testing } \\
\text { Channel }\end{array}$ & $\begin{array}{c}\text { Energy at } \\
\text { Culvert } \\
\text { Outlet (in) }\end{array}$ & $\begin{array}{c}\text { Energy in } \\
\text { Testing } \\
\text { Channel } \\
\text { (in) }\end{array}$ & $\begin{array}{c}\text { Non- } \\
\text { dimensional } \\
\text { Energy } \\
\text { Difference }\end{array}$ \\
\hline 50 & 1.11 & 17.9 & 10.8 & 3.00 & 0.521 & 6.57 & 1.26 & 0.809 \\
\hline 75 & 1.29 & 20.8 & 13.9 & 3.14 & 0.622 & 8.29 & 1.54 & 0.815 \\
\hline 100 & 1.37 & 22.2 & 17.4 & 3.23 & 0.754 & 9.73 & 1.76 & 0.819 \\
\hline 125 & 1.49 & 24.1 & 20.0 & 3.25 & 0.832 & 10.8 & 2.01 & 0.814 \\
\hline 150 & 1.65 & 26.7 & 21.6 & 3.32 & 0.858 & 12.0 & 2.26 & 0.812 \\
\hline 200 & 1.80 & 29.1 & 26.4 & 3.65 & 1.00 & 15.3 & 2.70 & 0.824 \\
\hline
\end{tabular}

\begin{tabular}{|c|c|c|c|c|c|c|c|c|}
\hline \multicolumn{7}{|c|}{ Table 4.7.4 Energy Calculations for 3/4 Diameter Cylinder Baffle at 8\% Culvert Slope } \\
\hline \multicolumn{2}{|c|}{ Testing Channel Data } & \multicolumn{2}{c|}{$\begin{array}{c}\text { Froude Number } \\
\text { Comparison }\end{array}$} & \multicolumn{3}{c|}{ Energy Calculations } \\
\hline $\begin{array}{c}\text { Flowrate } \\
\text { (gpm) }\end{array}$ & $\begin{array}{c}\text { Flow } \\
\text { Depth in } \\
\text { Channel } \\
\text { (in) }\end{array}$ & $\begin{array}{c}\text { Flow Area } \\
\text { (in }{ }^{2}\end{array}$ & $\begin{array}{c}\text { Velocity } \\
\text { (in/s) }\end{array}$ & $\begin{array}{c}\text { Froude } \\
\text { Number at } \\
\text { Culvert } \\
\text { Outlet }\end{array}$ & $\begin{array}{c}\text { Froude } \\
\text { Number in } \\
\text { Testing } \\
\text { Channel }\end{array}$ & $\begin{array}{c}\text { Energy at } \\
\text { Culvert } \\
\text { Outlet (in) }\end{array}$ & $\begin{array}{c}\text { Energy in } \\
\text { Testing } \\
\text { Channel } \\
\text { (in) }\end{array}$ & $\begin{array}{c}\text { Non- } \\
\text { dimensional } \\
\text { Energy } \\
\text { Difference }\end{array}$ \\
\hline 50 & 1.17 & 18.9 & 10.2 & 3.15 & 0.479 & 7.01 & 1.30 & 0.814 \\
\hline 75 & 1.31 & 21.2 & 13.6 & 3.35 & 0.604 & 9.01 & 1.55 & 0.828 \\
\hline 100 & 1.40 & 22.6 & 17.0 & 3.45 & 0.733 & 10.6 & 1.77 & 0.832 \\
\hline 125 & 1.46 & 23.6 & 20.4 & 3.48 & 0.859 & 11.8 & 2.00 & 0.830 \\
\hline 150 & 1.58 & 25.6 & 22.6 & 3.55 & 0.913 & 13.0 & 2.24 & 0.828 \\
\hline 200 & 1.79 & 29.0 & 26.6 & 3.78 & 1.01 & 16.0 & 2.70 & 0.831 \\
\hline
\end{tabular}




\subsection{1/2 D Cylinder Baffle Configuration}

The cylinder baffle arrangements were tested at two heights to try to minimize the amount of material needed for construction. The flow description for the $1 / 2 \mathrm{D}$ cylinder configuration was similar to the $3 / 4 \mathrm{D}$ configuration. However, with the $1 / 2 \mathrm{D}$ configuration the depth of flow exiting the test culvert was at times equal to the height of the cylinder. Vertical spray was still present, and the flow again split on the first cylinder and impacted the two downstream. The depth of water on the culvert apron was minimal. The $1 / 2 \mathrm{D}$ cylinder configuration is shown in Figure 4.8.1. Typical flow patterns are shown in Figures 4.8.2 and 4.8.3.

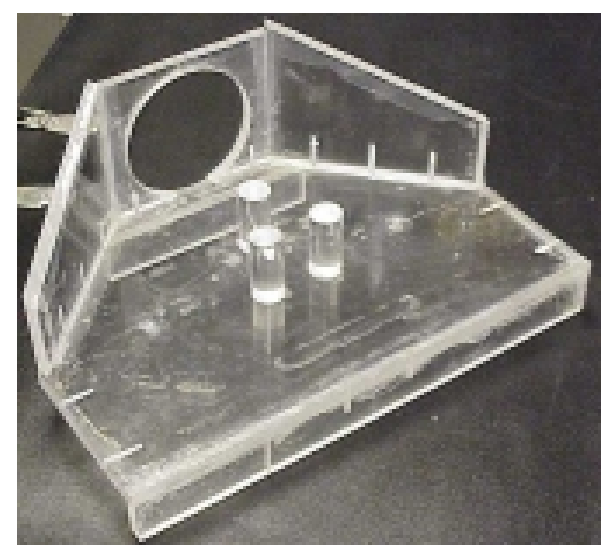

Figure 4.8.1 1/2 D Cylinder Baffle Model

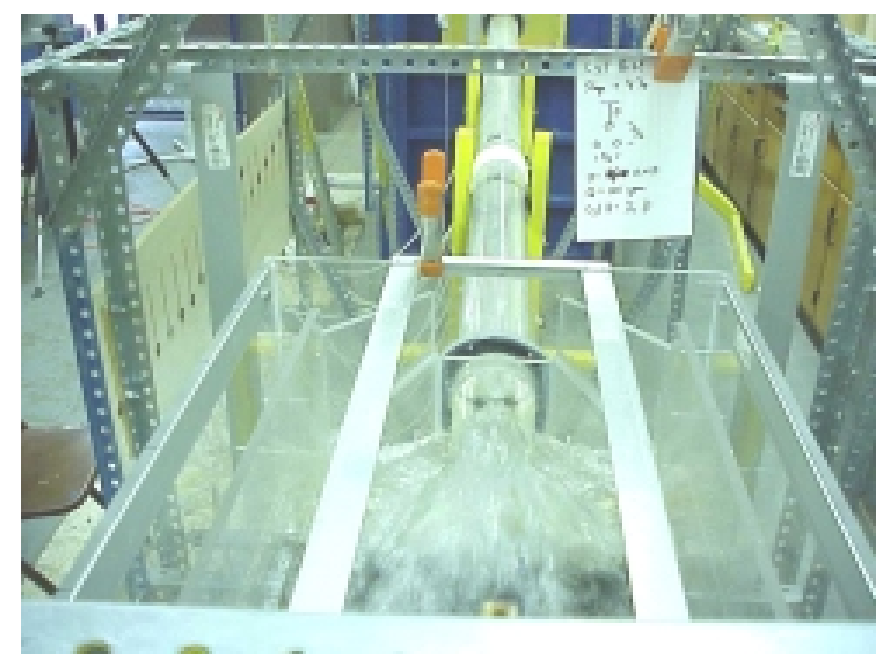

Figure 4.8.2 Plan of 1/2 D Cylinder Baffle at 4\% Culvert Slope and 125 gpm 


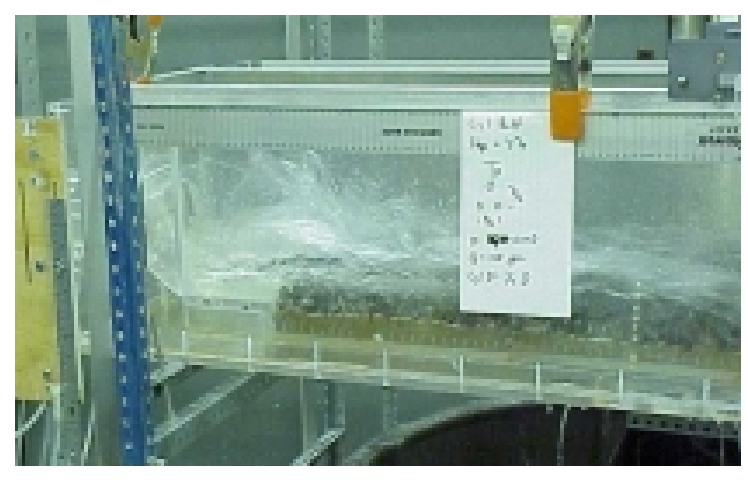

Figure 4.8.3 Profile of $1 / 2$ D Cylinder Baffle at 4\% Culvert Slope and 125 gpm

Graphs of water surface elevation are shown in Figures 4.8.4 through 4.8.7. Notice in the plots of depth for 6 and $8 \%$ slope, some data points are not plotted. The points were not plotted due to large scale turbulence at those locations. Energy calculations for the $1 / 2$ D Cylinder Baffle are shown in Tables 4.8.1 through 4.8.4.

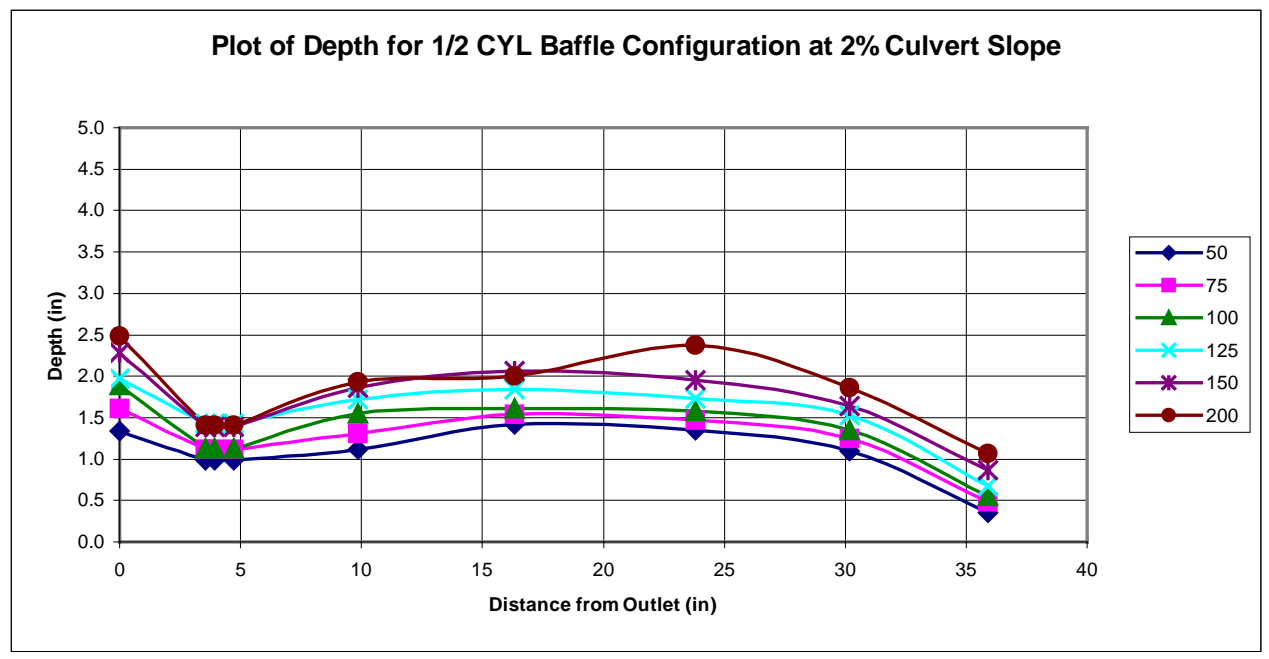

Figure 4.8.4 Plot of Depth for $1 / 2$ D Cylinder baffle at 2\% Culvert Slope and 50-200gpm 


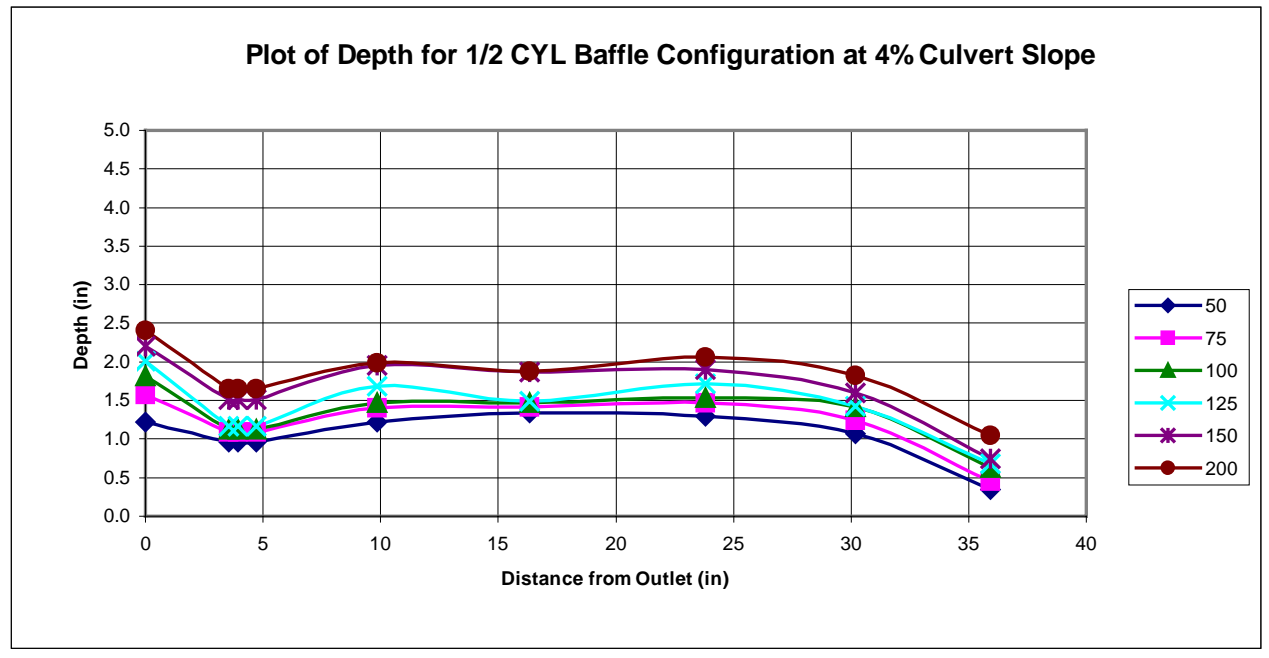

Figure 4.8.5 Plot of Depth for 1/2 D Cylinder baffle at 4\% Culvert Slope and 50-200 gpm

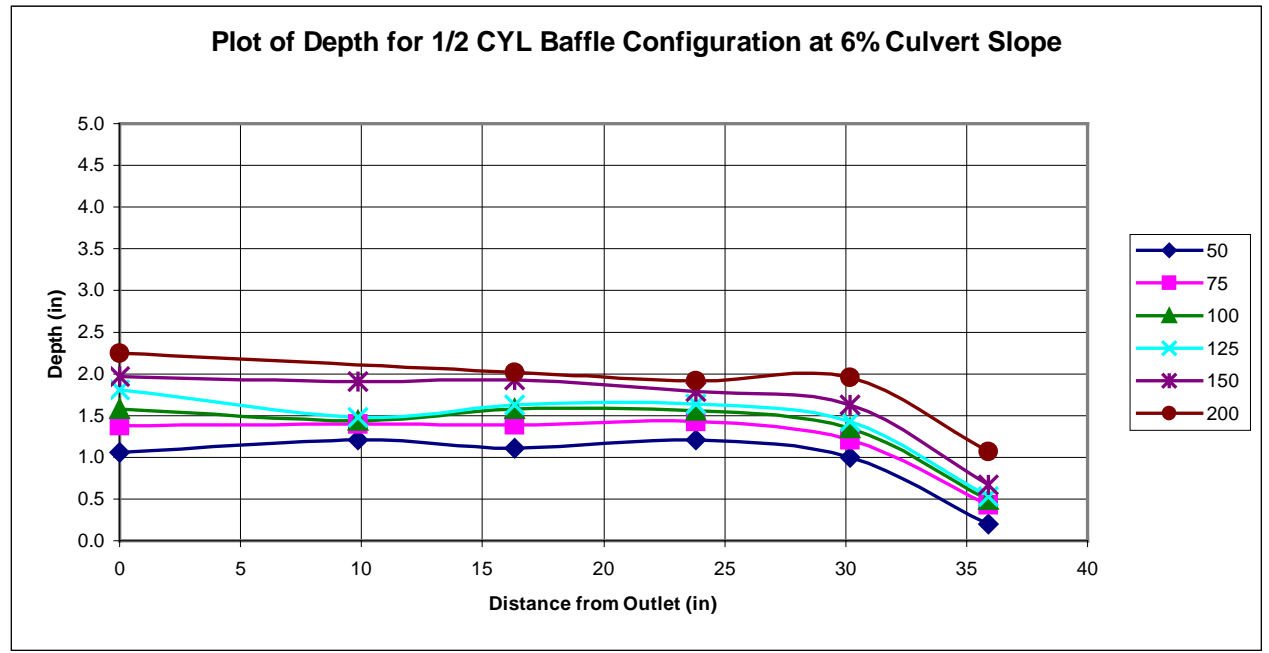

Figure 4.8.6 Plot of Depth for $1 \frac{1}{2}$ D Cylinder baffle at 6\% Culvert Slope and 50-200 gpm 


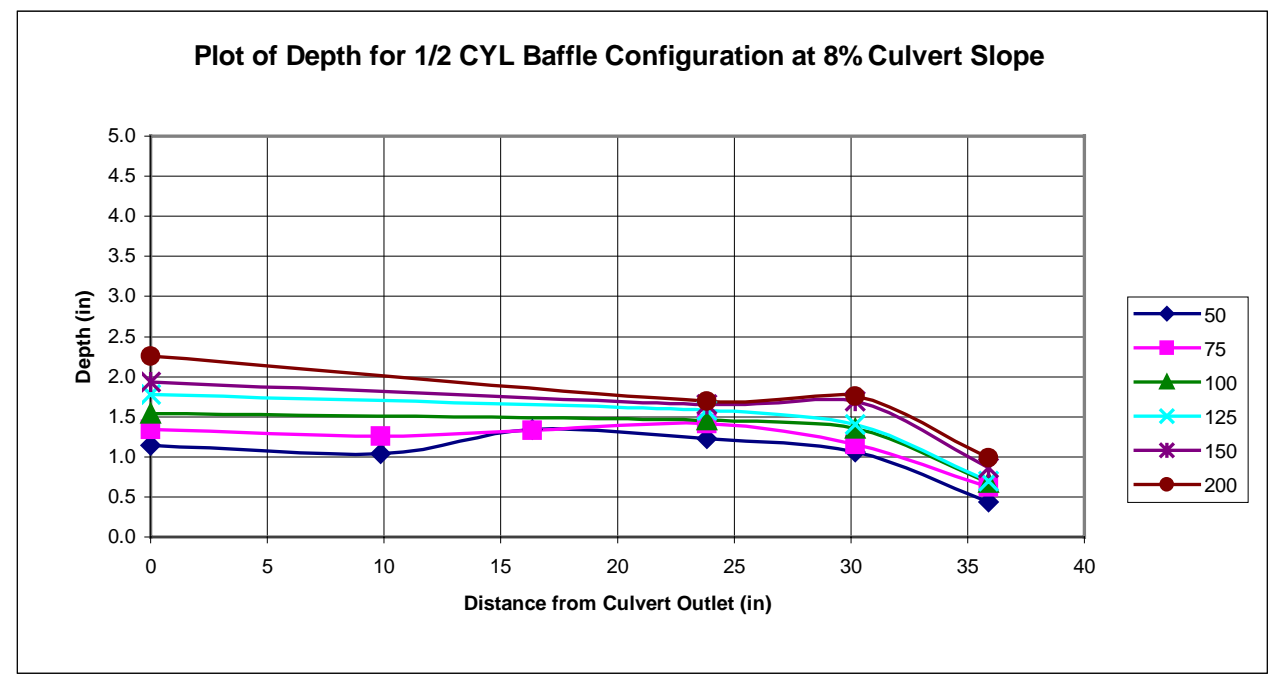

Figure 4.8.7 Plot of Depth for $1 \frac{1}{2}$ D Cylinder baffle at 8\% Culvert Slope and 50-200 gpm

\begin{tabular}{|c|c|c|c|c|c|c|c|c|}
\hline \multicolumn{7}{|c|}{ Table 4.8.1 Energy Calculations for 1/2 Diameter Cylinder Baffle at 2\% Culvert Slope } \\
\hline & \multicolumn{3}{|c|}{ Testing Channel Data } & \multicolumn{2}{c|}{$\begin{array}{c}\text { Froude Number } \\
\text { Comparison }\end{array}$} & \multicolumn{3}{c|}{ Energy Calculations } \\
\hline $\begin{array}{c}\text { Flowrate } \\
\text { (gpm) }\end{array}$ & $\begin{array}{c}\text { Flow } \\
\text { Depth in } \\
\text { Channel } \\
\text { (in) }\end{array}$ & $\begin{array}{c}\text { Flow Area } \\
\text { (in }{ }^{2}\end{array}$ & $\begin{array}{c}\text { Velocity } \\
\text { (in/s) }\end{array}$ & $\begin{array}{c}\text { Froude } \\
\text { Number at } \\
\text { Culvert } \\
\text { Outlet }\end{array}$ & $\begin{array}{c}\text { Froude } \\
\text { Number in } \\
\text { Testing } \\
\text { Channel }\end{array}$ & $\begin{array}{c}\text { Energy at } \\
\text { Culvert } \\
\text { Outlet (in) }\end{array}$ & $\begin{array}{c}\text { Energy in } \\
\text { Testing } \\
\text { Channel } \\
\text { (in) }\end{array}$ & $\begin{array}{c}\text { Non- } \\
\text { dimensional } \\
\text { Energy } \\
\text { Difference }\end{array}$ \\
\hline 50 & 1.24 & 20.1 & 9.57 & 1.98 & 0.436 & 4.23 & 1.36 & 0.678 \\
\hline 75 & 1.39 & 22.5 & 12.8 & 2.16 & 0.554 & 5.51 & 1.60 & 0.709 \\
\hline 100 & 1.52 & 24.6 & 15.6 & 2.25 & 0.645 & 6.54 & 1.84 & 0.719 \\
\hline 125 & 1.70 & 27.6 & 17.5 & 2.34 & 0.680 & 7.54 & 2.10 & 0.722 \\
\hline 150 & 1.88 & 30.4 & 19.0 & 2.49 & 0.705 & 8.72 & 2.35 & 0.731 \\
\hline 200 & 2.04 & 33.1 & 23.3 & 2.90 & 0.829 & 11.6 & 2.75 & 0.764 \\
\hline
\end{tabular}




\begin{tabular}{|c|c|c|c|c|c|c|c|c|}
\hline \multicolumn{7}{|c|}{ Table 4.8.2 Energy Calculations for 1/2 Diameter Cylinder Baffle at 4\% Culvert Slope } \\
\hline \multicolumn{2}{|c|}{ Testing Channel Data } & \multicolumn{2}{c|}{$\begin{array}{c}\text { Froude Number } \\
\text { Comparison }\end{array}$} & \multicolumn{3}{c|}{ Energy Calculations } \\
\hline $\begin{array}{c}\text { Flowrate } \\
\text { (gpm) }\end{array}$ & $\begin{array}{c}\text { Flow } \\
\text { Depth in } \\
\text { Channel } \\
\text { (in) }\end{array}$ & $\begin{array}{c}\text { Flow Area } \\
\text { (in) }\end{array}$ & $\begin{array}{c}\text { Velocity } \\
\text { (in/s) }\end{array}$ & $\begin{array}{c}\text { Froude } \\
\text { Number at } \\
\text { Culvert } \\
\text { Outlet }\end{array}$ & $\begin{array}{c}\text { Froude } \\
\text { Number in } \\
\text { Testing } \\
\text { Channel }\end{array}$ & $\begin{array}{c}\text { Energy at } \\
\text { Culvert } \\
\text { Outlet (in) }\end{array}$ & $\begin{array}{c}\text { Energy in } \\
\text { Testing } \\
\text { Channel } \\
\text { (in) }\end{array}$ & $\begin{array}{c}\text { Non- } \\
\text { dimensional } \\
\text { Energy } \\
\text { Difference }\end{array}$ \\
\hline 50 & 1.23 & 20.0 & 9.64 & 2.47 & 0.442 & 5.26 & 1.35 & 0.742 \\
\hline 75 & 1.38 & 22.3 & 13.0 & 2.62 & 0.562 & 6.70 & 1.59 & 0.762 \\
\hline 100 & 1.47 & 23.8 & 16.2 & 2.69 & 0.678 & 7.85 & 1.81 & 0.769 \\
\hline 125 & 1.55 & 25.0 & 19.2 & 2.78 & 0.787 & 9.00 & 2.02 & 0.775 \\
\hline 150 & 1.79 & 29.0 & 19.9 & 2.89 & 0.758 & 10.2 & 2.30 & 0.773 \\
\hline 200 & 1.92 & 31.1 & 24.7 & 3.31 & 0.907 & 13.6 & 2.72 & 0.800 \\
\hline
\end{tabular}

\begin{tabular}{|c|c|c|c|c|c|c|c|c|}
\hline \multicolumn{7}{|c|}{ Table 4.8.3 Energy Calculations for 1/2 Diameter Cylinder Baffle at 6\% Culvert Slope } \\
\hline \multicolumn{2}{|c|}{ Testing Channel Data } & \multicolumn{2}{c|}{$\begin{array}{c}\text { Froude Number } \\
\text { Comparison }\end{array}$} & \multicolumn{3}{|c|}{ Energy Calculations } \\
\hline $\begin{array}{c}\text { Flowrate } \\
\text { (gpm) }\end{array}$ & $\begin{array}{c}\text { Flow } \\
\text { Depth in } \\
\text { Channel } \\
\text { (in) }\end{array}$ & $\begin{array}{c}\text { Flow Area } \\
\text { (in) }\end{array}$ & $\begin{array}{c}\text { Velocity } \\
\text { (in/s) }\end{array}$ & $\begin{array}{c}\text { Froude } \\
\text { Number at } \\
\text { Culvert } \\
\text { Outlet }\end{array}$ & $\begin{array}{c}\text { Froude } \\
\text { Number in } \\
\text { Testing } \\
\text { Channel }\end{array}$ & $\begin{array}{c}\text { Energy at } \\
\text { Culvert } \\
\text { Outlet (in) }\end{array}$ & $\begin{array}{c}\text { Energy in } \\
\text { Testing } \\
\text { Channel } \\
\text { (in) }\end{array}$ & $\begin{array}{c}\text { Non- } \\
\text { dimensional } \\
\text { Energy } \\
\text { Difference }\end{array}$ \\
\hline 50 & 1.13 & 18.3 & 10.5 & 3.00 & 0.501 & 6.57 & 1.28 & 0.806 \\
\hline 75 & 1.36 & 22.0 & 13.1 & 3.14 & 0.573 & 8.29 & 1.58 & 0.809 \\
\hline 100 & 1.48 & 24.0 & 16.0 & 3.23 & 0.670 & 9.73 & 1.82 & 0.813 \\
\hline 125 & 1.55 & 25.0 & 19.3 & 3.25 & 0.788 & 10.8 & 2.02 & 0.812 \\
\hline 150 & 1.82 & 29.4 & 19.6 & 3.32 & 0.742 & 12.0 & 2.32 & 0.807 \\
\hline 200 & 1.96 & 31.8 & 24.2 & 3.65 & 0.880 & 15.3 & 2.72 & 0.822 \\
\hline
\end{tabular}

\begin{tabular}{|c|c|c|c|c|c|c|c|c|}
\hline \multicolumn{7}{|c|}{ Table 4.8.4 Energy Calculations for 1/2 Diameter Cylinder Baffle at 8\% Culvert Slope } \\
\hline \multicolumn{2}{|c|}{ Testing Channel Data } & \multicolumn{2}{c|}{$\begin{array}{c}\text { Froude Number } \\
\text { Comparison }\end{array}$} & \multicolumn{3}{c|}{ Energy Calculations } \\
\hline $\begin{array}{c}\text { Flowrate } \\
\text { (gpm) }\end{array}$ & $\begin{array}{c}\text { Flow } \\
\text { Depth in } \\
\text { Channel } \\
\text { (in) }\end{array}$ & $\begin{array}{c}\text { Flow Area } \\
\left.\text { (in }{ }^{2}\right)\end{array}$ & $\begin{array}{c}\text { Velocity } \\
\text { (in/s) }\end{array}$ & $\begin{array}{c}\text { Froude } \\
\text { Number at } \\
\text { Culvert } \\
\text { Outlet }\end{array}$ & $\begin{array}{c}\text { Froude } \\
\text { Number in } \\
\text { Testing } \\
\text { Channel }\end{array}$ & $\begin{array}{c}\text { Energy at } \\
\text { Culvert } \\
\text { Outlet (in) }\end{array}$ & $\begin{array}{c}\text { Energy in } \\
\text { Testing } \\
\text { Channel } \\
\text { (in) }\end{array}$ & $\begin{array}{c}\text { Non- } \\
\text { dimensional } \\
\text { Energy } \\
\text { Difference }\end{array}$ \\
\hline 50 & 1.14 & 18.4 & 10.4 & 3.15 & 0.497 & 7.01 & 1.28 & 0.817 \\
\hline 75 & 1.29 & 20.8 & 13.9 & 3.35 & 0.622 & 9.01 & 1.54 & 0.830 \\
\hline 100 & 1.40 & 22.7 & 16.9 & 3.45 & 0.728 & 10.6 & 1.78 & 0.832 \\
\hline 125 & 1.49 & 24.2 & 19.9 & 3.48 & 0.829 & 11.8 & 2.01 & 0.829 \\
\hline 150 & 1.67 & 27.1 & 21.3 & 3.55 & 0.838 & 13.0 & 2.26 & 0.826 \\
\hline 200 & 1.72 & 27.9 & 27.6 & 3.78 & 1.07 & 16.0 & 2.71 & 0.830 \\
\hline
\end{tabular}




\subsection{3/4 Diameter L-Baffle Configuration}

The L-baffle originally started as a single rectangular baffle located at the toe of the apron. Vertical spray was so pronounced that the $1 / 4 \mathrm{D}$ lip was added to produce a turning effect in the flow. The lip performed very well in eliminating the vertical spray. The flow exited the culvert and traveled down the apron until impact with the L-baffle. Upon impact the flow was forced upward toward the lip and outward laterally toward the wingwall extensions. Water collecting on the apron with the L-baffle was substantially more than with the Cylinder baffles but never to the extent of overflowing the wingwalls. The constructed model of the $3 / 4 \mathrm{D}$ L-baffle is shown in Figure 4.9.1. A typical flow regime is shown in Figures 4.9.2. Initial testing of the L-Baffle configuration to examine the flow pattern is shown in Figure 4.9.3.

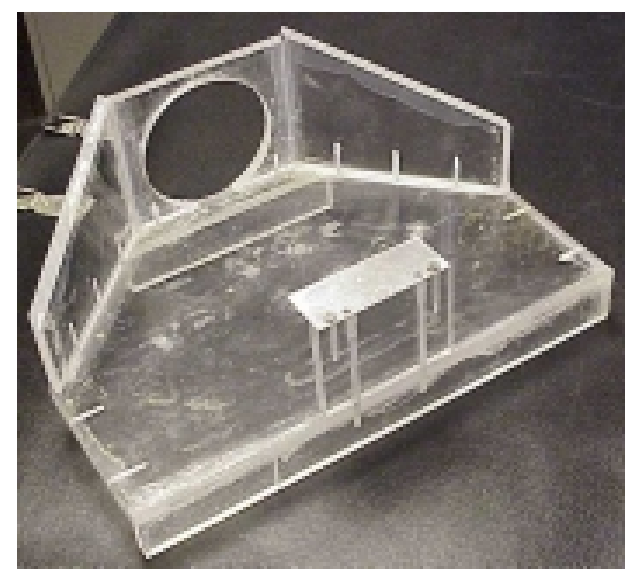

Figure 4.9.1 3/4 D L-Baffle Model

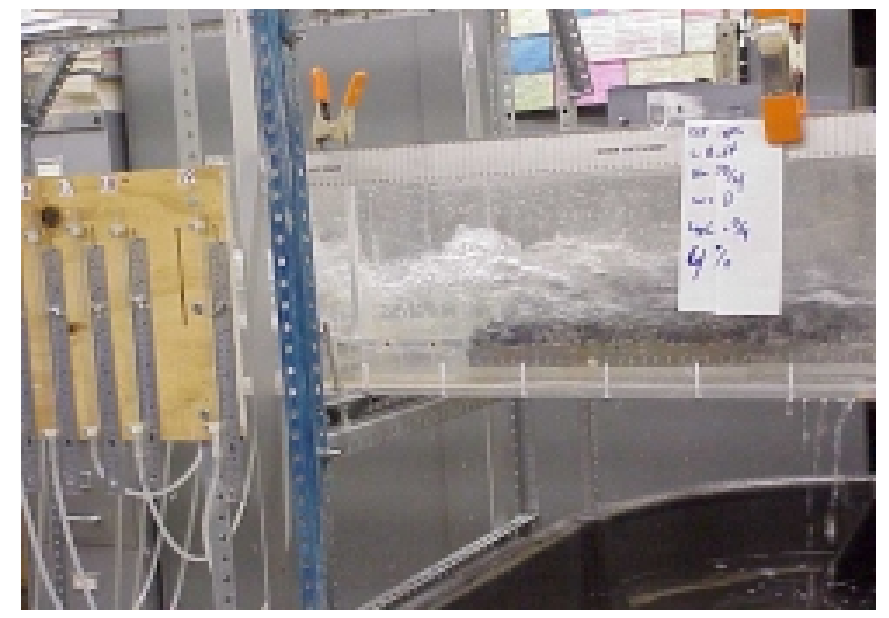

Figure 4.9.2 3/4 D L-Baffle at 4\% Culvert Slope and 125gpm 


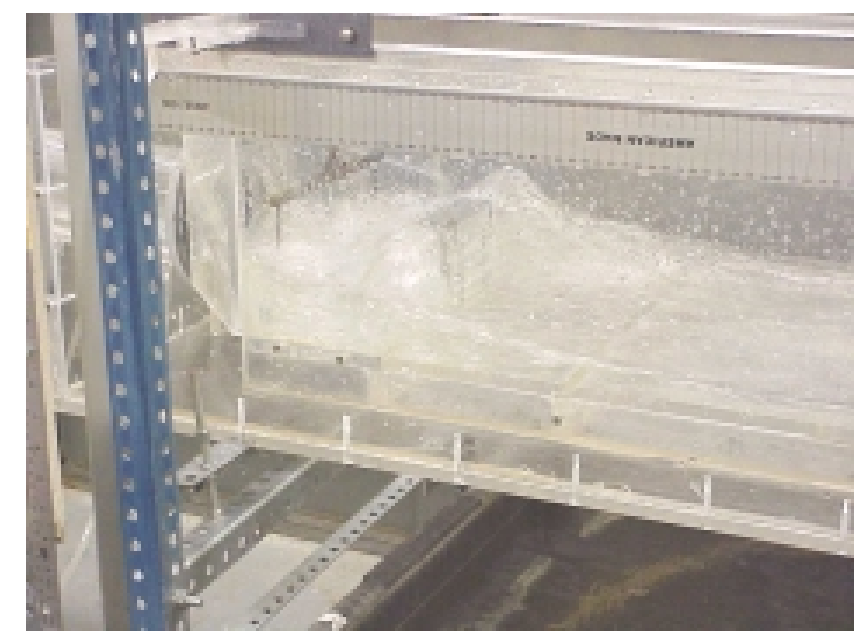

Figure 4.9.3 3/4 D L-Baffle Preliminary Test

Plots of water surface elevation are shown in Figures 4.9.4 through 4.9.7. Energy calculations performed on the $3 / 4 \mathrm{D}$ L-baffle are shown in Tables 4.9.1 through 4.9.4.

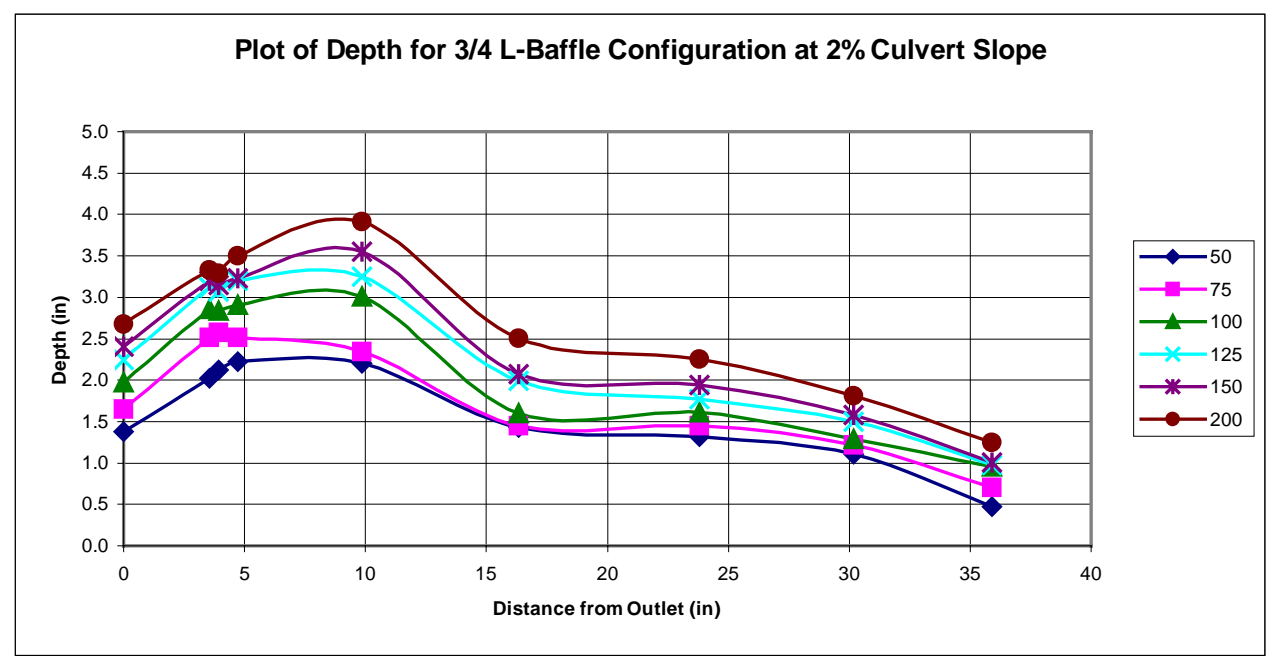

Figure 4.9.4 Plot of Depth for 3/4 D L-Baffle at 2\% Culvert Slope and 50-200 gpm 


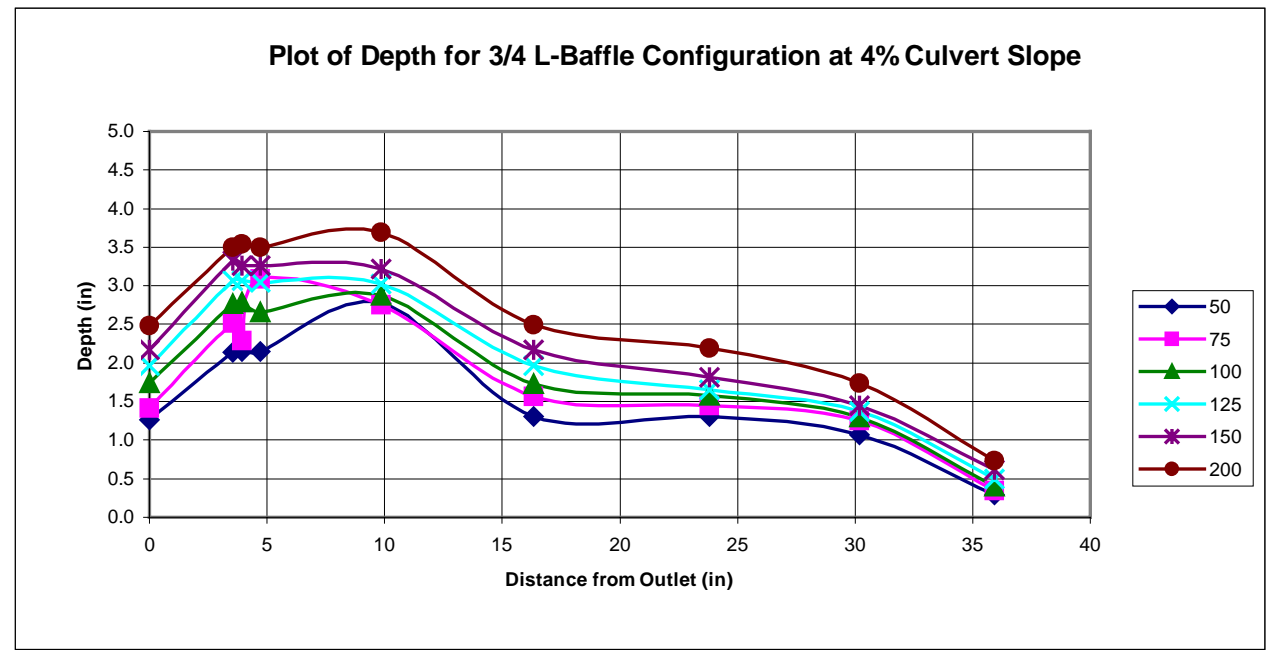

Figure 4.9.5 Plot of Depth for 3/4 D L-Baffle at 4\% Culvert Slope and 50-200 gpm

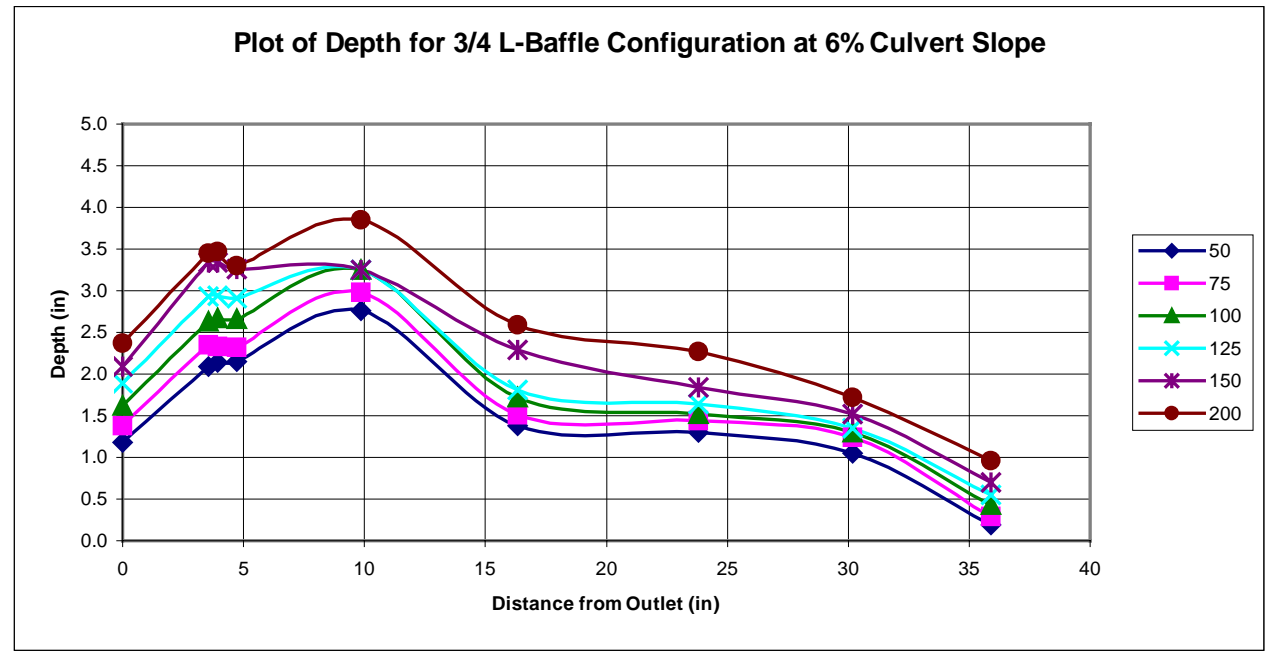

Figure 4.9.6 Plot of Depth for 3/4 D L-Baffle at 6\% Culvert Slope and 50-200 gpm 


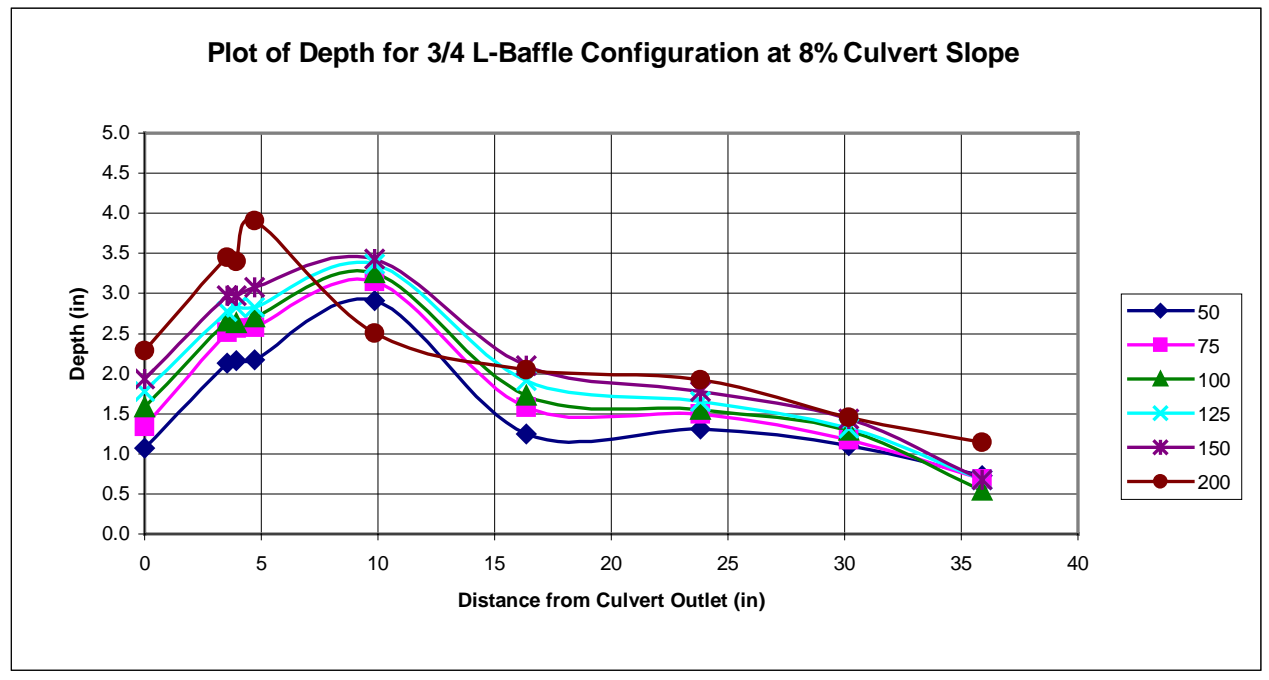

Figure 4.9.7 Plot of Depth for 3/4 D L-Baffle at 8\% Culvert Slope and 50-200 gpm

\begin{tabular}{|c|c|c|c|c|c|c|c|c|}
\hline \multicolumn{7}{|c|}{ Table 4.9.1 Energy Calculations for 3/4 Diameter L-Baffle at 2\% Culvert Slope } \\
\hline & \multicolumn{3}{|c|}{ Testing Channel Data } & \multicolumn{2}{c|}{$\begin{array}{c}\text { Froude Number } \\
\text { Comparison }\end{array}$} & \multicolumn{3}{|c|}{ Energy Calculations } \\
\hline $\begin{array}{c}\text { Flowrate } \\
\text { (gpm) }\end{array}$ & $\begin{array}{c}\text { Flow } \\
\text { Depth in } \\
\text { Channel } \\
\text { (in) }\end{array}$ & $\begin{array}{c}\text { Flow Area } \\
\text { (in) }\end{array}$ & $\begin{array}{c}\text { Velocity } \\
\text { (in/s) }\end{array}$ & $\begin{array}{c}\text { Froude } \\
\text { Number at } \\
\text { Culvert } \\
\text { Outlet }\end{array}$ & $\begin{array}{c}\text { Froude } \\
\text { Number in } \\
\text { Testing } \\
\text { Channel }\end{array}$ & $\begin{array}{c}\text { Energy at } \\
\text { Culvert } \\
\text { Outlet (in) }\end{array}$ & $\begin{array}{c}\text { Energy in } \\
\text { Testing } \\
\text { Channel } \\
\text { (in) }\end{array}$ & $\begin{array}{c}\text { Non- } \\
\text { dimensional } \\
\text { Energy } \\
\text { Difference }\end{array}$ \\
\hline 50 & 1.37 & 22.2 & 8.66 & 1.98 & 0.376 & 4.23 & 1.47 & 0.652 \\
\hline 75 & 1.45 & 23.5 & 12.3 & 2.16 & 0.519 & 5.51 & 1.65 & 0.701 \\
\hline 100 & 1.61 & 26.0 & 14.8 & 2.25 & 0.595 & 6.54 & 1.89 & 0.711 \\
\hline 125 & 1.88 & 30.4 & 15.8 & 2.34 & 0.586 & 7.54 & 2.20 & 0.708 \\
\hline 150 & 2.01 & 32.5 & 17.8 & 2.49 & 0.639 & 8.72 & 2.42 & 0.723 \\
\hline 200 & 2.38 & 38.5 & 20.0 & 2.90 & 0.660 & 11.6 & 2.90 & 0.751 \\
\hline
\end{tabular}

\begin{tabular}{|c|c|c|c|c|c|c|c|c|}
\hline \multicolumn{7}{|c|}{ Table 4.9.2 Energy Calculations for 3/4 Diameter L-Baffle at 4\% Culvert Slope } \\
\hline \multicolumn{2}{|c|}{ Testing Channel Data } & \multicolumn{2}{c|}{$\begin{array}{c}\text { Froude Number } \\
\text { Comparison }\end{array}$} & \multicolumn{3}{c|}{ Energy Calculations } \\
\hline $\begin{array}{c}\text { Flowrate } \\
\text { (gpm) }\end{array}$ & $\begin{array}{c}\text { Flow } \\
\text { Depth in } \\
\text { Channel } \\
\text { (in) }\end{array}$ & $\begin{array}{c}\text { Flow Area } \\
\left.\text { (in }{ }^{2}\right)\end{array}$ & $\begin{array}{c}\text { Velocity } \\
\text { (in/s) }\end{array}$ & $\begin{array}{c}\text { Froude } \\
\text { Number at } \\
\text { Culvert } \\
\text { Outlet }\end{array}$ & $\begin{array}{c}\text { Froude } \\
\text { Number in } \\
\text { Testing } \\
\text { Channel }\end{array}$ & $\begin{array}{c}\text { Energy at } \\
\text { Culvert } \\
\text { Outlet (in) }\end{array}$ & $\begin{array}{c}\text { Energy in } \\
\text { Testing } \\
\text { Channel } \\
\text { (in) }\end{array}$ & $\begin{array}{c}\text { Non- } \\
\text { dimensional } \\
\text { Energy } \\
\text { Difference }\end{array}$ \\
\hline 50 & 1.30 & 21.1 & 9.14 & 2.47 & 0.407 & 5.26 & 1.41 & 0.732 \\
\hline 75 & 1.51 & 24.4 & 11.8 & 2.62 & 0.491 & 6.70 & 1.69 & 0.748 \\
\hline 100 & 1.65 & 26.7 & 14.4 & 2.69 & 0.570 & 7.85 & 1.92 & 0.755 \\
\hline 125 & 1.81 & 29.3 & 16.4 & 2.78 & 0.622 & 9.00 & 2.16 & 0.760 \\
\hline 150 & 1.99 & 32.2 & 17.9 & 2.89 & 0.647 & 10.2 & 2.41 & 0.763 \\
\hline 200 & 2.34 & 37.9 & 20.3 & 3.31 & 0.675 & 13.6 & 2.88 & 0.788 \\
\hline
\end{tabular}




\begin{tabular}{|c|c|c|c|c|c|c|c|c|}
\hline \multicolumn{7}{|c|}{ Table 4.9.3 Energy Calculations for 3/4 Diameter L-Baffle at 6\% Culvert Slope } \\
\hline & \multicolumn{3}{|c|}{ Testing Channel Data } & \multicolumn{2}{c|}{$\begin{array}{c}\text { Froude Number } \\
\text { Comparison }\end{array}$} & \multicolumn{3}{|c|}{ Energy Calculations } \\
\hline $\begin{array}{c}\text { Flowrate } \\
\text { (gpm) }\end{array}$ & $\begin{array}{c}\text { Flow } \\
\text { Depth in } \\
\text { Channel } \\
\text { (in) }\end{array}$ & $\begin{array}{c}\text { Flow Area } \\
\left.\text { (in }{ }^{2}\right)\end{array}$ & $\begin{array}{c}\text { Velocity } \\
\text { (in/s) }\end{array}$ & $\begin{array}{c}\text { Froude } \\
\text { Number at } \\
\text { Culvert } \\
\text { Outlet }\end{array}$ & $\begin{array}{c}\text { Froude } \\
\text { Number in } \\
\text { Testing } \\
\text { Channel }\end{array}$ & $\begin{array}{c}\text { Energy at } \\
\text { Culvert } \\
\text { Outlet (in) }\end{array}$ & $\begin{array}{c}\text { Energy in } \\
\text { Testing } \\
\text { Channel } \\
\text { (in) }\end{array}$ & $\begin{array}{c}\text { Non- } \\
\text { dimensional } \\
\text { Energy } \\
\text { Difference }\end{array}$ \\
\hline 50 & 1.34 & 21.7 & 8.89 & 3.00 & 0.391 & 6.57 & 1.44 & 0.781 \\
\hline 75 & 1.47 & 23.8 & 12.1 & 3.14 & 0.508 & 8.29 & 1.66 & 0.799 \\
\hline 100 & 1.62 & 26.2 & 14.7 & 3.23 & 0.587 & 9.73 & 1.90 & 0.805 \\
\hline 125 & 1.72 & 27.9 & 17.3 & 3.25 & 0.670 & 10.8 & 2.11 & 0.804 \\
\hline 150 & 2.07 & 33.4 & 17.3 & 3.32 & 0.611 & 12.0 & 2.45 & 0.795 \\
\hline 200 & 2.43 & 39.3 & 19.6 & 3.65 & 0.639 & 15.3 & 2.93 & 0.809 \\
\hline
\end{tabular}

\begin{tabular}{|c|c|c|c|c|c|c|c|c|}
\hline \multicolumn{7}{|c|}{ Table 4.9.4 Energy Calculations for 3/4 Diameter L-Baffle at 8\% Culvert Slope } \\
\hline & \multicolumn{2}{|c|}{ Testing Channel Data } & \multicolumn{2}{c|}{$\begin{array}{c}\text { Froude Number } \\
\text { Comparison }\end{array}$} & \multicolumn{3}{|c|}{ Energy Calculations } \\
\hline $\begin{array}{c}\text { Flowrate } \\
\text { (gpm) }\end{array}$ & $\begin{array}{c}\text { Flow } \\
\text { Depth in } \\
\text { Channel } \\
\text { (in) }\end{array}$ & $\begin{array}{c}\text { Flow Area } \\
\text { (in) }\end{array}$ & $\begin{array}{c}\text { Velocity } \\
\text { (in/s) }\end{array}$ & $\begin{array}{c}\text { Froude } \\
\text { Number at } \\
\text { Culvert } \\
\text { Outlet }\end{array}$ & $\begin{array}{c}\text { Froude } \\
\text { Number in } \\
\text { Testing } \\
\text { Channel }\end{array}$ & $\begin{array}{c}\text { Energy at } \\
\text { Culvert } \\
\text { Outlet (in) }\end{array}$ & $\begin{array}{c}\text { Energy in } \\
\text { Testing } \\
\text { Channel } \\
\text { (in) }\end{array}$ & $\begin{array}{c}\text { Non- } \\
\text { dimensional } \\
\text { Energy } \\
\text { Difference }\end{array}$ \\
\hline 50 & 1.28 & 20.7 & 9.31 & 3.15 & 0.419 & 7.01 & 1.39 & 0.802 \\
\hline 75 & 1.54 & 25.0 & 11.6 & 3.35 & 0.474 & 9.01 & 1.72 & 0.810 \\
\hline 100 & 1.64 & 26.5 & 14.6 & 3.45 & 0.579 & 10.6 & 1.91 & 0.819 \\
\hline 125 & 1.78 & 28.8 & 16.7 & 3.48 & 0.636 & 11.8 & 2.14 & 0.818 \\
\hline 150 & 1.94 & 31.4 & 18.4 & 3.55 & 0.671 & 13.0 & 2.38 & 0.817 \\
\hline 200 & 1.98 & 32.1 & 24.0 & 3.78 & 0.867 & 16.0 & 2.73 & 0.829 \\
\hline
\end{tabular}




\subsection{0 $1 / 2$ D L-Baffle Configuration}

The L-baffles were tested at $1 / 2 \mathrm{D}$ and $3 / 4 \mathrm{D}$ to investigate difference in flow characteristics, as was done with the cylinder baffles. The flow pattern for the $1 / 2 \mathrm{D}$ was similar to that of the taller baffle, but the impact on the $1 / 2 \mathrm{D}$ baffle seemed to be more turbulent. As the vertical distance to the lip was less than with the taller baffle, the flow had less room to expand. Also like the $1 / 2 \mathrm{D}$ cylinder baffle, the $1 / 2 \mathrm{D}$ L-baffle was at times submerged by the flow exiting the test culvert. The model of the $1 / 2$ D L-baffle is shown in Figure 4.10.1, and typical flow patterns are shown in Figures 4.10.2 and 4.10.3.

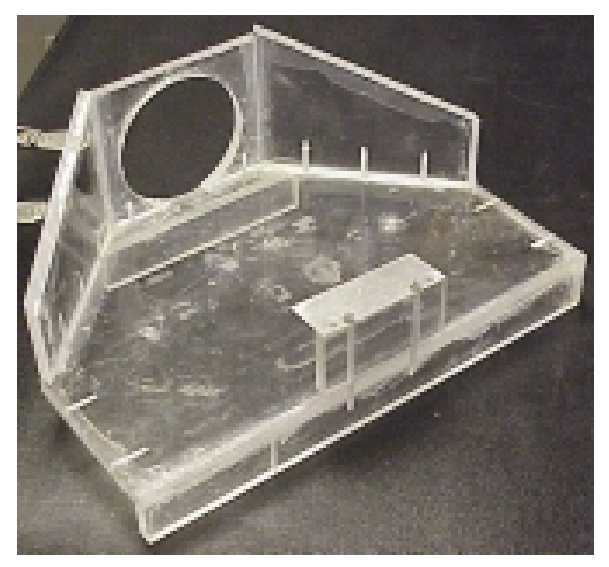

Figure 4.10.1 Model of $1 / 2$ D L- Baffle

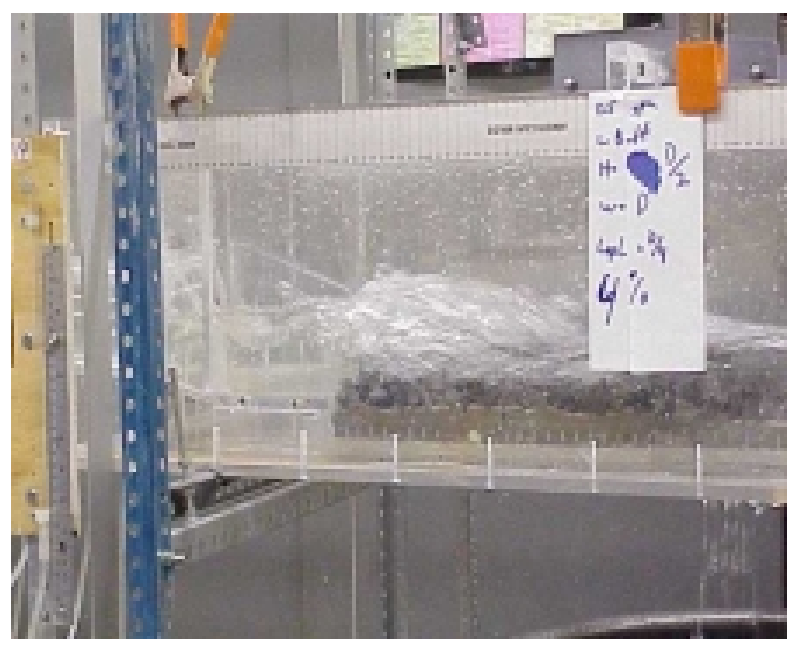

Figure 4.10.2 1/2 D L-Baffle at 4\% Slope and 125gpm 


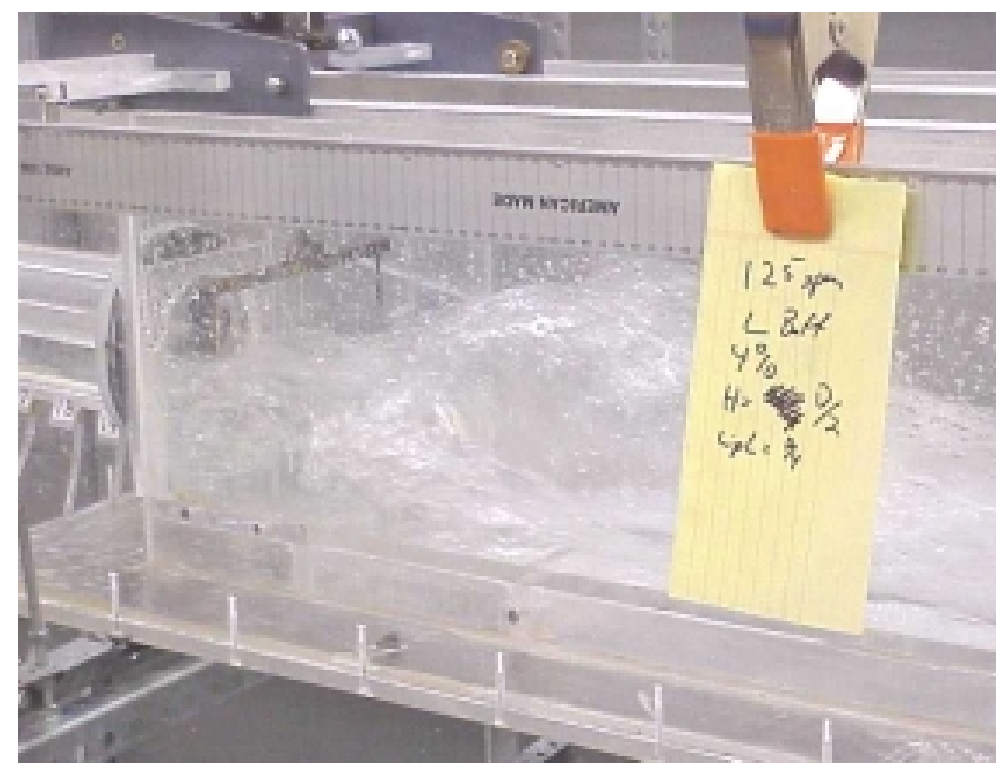

Figure 4.10.3 1/2 D L-baffle at 4\% Slope and 125gpm

Graphs of water surface elevation are shown in Figures 4.10.4 through 4.10.7. Energy calculations are shown in Tables 4.10.1 through 4.10.4.

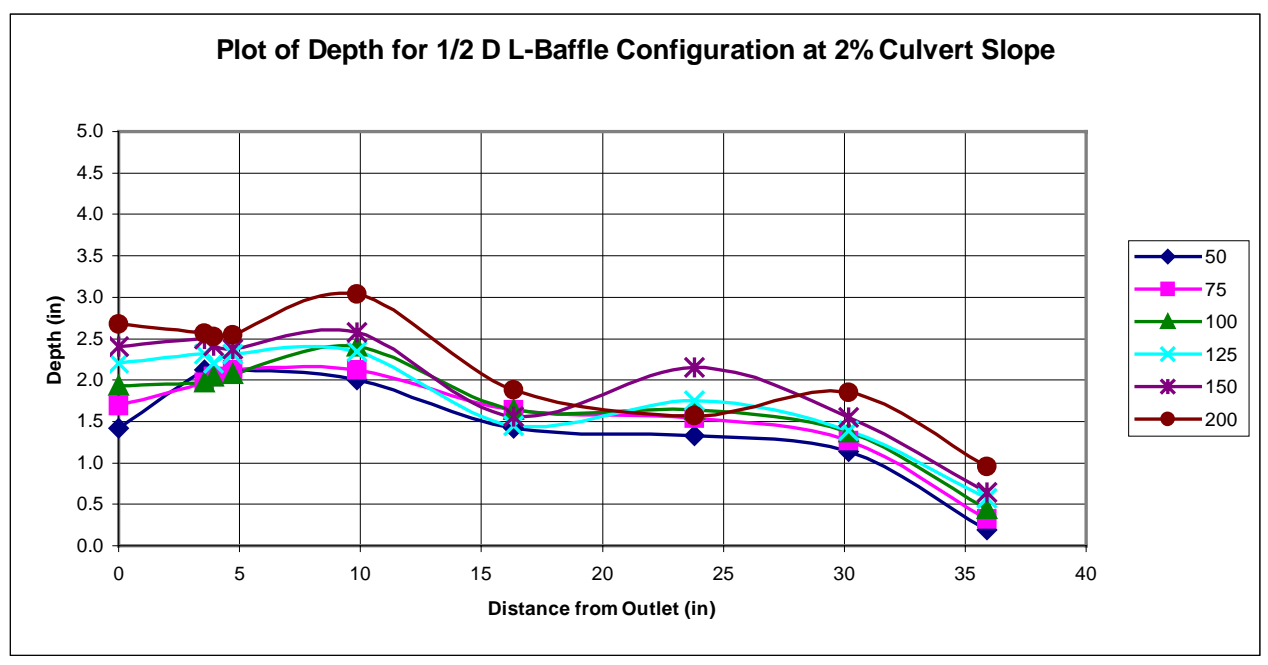

Figure 4.10.4 Plot of Depth for $1 \frac{1}{2}$ D L-baffle at 2\% Culvert Slope and 50-200 gpm 


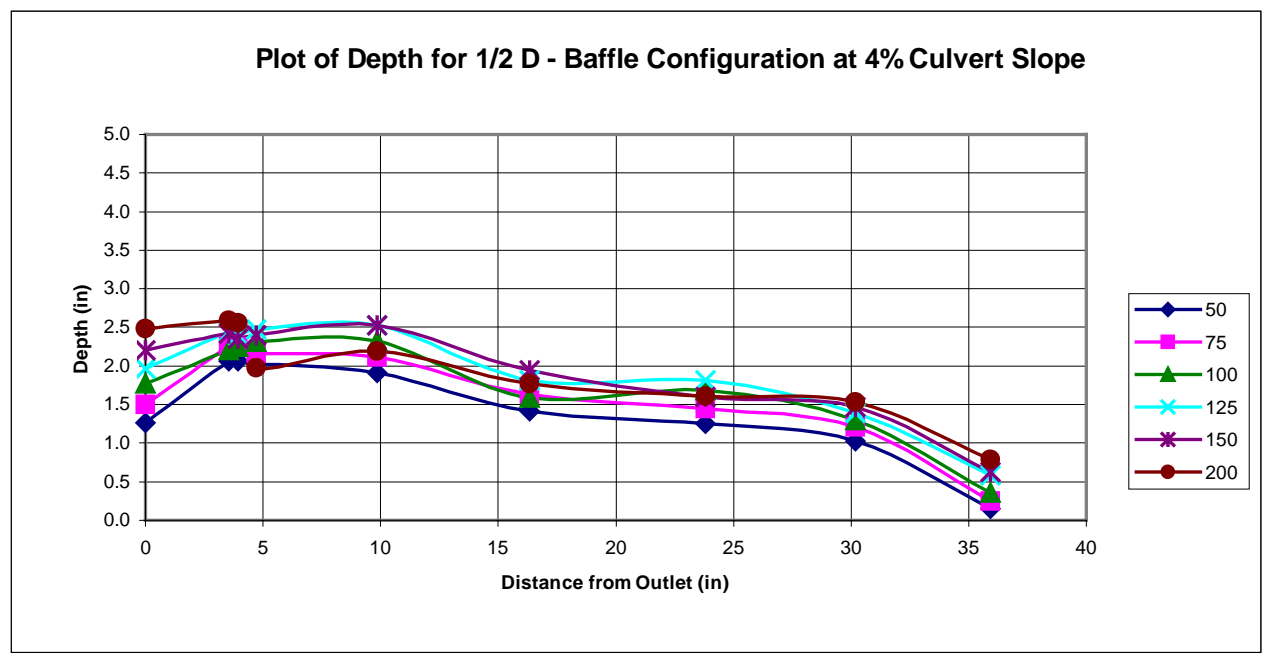

Figure 4.10.5 Plot of Depth for $1 / 2$ D L-baffle at 4\% Culvert Slope and 50-200 gpm

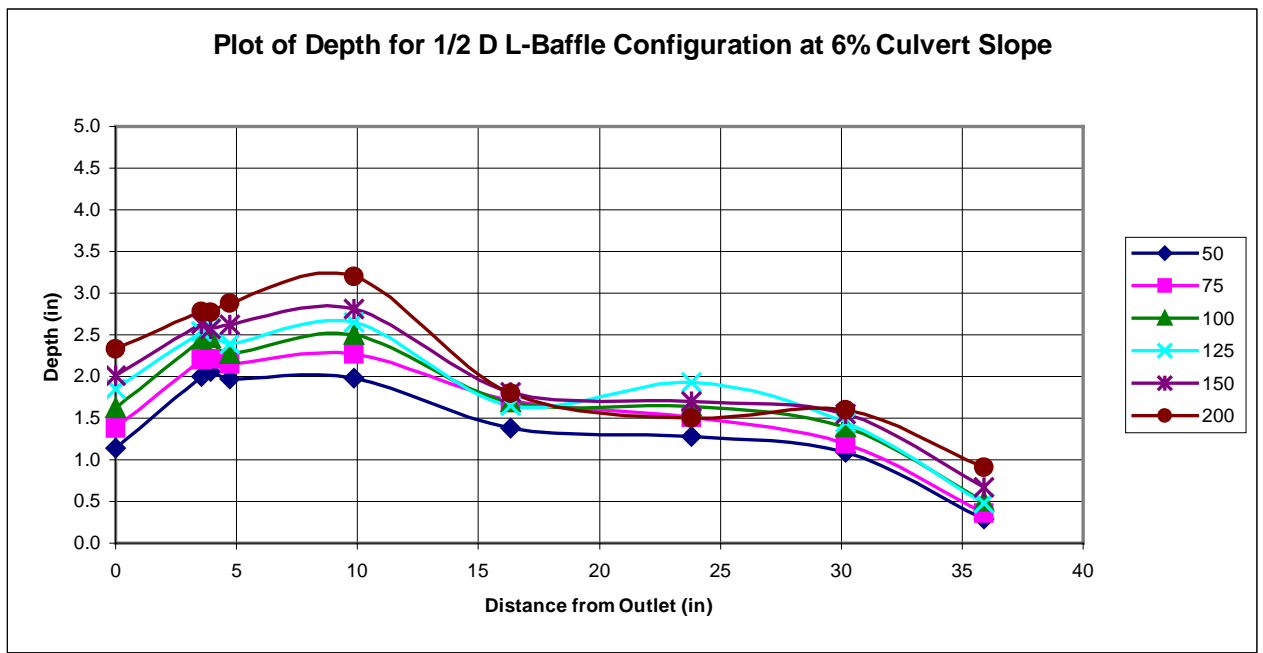

Figure 4.10.6 Plot of Depth for 1/2 D L-baffle at 6\% Culvert Slope and 50-200 gpm 


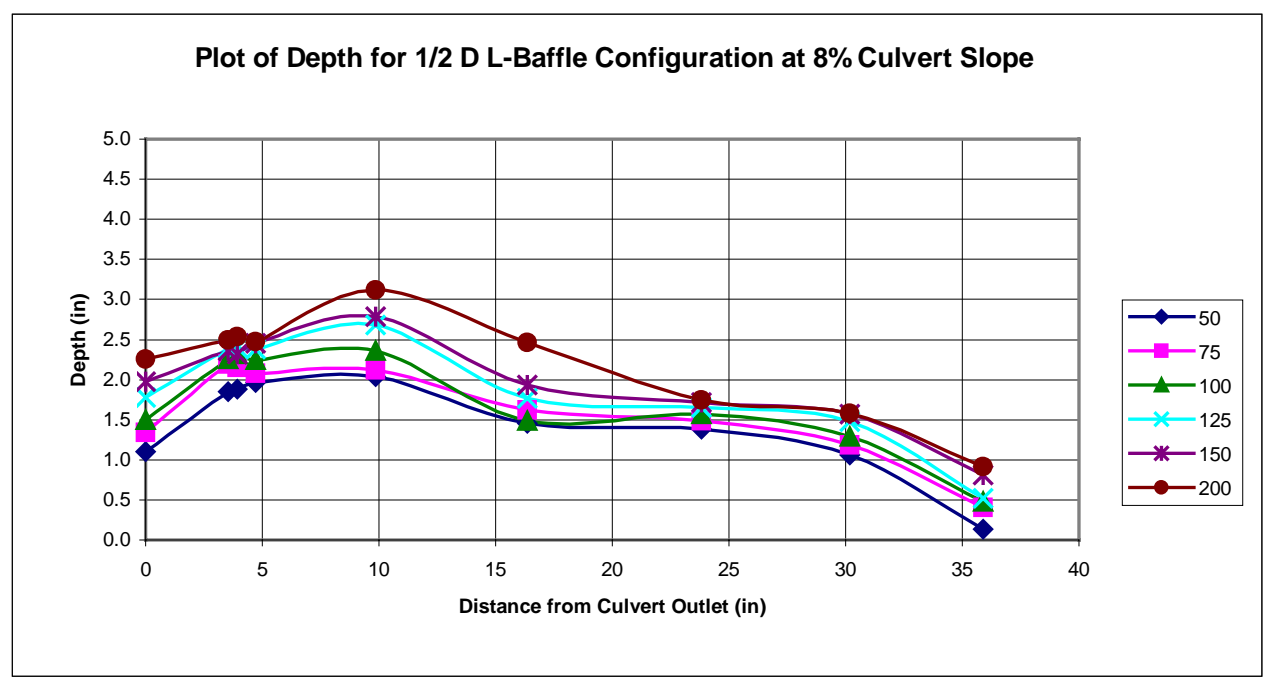

Figure 4.10.7 Plot of Depth for $1 / 2$ D L-baffle at 8\% Culvert Slope and 50-200 gpm

\begin{tabular}{|c|c|c|c|c|c|c|c|c|}
\hline \multicolumn{7}{|c|}{ Table 4.10.1 Energy Calculations for 1/2 Diameter L-Baffle at 2\% Culvert Slope } \\
\hline & \multicolumn{3}{|c|}{ Testing Channel Data } & \multicolumn{2}{c|}{$\begin{array}{c}\text { Froude Number } \\
\text { Comparison }\end{array}$} & \multicolumn{3}{c|}{ Energy Calculations } \\
\hline $\begin{array}{c}\text { Flowrate } \\
\text { (gpm) }\end{array}$ & $\begin{array}{c}\text { Flow } \\
\text { Depth in } \\
\text { Channel } \\
\text { (in) }\end{array}$ & $\begin{array}{c}\text { Flow Area } \\
\left.\text { (in }{ }^{2}\right)\end{array}$ & $\begin{array}{c}\text { Velocity } \\
\text { (in/s) }\end{array}$ & $\begin{array}{c}\text { Froude } \\
\text { Number at } \\
\text { Culvert } \\
\text { Outlet }\end{array}$ & $\begin{array}{c}\text { Froude } \\
\text { Number in } \\
\text { Testing } \\
\text { Channel }\end{array}$ & $\begin{array}{c}\text { Energy at } \\
\text { Culvert } \\
\text { Outlet (in) }\end{array}$ & $\begin{array}{c}\text { Energy in } \\
\text { Testing } \\
\text { Channel } \\
\text { (in) }\end{array}$ & $\begin{array}{c}\text { Non- } \\
\text { dimensional } \\
\text { Energy } \\
\text { Difference }\end{array}$ \\
\hline 50 & 1.37 & 22.2 & 8.66 & 1.98 & 0.376 & 4.23 & 1.47 & 0.652 \\
\hline 75 & 1.59 & 25.7 & 11.2 & 2.16 & 0.453 & 5.51 & 1.75 & 0.682 \\
\hline 100 & 1.64 & 26.6 & 14.5 & 2.25 & 0.576 & 6.54 & 1.91 & 0.708 \\
\hline 125 & 1.60 & 25.9 & 18.6 & 2.34 & 0.746 & 7.54 & 2.05 & 0.729 \\
\hline 150 & 1.86 & 30.0 & 19.2 & 2.49 & 0.717 & 8.72 & 2.33 & 0.732 \\
\hline 200 & 1.73 & 28.0 & 27.5 & 2.90 & 1.07 & 11.6 & 2.71 & 0.767 \\
\hline
\end{tabular}




\begin{tabular}{|c|c|c|c|c|c|c|c|c|}
\hline \multicolumn{7}{|c|}{ Table 4.10.2 Energy Calculations for 1/2 Diameter L-Baffle at 4\% Culvert Slope } \\
\hline \multicolumn{2}{|c|}{ Testing Channel Data } & \multicolumn{2}{|c|}{$\begin{array}{c}\text { Froude Number } \\
\text { Comparison }\end{array}$} & \multicolumn{3}{c|}{ Energy Calculations } \\
\hline $\begin{array}{c}\text { Flowrate } \\
\text { (gpm) }\end{array}$ & $\begin{array}{c}\text { Flow } \\
\text { Depth in } \\
\text { Channel } \\
\text { (in) }\end{array}$ & $\begin{array}{c}\text { Flow Area } \\
\text { (in }{ }^{2}\end{array}$ & $\begin{array}{c}\text { Velocity } \\
\text { (in/s) }\end{array}$ & $\begin{array}{c}\text { Froude } \\
\text { Number at } \\
\text { Culvert } \\
\text { Outlet }\end{array}$ & $\begin{array}{c}\text { Froude } \\
\text { Number in } \\
\text { Testing } \\
\text { Channel }\end{array}$ & $\begin{array}{c}\text { Energy at } \\
\text { Culvert } \\
\text { Outlet (in) }\end{array}$ & $\begin{array}{c}\text { Energy in } \\
\text { Testing } \\
\text { Channel } \\
\text { (in) }\end{array}$ & $\begin{array}{c}\text { Non- } \\
\text { dimensional } \\
\text { Energy } \\
\text { Difference }\end{array}$ \\
\hline 50 & 1.34 & 21.6 & 8.91 & 2.47 & 0.392 & 5.26 & 1.44 & 0.727 \\
\hline 75 & 1.54 & 24.9 & 11.6 & 2.62 & 0.475 & 6.70 & 1.71 & 0.744 \\
\hline 100 & 1.64 & 26.5 & 14.6 & 2.69 & 0.579 & 7.85 & 1.91 & 0.757 \\
\hline 125 & 1.81 & 29.3 & 16.4 & 2.78 & 0.620 & 9.00 & 2.16 & 0.760 \\
\hline 150 & 1.77 & 28.7 & 20.1 & 2.89 & 0.769 & 10.2 & 2.30 & 0.774 \\
\hline 200 & 1.69 & 27.4 & 28.1 & 3.31 & 1.10 & 13.6 & 2.72 & 0.800 \\
\hline
\end{tabular}

\begin{tabular}{|c|c|c|c|c|c|c|c|c|}
\hline \multicolumn{7}{|c|}{ Table 4.10.3 Energy Calculations for 1/2 Diameter L-Baffle at 6\% Culvert Slope } \\
\hline & \multicolumn{2}{|c|}{ Testing Channel Data } & \multicolumn{2}{c|}{$\begin{array}{c}\text { Froude Number } \\
\text { Comparison }\end{array}$} & \multicolumn{3}{c|}{ Energy Calculations } \\
\hline $\begin{array}{c}\text { Flowrate } \\
\text { (gpm) }\end{array}$ & $\begin{array}{c}\text { Flow } \\
\text { Depth in } \\
\text { Channel } \\
\text { (in) }\end{array}$ & $\begin{array}{c}\text { Flow Area } \\
\left.\text { (in }{ }^{2}\right)\end{array}$ & $\begin{array}{c}\text { Velocity } \\
\text { (in/s) }\end{array}$ & $\begin{array}{c}\text { Froude } \\
\text { Number at } \\
\text { Culvert } \\
\text { Outlet }\end{array}$ & $\begin{array}{c}\text { Froude } \\
\text { Number in } \\
\text { Testing } \\
\text { Channel }\end{array}$ & $\begin{array}{c}\text { Energy at } \\
\text { Culvert } \\
\text { Outlet (in) }\end{array}$ & $\begin{array}{c}\text { Energy in } \\
\text { Testing } \\
\text { Channel } \\
\text { (in) }\end{array}$ & $\begin{array}{c}\text { Non- } \\
\text { dimensional } \\
\text { Energy } \\
\text { Difference }\end{array}$ \\
\hline 50 & 1.33 & 21.6 & 8.93 & 3.00 & 0.394 & 6.57 & 1.44 & 0.782 \\
\hline 75 & 1.61 & 26.1 & 11.1 & 3.14 & 0.444 & 8.29 & 1.77 & 0.787 \\
\hline 100 & 1.67 & 26.9 & 14.3 & 3.23 & 0.563 & 9.73 & 1.93 & 0.802 \\
\hline 125 & 1.79 & 29.0 & 16.6 & 3.25 & 0.631 & 10.8 & 2.15 & 0.801 \\
\hline 150 & 1.76 & 28.4 & 20.3 & 3.32 & 0.779 & 12.0 & 2.29 & 0.809 \\
\hline 200 & 1.65 & 26.7 & 28.8 & 3.65 & 1.14 & 15.3 & 2.73 & 0.822 \\
\hline
\end{tabular}

\begin{tabular}{|c|c|c|c|c|c|c|c|c|}
\hline \multicolumn{7}{|c|}{ Table 4.10.4 Energy Calculations for 1/2 Diameter L-Baffle at 8\% Culvert Slope } \\
\hline \multicolumn{2}{|c|}{ Testing Channel Data } & \multicolumn{2}{c|}{$\begin{array}{c}\text { Froude Number } \\
\text { Comparison }\end{array}$} & \multicolumn{3}{c|}{ Energy Calculations } \\
\hline $\begin{array}{c}\text { Flowrate } \\
\text { (gpm) }\end{array}$ & $\begin{array}{c}\text { Flow } \\
\text { Depth in } \\
\text { Channel } \\
\text { (in) }\end{array}$ & $\begin{array}{c}\text { Flow Area } \\
\left.\text { (in }{ }^{2}\right)\end{array}$ & $\begin{array}{c}\text { Velocity } \\
\text { (in/s) }\end{array}$ & $\begin{array}{c}\text { Froude } \\
\text { Number at } \\
\text { Culvert } \\
\text { Outlet }\end{array}$ & $\begin{array}{c}\text { Froude } \\
\text { Number in } \\
\text { Testing } \\
\text { Channel }\end{array}$ & $\begin{array}{c}\text { Energy at } \\
\text { Culvert } \\
\text { Outlet (in) }\end{array}$ & $\begin{array}{c}\text { Energy in } \\
\text { Testing } \\
\text { Channel } \\
\text { (in) }\end{array}$ & $\begin{array}{c}\text { Non- } \\
\text { dimensional } \\
\text { Energy } \\
\text { Difference }\end{array}$ \\
\hline 50 & 1.42 & 22.9 & 8.40 & 3.15 & 0.359 & 7.01 & 1.51 & 0.785 \\
\hline 75 & 1.56 & 25.2 & 11.5 & 3.35 & 0.467 & 9.01 & 1.73 & 0.808 \\
\hline 100 & 1.53 & 24.8 & 15.6 & 3.45 & 0.640 & 10.6 & 1.84 & 0.825 \\
\hline 125 & 1.71 & 27.7 & 17.4 & 3.48 & 0.677 & 11.8 & 2.10 & 0.821 \\
\hline 150 & 1.82 & 29.5 & 19.6 & 3.55 & 0.737 & 13.0 & 2.32 & 0.822 \\
\hline 200 & 2.10 & 34.0 & 22.6 & 3.78 & 0.794 & 16.0 & 2.77 & 0.827 \\
\hline
\end{tabular}




\subsection{Standard Baffle}

The standard baffle configuration was tested for comparison with new designs and to identify problems that were present in the current design. One problem identified in the laboratory is that, at some flow rates, water will actually flow back over the wingwalls. WVDOH personnel found this interesting in that the current design could possibly erode the roadbed above the culvert in some instances. Testing of the standard baffle configuration also gave a representative view of an excellent energy dissipator. In fact the blockage of the flow was too extreme, which caused debris to block the culvert apron. The analysis performed later in this chapter will designate how much energy dissipation was required to reduce the flow at the culvert outlet to natural stream conditions. The model for the Standard baffle configuration is shown in Figure 4.11.1. Typical flow conditions are shown in Figures 4.11.2 and 4.11.3.

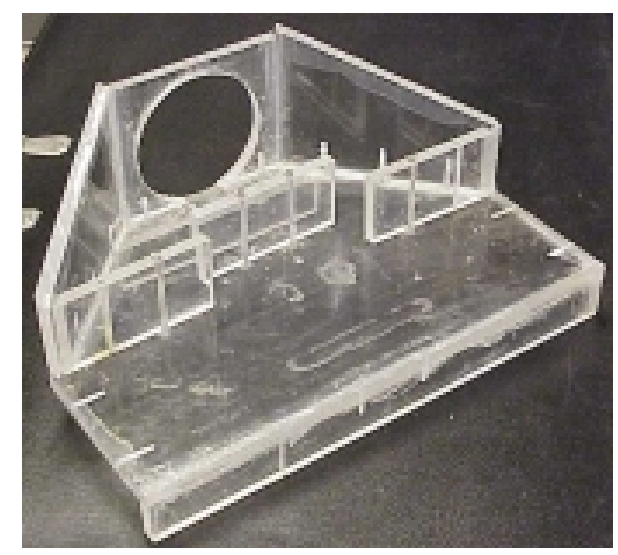

Figure 4.11.1 Model of Standard Baffle Configuration 


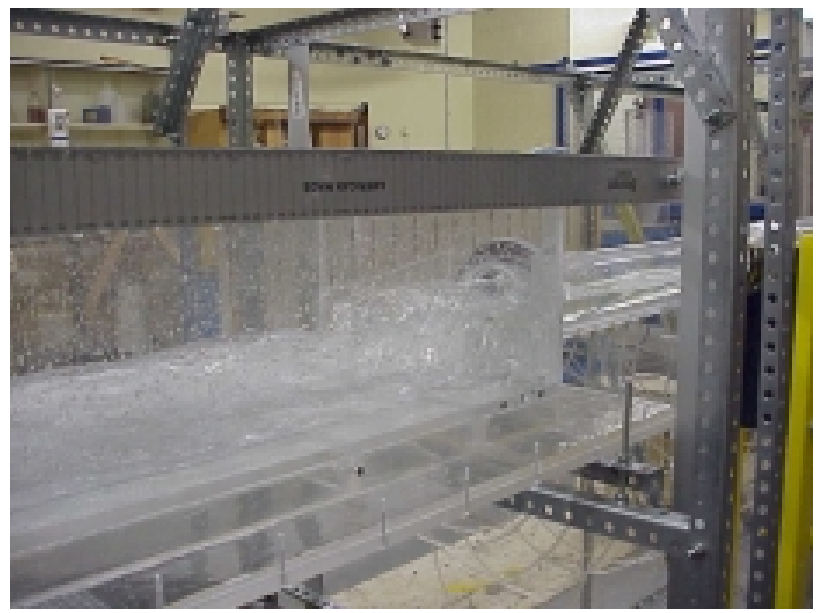

Figure 4.11.2 Standard Baffle Configuration (Initial Testing)

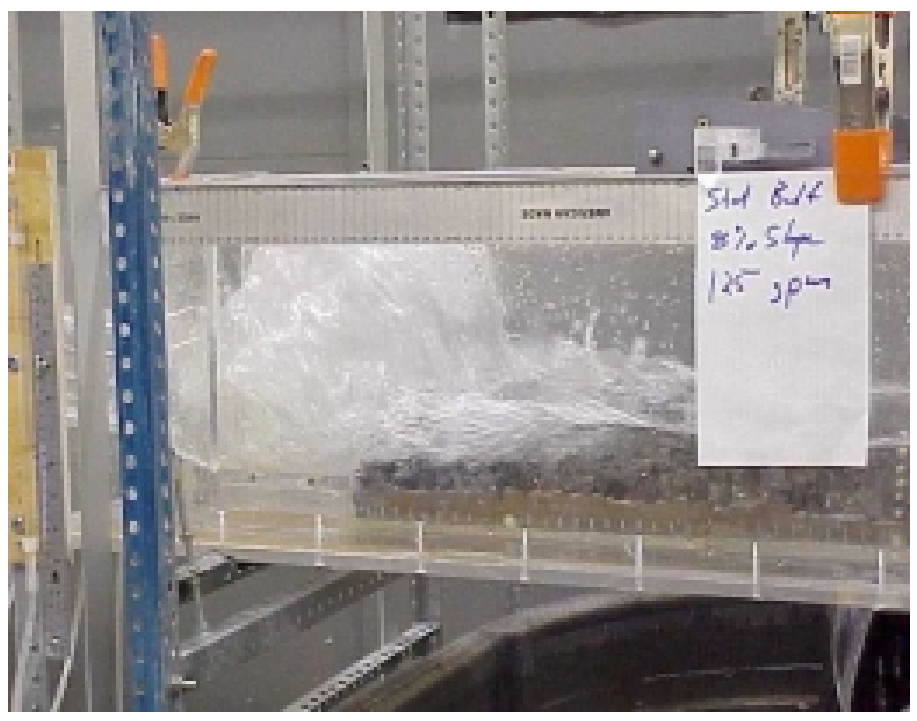

Figure 4.11.2 Standard Baffle Configuration at 8\% Culvert Slope and 125 gpm 
Graphs of depth for the Standard Baffle configuration are shown in Figures 4.11.4 through 4.11.7. Energy calculations performed on the Standard Baffle are shown in Tables 4.11.1 through 4.11.4.

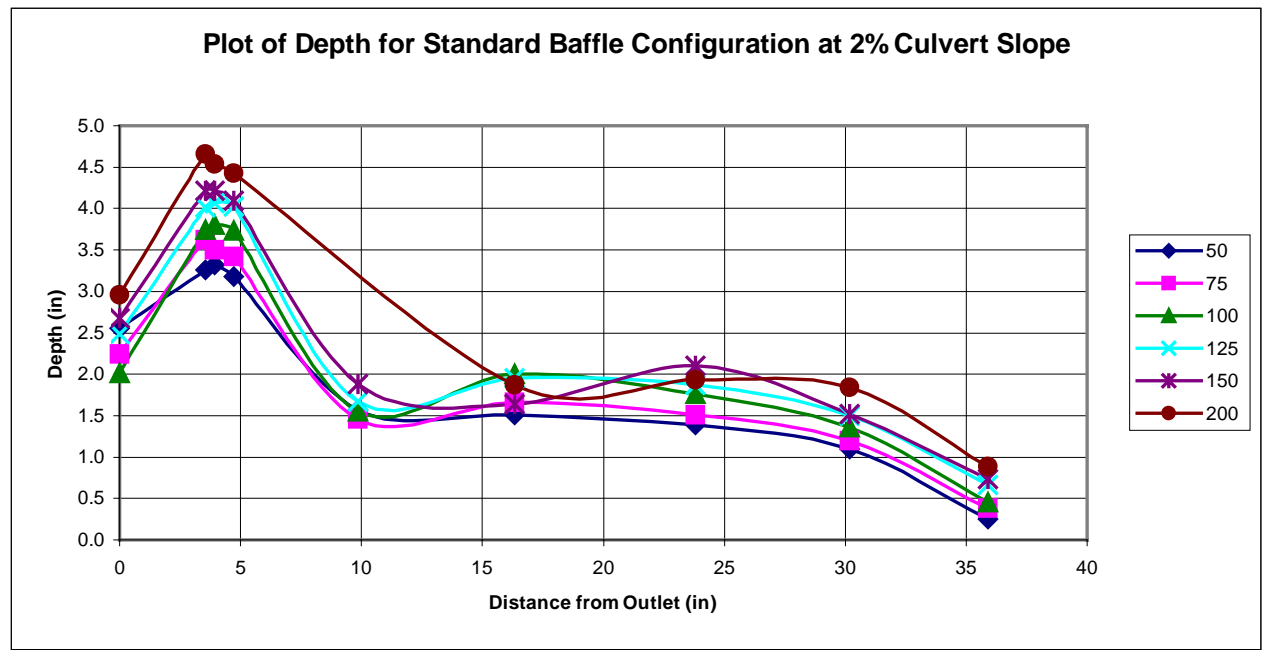

Figure 4.11.4 Plot of Depth for Standard Baffle at 2\% Culvert Slope and 50-200 gpm

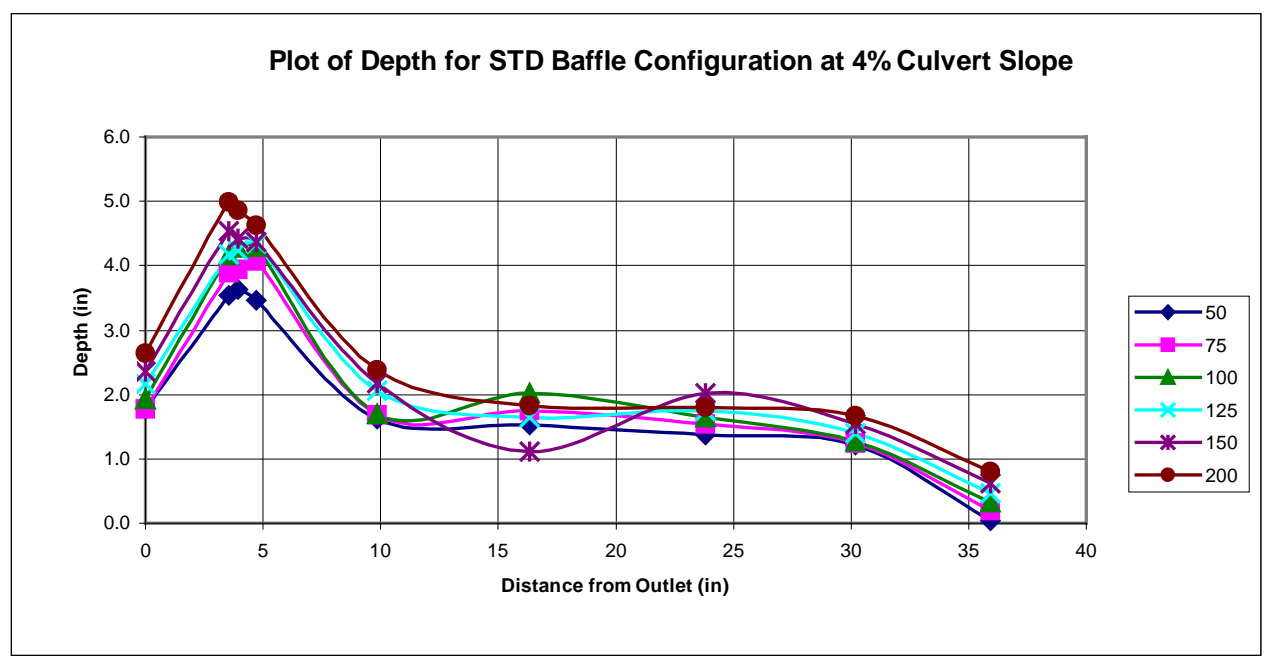

Figure 4.11.5 Plot of WSE for Standard Baffle at 4\% Culvert Slope and 50-200 gpm 


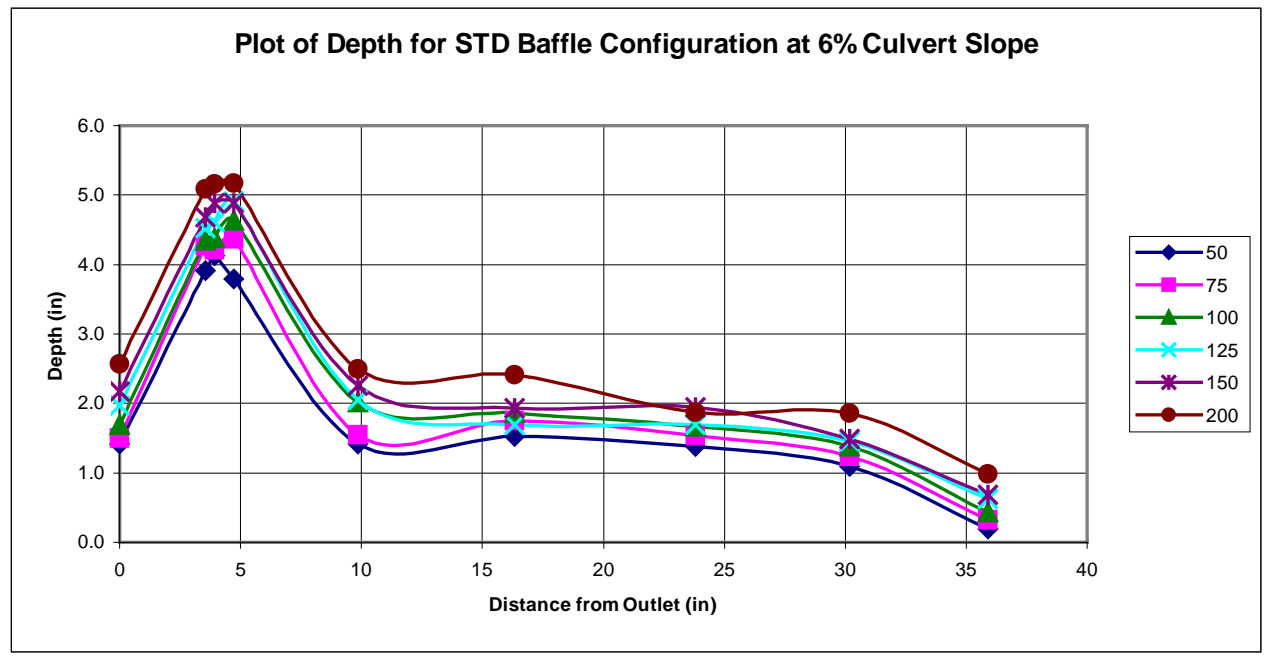

Figure 4.11.6 Plot of WSE for Standard Baffle at 6\% Culvert Slope and 50-200 gpm

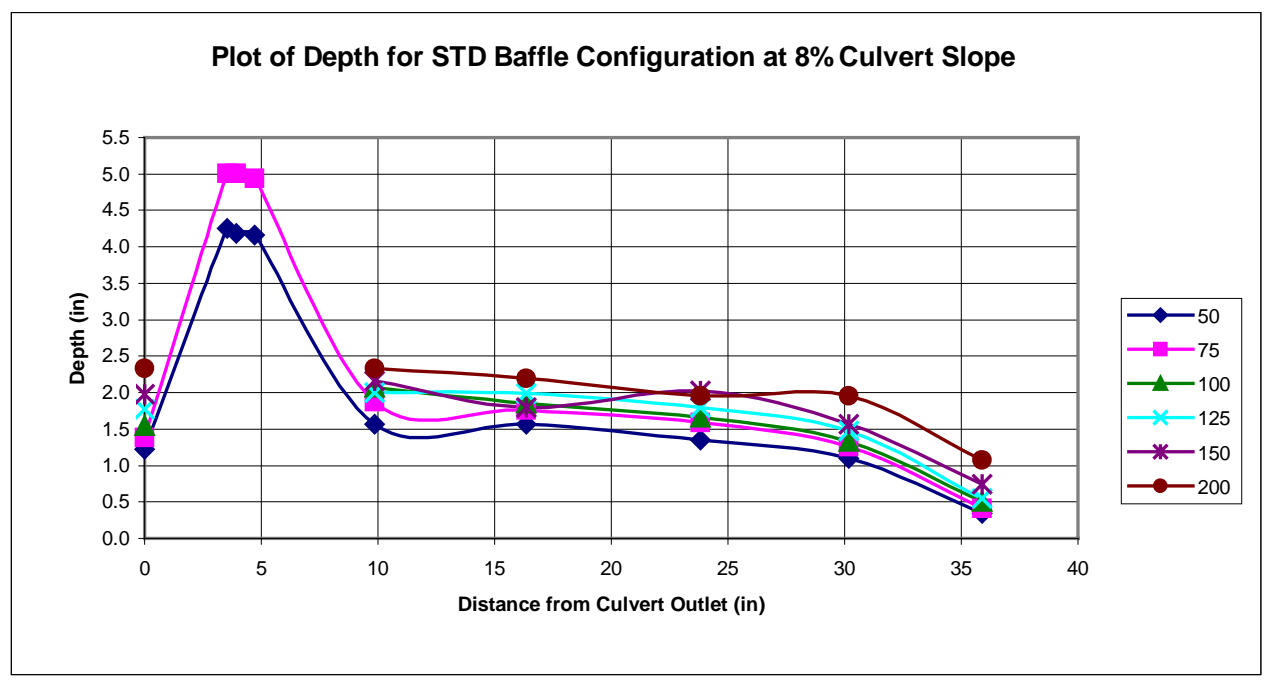

Figure 4.11.7 Plot of Depth for Standard Baffle at 8\% Culvert Slope and 50-200 gpm 


\begin{tabular}{|c|c|c|c|c|c|c|c|c|}
\hline \multicolumn{7}{|c|}{ Table 4.11.1 Energy Calculations for Standard Baffle at 2\% Culvert Slope } \\
\hline & \multicolumn{3}{|c|}{ Testing Channel Data } & \multicolumn{2}{c|}{$\begin{array}{c}\text { Froude Number } \\
\text { Comparison }\end{array}$} & \multicolumn{3}{c|}{ Energy Calculations } \\
\hline $\begin{array}{c}\text { Flowrate } \\
\text { (gpm) }\end{array}$ & $\begin{array}{c}\text { Flow } \\
\text { Depth in } \\
\text { Channel } \\
\text { (in) }\end{array}$ & $\begin{array}{c}\text { Flow Area } \\
\text { (in }{ }^{2}\end{array}$ & $\begin{array}{c}\text { Velocity } \\
\text { (in/s) }\end{array}$ & $\begin{array}{c}\text { Froude } \\
\text { Number at } \\
\text { Culvert } \\
\text { Outlet }\end{array}$ & $\begin{array}{c}\text { Froude } \\
\text { Number in } \\
\text { Testing } \\
\text { Channel }\end{array}$ & $\begin{array}{c}\text { Energy at } \\
\text { Culvert } \\
\text { Outlet (in) }\end{array}$ & $\begin{array}{c}\text { Energy in } \\
\text { Testing } \\
\text { Channel } \\
\text { (in) }\end{array}$ & $\begin{array}{c}\text { Non- } \\
\text { dimensional } \\
\text { Energy } \\
\text { Difference }\end{array}$ \\
\hline 50 & 1.49 & 24.1 & 7.98 & 1.98 & 0.333 & 4.23 & 1.57 & 0.628 \\
\hline 75 & 1.54 & 25.0 & 11.6 & 2.16 & 0.474 & 5.51 & 1.72 & 0.689 \\
\hline 100 & 1.77 & 28.7 & 13.4 & 2.25 & 0.513 & 6.54 & 2.01 & 0.694 \\
\hline 125 & 1.83 & 29.6 & 16.3 & 2.34 & 0.611 & 7.54 & 2.17 & 0.712 \\
\hline 150 & 1.87 & 30.3 & 19.0 & 2.49 & 0.708 & 8.72 & 2.34 & 0.731 \\
\hline 200 & 1.90 & 30.8 & 25.0 & 2.90 & 0.923 & 11.6 & 2.71 & 0.767 \\
\hline
\end{tabular}

\begin{tabular}{|c|c|c|c|c|c|c|c|c|}
\hline \multicolumn{7}{|c|}{ Table 4.11.2 Energy Calculations for Standard Baffle at 4\% Culvert Slope } \\
\hline & \multicolumn{3}{|c|}{ Testing Channel Data } & \multicolumn{2}{c|}{$\begin{array}{c}\text { Froude Number } \\
\text { Comparison }\end{array}$} & \multicolumn{3}{|c|}{ Energy Calculations } \\
\hline $\begin{array}{c}\text { Flowrate } \\
\text { (gpm) }\end{array}$ & $\begin{array}{c}\text { Flow } \\
\text { Depth in } \\
\text { Channel } \\
\text { (in) }\end{array}$ & $\begin{array}{c}\text { Flow Area } \\
\left.\text { (in }{ }^{2}\right)\end{array}$ & $\begin{array}{c}\text { Velocity } \\
\text { (in/s) }\end{array}$ & $\begin{array}{c}\text { Froude } \\
\text { Number at } \\
\text { Culvert } \\
\text { Outlet }\end{array}$ & $\begin{array}{c}\text { Froude } \\
\text { Number in } \\
\text { Testing } \\
\text { Channel }\end{array}$ & $\begin{array}{c}\text { Energy at } \\
\text { Culvert } \\
\text { Outlet (in) }\end{array}$ & $\begin{array}{c}\text { Energy in } \\
\text { Testing } \\
\text { Channel } \\
\text { (in) }\end{array}$ & $\begin{array}{c}\text { Non- } \\
\text { dimensional } \\
\text { Energy } \\
\text { Difference }\end{array}$ \\
\hline 50 & 1.43 & 23.2 & 8.30 & 2.47 & 0.352 & 5.26 & 1.52 & 0.710 \\
\hline 75 & 1.55 & 25.1 & 11.5 & 2.62 & 0.469 & 6.70 & 1.72 & 0.743 \\
\hline 100 & 1.66 & 26.8 & 14.3 & 2.69 & 0.566 & 7.85 & 1.93 & 0.755 \\
\hline 125 & 1.72 & 27.8 & 17.3 & 2.78 & 0.672 & 9.00 & 2.11 & 0.766 \\
\hline 150 & 1.71 & 27.6 & 20.9 & 2.89 & 0.813 & 10.2 & 2.27 & 0.777 \\
\hline 200 & 1.92 & 31.1 & 24.8 & 3.31 & 0.910 & 13.6 & 2.71 & 0.800 \\
\hline
\end{tabular}

\begin{tabular}{|c|c|c|c|c|c|c|c|c|}
\hline \multicolumn{7}{|c|}{ Table 4.11.3 Energy Calculations for Standard Baffle at 6\% Culvert Slope } \\
\hline & \multicolumn{3}{|c|}{ Testing Channel Data } & \multicolumn{2}{c|}{$\begin{array}{c}\text { Froude Number } \\
\text { Comparison }\end{array}$} & \multicolumn{3}{c|}{ Energy Calculations } \\
\hline $\begin{array}{c}\text { Flowrate } \\
\text { (gpm) }\end{array}$ & $\begin{array}{c}\text { Flow } \\
\text { Depth in } \\
\text { Channel } \\
\text { (in) }\end{array}$ & $\begin{array}{c}\text { Flow Area } \\
\text { (in) }\end{array}$ & $\begin{array}{c}\text { Velocity } \\
\text { (in/s) }\end{array}$ & $\begin{array}{c}\text { Froude } \\
\text { Number at } \\
\text { Culvert } \\
\text { Outlet }\end{array}$ & $\begin{array}{c}\text { Froude } \\
\text { Number in } \\
\text { Testing } \\
\text { Channel }\end{array}$ & $\begin{array}{c}\text { Energy at } \\
\text { Culvert } \\
\text { Outlet (in) }\end{array}$ & $\begin{array}{c}\text { Energy in } \\
\text { Testing } \\
\text { Channel } \\
\text { (in) }\end{array}$ & $\begin{array}{c}\text { Non- } \\
\text { dimensional } \\
\text { Energy } \\
\text { Difference }\end{array}$ \\
\hline 50 & 1.35 & 21.9 & 8.78 & 3.00 & 0.384 & 6.57 & 1.45 & 0.779 \\
\hline 75 & 1.52 & 24.6 & 11.7 & 3.14 & 0.485 & 8.29 & 1.70 & 0.795 \\
\hline 100 & 1.73 & 28.0 & 13.7 & 3.23 & 0.531 & 9.73 & 1.98 & 0.797 \\
\hline 125 & 1.72 & 27.9 & 17.3 & 3.25 & 0.670 & 10.8 & 2.11 & 0.804 \\
\hline 150 & 1.91 & 30.8 & 18.7 & 3.32 & 0.691 & 12.0 & 2.36 & 0.803 \\
\hline 200 & 2.16 & 35.0 & 22.0 & 3.65 & 0.762 & 15.3 & 2.79 & 0.818 \\
\hline
\end{tabular}




\begin{tabular}{|c|c|c|c|c|c|c|c|c|}
\hline \multicolumn{7}{|c|}{ Table 4.11.4 Energy Calculations for Standard Baffle at 8\% Culvert Slope } \\
\hline & \multicolumn{3}{|c|}{ Testing Channel Data } & \multicolumn{2}{c|}{$\begin{array}{c}\text { Froude Number } \\
\text { Comparison }\end{array}$} & \multicolumn{3}{|c|}{ Energy Calculations } \\
\hline $\begin{array}{c}\text { Flowrate } \\
\text { (gpm) }\end{array}$ & $\begin{array}{c}\text { Flow } \\
\text { Depth in } \\
\text { Channel } \\
\text { (in) }\end{array}$ & $\begin{array}{c}\text { Flow Area } \\
\text { (in }{ }^{2}\end{array}$ & $\begin{array}{c}\text { Velocity } \\
\text { (in/s) }\end{array}$ & $\begin{array}{c}\text { Froude } \\
\text { Number at } \\
\text { Culvert } \\
\text { Outlet }\end{array}$ & $\begin{array}{c}\text { Froude } \\
\text { Number in } \\
\text { Testing } \\
\text { Channel }\end{array}$ & $\begin{array}{c}\text { Energy at } \\
\text { Culvert } \\
\text { Outlet (in) }\end{array}$ & $\begin{array}{c}\text { Energy in } \\
\text { Testing } \\
\text { Channel } \\
\text { (in) }\end{array}$ & $\begin{array}{c}\text { Non- } \\
\text { dimensional } \\
\text { Energy } \\
\text { Difference }\end{array}$ \\
\hline 50 & 1.40 & 22.6 & 8.53 & 3.15 & 0.367 & 7.01 & 1.49 & 0.788 \\
\hline 75 & 1.62 & 26.2 & 11.0 & 3.35 & 0.440 & 9.01 & 1.78 & 0.803 \\
\hline 100 & 1.73 & 27.9 & 13.8 & 3.45 & 0.534 & 10.6 & 1.97 & 0.813 \\
\hline 125 & 1.82 & 29.4 & 16.4 & 3.48 & 0.617 & 11.8 & 2.16 & 0.816 \\
\hline 150 & 1.89 & 30.6 & 18.9 & 3.55 & 0.699 & 13.0 & 2.35 & 0.819 \\
\hline 200 & 2.11 & 34.1 & 22.6 & 3.78 & 0.790 & 16.0 & 2.77 & 0.827 \\
\hline
\end{tabular}




\subsection{Comparison to "Natural” Energy Grade Line}

In the beginning of this chapter, one criterion that needed to be met was to re-establish natural flow conditions downstream of the outlet. In order for this parameter to be examined, the headwater elevations above the invert of the culvert inlet, for the tested flowrates, were used to establish the "natural" energy grade line. The headwater elevation was taken as the location of the energy grade line above the culvert inlet and was extended parallel to the culvert, assuming uniform flow (at the respective slope setting). A representation of the physical setting for this calculation is shown in Figure 4.12.1.

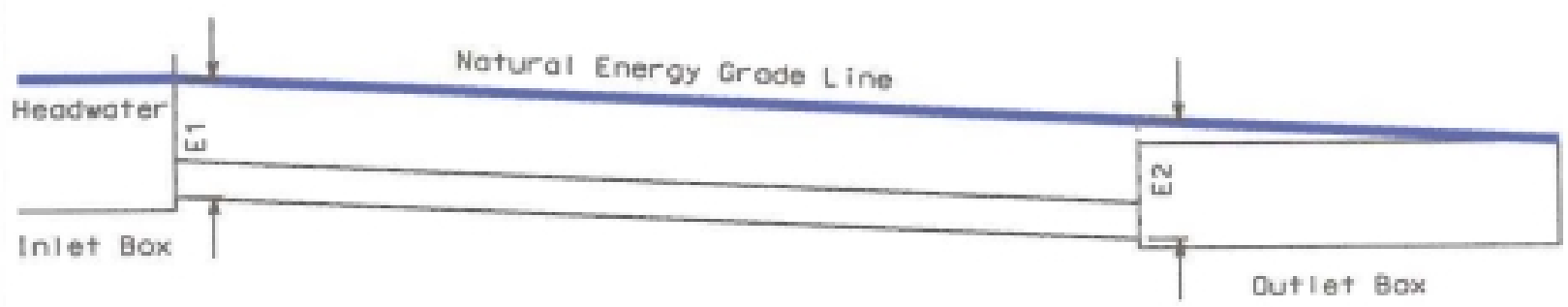

Figure 4.12.1 Energy Grade Line Establishment

Notice that the specific energy at the culvert inlet, E1, is equal to the elevation of the energy grade line at the culvert outlet, E2. Since, E1 and E2 were equal, the calculations to find the elevation of the energy grade line at a point in the testing channel would be performed from E2 for simplicity. The point selected to perform the comparison between the natural energy grade line and the total energy calculated from the three-point gage data was point $\mathrm{F}$ (refer to Chapter 3 Figure 3.9). Point $\mathrm{F}$ was selected because it was the center point on which the majority of average flow depths in the testing channel were calculated. Following the selection of the point for comparison, the elevation of the natural energy grade line was calculated based on simple trigonometry, right triangles and the Pythagorean theorem. The values for the elevation of the natural energy grade line, shown in red, were then compared to the values for total energy in the testing channel in Table 4.12.1. 


\begin{tabular}{|c|c|c|c|c|c|c|c|c|}
\hline $\begin{array}{c}\text { Flow rate } \\
\text { (gpm) }\end{array}$ & Slope \% & $\begin{array}{c}\text { "Natural" } \\
\text { Energy Grade } \\
\text { Line }\end{array}$ & $\begin{array}{c}\text { Base } \\
\text { Configuration }\end{array}$ & \begin{tabular}{|c} 
Cylinder \\
Baffle 3/4 \\
D
\end{tabular} & $\begin{array}{c}\text { Cylinder } \\
\text { Baffle 1/2 } \\
\text { D }\end{array}$ & $\begin{array}{c}\text { L-Baffle } \\
\text { 3/4 D }\end{array}$ & $\begin{array}{c}\text { L-Baffle } \\
\text { 1/2 D }\end{array}$ & $\begin{array}{c}\text { Standard } \\
\text { Baffle }\end{array}$ \\
\hline & & \multicolumn{7}{|c|}{ Total Energy in Testing Channel (in) } \\
\hline 50 & 2 & 2.72 & 1.36 & 1.34 & 1.36 & 1.47 & 1.47 & 1.57 \\
\hline 75 & 2 & 3.55 & 1.52 & 1.57 & 1.60 & 1.65 & 1.75 & 1.72 \\
\hline 100 & 2 & 4.53 & 1.76 & 1.80 & 1.84 & 1.89 & 1.91 & 2.01 \\
\hline 125 & 2 & 5.67 & 1.98 & 2.04 & 2.10 & 2.20 & 2.05 & 2.17 \\
\hline 150 & 2 & 7.01 & 2.26 & 2.29 & 2.35 & 2.42 & 2.33 & 2.34 \\
\hline 200 & 2 & 10.9 & - & 2.72 & 2.75 & 2.90 & 2.71 & 2.71 \\
\hline 50 & 4 & 2.25 & 1.19 & 1.30 & 1.35 & 1.41 & 1.44 & 1.52 \\
\hline 75 & 4 & 3.08 & 1.45 & 1.60 & 1.59 & 1.69 & 1.71 & 1.72 \\
\hline 100 & 4 & 4.06 & 1.72 & 1.80 & 1.81 & 1.92 & 1.91 & 1.93 \\
\hline 125 & 4 & 5.20 & 1.98 & 2.03 & 2.02 & 2.16 & 2.16 & 2.11 \\
\hline 150 & 4 & 6.54 & 2.27 & 2.27 & 2.30 & 2.41 & 2.30 & 2.27 \\
\hline 200 & 4 & 10.4 & - & 2.72 & 2.72 & 2.88 & 2.72 & 2.71 \\
\hline 50 & 6 & 1.78 & 1.16 & 1.26 & 1.28 & 1.44 & 1.44 & 1.45 \\
\hline 75 & 6 & 2.60 & 1.41 & 1.54 & 1.58 & 1.66 & 1.77 & 1.70 \\
\hline 100 & 6 & 3.59 & 1.70 & 1.76 & 1.82 & 1.90 & 1.93 & 1.98 \\
\hline 125 & 6 & 4.73 & 2.00 & 2.01 & 2.02 & 2.11 & 2.15 & 2.11 \\
\hline 150 & 6 & 6.07 & 2.28 & 2.26 & 2.32 & 2.45 & 2.29 & 2.36 \\
\hline 200 & 6 & 9.93 & - & 2.70 & 2.72 & 2.93 & 2.73 & 2.79 \\
\hline 50 & 8 & 1.30 & 1.12 & 1.30 & 1.28 & 1.39 & 1.51 & 1.49 \\
\hline 75 & 8 & 2.13 & 1.41 & 1.55 & 1.54 & 1.72 & 1.73 & 1.78 \\
\hline 100 & 8 & 3.12 & 1.77 & 1.77 & 1.78 & 1.91 & 1.84 & 1.97 \\
\hline 125 & 8 & 4.26 & 2.12 & 2.00 & 2.01 & 2.14 & 2.10 & 2.16 \\
\hline 150 & 8 & 5.60 & 2.60 & 2.24 & 2.26 & 2.38 & 2.32 & 2.35 \\
\hline 200 & 8 & 9.45 & - & 2.70 & 2.71 & 2.73 & 2.77 & 2.77 \\
\hline
\end{tabular}

From Table 4.12.1, one can see that the effectiveness of the baffle configurations increase with flowrate. Also, from left to right, the energy associated with selected baffle configurations tends to increase. This is misleading in that the specific energy does not represent the effect of the baffle configurations as desired. Further discussion of this analysis is presented in Chapter 5. All baffle configurations performed satisfactorily in reducing energy below natural levels, with the exception of three values that are highlighted in yellow. These instances are minor deviations at a low flow rate and are within the expected measurement error range. 


\subsubsection{Error Analysis}

Design of the testing flume was original in that it was required to meet specific unique research needs. Several modifications were made throughout the process of experimentation, therefore it was difficult to perform an error analysis. There were several reasons that made an in depth error analysis impractical. Due to the number of significant changes that occurred in design and in methods of calculation, it was difficult to follow the propagation of error to the final results. The raw depth measurements taken in the testing channel were subject to turbulence, aeration, and error on part of the researcher. These influences created the greatest source of error in the various experiments. Also, due to the time constraints of the project, establishing repeatability in depth measurements for a specific situation was not accomplished. However, trends in the data could be observed and explained.

The main measuring devices used in experiments performed with the testing flume include the following:

- Metric scales

- Headwater depth

- Piezometer depth

- Slope Adjustment

- Pitot tube readings

- Longitudinal distance along testing channel

- Digital scales

- Flowmeter

- Vernier scale

- Depth in testing channel

All of the metric scales were read to the nearest millimeter, based on the convention of best estimate. The Vernier scale was accurate to $.001 \mathrm{ft}$ and measurements were taken accordingly. Three significant figures applied for all measures of length. The flowmeter had a range of 40-450 gpm with $\pm 2.0 \%$ full-scale linearity and $\pm 1.0 \%$ full-scale repeatability. Expected values of uncertainty for several variables measured in the experiments are shown in Table 4.13.1. 


\begin{tabular}{|c|c|c|}
\hline \multicolumn{3}{|c|}{$\begin{array}{c}\text { Table 4.13.1 Expected Error for Various } \\
\text { Calculated Values }\end{array}$} \\
\hline Value & Test Culvert & $\begin{array}{c}\text { Testing } \\
\text { Channel }\end{array}$ \\
\hline Area & $3.4 \%$ & $8.4 \%$ \\
\hline Velocity & $5.4 \%$ & $10.4 \%$ \\
\hline $\begin{array}{c}\text { Froude } \\
\text { Number }\end{array}$ & $5.7 \%$ & $11.2 \%$ \\
\hline Energy & $9.0 \%$ & $21.3 \%$ \\
\hline Depth & $3.3 \%$ & $8.3 \%$ \\
\hline
\end{tabular}




\section{Chapter - 5 Results}

\subsection{Comparison of Baffle Configurations}

In order to compare the performance of each configuration, the values of nondimensional energy difference, equation 4.5.4, for each slope and discharge were compiled into a single table. Table 5.1.1 shows the summary of these data in terms of non-dimensional energy difference.

\begin{tabular}{|c|c|c|c|c|c|c|c|c|}
\hline \multicolumn{6}{|c|}{ Table 5.1.1 Comparison of Values for Non-Dimensional Energy Difference } \\
\hline $\begin{array}{c}\text { Flowrate } \\
\text { gpm }\end{array}$ & Slope \% & $\begin{array}{c}\text { Base } \\
\text { Configuration }\end{array}$ & $\begin{array}{c}\text { Cylinder } \\
\text { Baffle 3/4 } \\
\text { D }\end{array}$ & $\begin{array}{c}\text { Cylinder } \\
\text { Baffle 1/2 } \\
\text { D }\end{array}$ & $\begin{array}{c}\text { L-Baffle } \\
\text { 3/4 D }\end{array}$ & $\begin{array}{c}\text { L-Baffle } \\
1 / 2 \text { D }\end{array}$ & $\begin{array}{c}\text { Standard } \\
\text { Baffle }\end{array}$ \\
\hline & & \multicolumn{5}{|c|}{ Non-Dimensional Energy Difference } \\
\hline 50 & 2 & 0.680 & 0.683 & 0.678 & 0.652 & 0.652 & 0.628 \\
\hline 75 & 2 & 0.724 & 0.715 & 0.709 & 0.701 & 0.682 & 0.689 \\
\hline 100 & 2 & 0.731 & 0.725 & 0.719 & 0.711 & 0.708 & 0.694 \\
\hline 125 & 2 & 0.738 & 0.730 & 0.722 & 0.708 & 0.729 & 0.712 \\
\hline 150 & 2 & 0.741 & 0.738 & 0.731 & 0.723 & 0.732 & 0.731 \\
\hline 200 & 2 & - & 0.767 & 0.764 & 0.751 & 0.767 & 0.767 \\
\hline 50 & 4 & 0.774 & 0.754 & 0.742 & 0.732 & 0.727 & 0.710 \\
\hline 75 & 4 & 0.784 & 0.761 & 0.762 & 0.748 & 0.744 & 0.743 \\
\hline 100 & 4 & 0.781 & 0.770 & 0.769 & 0.755 & 0.757 & 0.755 \\
\hline 125 & 4 & 0.780 & 0.774 & 0.775 & 0.760 & 0.760 & 0.766 \\
\hline 150 & 4 & 0.777 & 0.777 & 0.773 & 0.763 & 0.774 & 0.777 \\
\hline 200 & 4 & - & 0.800 & 0.800 & 0.788 & 0.800 & 0.800 \\
\hline 50 & 6 & 0.823 & 0.809 & 0.806 & 0.781 & 0.782 & 0.779 \\
\hline 75 & 6 & 0.830 & 0.815 & 0.809 & 0.799 & 0.787 & 0.795 \\
\hline 100 & 6 & 0.825 & 0.819 & 0.813 & 0.805 & 0.802 & 0.797 \\
\hline 125 & 6 & 0.815 & 0.814 & 0.812 & 0.804 & 0.801 & 0.804 \\
\hline 150 & 6 & 0.810 & 0.812 & 0.807 & 0.795 & 0.809 & 0.803 \\
\hline 200 & 6 & - & 0.824 & 0.822 & 0.809 & 0.822 & 0.818 \\
\hline 50 & 8 & 0.840 & 0.814 & 0.817 & 0.802 & 0.785 & 0.788 \\
\hline 75 & 8 & 0.843 & 0.828 & 0.830 & 0.810 & 0.808 & 0.803 \\
\hline 100 & 8 & 0.833 & 0.832 & 0.832 & 0.819 & 0.825 & 0.813 \\
\hline 125 & 8 & 0.820 & 0.830 & 0.829 & 0.818 & 0.821 & 0.816 \\
\hline 150 & 8 & 0.801 & 0.828 & 0.826 & 0.817 & 0.822 & 0.819 \\
\hline 200 & 8 & - & 0.831 & 0.830 & 0.829 & 0.827 & 0.827 \\
\hline
\end{tabular}

Several conclusions can be drawn from the comparison of these results. For baffle-type configurations, the value for non-dimensional energy difference increases with increasing flowrate. Also, the value for non-dimensional energy difference increases with increase of slope. 
This trend seems plausible since the square of velocity at the culvert outlet increases with flowrate and slope faster than in the testing channel. Therefore the difference between the energy at the outlet and channel must increase to account for the divergence of the two velocities. Examination of the values from left to right in the table for all of the tested configurations shows a general decline in the value of non-dimensional energy loss in most cases. This can be explained by the amount of relative roughness seen by the flow. The values for average uniform flow depth are displayed in table 5.1.2. The first value for the test culvert was obtained from Section 4.3 and is the depth at the outlet. The depths for each configuration are the average depths, established in the testing channel over the stone bed. Notice the increase in depth from left to right. This indicates that as the flow depth in the testing channel increases, less energy, proportionally, is dissipated from the roughness of the downstream channel bed, as compared to the baffle. The rip-rap downstream of the culvert apron is most effective in energy dissipation when the depth is shallow and the velocity high. Since a depth increase in the testing channel means a lower velocity downstream, and more energy dissipation, proportionally by the baffle, it follows that the effectiveness of the tested dissipators can be ordered based on downstream velocity. Then it can be stated that from left to right, in Tables 5.1.1 and 5.1.2, the base configuration produces the least effect of velocity reduction and the standard baffle the greatest. The performance judgements therefore, cannot be based solely on the basis of non-dimensional energy difference. The effect of the downstream rock bed plays a large role in energy attenuation in the laboratory model. In the field however, the downstream rock would not be held in place rigidly and supporting bed material could be eroded away under high velocity flows.

Given the above discussion, it is clear that two measures of performance are required to support a decision as to which dissipator performs best. The non-dimensional energy difference, equation 4.5.4, is the first measure. A second measure is provided by the following ratio computed in the testing channel:

$$
\frac{y}{\left|\frac{V^{2}}{2 g}\right|}
$$


Where:

$$
\begin{aligned}
& y=\text { depth } \\
& V=\text { velocity } \\
& g=\text { gravitational acceleration }
\end{aligned}
$$

Erosive energy is minimized when the baffle produces greater depth and lower velocities in the testing channel. This is apparent in the comparison between velocity head at the culvert outlet and in the testing channel for each configuration shown in Table 5.1.3 Therefore, performance is maximized when both the energy difference and this latter ratio are both maximized. The depth to velocity head ratiois computed for each run and is presented in table 5.1.4. To summarize the

\begin{tabular}{|c|c|c|c|c|c|c|c|c|}
\hline $\begin{array}{c}\text { Flow rate } \\
\text { (gpm) }\end{array}$ & Slope \% & $\begin{array}{l}\text { Test Culvert } \\
\text { Outlet }\end{array}$ & $\begin{array}{c}\text { Base } \\
\text { Configuration }\end{array}$ & $\begin{array}{l}\text { Cylinder } \\
\text { Baffle 3/4 } \\
\text { D }\end{array}$ & $\begin{array}{c}\text { Cylinder } \\
\text { Baffle 1/2 } \\
\text { D }\end{array}$ & $\begin{array}{l}\text { L-Baffle } \\
\text { 3/4 D }\end{array}$ & $\begin{array}{c}\text { L-Baffle } \\
1 / 2 D\end{array}$ & $\begin{array}{l}\text { Standard } \\
\text { Baffle }\end{array}$ \\
\hline & & \multicolumn{7}{|c|}{ Uniform Flow Depth (in) } \\
\hline 50 & 2 & 1.41 & 1.24 & 1.22 & 1.24 & 1.37 & 1.37 & 1.49 \\
\hline 75 & 2 & 1.71 & 1.26 & 1.34 & 1.39 & 1.45 & 1.59 & 1.54 \\
\hline 100 & 2 & 1.98 & 1.38 & 1.46 & 1.52 & 1.61 & 1.64 & 1.77 \\
\hline 125 & 2 & 2.22 & 1.36 & 1.58 & 1.70 & 1.88 & 1.60 & 1.83 \\
\hline 150 & 2 & 2.40 & 1.35 & 1.75 & 1.88 & 2.01 & 1.86 & 1.87 \\
\hline 200 & 2 & 2.63 & - & 1.92 & 2.04 & 2.38 & 1.73 & 1.90 \\
\hline 50 & 4 & 1.24 & 1.01 & 1.16 & 1.23 & 1.30 & 1.34 & 1.43 \\
\hline 75 & 4 & 1.52 & 1.11 & 1.39 & 1.38 & 1.51 & 1.54 & 1.55 \\
\hline 100 & 4 & 1.78 & 1.24 & 1.46 & 1.47 & 1.65 & 1.64 & 1.66 \\
\hline 125 & 4 & 1.99 & 1.28 & 1.57 & 1.55 & 1.81 & 1.81 & 1.72 \\
\hline 150 & 4 & 2.19 & 1.32 & 1.69 & 1.79 & 1.99 & 1.77 & 1.71 \\
\hline 200 & 4 & 2.41 & - & 1.93 & 1.92 & 2.34 & 1.69 & 1.92 \\
\hline 50 & 6 & 1.11 & 0.97 & 1.11 & 1.13 & 1.34 & 1.33 & 1.35 \\
\hline 75 & 6 & 1.37 & 0.97 & 1.29 & 1.36 & 1.47 & 1.61 & 1.52 \\
\hline 100 & 6 & 1.59 & 1.11 & 1.37 & 1.48 & 1.62 & 1.67 & 1.73 \\
\hline 125 & 6 & 1.82 & 1.20 & 1.49 & 1.55 & 1.72 & 1.79 & 1.72 \\
\hline 150 & 6 & 2.00 & 1.30 & 1.65 & 1.82 & 2.07 & 1.76 & 1.91 \\
\hline 200 & 6 & 2.26 & - & 1.80 & 1.96 & 2.43 & 1.65 & 2.16 \\
\hline 50 & 8 & 1.08 & 0.89 & 1.17 & 1.14 & 1.28 & 1.42 & 1.40 \\
\hline 75 & 8 & 1.32 & 1.01 & 1.31 & 1.29 & 1.54 & 1.56 & 1.62 \\
\hline 100 & 8 & 1.53 & 0.94 & 1.40 & 1.40 & 1.64 & 1.53 & 1.73 \\
\hline 125 & 8 & 1.74 & 1.02 & 1.46 & 1.49 & 1.78 & 1.71 & 1.82 \\
\hline 150 & 8 & 1.92 & 1.02 & 1.58 & 1.67 & 1.94 & 1.82 & 1.89 \\
\hline 200 & 8 & 2.21 & - & 1.79 & 1.72 & 1.98 & 2.10 & 2.11 \\
\hline
\end{tabular}
relative performance of each design graphically, the measures are plotted against one another in Figure 5.1.1. 


\begin{tabular}{|c|c|c|c|c|c|c|c|c|}
\hline $\begin{array}{c}\text { Flow rate } \\
\text { (gpm) }\end{array}$ & Slope \% & $\begin{array}{c}\text { Velocity Head } \\
\text { at Culvert } \\
\text { Outlet }\end{array}$ & $\begin{array}{c}\text { Base } \\
\text { Configuration }\end{array}$ & $\begin{array}{c}\text { Cylinder } \\
\text { Baffle 3/4 } \\
\text { D }\end{array}$ & $\begin{array}{l}\text { Cylinder } \\
\text { Baffle 1/2 } \\
\text { D }\end{array}$ & $\begin{array}{c}\text { L-Baffle } \\
\text { 3/4 D }\end{array}$ & $\begin{array}{c}\text { L-Baffle } \\
\text { 1/2 D }\end{array}$ & $\begin{array}{l}\text { Standard } \\
\text { Baffle }\end{array}$ \\
\hline & & \multicolumn{7}{|c|}{ Velocity Head (in) } \\
\hline 50 & 2 & 2.82 & 0.12 & 0.12 & 0.12 & 0.10 & 0.10 & 0.08 \\
\hline 75 & 2 & 3.81 & 0.26 & 0.23 & 0.21 & 0.20 & 0.16 & 0.17 \\
\hline 100 & 2 & 4.57 & 0.39 & 0.35 & 0.32 & 0.28 & 0.27 & 0.23 \\
\hline 125 & 2 & 5.33 & 0.62 & 0.46 & 0.39 & 0.32 & 0.45 & 0.34 \\
\hline 150 & 2 & 6.32 & 0.91 & 0.54 & 0.47 & 0.41 & 0.48 & 0.47 \\
\hline 200 & 2 & 9.02 & - & 0.79 & 0.70 & 0.52 & 0.98 & 0.81 \\
\hline 50 & 4 & 4.02 & 0.18 & 0.14 & 0.12 & 0.11 & 0.10 & 0.09 \\
\hline 75 & 4 & 5.19 & 0.33 & 0.21 & 0.22 & 0.18 & 0.17 & 0.17 \\
\hline 100 & 4 & 6.08 & 0.48 & 0.34 & 0.34 & 0.27 & 0.27 & 0.27 \\
\hline 125 & 4 & 7.01 & 0.70 & 0.47 & 0.48 & 0.35 & 0.35 & 0.39 \\
\hline 150 & 4 & 7.99 & 0.95 & 0.58 & 0.51 & 0.42 & 0.52 & 0.56 \\
\hline 200 & 4 & 11.16 & - & 0.79 & 0.79 & 0.53 & 1.02 & 0.79 \\
\hline 50 & 6 & 5.47 & 0.20 & 0.15 & 0.14 & 0.10 & 0.10 & 0.10 \\
\hline 75 & 6 & 6.93 & 0.44 & 0.25 & 0.22 & 0.19 & 0.16 & 0.18 \\
\hline 100 & 6 & 8.14 & 0.59 & 0.39 & 0.33 & 0.28 & 0.26 & 0.24 \\
\hline 125 & 6 & 8.96 & 0.80 & 0.52 & 0.48 & 0.39 & 0.36 & 0.39 \\
\hline 150 & 6 & 9.99 & 0.98 & 0.61 & 0.50 & 0.39 & 0.53 & 0.45 \\
\hline 200 & 6 & 13.08 & - & 0.90 & 0.76 & 0.50 & 1.08 & 0.63 \\
\hline 50 & 8 & 5.94 & 0.23 & 0.13 & 0.14 & 0.11 & 0.09 & 0.09 \\
\hline 75 & 8 & 7.70 & 0.41 & 0.24 & 0.25 & 0.17 & 0.17 & 0.16 \\
\hline 100 & 8 & 9.04 & 0.82 & 0.38 & 0.37 & 0.27 & 0.31 & 0.25 \\
\hline 125 & 8 & 10.03 & 1.09 & 0.54 & 0.51 & 0.36 & 0.39 & 0.35 \\
\hline 150 & 8 & 11.12 & 1.57 & 0.66 & 0.59 & 0.44 & 0.50 & 0.46 \\
\hline 200 & 8 & 13.78 & - & 0.92 & 0.99 & 0.75 & 0.66 & 0.66 \\
\hline
\end{tabular}




\begin{tabular}{|c|c|c|c|c|c|c|c|}
\hline \multicolumn{8}{|c|}{ Table 5.1.4 Depth to velocity head ratio } \\
$\begin{array}{c}\text { Flow rate } \\
\text { (gpm) }\end{array}$ & Slope \% & $\begin{array}{c}\text { Base } \\
\text { Configuration }\end{array}$ & $\begin{array}{c}\text { Cylinder } \\
\text { Baffle 3/4 } \\
\text { D }\end{array}$ & $\begin{array}{c}\text { Cylinder } \\
\text { Baffle 1/2 D }\end{array}$ & $\begin{array}{c}\text { L-Baffle } \\
3 / 4 ~ D\end{array}$ & $\begin{array}{c}\text { L-Baffle } \\
1 / 2 \text { D }\end{array}$ & $\begin{array}{c}\text { Standard } \\
\text { Baffle }\end{array}$ \\
\hline & \multicolumn{7}{|c|}{ Depth to Velocity Head Ratio } \\
\hline 50 & 2 & 10.31 & 9.83 & 10.50 & 14.16 & 14.16 & 18.06 \\
\hline 75 & 2 & 4.89 & 5.81 & 6.52 & 7.43 & 9.76 & 8.90 \\
\hline 100 & 2 & 3.56 & 4.22 & 4.80 & 5.64 & 6.03 & 7.60 \\
\hline 125 & 2 & 2.21 & 3.42 & 4.32 & 5.81 & 3.59 & 5.35 \\
\hline 150 & 2 & 1.48 & 3.23 & 4.02 & 4.90 & 3.89 & 3.99 \\
\hline 200 & 2 & - & 2.43 & 2.91 & 4.59 & 1.76 & 2.35 \\
\hline 50 & 4 & 5.59 & 8.51 & 10.26 & 12.05 & 12.99 & 16.10 \\
\hline 75 & 4 & 3.34 & 6.50 & 6.32 & 8.29 & 8.85 & 9.11 \\
\hline 100 & 4 & 2.58 & 4.24 & 4.35 & 6.17 & 5.97 & 6.23 \\
\hline 125 & 4 & 1.83 & 3.36 & 3.23 & 5.17 & 5.20 & 4.43 \\
\hline 150 & 4 & 1.38 & 2.91 & 3.48 & 4.77 & 3.38 & 3.03 \\
\hline 200 & 4 & - & 2.44 & 2.43 & 4.39 & 1.65 & 2.42 \\
\hline 50 & 6 & 4.95 & 7.38 & 7.96 & 13.08 & 12.90 & 13.57 \\
\hline 75 & 6 & 2.21 & 5.17 & 6.09 & 7.76 & 10.15 & 8.51 \\
\hline 100 & 6 & 1.88 & 3.52 & 4.46 & 5.80 & 6.30 & 7.08 \\
\hline 125 & 6 & 1.49 & 2.89 & 3.22 & 4.46 & 5.02 & 4.46 \\
\hline 150 & 6 & 1.32 & 2.72 & 3.64 & 5.36 & 3.30 & 4.19 \\
\hline 200 & 6 & - & 1.99 & 2.59 & 4.90 & 1.53 & 3.45 \\
\hline 50 & 8 & 3.82 & 8.71 & 8.09 & 11.40 & 15.50 & 14.82 \\
\hline 75 & 8 & 2.47 & 5.49 & 5.17 & 8.90 & 9.16 & 10.32 \\
\hline 100 & 8 & 1.15 & 3.72 & 3.78 & 5.97 & 4.89 & 7.01 \\
\hline 125 & 8 & 0.94 & 2.71 & 2.91 & 4.94 & 4.37 & 5.25 \\
\hline 150 & 8 & 0.65 & 2.40 & 2.85 & 4.44 & 3.68 & 4.10 \\
\hline 200 & 8 & - & 1.96 & 1.74 & 2.66 & 3.17 & 3.20 \\
\hline
\end{tabular}

In Figure 5.1.1 the average of Non-dimensional energy difference and depth to velocity head ratio are averaged for each slope. This was done to allow for easier interpretation of the plot. Both L-baffle configurations perform the closest to the standard baffle upon inspection of the above mentioned parameters. Since the difference between the $3 / 4$ and $1 / 2$ L-baffle configurations is not dramatic the $1 / 2 \mathrm{D}$ L-baffle was selected as the material needed for its construction would be less. 


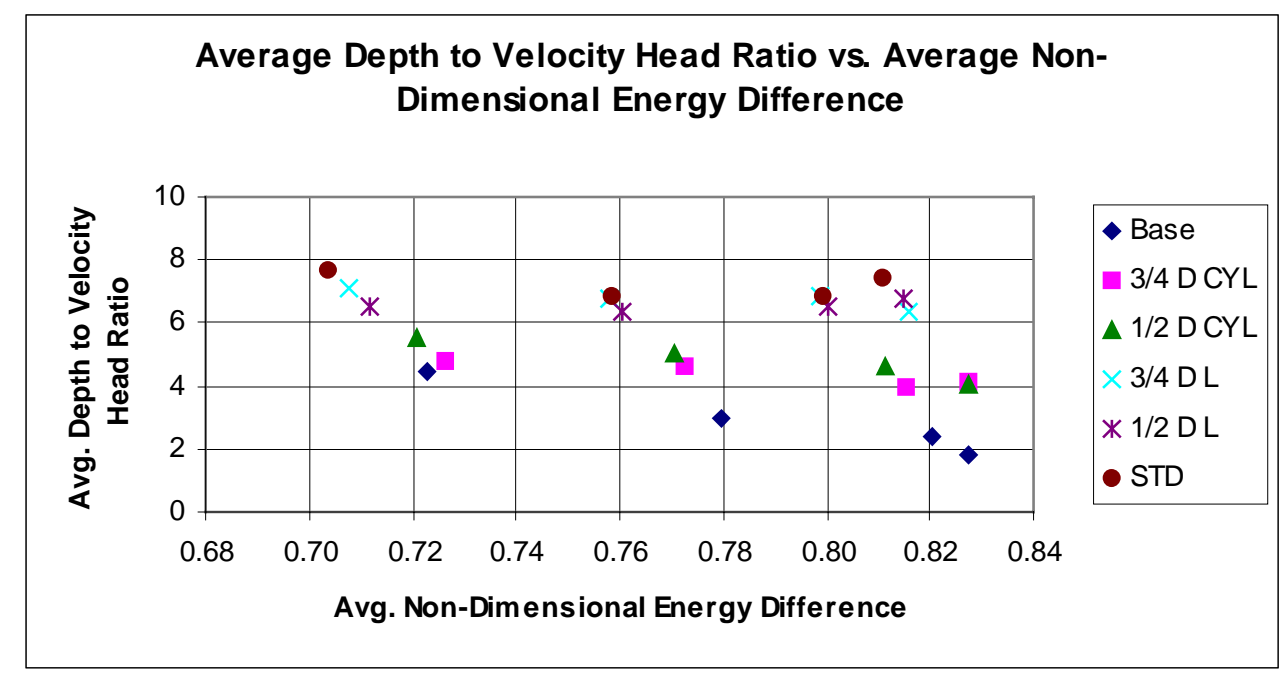

Figure 5.1.1 Average Depth to Velocity Head Ratio vs. Average Non-Dimensional Energy Difference 


\subsection{Froude Number and Non-Dimensional Energy Difference}

Graphical representations of hydraulic performance measurements were desired to produce further understanding of the test results obtained. The plots were made non-dimensional to provide the best comparative presentation of the experiments performed. It was decided to plot Froude number versus non-dimensional energy difference. At first the plots seemed inconclusive but once the data was separated by slope several interesting conclusions could be made. For the following discussion refer to the Figures listed below:

- Figure 5.2.1 Base Configuration Froude Number at Culvert Outlet vs. Nondimensional Energy Difference

- Figure 5.2.2 3/4 D Cylinder Configuration Froude Number at Culvert Outlet vs. Nondimensional Energy Difference

- Figure 5.2.3 1/2 D Cylinder Configuration Froude Number at Culvert Outlet vs. Nondimensional Energy Difference

- Figure 5.2.4 3/4 D L-baffle Configuration Froude Number at Culvert Outlet vs. Nondimensional Energy Difference

- Figure 5.2.5 1/2 D L-baffle Configuration Froude Number at Culvert Outlet vs. Nondimensional Energy Difference

- Figure 5.2.6 Standard Baffle Configuration Froude Number at Culvert Outlet vs. Non-dimensional Energy Difference

In Figure 5.2.1 four well-defined arcs are formed. For the base configuration the flow spreads out across the apron and flows into the channel with no influence of baffles. Then the only parameter that could cause the obvious separation of data is the slope. The several changes of direction from the outlet of the culvert to the apron floor help reduce the amount of energy in the flow. This energy attenuation is caused by the introduction of turbulence into the flow. The angle formed by the slope of the culvert meeting the apron floor can provide a means of introducing turbulence and serves to help expand the flow. Then the introduction of baffles into the flow path will dramatically disturb the flow further to the extent that the effect of impact angle of the culvert and apron floor should no longer be apparent. This phenomenon would be apparent if the test culvert slope could no longer be a means of separating the data for the different trials.

In Figures 5.2.2 and 5.2.3 the data is not nearly as easy to separate as compared to the base configuration, as the trend of Froude number vs. non-dimensional energy difference becomes similar. The cylinder configurations are therefore beginning to introduce more 
turbulence into the flow and in turn reduce the amount of energy present. It is difficult to discern which configuration is adding more turbulence to the flow from Figures 5.2.2 and 5.2.3. Looking back at the data from Tables 5.1.1 and 5.2.2. indicated that the $1 / 2 \mathrm{D}$ Cylinder baffle performed better. The performance of the $1 / 2 \mathrm{D}$ cylinder baffle was due to its height. Recall that at some flows the cylinders were submerged, which added more roughness to the flow path, outperforming the $3 / 4 \mathrm{D}$ cylinders.

Examination of the L-baffles indicated that indeed more turbulence was added to the flow as the data become even more difficult to separate based on slope. The performance of the Lbaffles was easier to evaluate than the cylinder baffles. As seen in Figure 5.2.5 the data lies along a smooth arc but in Figure 5.2.4 the data is more separated. In conjunction with Tables 5.1.1 and 5.1.2, it becomes apparent that the $1 / 2 \mathrm{D}$ L-baffle performance was more desirable than the $3 / 4$ D. Again the shorter height aided in reducing the velocity of the flow by adding roughness and by increasing pressure on the lip of the L-baffle.

Finally in Figure 5.2.6 the impact angle cannot be readily noticed. Then the addition of the various baffles has greatly decreased the amount of energy present in the flow. Due to problems in the field the standard baffle was no longer a design option, but proved an excellent model to investigate for comparison purposes.

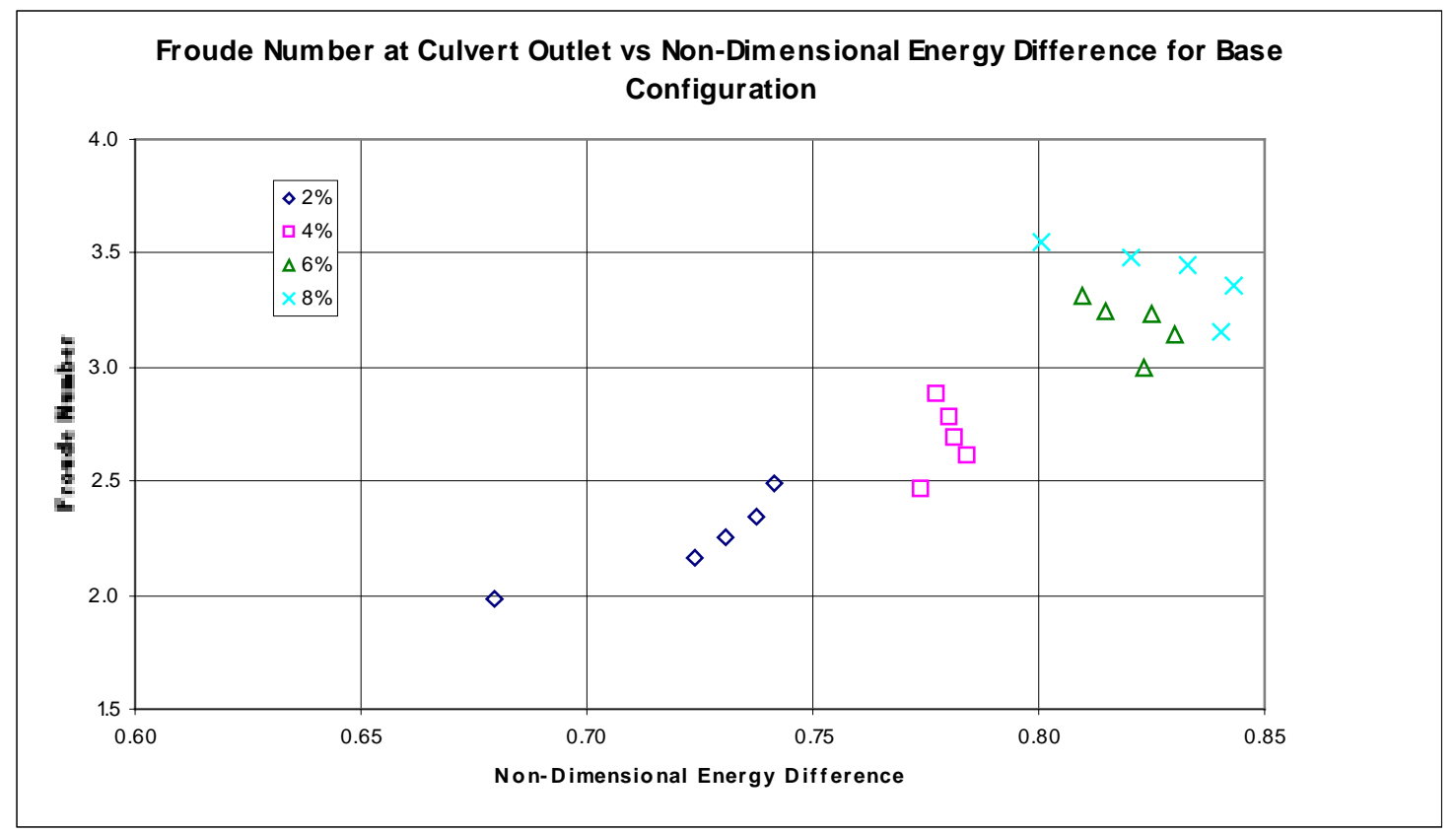

Figure 5.2.1 Base Configuration Froude Number at Culvert Outlet vs. Non-dimensional Energy Difference 


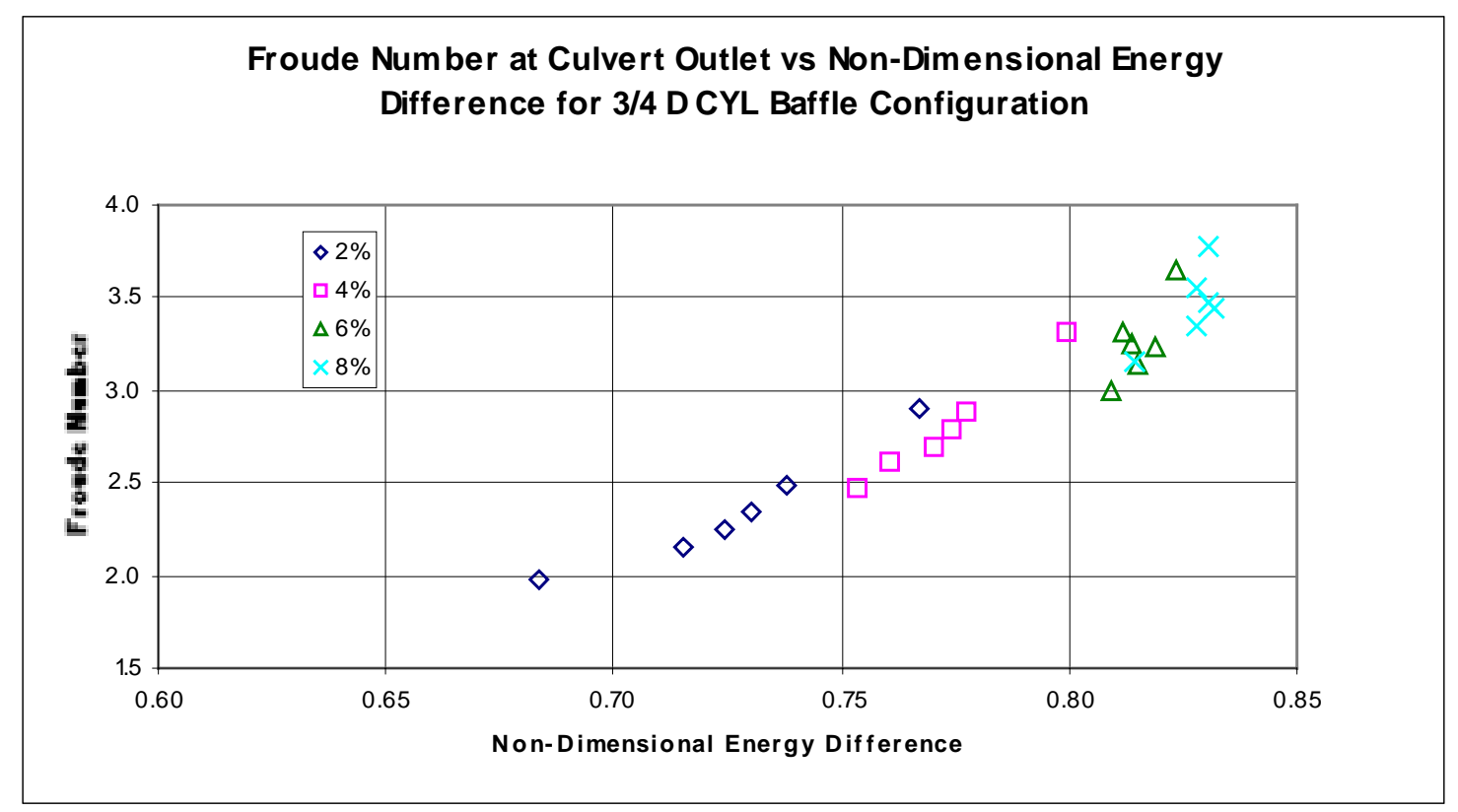

Figure 5.2.2 3/4 D Cylinder Configuration Froude Number at Culvert Outlet vs. Nondimensional Energy Difference

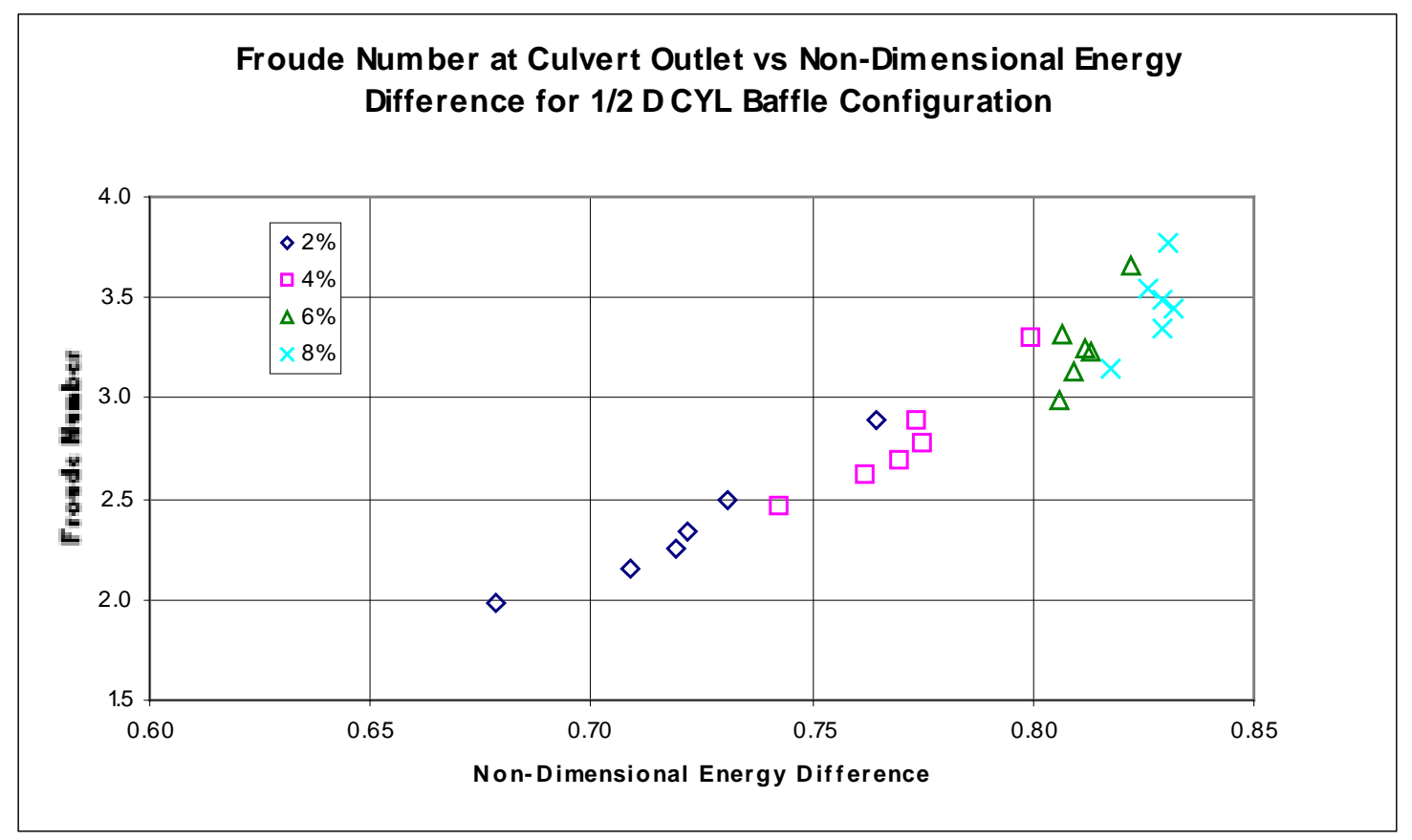

Figure 5.2.3 1⁄2 D Cylinder Configuration Froude Number at Culvert Outlet vs. Nondimensional Energy Difference 


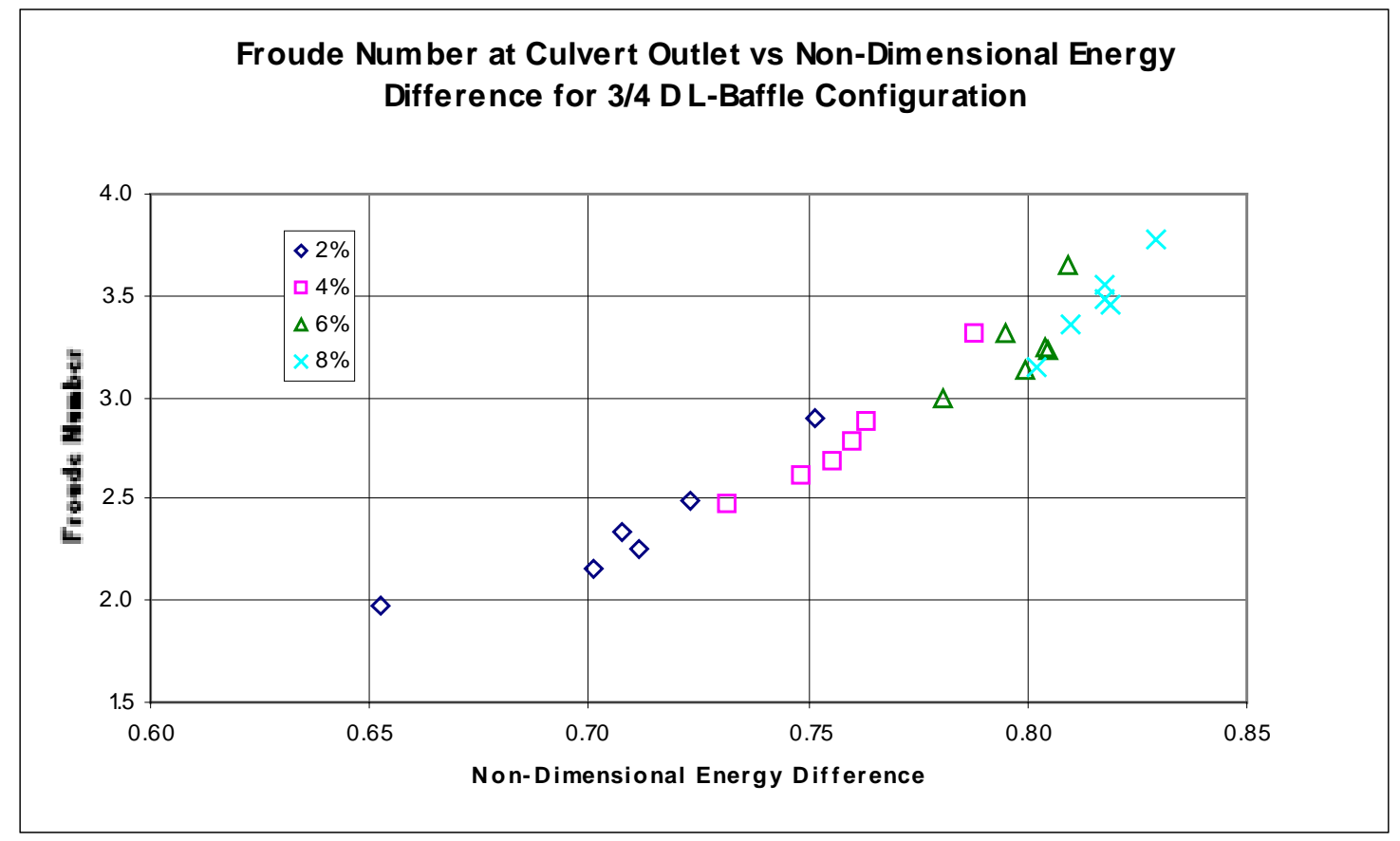

Figure 5.2.4 3/4 D L-baffle Configuration Froude Number at Culvert Outlet vs. Nondimensional Energy Difference

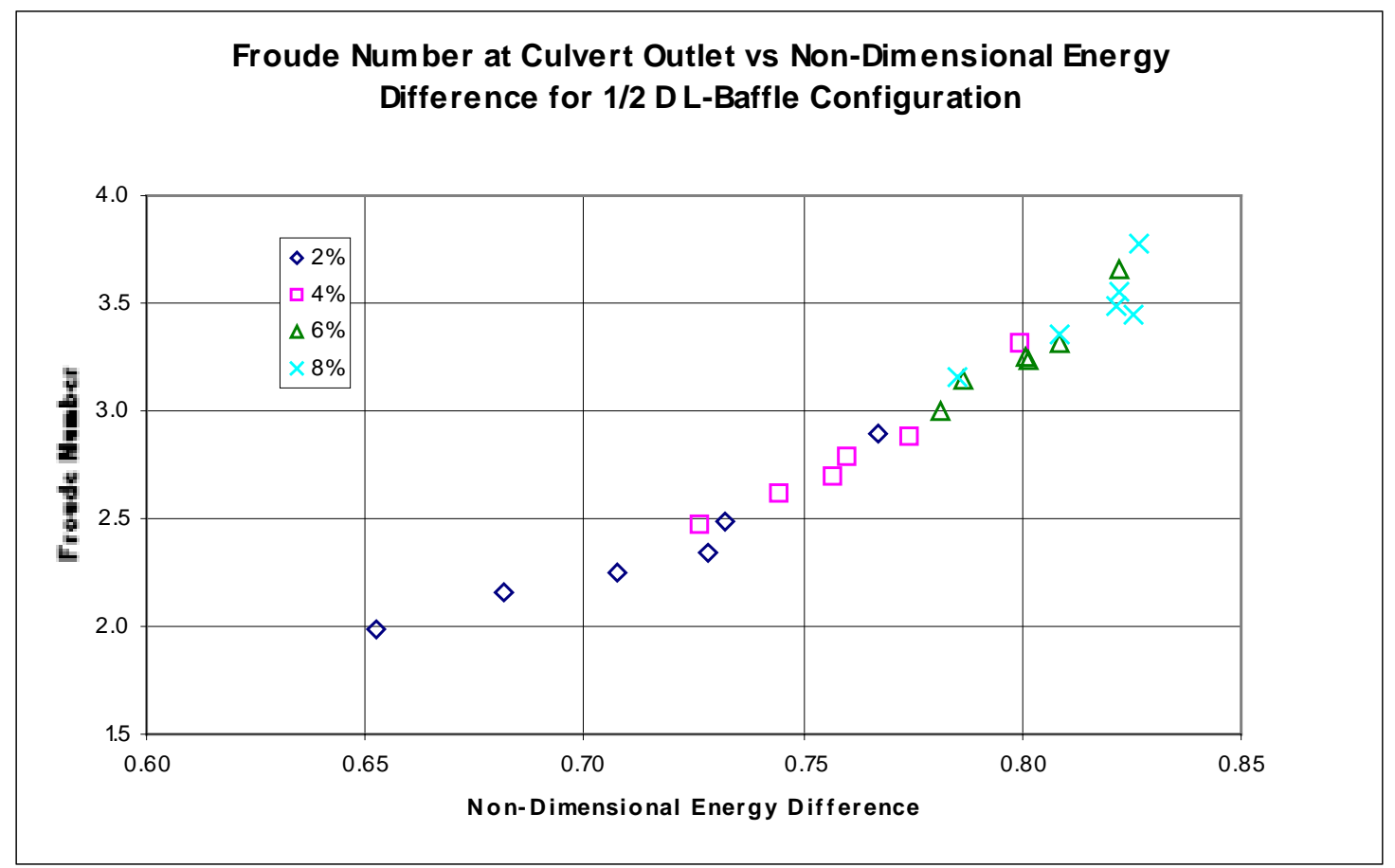

Figure 5.2.5 1/2 D L-baffle Configuration Froude Number at Culvert Outlet vs. Nondimensional Energy Difference 


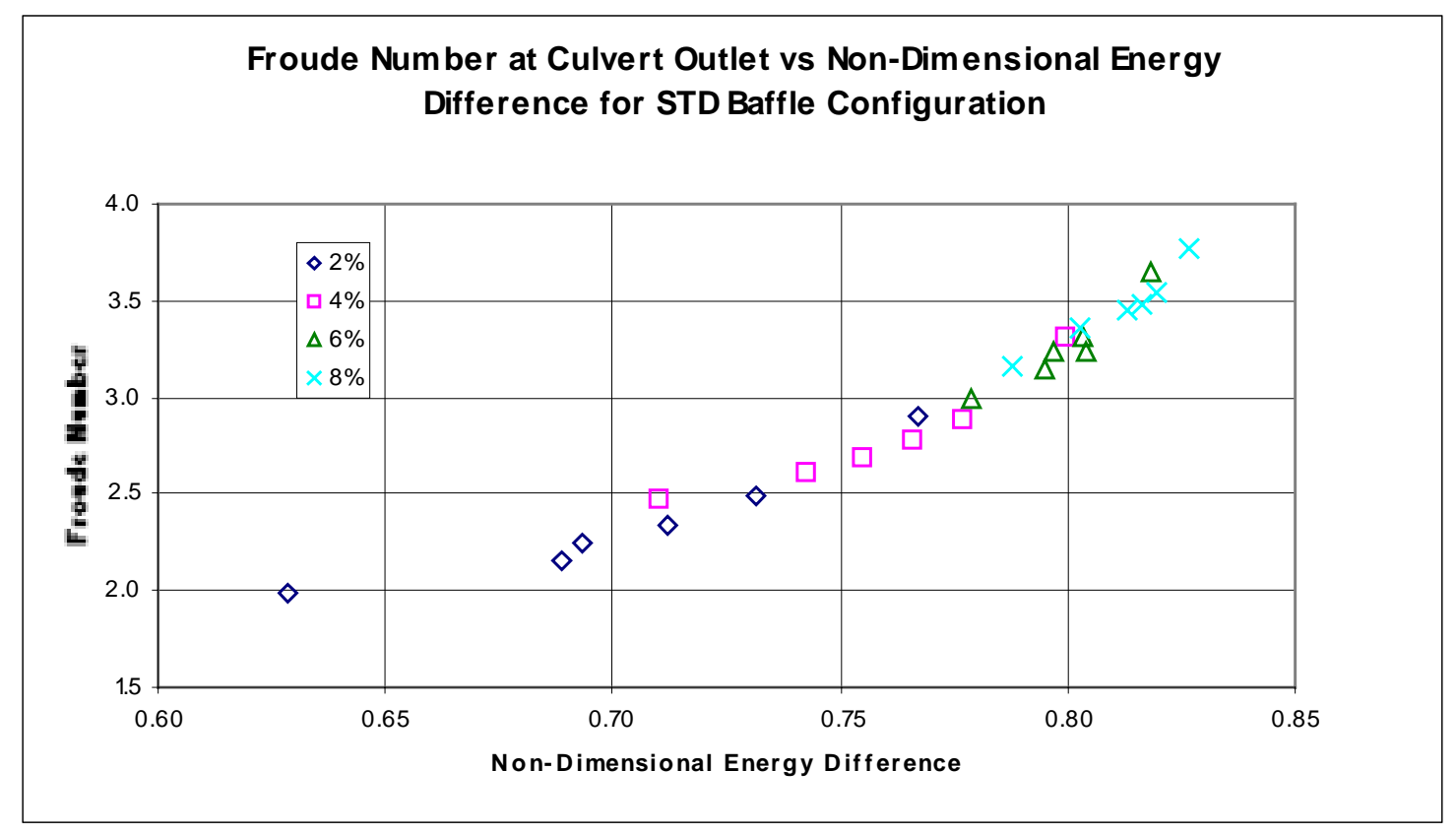

Figure 5.2.6 Standard Baffle Configuration Froude Number at Culvert Outlet vs. Nondimensional Energy Difference 


\subsection{Energy Dissipation Performance Parameter}

The next conclusion drawn from the experimental data in evaluation of the various baffle configurations was the deviation from the natural energy grade line, established in Section 4.12. It was decided to present the data in graphical and tabular form in order to draw conclusions about the performance of each baffle configuration. The difference between the elevation of the natural energy grade line and the total energy, calculated in the testing channel, was nondimensionalized and termed the energy dissipation performance parameter, (EDPP). The value used to create the non-dimensional parameter was the amount the natural energy grade line deviated from the horizontal at the center point of the testing channel, shown as E3 in Figure 5.3.1. The values for E3 are shown for each culvert slope in Table 5.3.1.

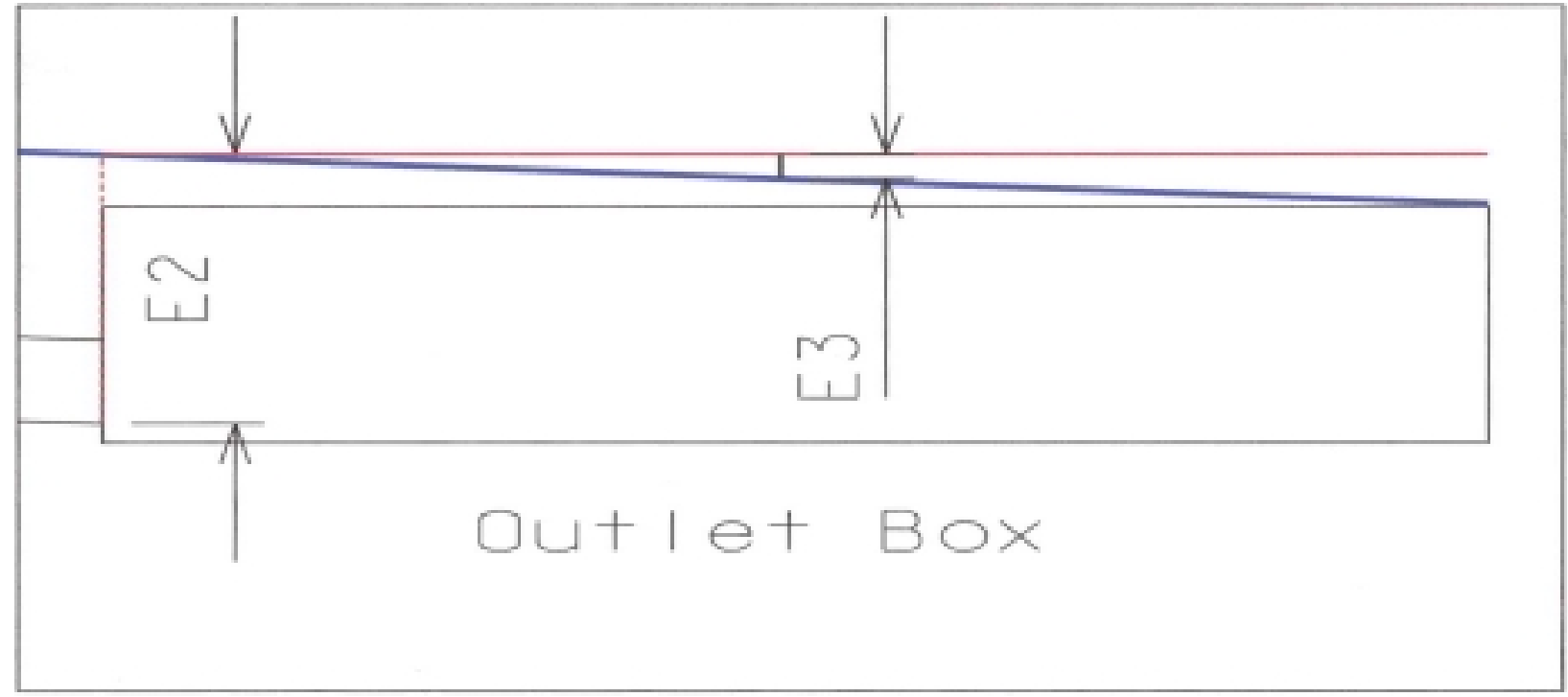

Figure 5.3.1 Location of E3, Value for Establishing the Energy Dissipation Performance Parameter

\begin{tabular}{|c|c|}
\hline \multicolumn{2}{|c|}{$\begin{array}{c}\text { Table 5.3.1 Values for E3 } \\
\text { at Given Culvert Slopes }\end{array}$} \\
\hline Slope \% & E3 (in) \\
\hline 2 & 0.470 \\
\hline 4 & 0.941 \\
\hline 6 & 1.41 \\
\hline 8 & 1.88 \\
\hline
\end{tabular}

The following expression was used to determine the values for the energy dissipation performance parameter. 
$E D P P=\frac{E 2-E_{F}}{E 3}$

Where:

$E D P P=$ Energy Dissipation Performance Parameter

$E 2$ = Elevation of the natural energy grade line at the culvert outlet

$E_{F}=$ Total energy calculated from the three-point gage at Point $\mathrm{F}$

$E 3=$ Drop in the natural energy grade line from the outlet to the testing channel

The values for the energy dissipation performance parameter were then organized for comparison, shown in Table 5.3.2. In Table 5.3.2, positive values, $\left(\mathrm{E} 2>\mathrm{E}_{\mathrm{F}}\right)$, indicate that the energy in the flow has been decreased below the natural energy grade line assumption established at the culvert outlet. Negative values indicate no effect in decreasing the energy of the flow.

\begin{tabular}{|c|c|c|c|c|c|c|c|}
\hline $\begin{array}{c}\text { Flow rate } \\
\text { (gpm) }\end{array}$ & Slope \% & $\begin{array}{c}\text { Base } \\
\text { Configuration }\end{array}$ & $\begin{array}{c}\text { Cylinder } \\
\text { Baffle 3/4 } \\
\text { D }\end{array}$ & $\begin{array}{c}\text { Cylinder } \\
\text { Baffle 1/2 } \\
\text { D }\end{array}$ & $\begin{array}{c}\text { L-Baffle } \\
\text { 3/4 D }\end{array}$ & $\begin{array}{c}\text { L-Baffle } \\
\text { 1/2 D }\end{array}$ & $\begin{array}{l}\text { Standard } \\
\text { Baffle }\end{array}$ \\
\hline & & \multicolumn{6}{|c|}{ Energy Difference Performance Parameter } \\
\hline 50 & 2 & 2.90 & 2.93 & 2.89 & 2.65 & 2.65 & 2.44 \\
\hline 75 & 2 & 4.31 & 4.21 & 4.13 & 4.04 & 3.81 & 3.89 \\
\hline 100 & 2 & 5.89 & 5.80 & 5.73 & 5.62 & 5.57 & 5.37 \\
\hline 125 & 2 & 7.86 & 7.73 & 7.60 & 7.38 & 7.71 & 7.45 \\
\hline 150 & 2 & 10.1 & 10.0 & 9.92 & 9.77 & 9.95 & 9.93 \\
\hline 200 & 2 & - & 17.3 & 17.3 & 17.0 & 17.4 & 17.4 \\
\hline 50 & 4 & 1.13 & 1.01 & 0.95 & 0.89 & 0.86 & 0.77 \\
\hline 75 & 4 & 1.73 & 1.57 & 1.58 & 1.48 & 1.45 & 1.44 \\
\hline 100 & 4 & 2.49 & 2.40 & 2.39 & 2.27 & 2.29 & 2.27 \\
\hline 125 & 4 & 3.43 & 3.37 & 3.38 & 3.23 & 3.23 & 3.29 \\
\hline 150 & 4 & 4.54 & 4.54 & 4.50 & 4.40 & 4.51 & 4.54 \\
\hline 200 & 4 & - & 8.17 & 8.17 & 8.00 & 8.17 & 8.17 \\
\hline 50 & 6 & 0.43 & 0.37 & 0.35 & 0.24 & 0.24 & 0.23 \\
\hline 75 & 6 & 0.85 & 0.76 & 0.72 & 0.67 & 0.59 & 0.64 \\
\hline 100 & 6 & 1.33 & 1.29 & 1.26 & 1.20 & 1.18 & 1.14 \\
\hline 125 & 6 & 1.94 & 1.93 & 1.92 & 1.86 & 1.83 & 1.86 \\
\hline 150 & 6 & 2.69 & 2.70 & 2.66 & 2.56 & 2.68 & 2.63 \\
\hline 200 & 6 & - & 5.12 & 5.10 & 4.96 & 5.10 & 5.06 \\
\hline 50 & 8 & 0.10 & 0.00 & 0.01 & -0.05 & -0.11 & -0.10 \\
\hline 75 & 8 & 0.38 & 0.31 & 0.32 & 0.22 & 0.21 & 0.19 \\
\hline 100 & 8 & 0.72 & 0.71 & 0.71 & 0.64 & 0.68 & 0.61 \\
\hline 125 & 8 & 1.14 & 1.20 & 1.19 & 1.12 & 1.14 & 1.11 \\
\hline 150 & 8 & 1.59 & 1.78 & 1.77 & 1.71 & 1.74 & 1.72 \\
\hline 200 & 8 & - & 3.58 & 3.58 & 3.57 & 3.55 & 3.55 \\
\hline
\end{tabular}


Values of EDPP between 0 and 1 indicate performance is positive but less than desired. A value of 1 or greater indicates performance is sufficient to return the energy in the flow to that assumed under natural conditions, or to reduce it to lower levels than under natural conditions. Plots of the energy dissipation performance parameter were then made for each baffle configuration, shown in Figures 5.3.2 through 5.3.7. Each plot shows the energy dissipation performance parameter vs. flowrate. These plots are very similar, but examination of Table 5.3.2 displays the differences between each data series. The plots were generated to display the trends similar to each configuration. The effectiveness of all the baffle configurations increased with flowrate and decreases with slope.

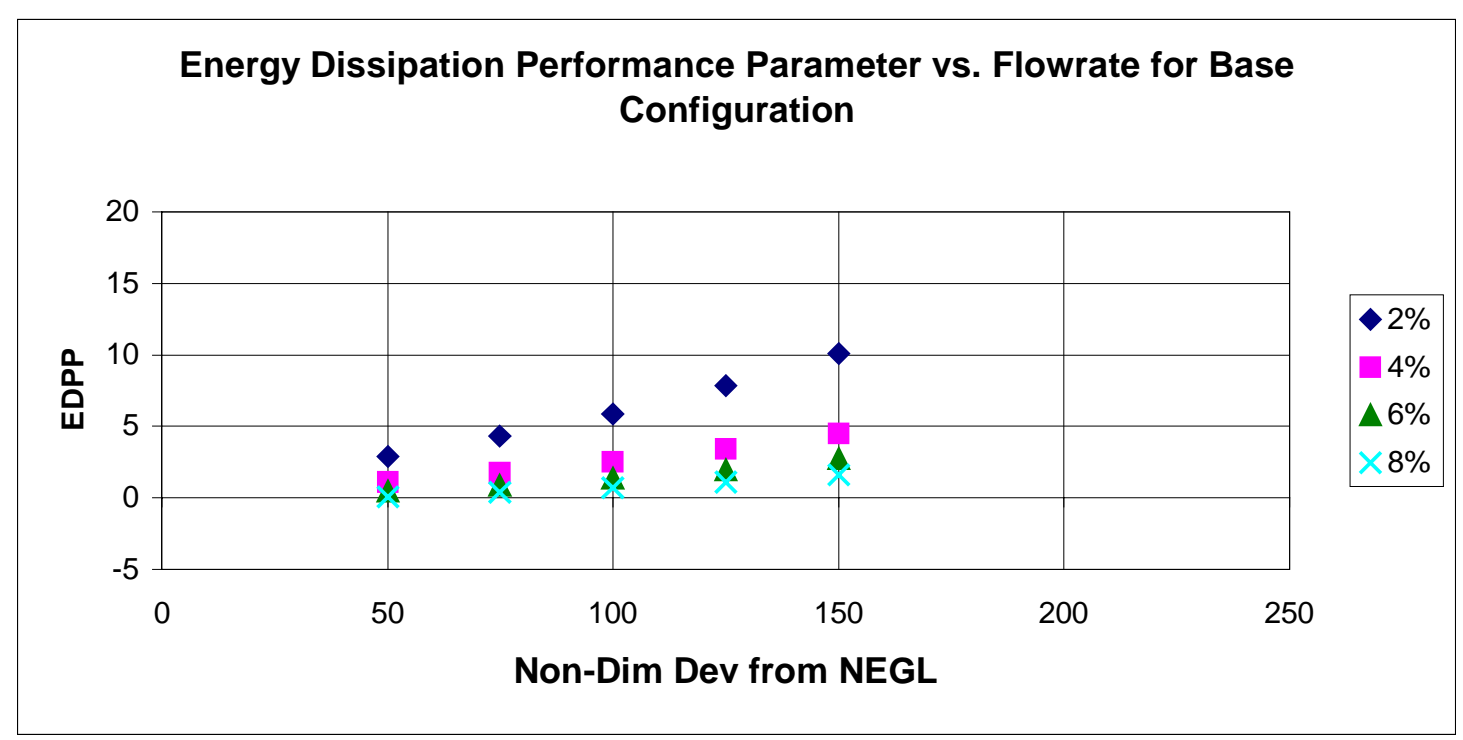

Figure 5.3.2 EDPP vs. Flowrate for Base Configuration 


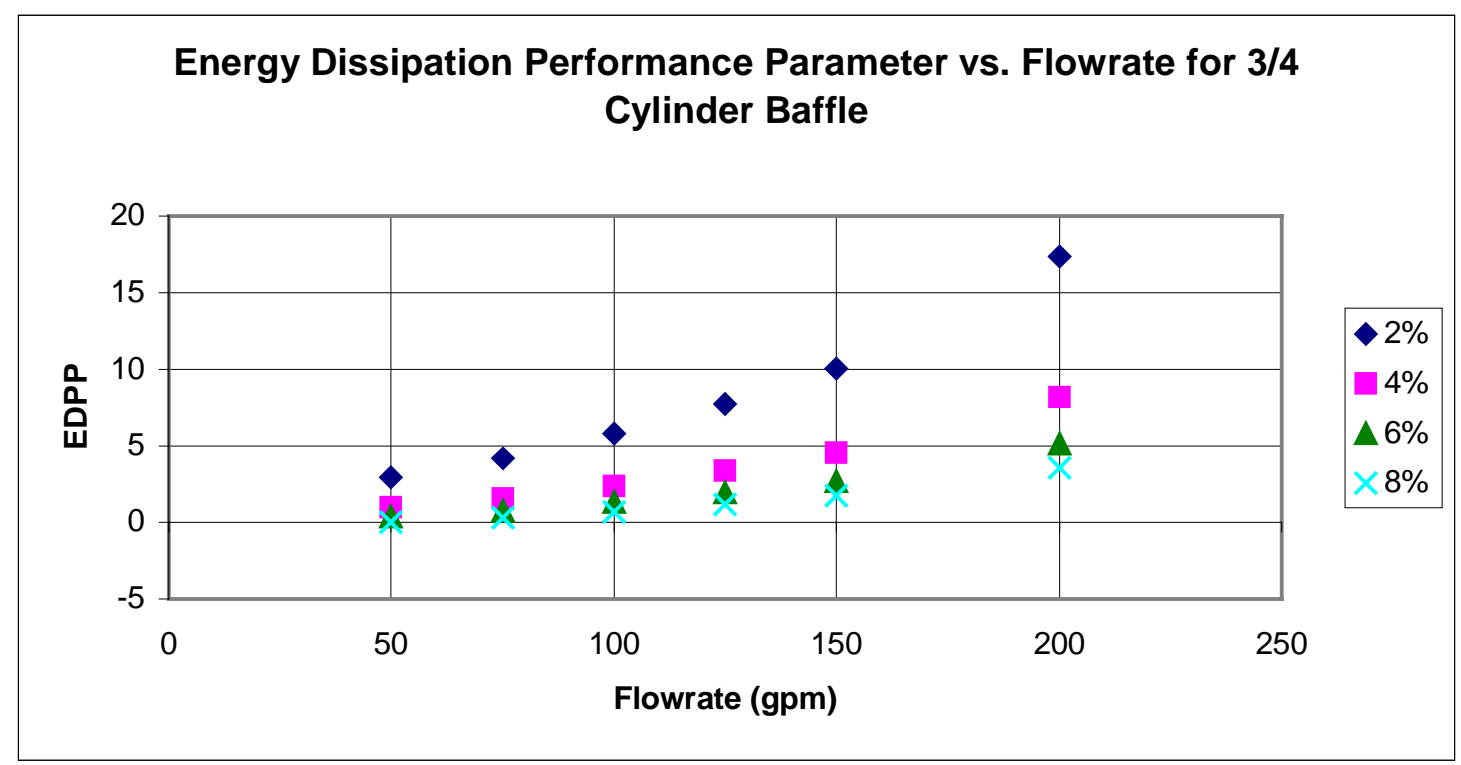

Figure 5.3.3 EDPP vs. Flowrate for 3/4 D Cylinder Baffle

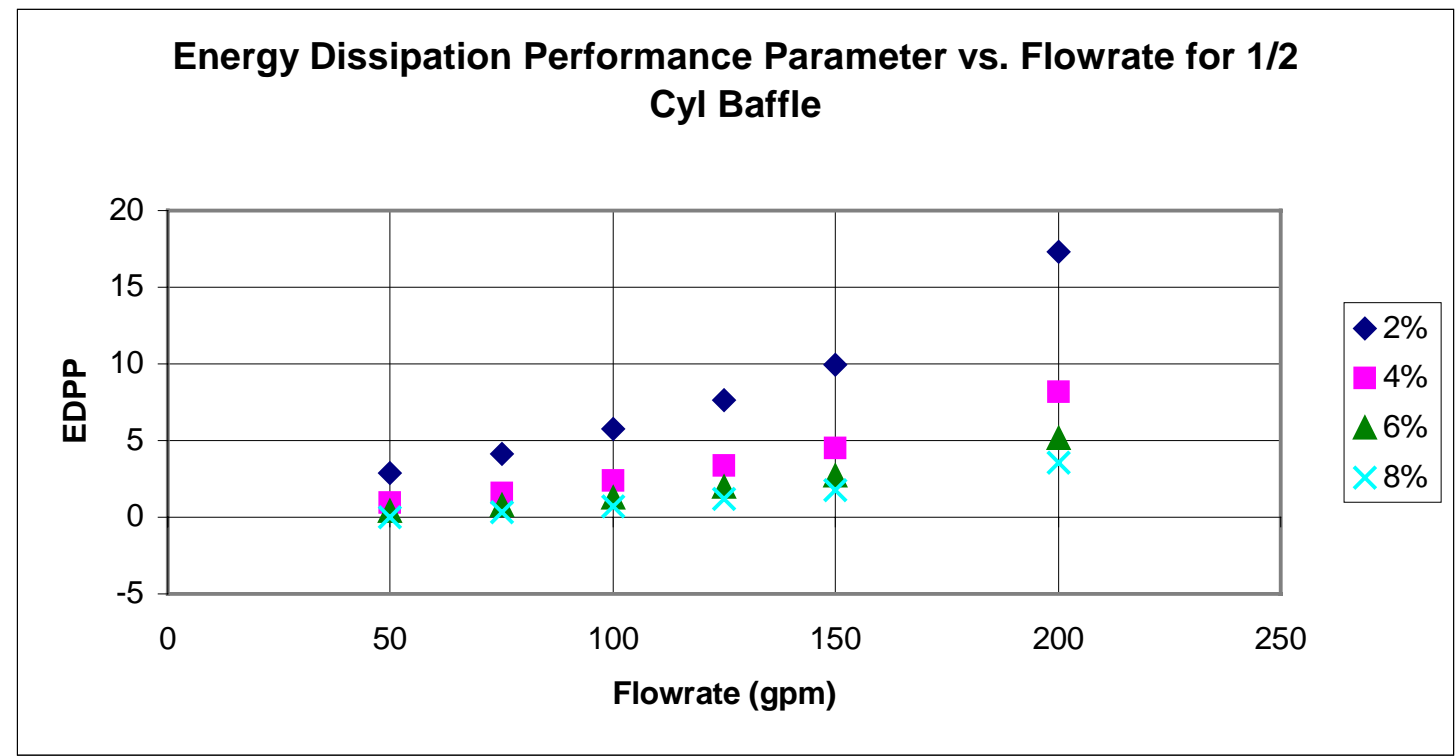

Figure 5.3.4 EDPP vs. Flowrate for $1 \frac{1}{2}$ D Cylinder Baffle 


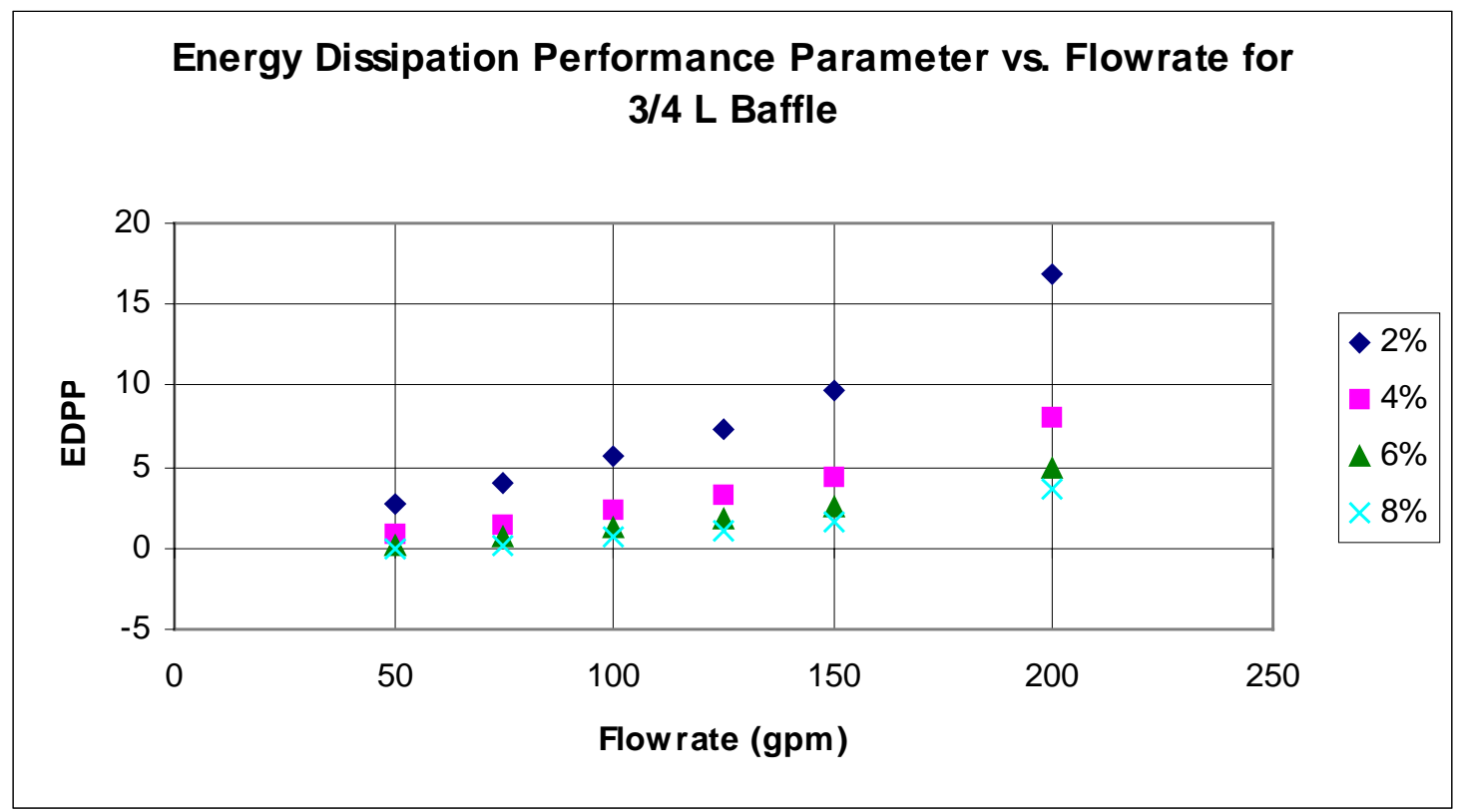

Figure 5.3.5 EDPP vs. Flowrate for 3/4 D L-Baffle

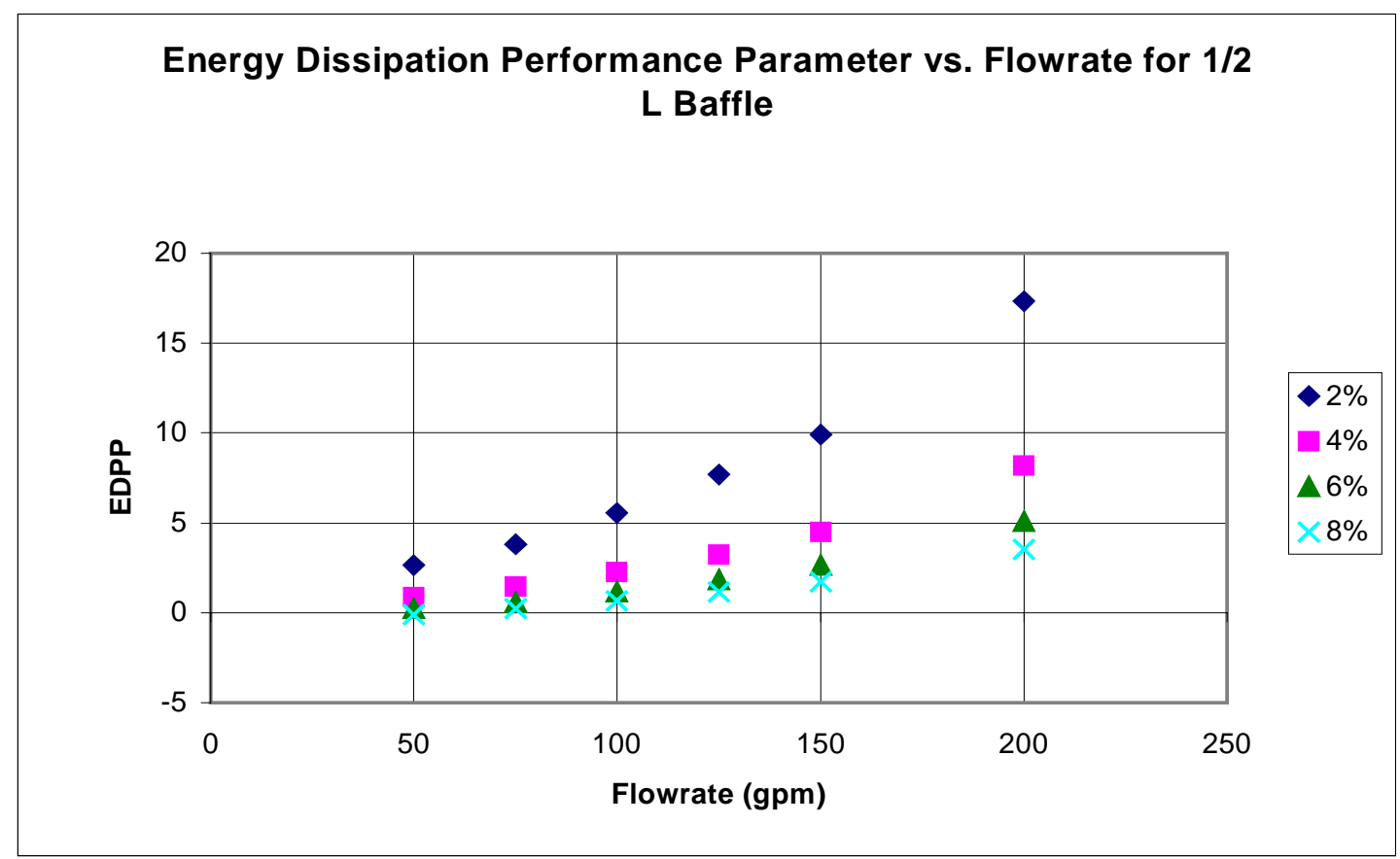

Figure 5.3.6 EDPP vs. Flowrate for $1 / 2$ D L-Baffle 


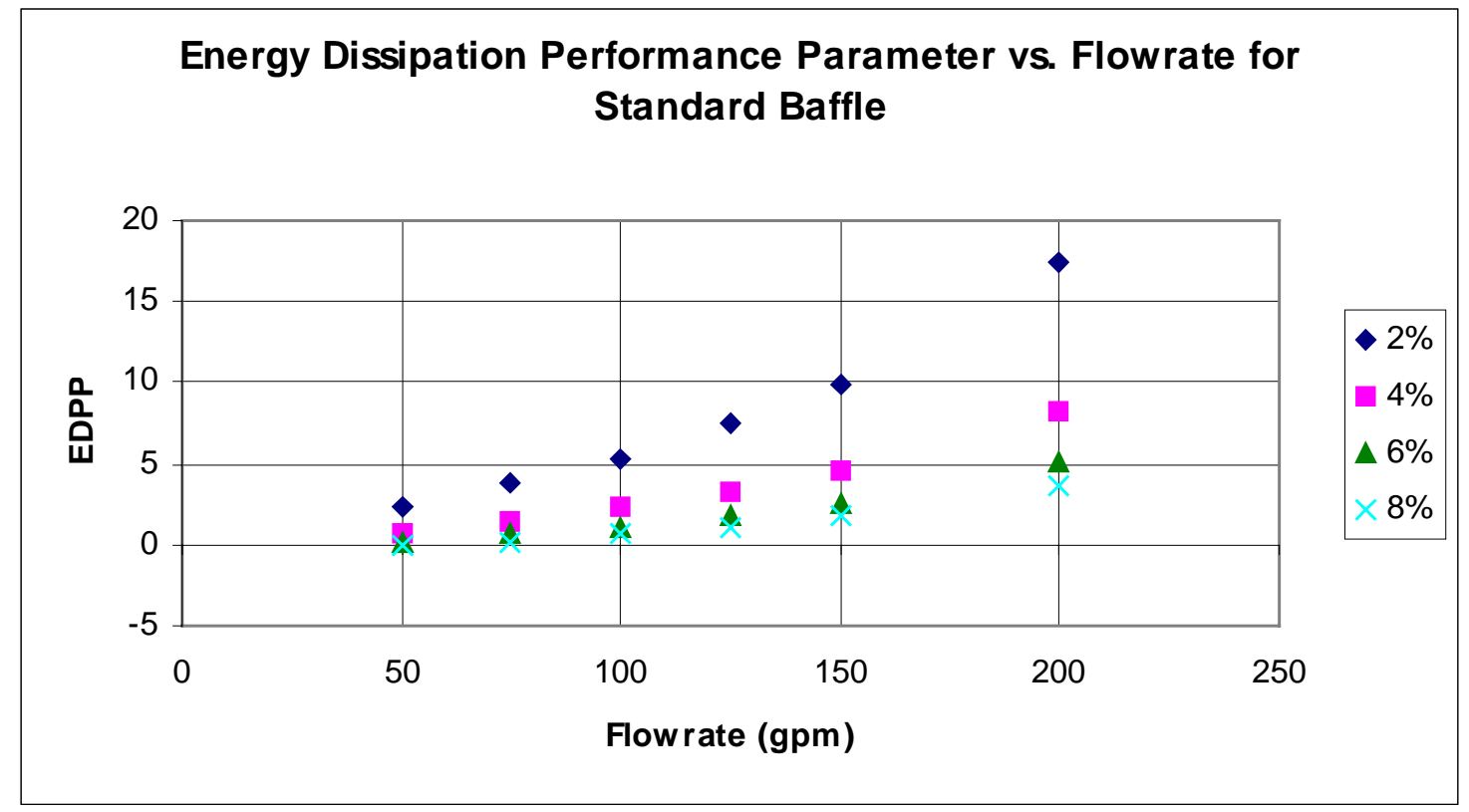

Figure 5.3.7 EDPP vs. Flowrate for Standard Baffle 


\section{Conclusions and Recommendations}

Based on the results presented in Sections 5.1 through 5.3, the baffle configuration that best satisfied the established criteria was the $1 / 2$ diameter L-baffle. The $1 / 2$ diameter L-baffle gave the best overall performance while meeting economic goals. The effectiveness of this configuration was closest to the standard baffle configuration, without the standard baffle's negative aspects. The sedimentation characteristics were examined by allowing small diameter stones to travel down the test culvert and across the culvert apron, no significant sedimentation was detected. The $1 / 2$ diameter L-baffle would be easy to construct with standard forms. Steel stock could be cut to produce the $1 / 4$ diameter lip and fastened in place with standard bolting devices. The wingwalls were extended along the apron to contain any lateral flow from the baffle. The material needed for the construction of the L-baffle design should be no more than that needed for the standard baffle design.

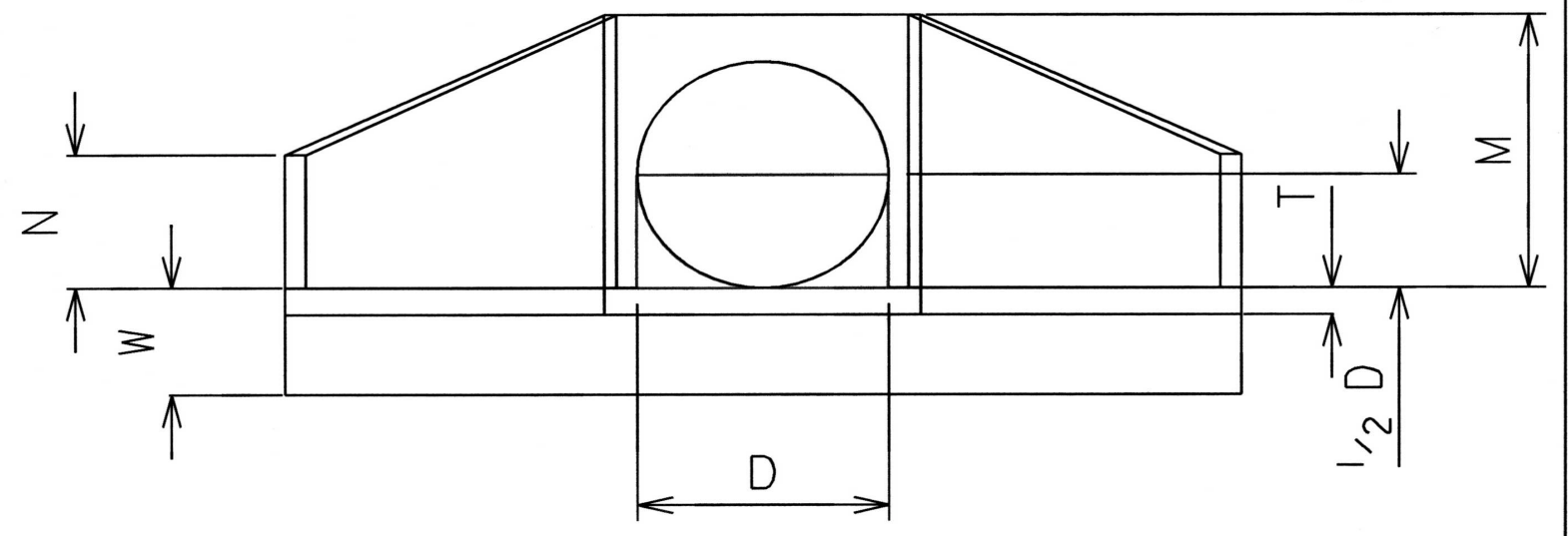

Figure 6.1 Front View of L-Baffle Dissipator

Downstream of the dissipator, the requirements of returning natural stream conditions were met. In winter conditions the baffle would have little to zero icing effects on nearby roadways, since vertical spray was eliminated by the lip of the baffle. Figures 6.1 and 6.2 show the dimensions 
for the L-baffle based on culvert diameter. The dimensions of the culvert apron remain unchanged from the current design. (refer to Table 1.3.1.)

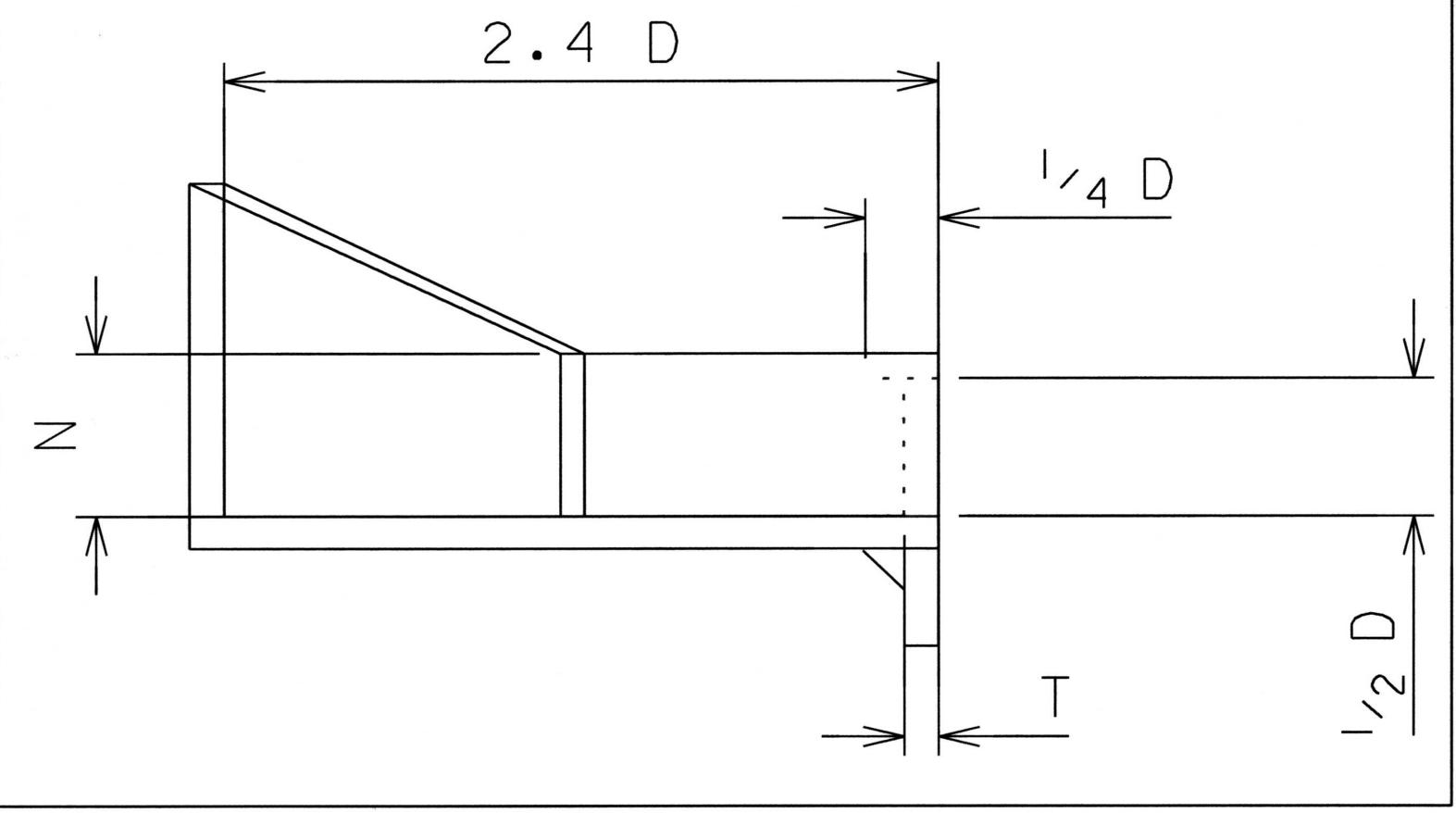

Figure 6.2 Profile View of L-Baffle Dissipator

Since this research was a preliminary investigation of culvert outlet baffle block geometry and energy dissipation, further research is needed to provide a better understanding of this baffle configuration. A large portion of the time available for this project was used in the development of the testing flume. Further investigation of the L-baffle configuration could include:

- Further analysis of error associated with the testing flume

- Larger range of culvert slopes

- Greater accuracy measuring velocities and depths (Laser Doppler Anemometer)

- Longer testing channel to allow for better establishment of uniform flow

- Construction of a non-rigid downstream bed to examine scour characteristics

- Examination of full scale prototype in the field 
The above areas of interest are suggestions to create a better understanding of the flow characteristics of the L-Baffle configuration. Upon the completion of this thesis the WVDOH will construct the full-scale prototype, possibly on the Corridor $\mathrm{H}$ project, where further analysis of the L-baffle configuration can begin. A conceptual view of the new design is shown in Figure 6.3.

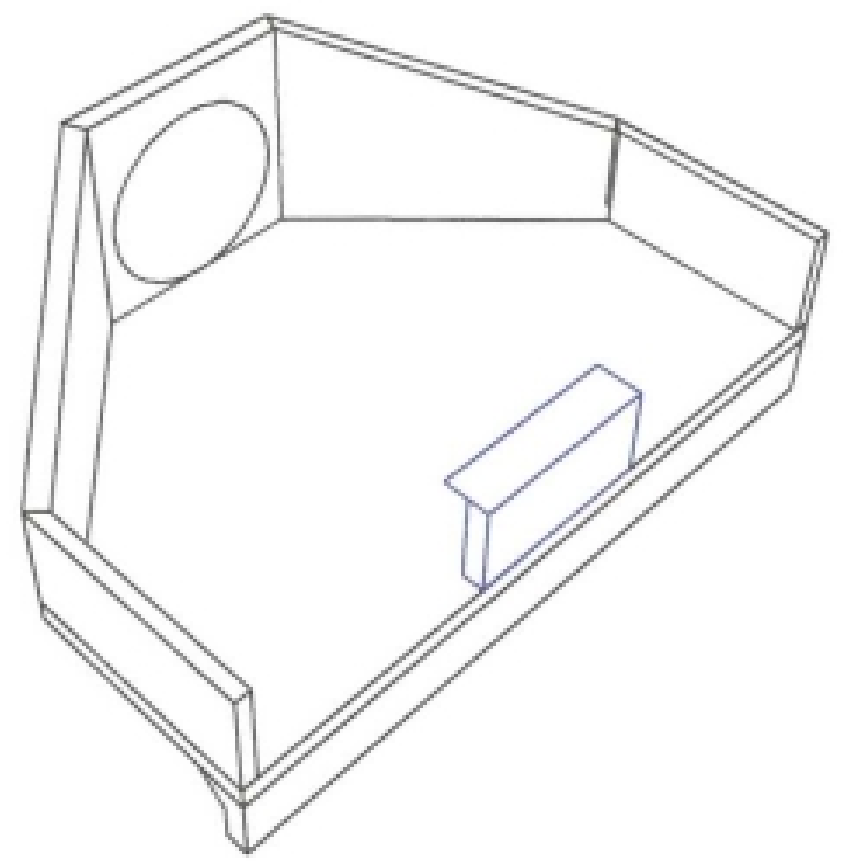

Figure 6.3 1 1/2 Diameter L-Baffle Right Isometric View 


\section{References}

Abt, S.R., Hamilton, D. and Watson, "Rip-Rap Sizing for Modified ARS-type Basins." Journal of Hydraulic Engineering 120 1994: 260-67.

Bakhmeteff, B.A. Hydraulics of Open Channels. New York: McGraw-Hill Book Company 1932.

Bakhmeteff, B.A. and Matzke, A.E. "The Hydraulic Jump in Terms of Dynamic Similarity." Trans. ASCE 100 1936: 630-80.

Ball, J.W. Tullis, J.P. and Stripling, T. "Predicting Cavitation in Sudden Enlargements." ASCE Journal of the Hydraulics 101 1975: 857.

Bhowmik, N.G. "Stilling Basins for Low Froude Numbers." ASCE Journal of the Hydraulics 101 1975: 901-15.

Burgi, B.H. "Hydraulic Design of Vertical Stilling Wells." ASCE Journal of the Hydraulics 101 1975: 801-16.

Chaudhry, M.H. Open-Channel Flow. New Jersey: Prentice Hall, 1993.

Chow, V.T. Open Channel Hydraulics. New York: McGraw-Hill Book Company, 1959.

Corry, M.L. and Thompson, P.L. "Hydraulic Design of Energy Dissipators for Culverts and Channels." Federal Highway Administration 1975.

Flammer, G.H., Skogerboe, G.V., Wei, C.Y., and Rasheed, H. "Closed Conduit to Open Channel Stilling Basin." ASCE Journal of Irrigation and Drainage Engineering 1970.

French, R.H. Open Channel Hydraulics. New York: McGraw-Hill Book Company, 1985.

Gray, D.D. A First Course In Fluid Mechanics for Civil Engineers, Water Resources Publications, LLC. Highlands Ranch, CO, 1999.

Hager, W.H. "Energy Dissipators and Hydraulic Jump." Water Science and Technology Library Vol. 8, Boston: Kluwer Academic Publishers, 1992.

Henderson, F.M. Open Channel Flow. New York: The Macmillian Company, 1966.

Hey, R.D. "Flow Resistance in Gravel Bed Rivers." Journal of the Hydraulics Division 105 1979: 365-79. 
"Hydraulic Design of Energy Dissipators for Culverts and Channels." Hydraulic Engineering Circular Number 14. U.S. Department of Transportation: Federal Highway Administration. Sep. 1983.

"Hydraulic Design of Highway Culverts" Hydraulic Design Series Number 5. U.S. Department of Transportation: Federal Highway Administration. Sep 1985.

"Hydraulic Design of Stilling Basins." Journal of the Hydraulics Division, A.S.C.E., paper, October 1957.

Hydraulics of Energy Dissipators. Videocassette. FHWA-DOT. 1987.

Keim, R.S., "The Contra Costa Energy Dissipator.” Journal of the Hydraulics Division, A.S.C.E. paper 3077, March 1962, 109.

Khatsuria, R.M. "Dispersive-Flow Energy Dissipator." Journal of Hydraulic Engineering 122 1996: 361.

MacDonald, T.C., "Model Studies of Energy Dissipators for Large Culverts." Hydraulic Engineering Laboratory Study HEL-13-5, University of California, Berkeley, November 1967.

Ohtsu, I., Yasuda, Y. and Hashiba. "Incipient Jump Conditions for Flows Over a Vertical Sill." Journal of Hydraulic Engineering 122 1996: 465-69.

Peterka, A.J. "Hydraulic Design of Stilling Basins and Energy Dissipators." Department of the Interior, Bureau of Reclamation. 1958 (also appeared as $7^{\text {th }}$ printing in 1983).

Pillai, N.N., Goel, A. and Dubey, A.K. "Hydraulic Jump Type Stilling Basin for Low Froude Number." Journal of Hydraulic Engineering 115 1989: 989-94.

Rice, C.E. and Kadavy, K.C. "Model Study of a Roller Compacted Concrete Stepped Spillway." Journal of Hydraulic Engineering 122 1996: 292-97.

Rice, C.E. and Kadavy, K.C. "Protection Against Scour at SAF Stilling Basin." Journal of Hydraulic Engineering 119 1993: 133-39.

Rhone, T.J. "Baffled Apron as Spillway Energy Dissipator." ASCE Journal of the Hydraulics 103 1977: 1391-1401.

Roberson, J.A., Cassidy, J.J, and Chaudry, M.H. Hydraulic Engineering. John Wiley and Sons: New York, 1995. 
White, F.M. Viscous Fluid Flow New York: McGraw-Hill, 1991.

Yang, S.L. "Dispersive-Flow Energy Dissipators." Journal of Hydraulic Engineering 120 1994: 1401-08. 


\section{Vita}

Conrad Russell Baston was born in Buckhannon, West Virginia on October 1, 1976. He was raised in French Creek West Virginia, attended Buckhannon Upshur High School and graduated in 1994. In May of 1998, he graduated from West Virginia University with a Bachelor of Science in Civil Engineering. He then became a graduate research assistant under Dr. Robert Eli, with special interest in Hydrotechnical Engineering. He has accepted a position as an engineering consultant and will be working toward obtaining his professional engineering license. 